\title{
INTEGRATED UNCERTAINTY TECHNIQUES IN AIRCRAFT DERIVATIVE DESIGN OPTIMIZATION
}

\author{
by \\ Hyeong-Uk Park \\ Bachelor of Engineering, Department of Aerospace Information Engineering \\ Konkuk University, 2005 \\ Master of Applied Science, Department of Aerospace Information Engineering \\ Konkuk University, 2007
}

\author{
A dissertation \\ presented to Ryerson University \\ in partial fulfilment of the \\ requirements for the degree of \\ Doctor of Philosophy \\ in the program of \\ Aerospace Engineering
}

Toronto, Ontario, Canada, 2014

(C) Hyeong-Uk Park 2014 
I hereby declare that I am the sole author of this dissertation. This is a true copy of the dissertation, including any required final revisions, as accepted by my examiners.

I authorize Ryerson University to lend this dissertation to other institutions or individuals for the purpose of scholarly research.

I further authorize Ryerson University to reproduce this dissertation by photocopying or by other means, in total or in part, at the request of other institutions or individuals for the purpose of scholarly research.

I understand that my dissertation may be made electronically available to the public. 


\title{
INTEGRATED UNCERTAINTY TECHNIQUES IN AIRCRAFT DERIVATIVE DESIGN OPTIMIZATION
}

\section{Doctor of Philosophy, 2014}

Hyeong-Uk Park

Aerospace Engineering, Ryerson University

\begin{abstract}
Aircraft manufacturing companies have to consider multiple derivatives to satisfy various market requirements. They modify or extend an existing aircraft to meet the new market demands while keeping the development time and the cost to a minimum. Many researchers have studied the derivative design process, but these research considered the baseline and the derivatives together, while using the whole set of design variables. Therefore, an efficient process that can reduce the cost and the time for the aircraft derivative design is needed. In this dissertation, Aircraft Derivative Design Optimization process (ADDOPT) was developed which obtains the global changes from the local changes in the aircraft design to develop the aircraft derivatives efficiently. The sensitivity analysis was implemented to ignore design variables that have low impact on the objective function. This avoids wasting computational effort and time on low priority variables for design requirements and objectives. Additionally, the classification of uncertainty from its characteristics and sources of uncertainty involved in the aircraft design process were suggested to consider with design optimization. Uncertainty from the fidelity of analysis tools was applied in design optimization to increase the probability of optimization results. To handle uncertainty in low fidelity analysis tools on aircraft conceptual design optimization, Reliability Based Design
\end{abstract}


Optimization (RBDO) and Possibility Based Design Optimization (PBDO) methods were performed.

In this research, Extended Fourier Amplitude Sensitivity Test (eFAST) method was implemented in ADDOPT for Global Sensitivity Analysis (GSA) method and Collaborative Optimization (CO) based framework with RBDO and PBDO were also used. These methods were evaluated using numerical examples. ADDOPT was carried through on the civil jet aircraft derivative design. The objective of the optimization problem was to increase cruise range while satisfying the requirement such as the number of passengers. The proposed process reduced computation effort by reducing the number of design variables and achieved the target probability of failure when considering uncertainty from low fidelity analysis tools. 


\section{Acknowledgments}

I would like to thank my advisor, Dr. Joon Chung for his many years of patience, support, and advice. I also want to thank Dr. Kamran Behdinan, co-supervisor who constantly provided valued advice and motivation to improve. I would like to express my sincere appreciation to Dr. Jae-Woo Lee for his guidance and support throughout this thesis effort.

I would like to thank my parents and brother for their endless love and unwavering support throughout my studies. They are the one to encourage me to take this path and I'm eternally grateful for that. 


\section{Table of Contents}

Chapter 1 Introduction...............................................................................................................................

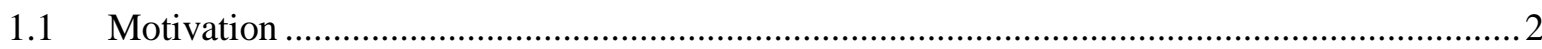

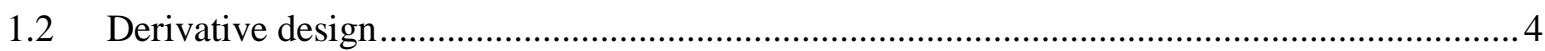

1.3 Multidisciplinary Design Optimization (MDO) …………….............................................. 14

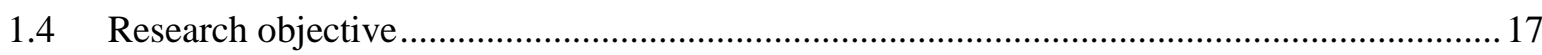

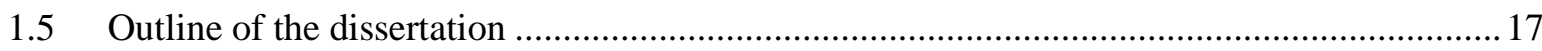

Chapter 2 Uncertainty in Aircraft Design .........................................................................19

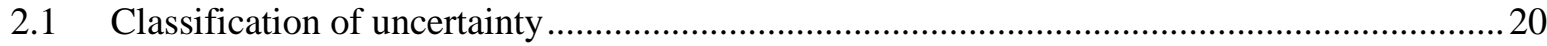

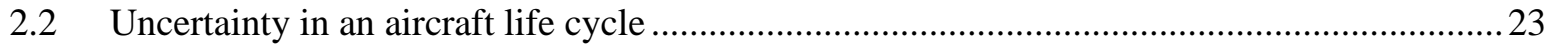

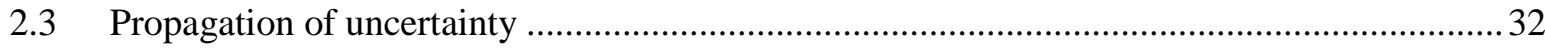

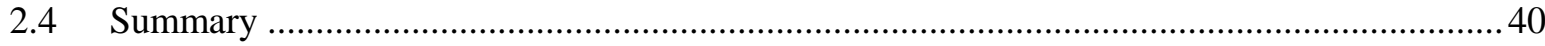

Chapter 3 Aircraft Derivative Design Optimization (ADDOPT) Process .............................42

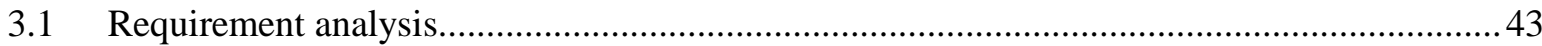

3.2 Global sensitivity analysis ............................................................................................. 46

3.3 Uncertainty based Multidisciplinary Design Optimization (MDO) ………………………....50

$3.4 \quad$ Validations of implemented methods …………………………………………………....53

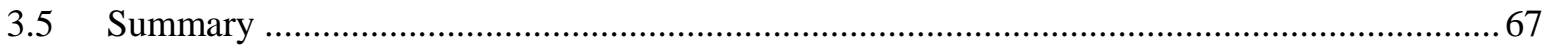

Chapter 4 Wing Box Design ...................................................................................................................69

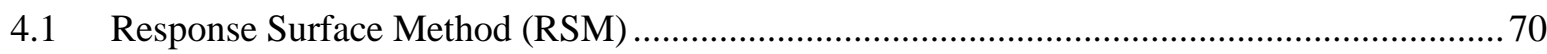

$4.2 \quad$ Problem definition ...................................................................................................

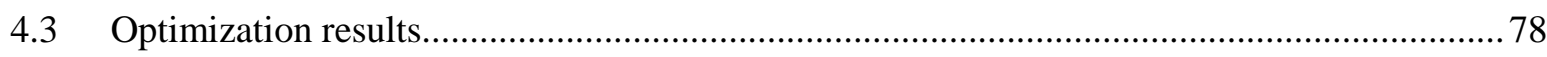

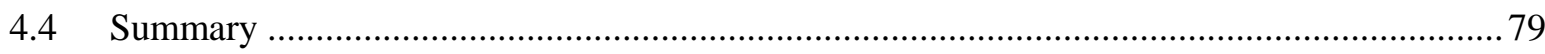


Chapter 5 Conceptual Design for Aircraft Derivative ...................................................................81

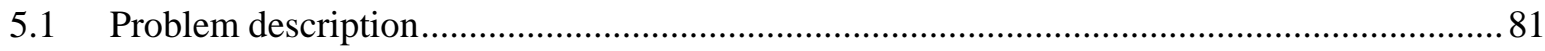

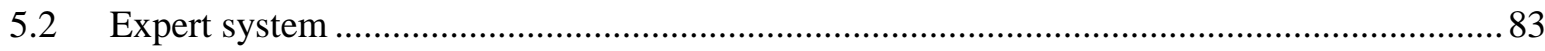

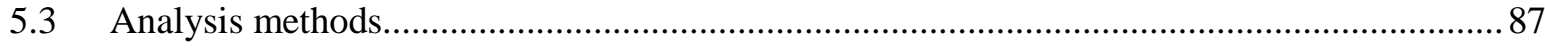

5.4 Global sensitivity analysis for aircraft conceptual design ..................................................95

5.5 Uncertainty based design optimization for aircraft conceptual design ....................................98

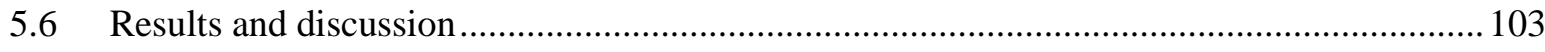

Chapter 6 Conclusion and Future Work ........................................................................................105

6.1 Conclusion …………………………………………………………………………... 105

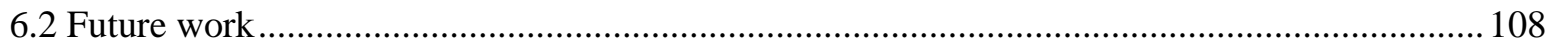

Appendix A Finite Element Analysis Results of Wing Box.....................................................114

Appendix B Light Jet Aircraft Specifications for Database ...................................................119

Appendix C Civil Jet Aircraft Specifications for Database ....................................................124

Appendix D Flow Chart of Aircraft Derivative Design Optimization (ADDOPT)

Process........................................................................................................................................................134

References............................................................................................................................................137 


\section{List of Tables}

3.1 Design variables and its range for fuzzy function .............................................. 53

3.2 Design variables of baseline configuration ............................................................. 56

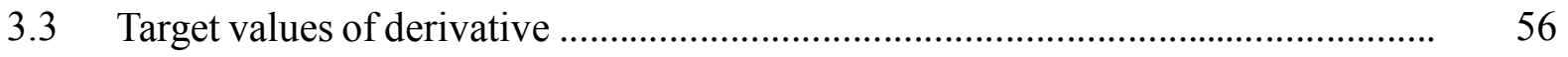

$3.4 \quad$ Range of design variables ............................................................................ 57

3.5 Design variables and its range ……………………........................................... 59

3.6 Loading condition for 18 bar truss problem …………………………………....... 60

3.7 Sensitivity indices for 18 bar truss problem ………………………………......... 60

3.8 Comparison of design result .............................................................................. 61

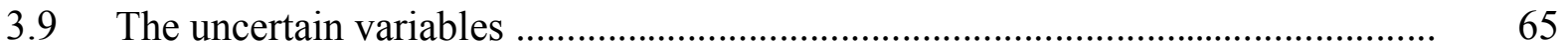

3.10 Optimization results ................................................................................... 66

4.1 Design variables for wing box and its range ………………………………........ 74

4.2 Sensitivity indices of design variables ………………………….......................... 75

4.3 Constraints for wing box conceptual design ......................................................... 77

$4.4 \quad$ Formulations for structures discipline ……………............................................. 77

$4.5 \quad$ Comparison of design result .............................................................................. 78

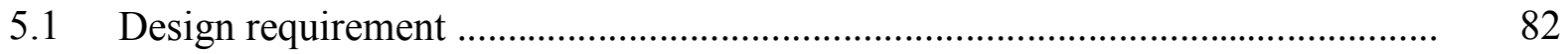

5.2 Design variables and its range for fuzzy function ............................................... 84

5.3 Normalized value and real value of design variables ........................................... 86

$5.4 \quad$ Feasible range of design variables ..................................................................... 86

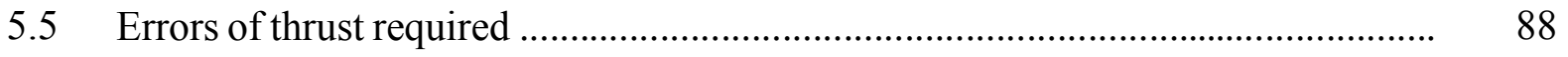

5.6 Errors of empty weight of aircraft …………………………………………... 90

5.7 Errors of cruise range of aircraft ............................................................................ 93

5.8 Stability constraints .................................................................................. 95

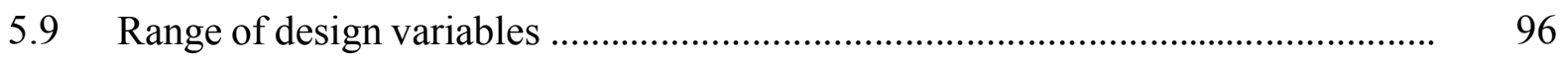




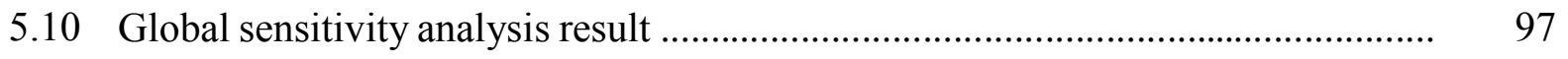

5.11 Comparison of design results (B737-800) …................................................... 100

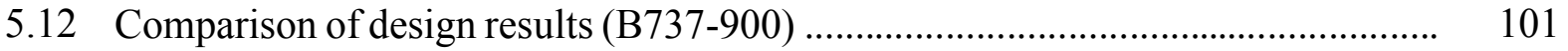




\section{List of Figures}

$1.1 \quad$ Derivatives of B737 .........................................................................................

1.2 Extension of upper deck .................................................................................... 6

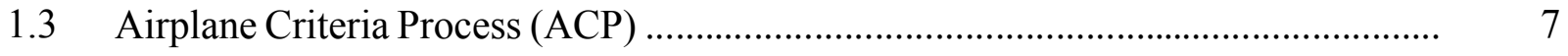

$1.4 \quad$ Aircraft design from emerged requirements ............................................................. 8

$1.5 \quad$ Aircraft family design using MOGA ..................................................................... 10

$1.6 \quad 11$

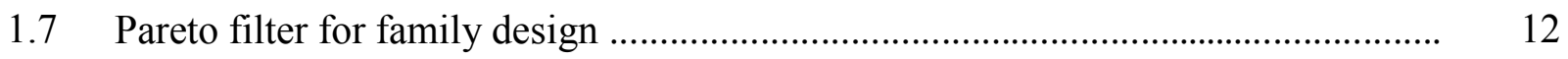

$1.8 \quad$ Combined platform with Pareto filter .................................................................... 13

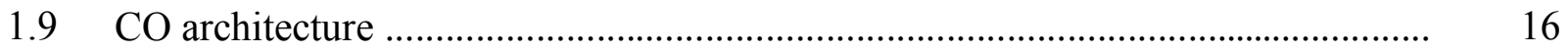

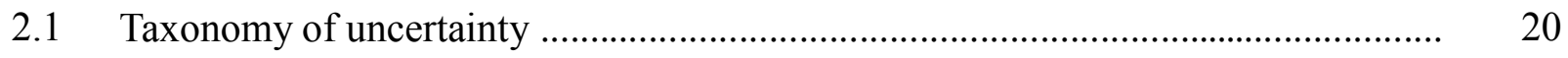

2.2 General aircraft life cycle ................................................................................ 24

2.3 Sources of uncertainty on simulation based analysis model .................................... 26

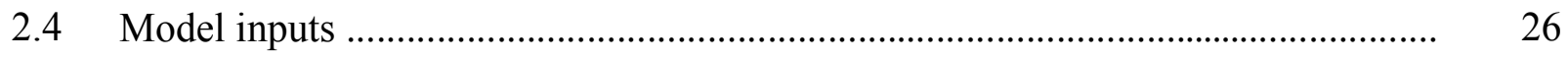

2.5 Uncertainties from engineering model .................................................................. 27

2.6 The optimum result of RBDO ....................................................................... 34

2.7 The optimum result of PBDO …………………................................................. 37

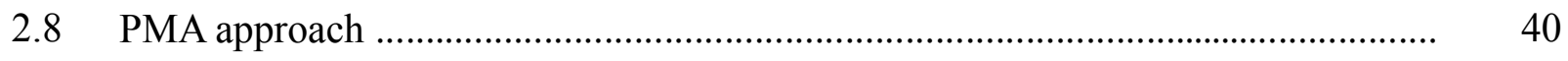

3.1 Aircraft Derivative Design Optimization (ADDOPT) process ................................. 43

3.2 Requirement analysis and expert system .......................................................... 44

3.3 Concept of expert system ……………………………………………………. 45

3.4 Sensitivity analysis to identify the important design variables ................................ 47

3.5 Uncertainty based MDO for derivative design ..................................................... 50

3.6 Concept of expert system for light jet aircraft ………………………………….... 54 


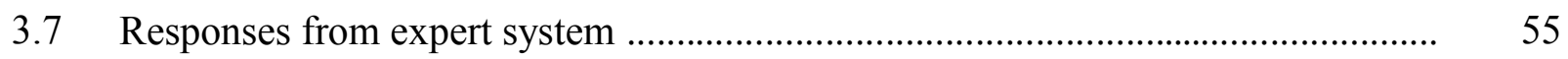

$3.8 \quad$ Initial 18 bar truss ....................................................................................... 57

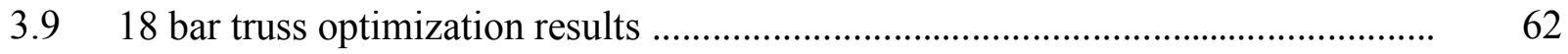

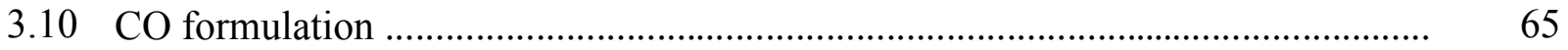

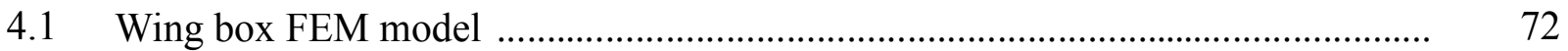

4.2 Process of Response Surface Model development for wing box ............................. 72

4.3 Wing box shape and design variables .................................................................. 74

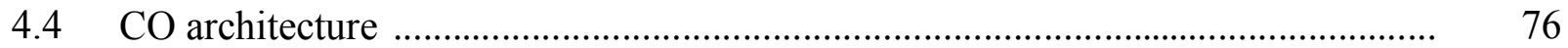

$5.1 \quad$ Procedure of derivative design ........................................................................... 82

5.2 Concept of expert system for civil jet aircraft .........................................................

5.3 Feasible region of major design variables from expert system …………………... $\quad 85$

5.4 Aerodynamics analysis module ………………….......................................... 87

$5.5 \quad$ Weight analysis module ………………………………………………….... 89

5.6 Performance analysis module ............................................................................. 92

5.7 Stability and control analysis module ……………................................................ 95

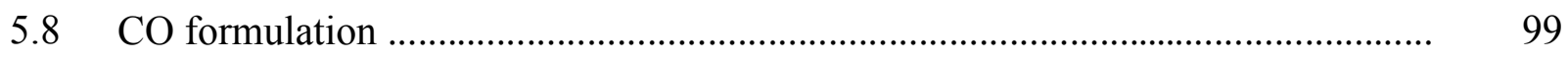

5.9 Comparison of aircraft design result with B737-800 ………………………….... 102

5.10 Comparison of aircraft design result with B737-900 .............................................. 102 


\section{Nomenclature}

\section{Acronyms}

\begin{tabular}{ll} 
ACP & Airplane Criteria Process \\
ADDOPT & Aircraft Derivative Design Optimization \\
BLISS & Bi-Level Integrated System Synthesis \\
CDF & Cumulative Distribution Function \\
CFD & Computational Fluid Dynamics \\
CO & Collaborative Optimization \\
COV & Coefficient of Variation \\
CSSO & Concurrent Sub-System Optimization \\
DOE & Design of Experiment \\
eFAST & Extended Fourier Amplitude Sensitivity Test \\
FE & Finite Element \\
FEA & Finite Element Analysis \\
FEM & Finite Element Method \\
FORM & First-Order Reliability Method \\
GA & Genetic Algorithm \\
GSA & Global Sensitivity Analysis \\
IDF & Individual Disciplinary Feasible \\
JPDF & Joint Probability Density Function \\
KKT & Karush-Kuhn-Tucker \\
\hline
\end{tabular}




\begin{tabular}{|c|c|}
\hline MCS & Monte-Carlo Simulation \\
\hline MDF & Multi-Disciplinary Feasible \\
\hline MDO & Multidisciplinary Design Optimization \\
\hline MOGA & Multi-Objective Genetic Algorithm \\
\hline MPFD & Market-driven Product Family Design \\
\hline MPP & Most Probable Point \\
\hline PBDO & Possibility Based Design Optimization \\
\hline PDF & Probability Density Function \\
\hline PMA & Performance Measure Approach \\
\hline PMS & Performance Management System \\
\hline RBDO & Reliability Based Design Optimization \\
\hline RIA & Reliability Index Approach \\
\hline RSM & Response Surface Method \\
\hline SORM & Second-Order Reliability Method \\
\hline UCAV & Unmanned Combat Aerial Vehicle \\
\hline
\end{tabular}

\section{Symbols}

Aaero Auxiliary constraints of aerodynamics

$A R_{H} \quad$ Aspect ratio of horizontal tail

$A R_{V} \quad$ Aspect ratio of vertical tail

$A R_{W} \quad$ Aspect ratio of main wing

$A_{\text {struct }} \quad$ Auxiliary constraints of structures 


\begin{tabular}{|c|c|}
\hline$b_{i}$ & Coefficients of the regression function \\
\hline$C_{\text {Root_H }}$ & Root chord length of horizontal tail, $f t$ \\
\hline$C_{\text {Root_V }}$ & Root chord length of vertical tail, $f t$ \\
\hline$C_{\text {Root_W }}$ & Root chord length of main wing, $f t$ \\
\hline$d$ & Design variable vector \\
\hline$d_{i}$ & Maximal grade of membership function \\
\hline$d^{L}$ and $d^{U}$ & Lower boundary and upper boundary of design variables \\
\hline$F_{X}(x)$ & Cumulative distribution function \\
\hline$f_{X}(x)$ & Probability density function \\
\hline$G$ & First order probability performance measure \\
\hline$G_{i}(X)$ & $i^{\text {th }}$ constraint function \\
\hline$G_{p i}^{R I A}$ & Probabilistic constraint in the RIA \\
\hline$G_{p i}^{P M A}$ & Probabilistic constraint in the PMA \\
\hline$g_{i}$ & $i^{t h}$ disciplinary constraint on $\mathrm{CO}$ \\
\hline$h_{c r}$ & Cruise altitude, $f t$ \\
\hline$J$ & Compatibility constraints for each discipline on $\mathrm{CO}$ \\
\hline$K$ & Buckling coefficient \\
\hline$k_{n}$ & Static margin \\
\hline$L$ & Element length, $f t$ \\
\hline$L_{f}$ & Length of fuselage, $f t$ \\
\hline$L_{T}$ & Tail length, $f t$ \\
\hline$L / D$ & Lift to drag ratio \\
\hline$M_{c r}$ & Cruise Mach number, $M$ \\
\hline
\end{tabular}




\begin{tabular}{|c|c|}
\hline$M_{p l}$ & Payload mass, $l b$ \\
\hline$m$ & Number of response function coefficient \\
\hline$N$ & Sample size \\
\hline$N_{P A X}$ & Number of passengers \\
\hline$N_{R}$ & Re-sampling size \\
\hline$N_{S}$ & Total number of samples \\
\hline$n$ & Number of design variable \\
\hline$n d v$ & Number of design vector \\
\hline$n p$ & Number of possible constraints \\
\hline$n r$ & Number of fuzzy variables \\
\hline$n r v$ & Number of random vector \\
\hline$p$ & Uncertain parameters \\
\hline$P(\bullet)$ & Probability measure \\
\hline$P_{t}$ & Target probability of feasibility \\
\hline$R$ & Cruise range, $N M$ \\
\hline$R_{a d j}^{2}$ & Adjust R-square \\
\hline$S_{c i}$ & Complementary set of parameters \\
\hline$S_{H}$ & Wing area of horizontal tail, $f t^{2}$ \\
\hline SL & System level \\
\hline$S_{i}$ & Sensitivity index \\
\hline$S S_{E}$ & Error sum of squares \\
\hline$S S_{y}$ & Total sum of squares \\
\hline$S_{T i}$ & Total sensitivity index \\
\hline
\end{tabular}




$\begin{array}{ll}S_{V} & \text { Wing area of vertical tail, } f t^{2} \\ S_{W} & \text { Wing area of main wing, } f t^{2} \\ S_{\text {total }} & \text { Fraction of total variance } \\ T & \text { Thrust, } l b f \\ T(\cdot) & \text { Transformation } \\ T R_{H} & \text { Taper ratio of horizontal tail } \\ T R_{V} & \text { Taper ratio of vertical tail } \\ T R_{W} & \text { Taper ratio of main wing } \\ U & \text { Design space } \\ \boldsymbol{u} & \text { Direction vector } \\ V_{a} & \text { Approach speed, } k t s \\ V_{i} & \text { Fuzzy variables } \\ W_{e} & \text { Empty weight, } l b \\ W_{f} & \text { Fuel weight, } l b \\ X & \text { The random variable } \\ X_{X} & \text { The random vector } \\ x_{j} & \text { Lower and upper boundaries of random variable } \\ X_{i} & \text { Non-interactive fuzzy variables } \\ X_{j} & \text { Normalict }\end{array}$




\section{$z^{*}, y^{*}$ and $x^{*}$ Optimal disciplinary optimization level results on $\mathrm{CO}$}

$\alpha_{t} \quad$ Target possibility of failure

$\beta_{t} \quad$ Target reliability

$\Lambda_{L E_{-} H} \quad$ Swept back angle of horizontal tail leading edge, deg

$\Lambda_{L E_{-} V} \quad$ Swept back angle of vertical tail leading edge, deg

$\Lambda_{L E_{-} W} \quad$ Swept back angle of main wing leading edge, deg

$\sigma \quad$ Maximum stress, $M p a$

$\sigma_{b} \quad$ Buckling stress, $M p a$

$\lambda_{\text {real }} \quad$ Motion equation eigenvalues

$\Phi(\bullet) \quad$ Standard normal CDF

$\Omega \quad$ Fuzzy event of whole space

$\Pi(\bullet) \quad$ Possibility measure

$\Pi_{X_{i}, L}\left(X_{i}\right) \quad$ Left side of the membership function of the input fuzzy variable $X_{i}$

$\Pi_{X_{i}, R}\left(X_{i}\right) \quad$ Right side of the membership function of the input fuzzy variable $X_{i}$

$\emptyset \quad$ Empty event 


\section{Chapter 1}

\section{Introduction}

Engineers must consider all possible design derivatives in order to reduce the life cycle cost and to increase the efficiency of operation [1]. New customer demands produce needs on the derivative designs of engineering products to reduce the manufacturing and operational cost. However, user requirements can change drastically. The whole process of engineering product design cannot quickly respond to such a wide variety of changes. Modern engineering products especially extremely complex systems such as aircraft, are strongly influenced by structural and aerodynamic analysis, propulsion systems and avionics, stability and control [2]. The design of a new commercial aircraft constitutes a massive investment over a long development period. Incorporating changing customer requirements necessitates the efficient and the reliable process for the derivative designs.

This research proposes ADDOPT, an effective aircraft derivative design optimization 
process to meet the requirement changes from the market demand. User requirements were analyzed and identified for quantifiable factors which can be implemented to generate target specifications. The database of baseline designs and their derivatives was implemented in the expert system to identify design trends for the new required demands [3]. In addition, a fuzzy logic function of the expert system also defines the range of design parameters [4]. The selected design variables and their ranges were utilized in a Global Sensitivity Analysis (GSA). The analysis result

determined the necessary design parameters to achieve the desired specifications [5]. Although decreasing the number of design variables and their range generated small errors, the benefits from the reduced computation time far outweighed the increased error. Furthermore, Reliability Based Design Optimization (RBDO) and Possibility Based Design Optimization (PBDO) methods were performed with Multidisciplinary Design Optimization (MDO) in order to increase the reliability of results by considering uncertainty $[6,7,8,9,10]$. To increase the reliability and the efficiency of derivative design, these techniques were applied in ADDOPT process.

\subsection{Motivation}

Manufacturers develop new products by modifying and extending existing products in order to achieve new market demands with minimum development time and manufacturing cost [1]. The design of complex systems such as the new commercial aircraft requires huge amount of investments and research during the period of the development. Therefore redesigning an existing aircraft for the new market demands requires large amounts of additional developmental resources 
and time. Traditional derivative design processes considered the whole set of design variables even for minor design changes $[11,12,13]$. General design processes with fixed design requirements can easily carry out the design of engineering products. However, these baseline designs cannot easily adapt to changes in market demands and its performance requirements. Designing the new aircraft to satisfy the new market takes a substantial amount of time and money. Moreover, the market requirements may change again before the development of the new aircraft is completed. Consequently, the new procedure for redesign and analysis is required to consider the influence of changing design requirements on the derivative design; new design process that can reduce cost and time for the aircraft derivative designs is required.

This dissertation proposed ADDOPT process to meet requirement changes from the market demand. User requirements were analyzed and identified for quantifiable factors that can be used to generate specifications. Design trends for the new requirements were identified by the expert system with the database of baseline designs and their derivatives, and the range of design parameters was also defined by fuzzy logic function of the expert system $[3,4]$. These results increased efficiency and accuracy of GSA result to identify the necessary design parameters to achieve new requirements from market [5]. The decreased number of design variables and their ranges reduced the computation time and the cost for redesign. MDO problem for the derivative design was formulated using the selected design variables. Furthermore, the design optimization techniques for uncertainty from design variables and responses of disciplines were considered to increase the reliability of MDO results $[7,8,9]$.

The main contributions of this dissertation were increasing efficiency with reasonable accuracy by reducing number of design variables with consideration of sensitivity for the objectives. The uncertainty of design parameters and discipline responses were considered as well 
to enhance the efficiency and the reliability of the MDO result. To accomplish these objectives, the software package was developed which integrated GSA, MDO with RBDO, and MDO with PBDO. The developed software package, ADDOPT process was evaluated by numerical examples and practical engineering problems. Each module was evaluated by well-known numerical examples and 18 bar truss optimization problem which were performed in many previous research of deterministic optimization. Moreover, the proposed design process was implemented on practical engineering problem as wing box design; a general structural analysis problem on aerospace engineering. ADDOPT process was implemented on aircraft derivative design, the essential work of this dissertation. Error of each analysis module was considered as uncertain parameter to consider uncertainty from fidelity of analysis model. In addition, database was constructed to compare with predicted results from developed aircraft analysis modules.

\subsection{Derivative design}

The life cycle cost can be reduced and operation efficiency can be increased by considering

all possible derivatives in aircraft development and manufacturing stage [1]. In the aerospace field, the commonality of the baseline aircraft and its derivatives is beneficial for both airlines and manufacturers. These advantages include efficiency of maintenance procedures, flexibility in scheduling and reduction of spare-parts stock. Airlines operate with several derivative aircraft types in order to reduce the required pilot training time for transitioning from one type to another [12]. Figure 1.1 shows the example of derivatives of B737. Yet, in some ways, the derivative design 
is more difficult to complete than new design, because the possible alternatives are constrained by the existing baseline design. This is especially complex in the area of systems integration. Derivative design methods have been considered by many researchers because it advantages both airliners and manufacturers. In this section, previous research on derivative design was surveyed in order to show differences and benefits of the proposed process, ADDOT.

\section{Original Models}

B737-100 $\rightarrow$ B737-200 Extended fuselage

$\longrightarrow$ B737-200Advanced Improved aerodynamics, automatic wheel rakes,

Classic Models

powerful engine, more fuel capacity, longer range

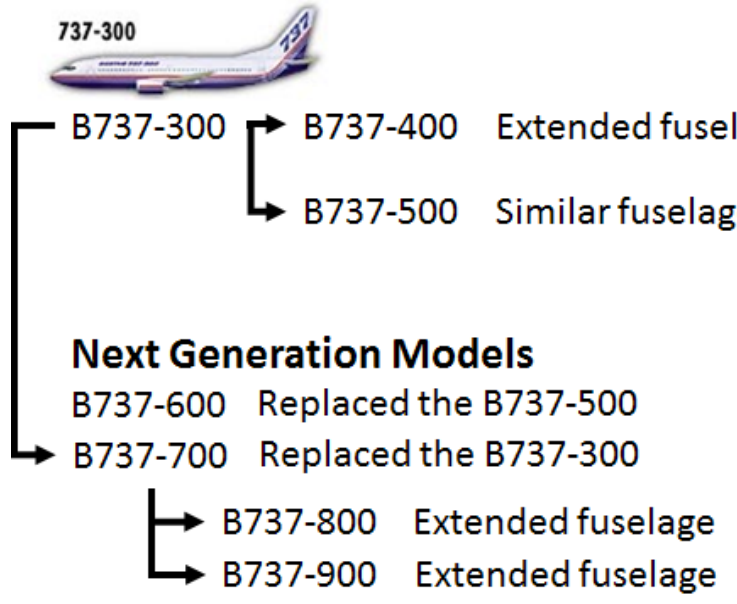

Figure 1.1. Derivatives of B737 [14]

\subsubsection{Market driven approach}

Boeing B747 family has many members developed from 1960 to satisfy requirements of the market. The development of an aircraft family can save the cost on design, manufacturing and 
operation. D.L. Robinson et al. introduced the development procedure of B747 family from market demands [1]. The Boeing Company predicted the demands of air traffic will increase by 10 percent for every year between 1975 1979. From this prediction, the new airplane was needed to carry more passengers. The Boeing Company used the Performance Management System (PMS) and generated 10 models using potential application matrix to develop B747-300. These models considered 19 engines and 112 combinations of engines and configurations. Finally, the configuration which had the extended upper deck was selected and emergency exit was added to satisfy the regulations. Figure 1.2 shows this result for B747 family. The cost effective solution was proposed to increase the number of passengers. This experience with derivative design left the Boeing Company with a number of other useful derivatives such as the fuselage extension model [1].

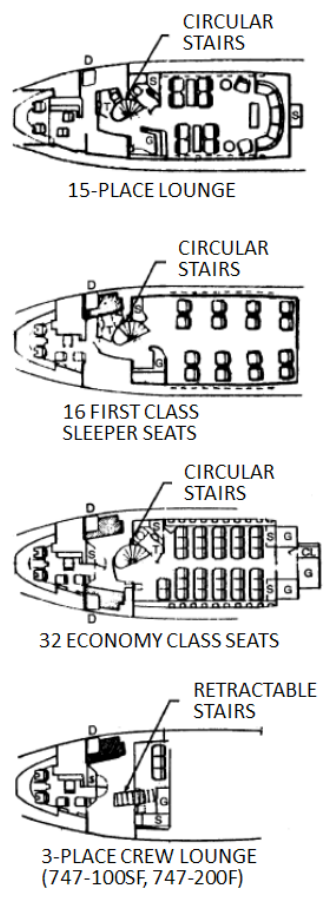

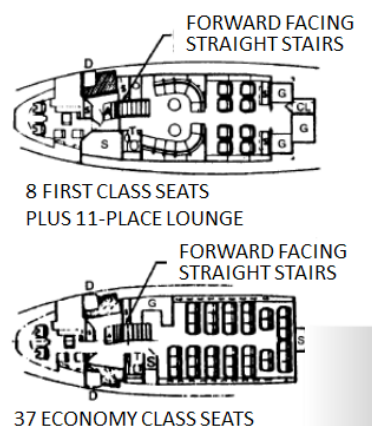

37 ECONOMY CLASS SEATS

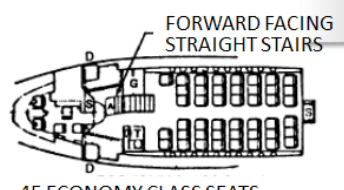

45 ECONOMY CLASS SEATS

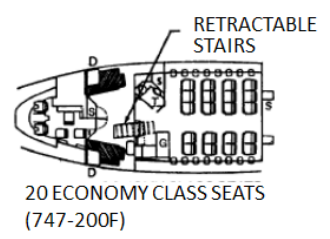

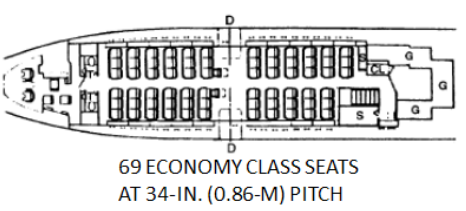
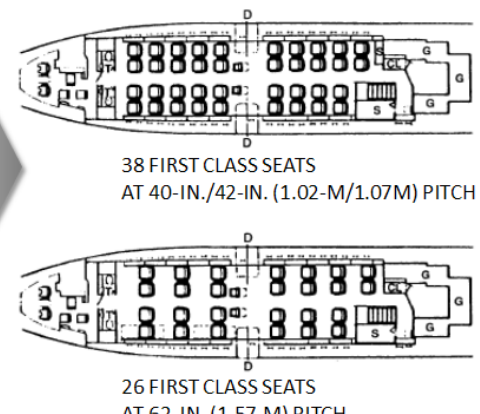

AT 62-IN. (1.57-M) PITCH

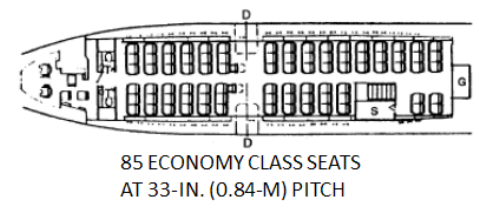

Figure 1.2. Extension of upper deck [14]

(B747-100/200: left side, B747-300: right side) 
Another researcher, R.H. Fulford, proposed the Airplane Criteria Process (ACP) to develop derivatives [15]. The ACP began with the discovery of needs and wants in airlines for future consideration and airplane agencies, within the scope of the airplane definition. The criteria driven from R.H. Fulford's research means the product definition activity is led by criteria development. The criteria were classified by two categories [15]. The first was the mandatory criteria that must be satisfied during design. The other was prioritized criteria and these were prioritized needs that must be optimally satisfied. They do not have a negative impact on the mandatory and higher priority criteria. This classification provided a priority of which criteria should be satisfied at the earliest stage in the airplane design. These criteria were derived from the requirement analysis of market, airliner and manufacturer. In addition, the proposed process applied the top-down concept meaning that the elements were developed from the highest criteria first - airplane design and then the lowest criteria - systems and components. This process provided a continuous and iterative process to the direction for development of a derivative or a new airplane design. In addition, this process provided traceability of the original customer needs throughout the airplane development procedure. The simplified procedure of this process is shown in Figure 1.3.

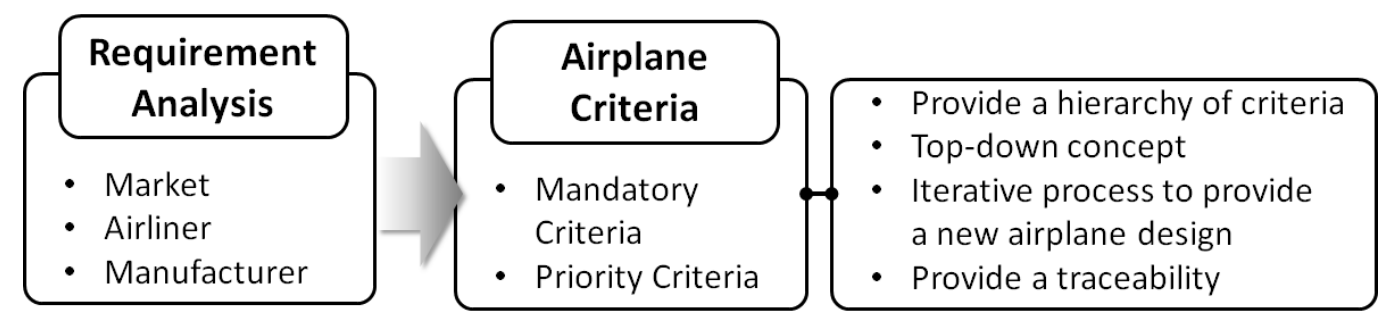

Figure 1.3. Airplane Criteria Process (ACP)

The aircraft family design method based on the market growth ratio was developed by R.B. Brown et al. [16]. In this research, the growth rate of the aircraft market was predicted with the 
needs of economy passenger being considered. It assumed 5\% air traffic growth rate per year and improvement in all aspects of air travel. Increases of gate slot flow, safe lading frequency, high initial cruise altitude over-files, and reduction of noise level were considered. Moreover, it weighed the customer requirements such as low ticket price, quick load and unload, safe overhead stowage, minimal middle seats, etc. The research focused on the requirements of the economic passengers. The design result showed the family of aircraft that had 150 900 economy passengers with low noise level and the ability to use all regional and big city secondary airports while satisfying the requirements from the market prediction [16]. The summary of this research is shown in Figure 1.4 .

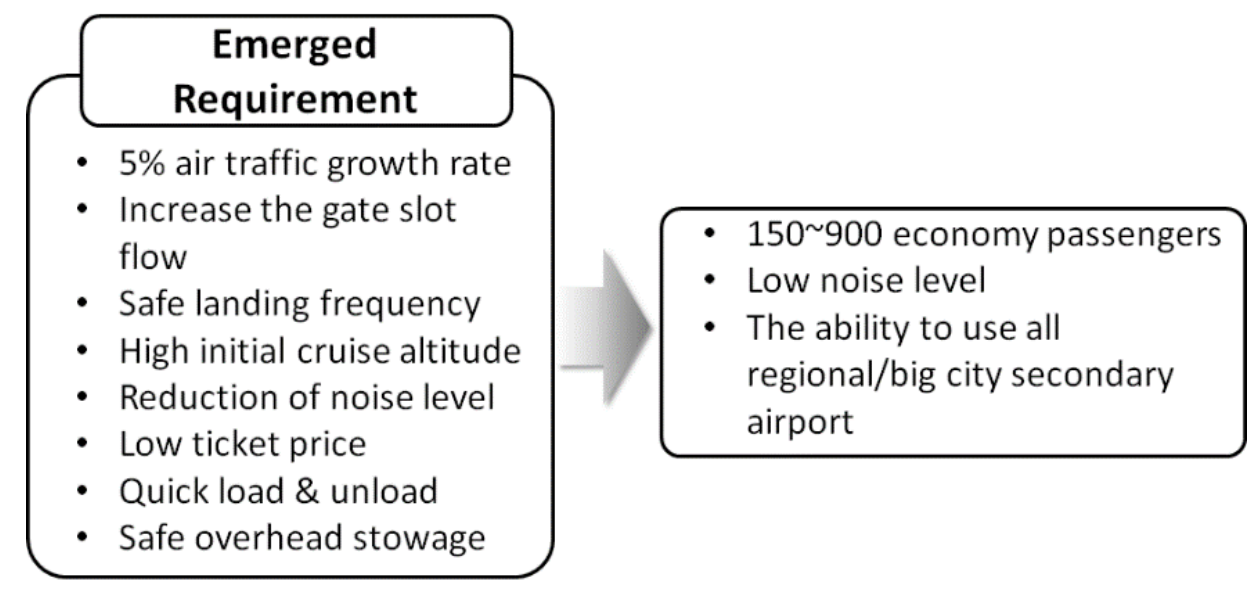

Figure 1.4. Aircraft design from emerged requirements

The product family design should consider the engineering knowledge and the awareness of impact on manufacturing and marketing. The product family design process that regarded the product line positioning was researched by D. Kumar et al. [17]. This research integrated the market considerations as the traditional product family. In addition, the novel Market-driven Product Family Design (MPFD) method was proposed to simultaneously model the product 
platform and a product line positioning considerations. The proposed method considered the minimum manufacturing complexity while satisfying the market demands. The decisions from this method were based on engineering, manufacturing feasibility and economic model for the market prediction. This method examined the impact of increasing the diversity of product contributions throughout disparate market segments and explored the cost saving associated with commonality determinations. The proposed method was applied to the design for the family of universal motors [17].

\subsubsection{Using Multi-Objective Genetic Algorithm (MOGA)}

Researchers have used the multi-objective optimization method for the aircraft family design. T.W. Simpson et al. introduced the genetic algorithm based approach for the product family design and applied to the general aviation product family design problem [18]. This approach designed the product platform simultaneously and its family while reflecting on altering levels of platform commonality within the product family using MOGA. A modified genetic algorithm was used to allow designers to assess altering levels of commonality within a family of products and captured the corresponding Pareto frontier of the family. This method allowed more flexibility to the designer when formulating the product family optimization problem [18].

The proposed method was applied to the general aviation aircraft family that has two, four and six seats for accommodation where the configuration was a fixed wing, single engine and single pilot for the propeller driven aircraft. Its baseline was from Beechcraft Bonanza B36TC. The family design of this research implemented six design variables and various parameters from 
the baseline aircraft. Figure 1.5 shows this proposed design approach.

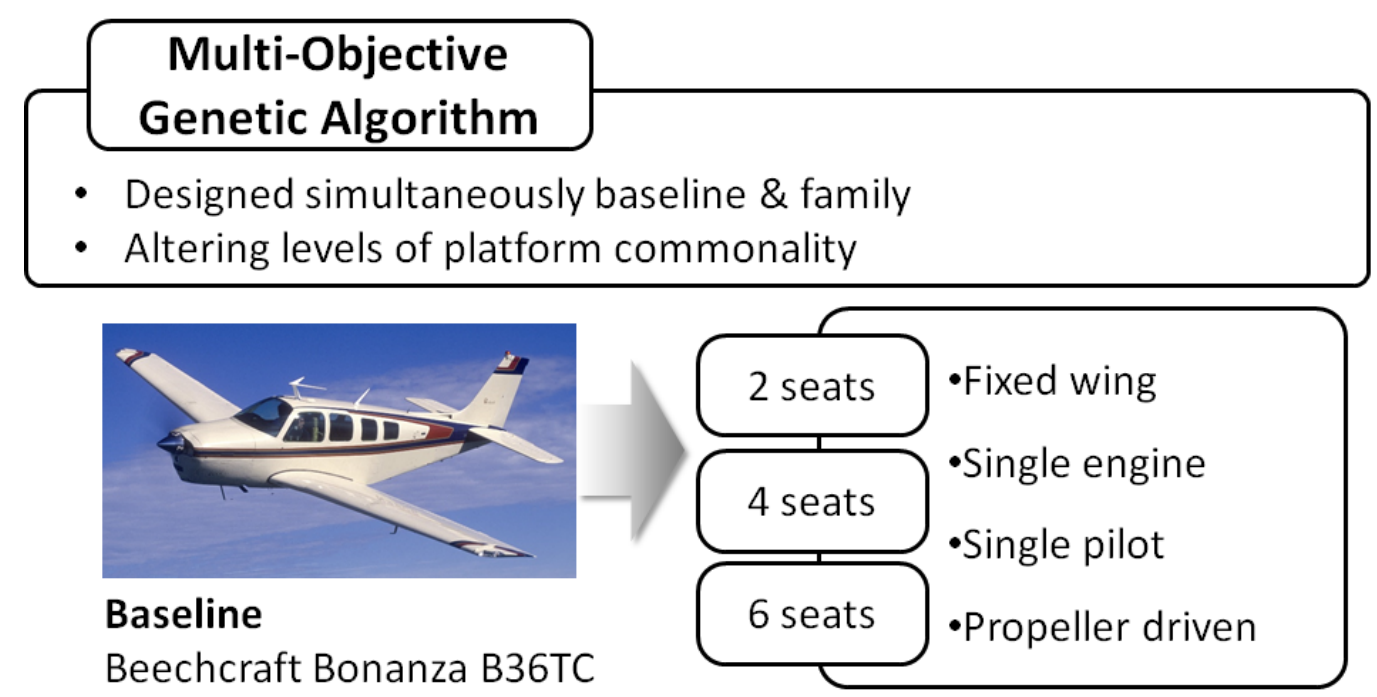

Figure 1.5. Aircraft family design using MOGA

Valliyappan et al. [13] researched the implementation of Genetic Algorithm (GA) in which allows exploration of the multiple families based on the multiple platforms. Visualization strategies were implemented to support the product family design optimization with GA. These strategies were applied to identify the best solution. It included several test problems for creating the product family design. The proposed method was applied to the general aviation aircraft family design with one, three and five passengers and one pilot. The forty design variables for configuration and thrust, as well as the forty platform variables per the family were considered. The configurations of the aircraft were compared using the visualization strategies and the configurations that had higher commonality within the selection of desired performance range. Figure 1.6 shows this procedure. 


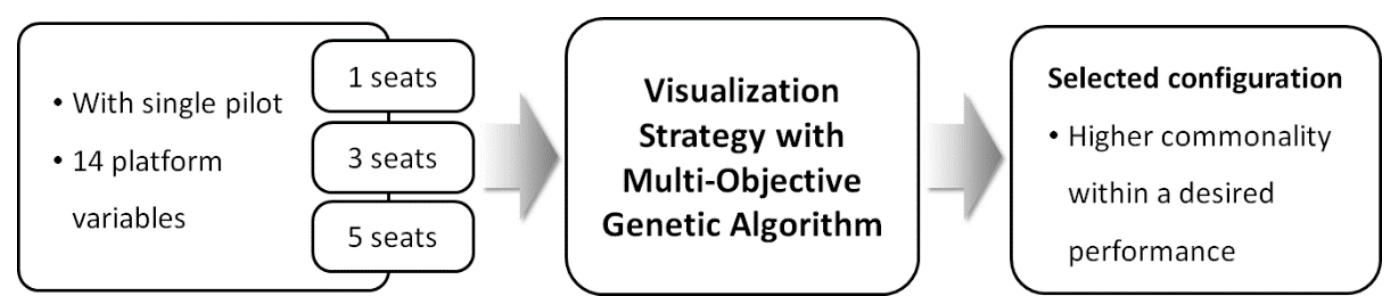

Figure 1.6. Visualization strategy with MOGA

Khajavirad et al. [19] proposed a single stage optimization approach for family product design implementing an efficient decomposition solution strategy. The all-in-one MOGA method was performed to solve the joint product family problem with a generalized commonality chromosome. The researchers implemented the MOGA formulation to determine the Pareto front describing the trade-off between commonality and individual variant performance of the family [19].

\subsubsection{Pareto filtering method}

Yearsley et al. [11, 20] employed the Pareto frontier and decided the number of members to involve in the product family, identify the members themselves and define the product platform. A discrete representation of the Pareto frontier was generated from the multi-objective optimization. The Pareto solution was a non-dominated solution, meaning that improvement in any design objective can only occur at the expense of at least one other design objective. The Pareto frontier was the collective of all Pareto solutions and was a representation of the trade-off between conflicting design objectives. The candidate product family members were identified through the generation of the Pareto frontier.

Yearsley et al. [11] identified the optimal set of the family members that balanced product 
commonality, performance and distinctiveness by identifying a minimal representation of the Pareto frontier, including only those points that corresponding to designs of sufficiently different, yet optimal, product performance. The Pareto filter decreased the number of family sets where this method determines which design variables were best suited as platform variables and the scalable variables. The proposed method was applied to the pressure vessel and the universal electric motor in which the common platform shared in the product family. The research compared sets of individually optimized products to show the performance change from the implementation of the product family. This process is shown in Figure 1.7.

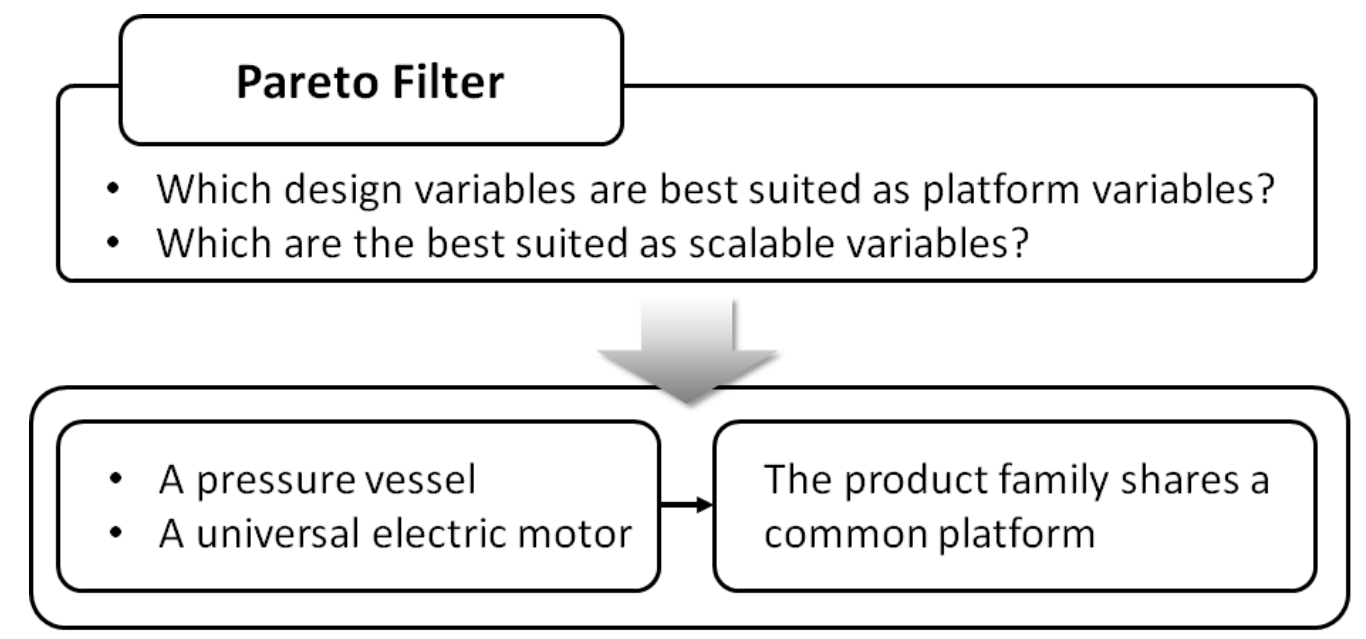

Figure 1.7. Pareto filter for family design

The interactive design method of the combined scale-based and module-based product family platform was researched [20]. The scale-based platform is fundamental for related products with differing functions, it works through scaling of non-platform design features. A module-based platform is the foundation for a collection of related products with differing functions, and it works through the addition or subtraction of modules. Combination of these two methods for product 
family design required fewer total components in manufacture process of all product family members than using the scale-based or the module-based platform. In order to select the family numbers from multi-objective optimization results, the smart Pareto filtering was applied, which is briefly introduced on Figure 1.8.

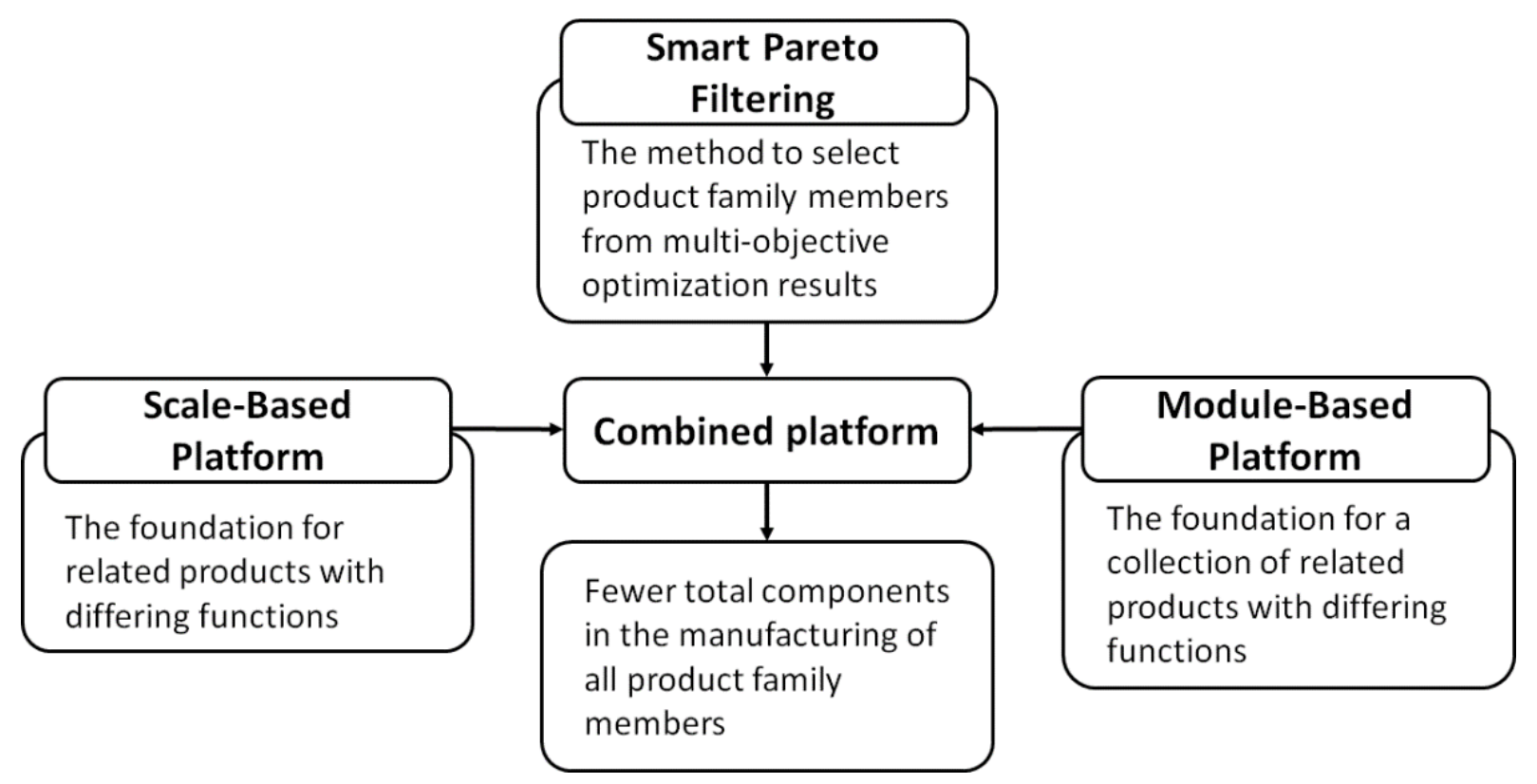

Figure 1.8. Combined platform with Pareto filter

\subsubsection{Proposed derivative design method}

The research in the previous considered entire range of the design variables for each derivative design. Moreover, these methods needed designer's decision to establish a performance requirement for each derivative design. However, these methods did not provide the way to handle market changes that occurs after the completion of baseline design. These researches merely considered the derivatives on the conceptual design stage by assuming only expected changes in the product requirements. However, these assumptions may not accurately reflect the changes in 
future market. Furthermore, these frozen requirements for the design need to be redefined for the derivatives with the emergence of new requirements.

This research proposes ADDOPT, an effective derivative design process to obtain global changes by employing local changes in the engineering product design. By implementing the expert system and GSA, it defines the necessary design variables and parameters. Furthermore, ADDOPT implemented uncertainty base multidisciplinary design optimization to consider uncertainty in design process. The proposed derivative design process applies to the aircraft design as well as any other engineering product design. Chapter 3 describes the details of this proposed method, Chapter 4 and Chapter 5 show the applications of ADDOPT process.

\subsection{Multidisciplinary Design Optimization (MDO)}

The MDO is methodology applied in the design for systems interacting in multiple disciplines. This method developed from the structural design optimization in order to consider the subsystem interaction when the structure has an attachment to the subsystem [21 - 28]. It is applied in an aerospace field when interdisciplinary coupling between structures is too strong to be neglected. After this, the other disciplines such as aerodynamics, performance, propulsion, and stability are included in MDO and it has extended to the entire aircraft system. Generally, the optimization requires number of iterations and MDO can reduce the time required to execute the design process. By using MDO methods, designer may quickly and efficiently compute alternative design points over wide range of parameters [29 - 34].

MDO problem consists of multiple interacting disciplines. In this dissertation, it assumed 
each discipline was described by the following mathematical representation $[35,36]$ :

$$
y_{i}=f\left(\boldsymbol{x}_{i}, \boldsymbol{y}_{i}, \mathbf{z}\right), \quad i, j=1, \ldots, n \quad j \neq i
$$

where $n$ is the total number of coupled disciplines, counted by $i$, representing the $i^{t h}$ discipline, $\boldsymbol{x}_{i}$ is the local variable vector, the vector $\boldsymbol{y}_{i}$ corresponds to interdisciplinary couplings, and $\boldsymbol{z}$ denotes the global or shared variable vector. A set of parameters $p$ is required for each discipline, but does not vary over a design process. These parameters may be shared by multiple disciplines.

Many methods for MDO have been proposed such as Multi-Disciplinary Feasible (MDF) [37, 38, 39, 40], Individual Disciplinary Feasible (IDF) [37, 41, 42], Collaborative Optimization (CO) $[39,43,44,45,46,47]$, Concurrent Subsystem Optimization (CSSO) $[48,49,50,51]$ and Bi-Level Integrated Synthesis System (BLISS) [52, 53, 54, 55]. CO method was performed in this dissertation to consider uncertainty on the design optimization. The general idea of CO is explained in following section and $\mathrm{CO}$ with uncertainty is described in Chapter 2

\subsubsection{Collaborative Optimization (CO) method}

CO method introduces a decomposed and decentralized bi-level optimization method. Target values for global design variables $z$ and system responses $y$ are provided from a system level optimizer. A local disciplinary level optimizer ensures that the conflicts between disciplines disappear by enforcing compatibility constraints. It is constructed to minimize the interdisciplinary inconsistency while satisfying particular local constraints. CO formulation can be stated at the 
system level $[44,45]$ :

$$
\begin{aligned}
& \text { minimize } f\left(z_{S L}, y_{S L}\right) \\
& \text { subject to } J_{i}\left(z_{S L}, z_{i}^{*}, y_{S L}, y_{i}^{*}\left(x_{i}^{*}, y_{j}, z_{i}^{*}\right)\right)=0, \\
& \quad j=1,2, \cdots, n, \quad j \neq i
\end{aligned}
$$

where, $J$ represents compatibility constraints, one for each discipline, and $z^{*}, y^{*}$ and $x^{*}$ are the optimal disciplinary optimization level results. The subscript $S L$ is system level. The $i^{\text {th }}$ disciplinary level optimization problem is formulated as:

$$
\begin{aligned}
& \text { minimize } J_{i}=\sum\left(z_{S L}-z_{i}\right)^{2}+\sum\left(y_{S L}-y_{i}\right)^{2} \\
& \text { subject to } g_{i}\left(x_{i}, z_{i}, y_{i}\left(x_{i}, y_{j}, z_{i}\right)\right) \leq 0
\end{aligned}
$$

where, $g_{i}$ is the $i$-th disciplinary constraint. The diagram of CO method is shown in Figure 1.9.

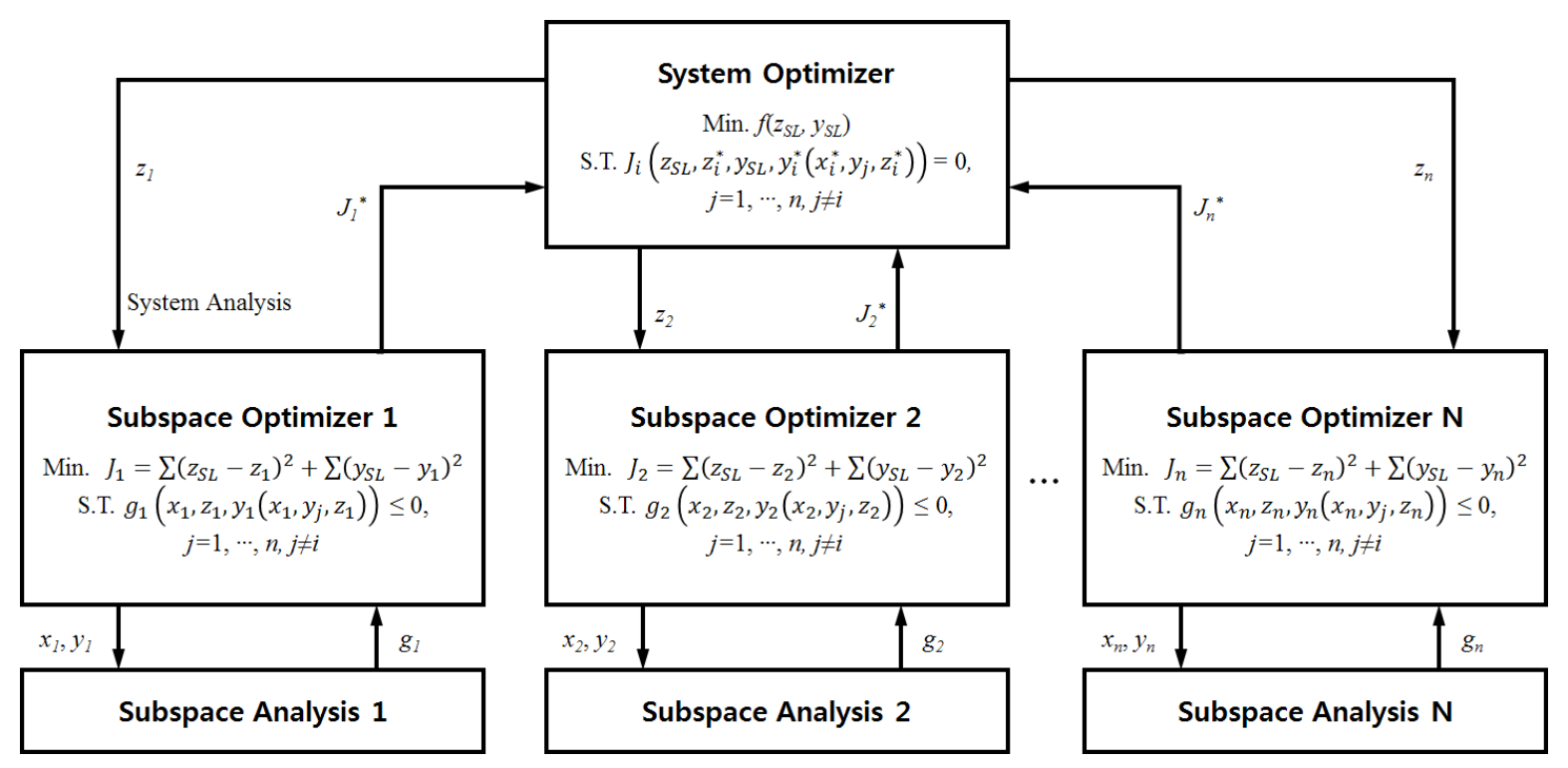

Figure 1.9. $\mathrm{CO}$ architecture $[44,45]$ 


\subsection{Research objective}

The main objective of this research was to increase efficiency with reasonable accuracy of the optimization result by reducing the number of design variables, as well as the boundaries of the design space. The uncertainty of design parameters and discipline responses were considered to enhance efficiency and reliability of the design results. To accomplish the objective, a software package through ADDOPT process was developed and evaluated in this dissertation. ADDOPT process integrated GSA, MDO with RBDO, and MDO with PBDO.

The expert system and GSA were implemented in order to reduce the computation time by select important parameters for the new requirements. The expert system employed the database of similar engineering products to the baseline design. The results of expert system identified the range of the design variables needed to be manipulated to accomplish the new requirements. GSA was implemented to identify necessary parameters and disciplines that affect each requirement based on the expert system results. MDO problem for the derivative design was formulated using selected design variables and disciplines to increase efficiency. Design optimization techniques for uncertainty of design variables and responses of disciplines were operated to increase the reliability of MDO results.

\subsection{Outline of the dissertation}

This thesis consists of 6 chapters. Chapter 1 descries the introduction and research 
motivation. Chapter 2 reviews uncertainty in the aerospace system design. This chapter describes the uncertainty and its sources in aerospace system for better understanding of terminology and uncertainty based design optimization methods. Section 2.1 introduces the classification of this uncertainty. Section 2.2 describes uncertainty in an aircraft design process. Section 2.3 reviews different strategies for uncertainty modeling and uncertainty based design optimization methods. Chapter 3 introduces the development of ADDOPT, the proposed design process in this dissertation. Section 3.1 describes methodologies for the proposed enhanced derivative design process and Section 3.2 shows ADDOPT, the proposed derivative design process. Chapter 4 implements ADDOPT process with the wing box conceptual design problem. The response surface was developed from the high fidelity analysis results of the wing box structure and uncertainty from the approximation method was considered. Chapter 5 describes the implementation of ADDOPT to aircraft derivative design with uncertainty based design optimization methods. Uncertainty on the low fidelity analysis tools for the aircraft conceptual design was weighed. Chapter 6 leads to the conclusion and the overview of future research. 


\section{Chapter 2}

\section{Uncertainty in Aircraft Design}

In recent years, various sorts of uncertainty were introduced in mathematical models and simulation tools $[56,57]$. Scientists, engineers and decision makers in various fields have been characterizing and differentiating between the different forms of uncertainty as well as their sources. Uncertainty characterizes as incompleteness of knowledge due to deficiencies in information from the engineering analysis and design. Material properties, costs, operational environment and human factors defines uncertainty in design. Uncertainty can cause losses and violate constraints in the optimized design results. Understanding and identifying uncertainty are crucial to the designer since the type of uncertainty applicable to a given problem plays a key role in the quantification of its effect. Various sources of uncertainty exist and the understanding of these can provide guidance on how to reduce uncertainty in the prediction [58].

This chapter introduces the classification of uncertainty from its characteristics and the 
sources of uncertainty involved in the aircraft design process. The first section presents the classification of uncertainty. The sources of uncertainty from an aerospace system designs are described in the subsequent section and lastly the design optimization method with uncertainty are discussed.

\subsection{Classification of uncertainty}

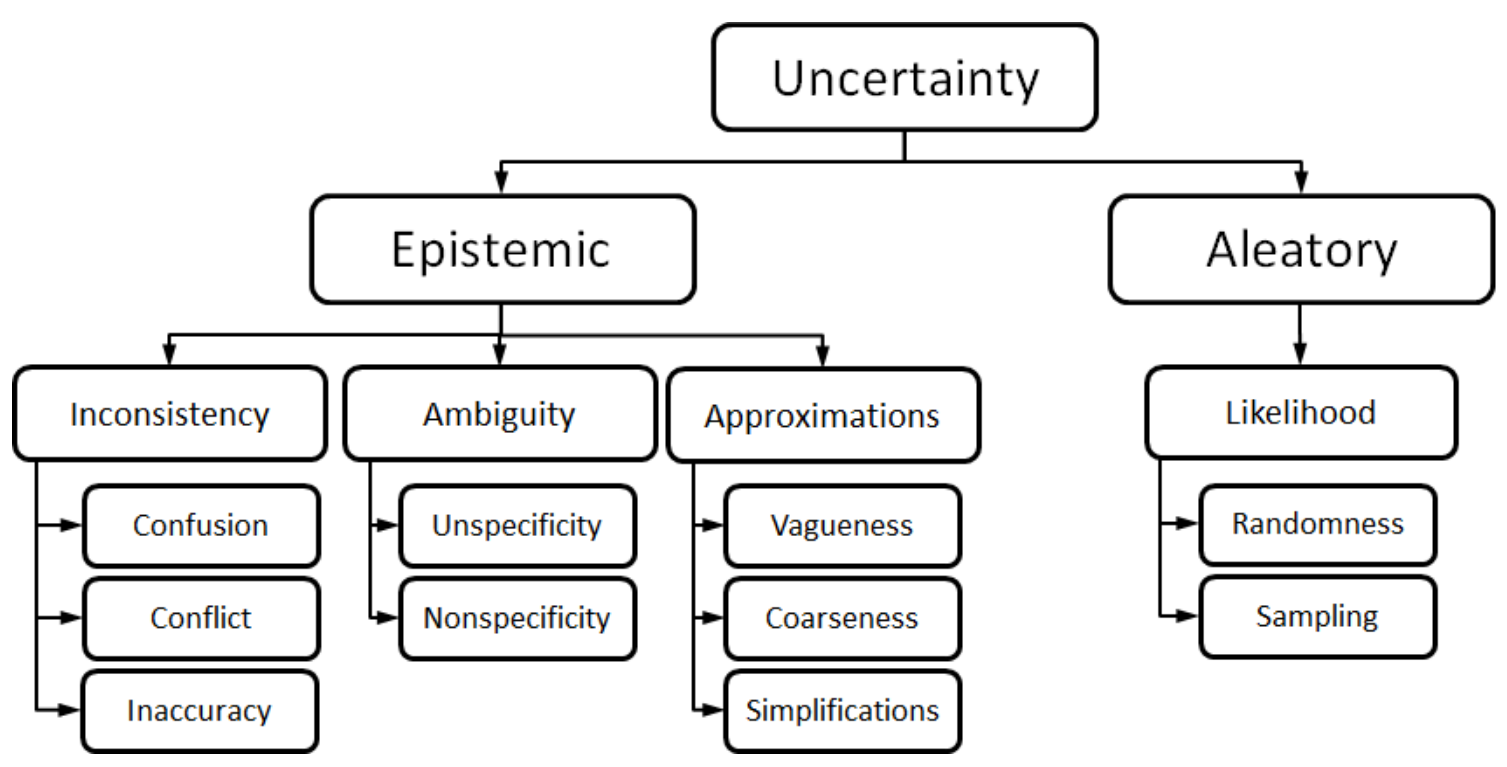

Figure 2.1 Taxonomy of uncertainty [59]

Uncertainty is inherent in any form of the simulation-based design. The classification of uncertainty is important when running simulations and design optimizations because these methods are depended on uncertainty type. In general, the classification can be made between 
epistemic uncertainty and aleatory uncertainty. Figure 2.1 shows the hierarchy of uncertainty [59].

\subsubsection{Epistemic uncertainty}

Epistemic uncertainty goes by other names such as reducible uncertainty, model form uncertainty, data uncertainty and state of knowledge [60]. Epistemic uncertainty is also known as a subjective uncertainty. It arises due to the ignorance of the physical phenomena, simplifying assumptions in simulation based modeling or general lack of knowledge of the system characteristics, and environment or range of the conditions for the system to operate [59]. It is associated with inappropriate models of the system and the deficient nature of unified modeling technique. Round off errors and tolerances can be treated as epistemic uncertainty. The higher fidelity analysis methods usually have lower epistemic uncertainty [60]. It can be reduced by enhancing the state of knowledge by using resources to acquire more sample data for uncertain parameters.

From Figure 2.1, epistemic uncertainty can be classified as inconsistency, ambiguity or approximations. Inconsistency in knowledge ascribes to misrepresented information from the result of inaccuracy, conflict, contradiction or confusion. The inconsistent assignment and substitutions can give confusion and conflict results, whereas a level bias or error in these assignments and substitutions show inaccuracy results [59].

Ambiguity comes from the possibility where processes or systems lead to multiple outcomes. It can be categorized in un-specificity and non-specificity. Un-specificity is incompletely defined results and non-specificity is improperly or incorrectly defined results. 
Approximation process involves the use of imprecise expressions in language, approximate deducing and dealing with complexity by highlighting relevance. Approximation is classified as vagueness, coarseness or simplification. Vagueness comes from imprecise concept of interest or unclear definitions, whereas coarseness results from approximation that would bound the crisp set of interest. Simplifications are assumptions to make complex problems manageable.

Examples of epistemic uncertainty include lack of data from a physical parameter, limited understanding of process or function and the modeling of an environmental condition. The Unmanned Combat Aerial Vehicle (UCAV) and the cruise missile need the path to the target. However, it was not able to figure out the location of all ground-to-air weapons on the path. The uncertainty of the path planning can be reduced with more information regarding enemy locations and numbers.

\subsubsection{Aleatory uncertainty}

Aleatory uncertainty describes the inborn variation of the physical system. This uncertainty can appear in the form of manufacturing tolerance and uncontrollable variations in the external environment such as atmospheric properties. Aleatory uncertainty has various names as: variability, irreducible uncertainty, inherent uncertainty, stochastic uncertainty, intrinsic uncertainty, underlying uncertainty, physical uncertainty and probabilistic uncertainty. They are usually modeled as random phenomenon characterized by the probability distributions and require large amounts of information [61]. The probability distributions can be generated based on actual 
measurements, statistical estimation or expert opinion. A designer has small control of aleatory uncertainty in the design and development of complex systems. Most often this information is not obtained and the designer usually makes assumptions on the characteristics of the random phenomenon causing the variation [62]. From Figure 2.1, the aleatory uncertainty encapsulates the likelihood. The likelihood is a function of how likely it is that an event will occur and it can be defined in the circumstances of chance, odds and gambling [59]. The primary components of the likelihood are randomness and sampling. Randomness holds back from the non-predictability of consequences. Engineers and scientists generally use samples to typify populations.

An example of aleatory uncertainty is the material property. An aluminum alloy piece may not have the uniform tensile strength and the actual strength at a particular point which may not coincide with the data from the structural analysis. The characteristics vary and it is impossible to have exact data without testing an individual piece. The distribution of the material properties can be developed from the sample test and can then be used for uncertainty in the design optimization.

Depending on the given problem, the classification of uncertainty may change. For example, tossing a coin has a random change of $50 \%$ for each side. However, when one considers the initial position of a coin and the hitting force, uncertainty type can be changed since it is not random any more. Such information changes uncertainty surrounding this event from aleatory to epistemic. The definition of a problem is important to define the type of uncertain parameters in a given problem.

\subsection{Uncertainty in an aircraft life cycle}




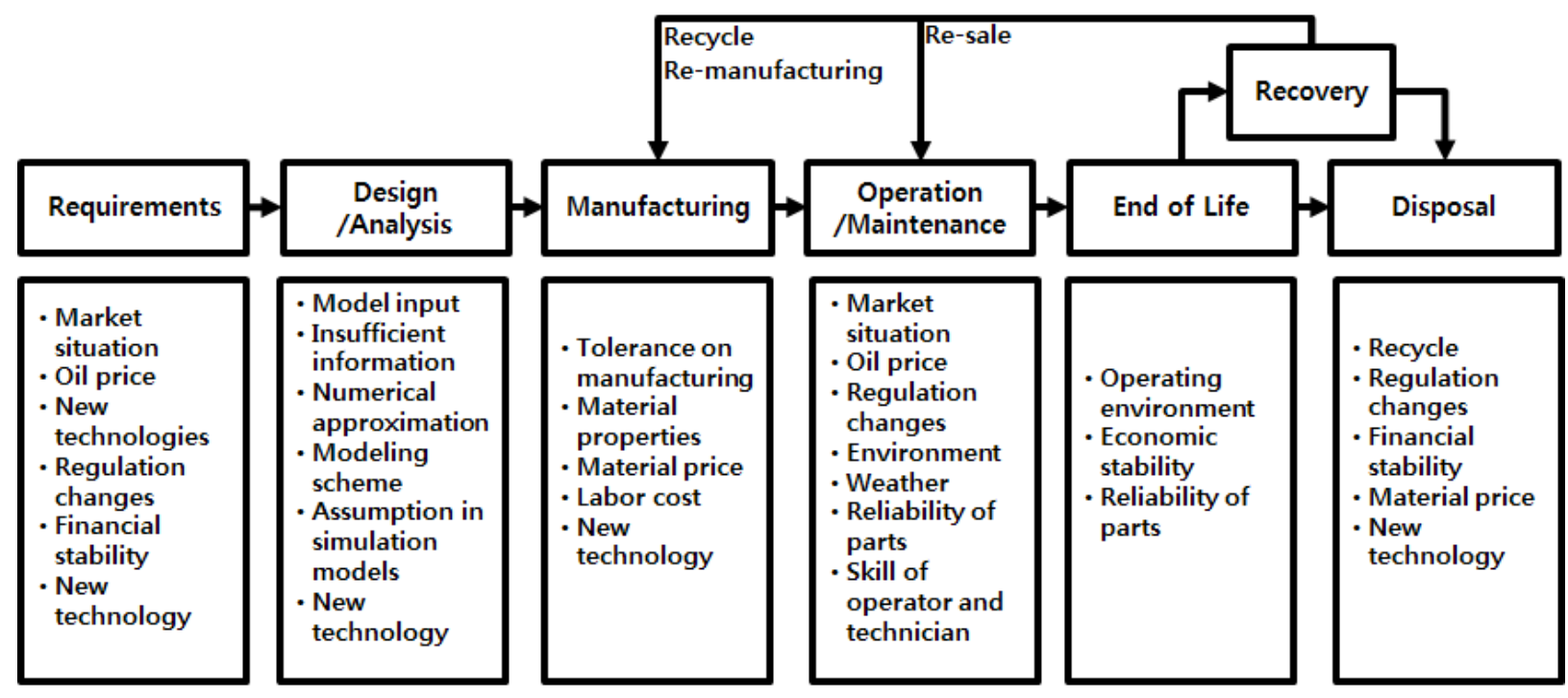

Figure 2.2. General aircraft life cycle

An identification of uncertainty source is key to developing a general methodology to quantify uncertainty. Uncertainty occurs in different phases of the aircraft life cycle. Figure 2.2 shows a general aircraft life cycle and source of uncertainty. This chapter describes how uncertainty is considered in the requirements and the design phase.

\subsubsection{Requirements}

Requirements are defined in the early stage of a general engineering design process. It gives a clear guidance to designers to consider a function and a performance level that are to be achieved in a product or a system. However, uncertainty in the requirement analysis phase have an impact on the whole design procedure and the final product itself. The sources of uncertainty can be found in the properties of the product itself or external to the product. The external 
uncertainty such as the market changes and the accidents are hard to predict. Fluctuations in exchange rate, material price and oil price have a huge impact on manufacturing cost. Regulations can be changed to incorporate new environmental considerations. Moreover, uncertainty exists when designers cannot understand customer needs or exact performance requirements. Uncertainty is fatal at the preliminary design stage since they may lead to an improper design. The voice of customer is expressed verbally and there can be unspoken requirements which are sometimes vaguely defined. In the market driven design, it is difficult to translate customer preferences into the design specifications. Once designers are able to define the actual and perceived customer needs, large amount of uncertainty is reduced. This type of uncertainty is exasperated during the design process when design requirements change as a result of random market changes or external environmental changes. Staying in touch with the customer and a continual review the market force can help managing these issues.

\subsubsection{Design stage}

The conceptual design phase deals with configuration arrangement, size, weight and performance. In this stage, new ideas and problems emerge within the design investigation when increasing the details required for design. The aircraft conceptual design utilizes many types of low fidelity analysis method which have fast computation time, but comparably low in accuracy. These analysis tools have uncertainty on its model input, numerical approximation and model form. Uncertainty on simulation based analysis model is shown in Figure 2.3. 


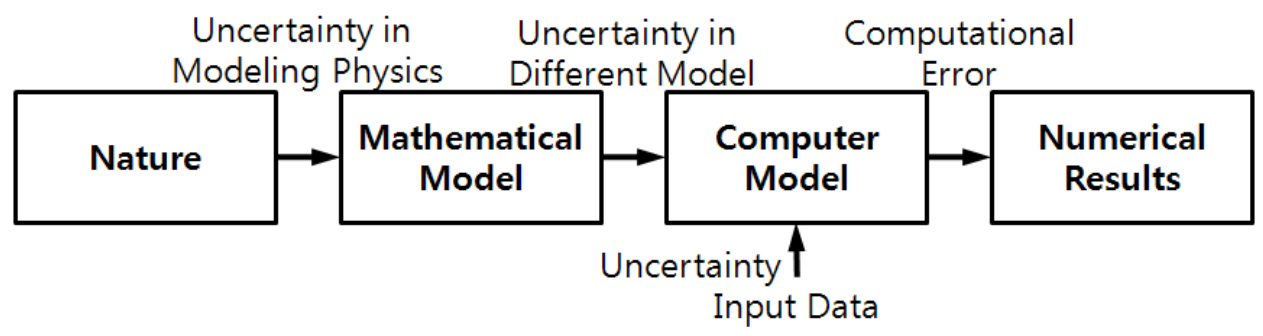

Figure 2.3. Sources of uncertainty on simulation based analysis model

\section{- Uncertainty in model input}

The model inputs include not only the parameters used in the model of the system but also the environmental data. The model input data involves geometry, essential model parameters, initial conditions, range of sources including experimental results, theory, computational simulations, and expert opinions. Figure 2.4 shows a model input for the design.

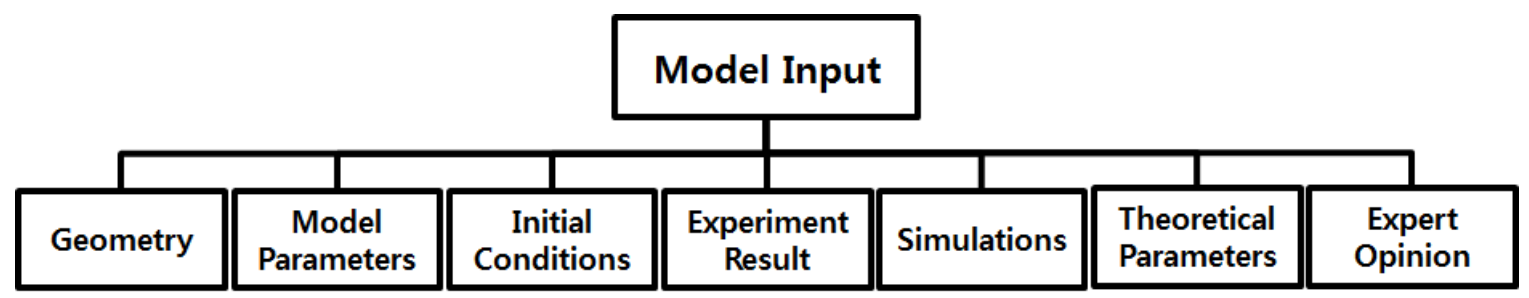

Figure 2.4. Model inputs [59]

Design variables can be taken into account as uncertainty for the following two reasons: incomplete information for the design stage simulation or inherent randomness. Simplification of the input data often ignores certain phenomena in an engineering system. Lack of information regards to design parameters and the system environments can cause errors in the design results too. 
For example, composite materials have been used less frequently for the aircraft than metallic materials such as aluminum. Therefore, the pool of data dealing with the composite material properties is smaller than other metallic materials. One could call this uncertainty from incomplete information. The general status of the atmosphere can be predicted but random fluctuations can still be found in a smaller scale. These small changes in the nature can be treated as another type of uncertainty.

\section{- Uncertainty in the engineering model}

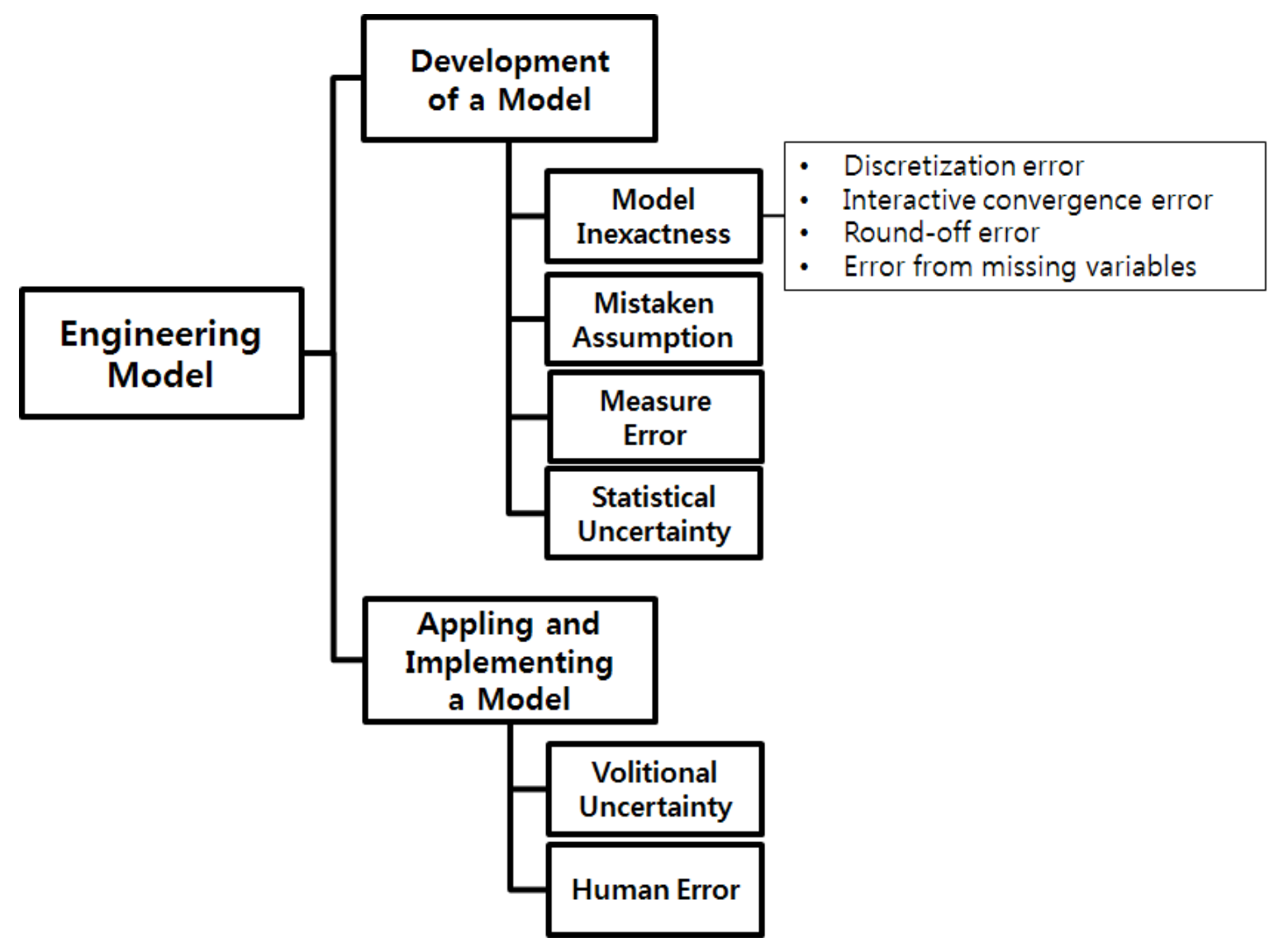

Figure 2.5. Uncertainty from engineering model [59] 
A number of mathematical models are developed for the subsystems from the design experience and the knowledge of each discipline to simulate real engineering phenomena. Designers make various assumptions and approximations to establish this mathematical model. Assumption, abstraction, and mathematical formulation on developed models have errors when compared with the high fidelity analysis tool or the actual engineering system.

Uncertainty in the engineering model can be classified by two main stages of modeling.

These stages are distinguished as the development of the model, and application and implementation of the model. Uncertainty from each stage are shown in Figure 2.5.

\section{Development of a model}

a. Model inexactness

The approximation models and the low fidelity analysis tools are used in the conceptual design phase to decrease computation time rather than the experiment data or the high fidelity analysis results. Uncertainty in numerical approximation is classified as discretization error, iterative convergence error, round-off error and error from missing variables [59]. These errors are defined as followings:

Discretization error: This type of error emerges at following cases: 1) the spatial domain is decomposed into a limited number of nodes and elements, 2) the problem is unsteady, or 3) time is advanced with a finite time step. For example, the linear model can cause errors when the actual phenomenon has nonlinear form. 
Iterative convergence errors: This type of error appears when the algebraic equations are solved approximately or when relaxation methods are performed to get a steady-state solution.

Round-off errors: Round-off error is the difference between the predicted result from the approximation model and the actual value of the real phenomena. It is generated due to limited precision of number on significant figures.

Error from missing variables: An approximation model contains only a subset of the variables that affect the quantity of interest. Therefore, some parameters and variables affecting the result can be neglected.

\section{b. Mistaken assumption}

The simulation based models are generated with many sets of assumptions. If incorrect assumptions are used, the model therefore cannot show accurate result. This type of uncertainty can be seen in the low fidelity analysis tool.

\section{c. Measure error}

The sample data from experimental measurements is utilized either to develop the empirical equations or the approximation models. However, the observations may not contain exact values because of unavoidable measurement errors due to an environment and human factors. If the calibrations for models and samples use inaccurate data, the results of developed models will also show incorrect values. The experimental data for the model validation contains aleatory 
uncertainty and may contain epistemic uncertainty from unknown bias errors.

\section{d. Statistical uncertainty}

Approximation methods using sample cases and large number of samples can guarantee an accurate surrogate model. However, there are many cases of engineering experiments that cannot provide a sufficient sample size for approximation because of cost and time limitations. Uncertainty on a developed approximation model also made in this deficiency of information.

\section{Applying and implementing a model}

a. Volitional uncertainty

A designer makes decisions for a design based on experiences and ideas. However, various engineers have different experiences and may have different point of view on design. This difference necessitate the use of different models, different analysis tools for the design and can result the derivation of different configurations.

b. Human error

This type of the uncertainty comes from humans when a designer applies a model to engineering problem. The incorrect boundary of design variables, unsuitable theory and analysis tools for the problem can give inaccurate results.

\subsubsection{Manufacturing stage}


Tolerance of manufacturing tools causes errors to the fabricating process. A design optimization shows the specific numbers required for an optimal product. However, the manufacturing cost may increase in order to satisfy the optimization result. The new technology also causes uncertainty in the manufacturing stage. This technology can be implemented to reduce cost and time, and increase efficiency. However, the immature technology can occur errors in the real field and the operator (human) can easily make mistake during at installation and operation. The labor cost is another uncertainty in the manufacturing phase. It increases the total cost of the product and can exceed the total budget. The cost changes can have an effect on the total number of products.

\subsubsection{Operation stage}

Most of operational environment are uncontrollable (i.e. weather factors) and these can be handled as uncertainty. It also comes from how the aircraft is operated in that environment. For example, an aircraft can take-off in an unexpected runway condition such as sand and water on the runway. To consider these factors, the engineering product must be designed in a robust manner.

The environmental circumstances and accidents change the regulations for the aircraft operation. The changes in regulation may affect additional devices, part changes, etc. The fluctuations in oil prices and labor fees will change the cost of operation as well. This affects the operation policy of an aircraft and its lift cycle. Reliability of each part and skill of a technician can also affect the aircraft life cycle. 


\subsubsection{Disposal and recycle stage}

An aircraft must be disposed when an accident occurs or it reaches the end of its life cycle. Some parts and materials that have longer life cycle can be reused and recycled. However, the disposal and the recycle cost changes with fluctuations in labor cost, material cost and regulations. Due to this matter, the disposal and the recycle cost are hard to predict in the design stage.

\subsection{Propagation of uncertainty}

\subsubsection{Probability method}

The probability method simulates uncertainty using random variables. The probability information is represented by Probability Density Function (PDF). The random variable probability under PDF of its limits is given in Equation 2.1 [61].

$$
P\left(x_{1}<X<x_{2}\right)=\int_{x_{1}}^{x_{2}} f_{X}(x) d x
$$

where $X$ is the random variable, $x_{1}$ and $x_{2}$ represent the lower and upper boundaries of the random

variable respectively, and $f_{X}(x)$ is PDF. $P(X \leq x)$ is denoted as $F_{X}(x)$, Cumulative Distribution 
Function (CDF) that the area under PDF. It needs to be integrated for all possible values of $X$ less than or equal to $x$. It is represented as Equation 2.2 [61].

$$
P(X \leq x)=F_{X}(x)=\int_{-\infty}^{x} f_{X}(x) d x
$$

CDF quantifies the probability of a random variable limited by a certain value. The characteristics of uncertainty can be defined by the probability identified using CDF. This can be used to resolve the corresponding value of the input quantity. Both form of $\mathrm{CDF}$ and the parameters describing the distribution of the population can be resolved when a designer has sufficient number of samples for PDF.

\subsubsection{Possibility methods}

The possibility based method treats input as the fuzzy variables. This method yields more conservative optimum design than the probability based method if there is insufficient information used in the input statistical model $[63,64]$. Input variables of the fuzzy analysis can be defined easier than the random variable inputs when it has not enough statistical data. It gives an advantage compared to the probability analysis method [65]. The fuzzy variables with the membership functions are implemented for the possibility method, instead of PDF of random variables.

The possibility measure $(I)$ should comply with the following axioms [66]:

1. Boundary requirement : $\Pi(\emptyset)=0, \Pi(\Omega)=1$, 
2. Monotonicity : if $A_{1} \subseteq A_{2}$, then $\Pi\left(A_{1}\right) \leq \Pi\left(A_{2}\right)$

3. Union measure : $\Pi\left(\cup_{i} \in I A i\right)=\max i \in I\{\Pi(A i)\}$,

where $\emptyset$ is the empty event and $\Omega$ is the fuzzy event of whole space. $\left\{A_{i}, i \in I\right\}$ is the partition of universal event $\Omega$.

\subsubsection{Reliability Based Design Optimization (RBDO)}

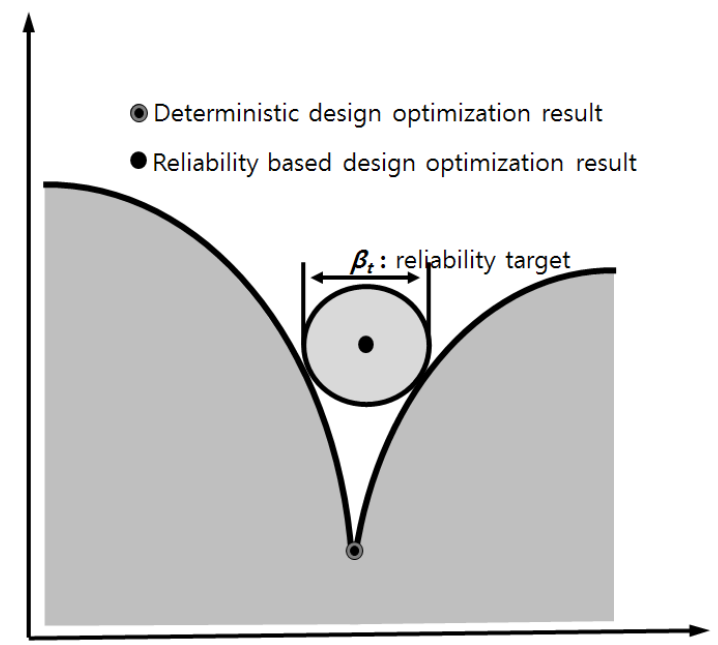

Figure 2.6. The optimum result of RBDO [66]

The basic idea behind RBDO employs the numerical optimization algorithms in order to gain the optimal design result with reliability [67]. When the optimization is performed without uncertainty consideration, certain active constraints in the deterministic optimization result may cause system failure. The reliable solution lies farther inside the feasible design region than the deterministic optimization result, while satisfying targeted reliability level. Figure 2.6 shows this concept. 
In most cases, the probability theory is implemented to model uncertainty on the simulation based design. The statistical models are performed to derive the probability distribution of random input variables. The identification of uncertain variables and the failure modes are the first task in RBDO. The probability of failure equivalent to the failure mode can be gained and can be modeled as constraints in the optimization problem to acquire the reliable design results [66].

In general RBDO formulation uses constraints on the probability of failure related to each failure mode or on the system probability of failure instead of the critical failure modes of the deterministic design optimization. The probabilistic reliability analysis was implemented to calculate probability of failure. The general formulation of RBDO is defined as below [63];

$$
\begin{aligned}
& \operatorname{Min.} \operatorname{Cost}(d) \\
& \text { subject to } P\left(G_{i}(X) \leq 0\right)-\Phi\left(-\beta_{t}\right) \leq 0, i=1,2, \cdots, n p \\
& \qquad d^{L} \leq d \leq d^{U}, d \in R^{n d v} \text { and } X \in R^{n r v}
\end{aligned}
$$

where $X$ is the random vector, $d=\mu(X)$ represents the design vector which is the mean value of $X$, $d^{L}$ and $d^{U}$ are the lower and the upper bounds of design parameter $d$ respectively, and $\Phi(\bullet)$ is the standard normal CDF. $G_{i}(X)$ represents the probabilistic constraints, $n d v$ and $n r v$ are the number of design vector and number of random vector respectively, and $\beta_{t}$ is the probability distributions and their prescribed reliability target.

$\mathrm{CDF}, F_{G i}(0)$ characterizes the failure of the performance function $G_{i}(X)$ as

$$
P\left(G_{i}(X) \leq 0\right)=F_{G i}(0) \leq \Phi\left(-\beta_{t}\right)
$$

where CDF is described as 


$$
F_{G i}(0)=\int_{G_{i}(x) \leq 0} \cdots \int f_{x}(x) d x
$$

$f_{x}(x)$ represents Joint Probability Density Function (JPDF) of all random parameters. The evaluation of the probabilistic reliability analysis needs constraints in Equation 2.4 as given in Equation 2.5. To furnish an effective solutions, approximate probability integration methods have been developed such as First-Order Reliability Method (FORM) and asymptotic SecondOrder Reliability Method (SORM). These methods have rotationally invariant measure as the reliability [68, 69]. FORM can provide sufficient accuracy and is widely used in RBDO applications. In FORM, transformation $(T)$ from the original random parameter $(X)$ to the independent and standard normal random parameter $(U)$ is required for the reliability analysis [70]. The performance function $G(X)$ in $X$-space can be assigned into $G(T(X)) \equiv G(U)$ in $U$-space.

The probabilistic constraint in Equation 2.4 can be also demonstrated by using two methods through the inverse transformation [67].

$$
\begin{gathered}
G_{p i}^{R I A}=\beta_{s i}-\beta_{t}=-\Phi^{-1}\left(F_{G i}(0)\right)-\beta_{t} \geq 0 \\
G_{p i}^{P M A}=F_{G i}^{-1}\left(\Phi\left(-\beta_{t}\right)\right) \geq 0
\end{gathered}
$$

where, $G_{p i}^{R I A}$ is the probabilistic constraint in Reliability Index Approach (RIA) and $G_{p i}^{P M A}$ is the probabilistic constraint in Performance Measure Approach (PMA).

RIA is developed to describe the probabilistic constraint in Equation 2.3. However, RIA has slow converging speeds or fails to converge at all for problems with large number of inactive constraints or violate the limits of the constraints [67]. PMA can be used instead of the probabilistic constraint in Equation 2.3 with the performance measure. The details of PMA are shown in 
following section.

\subsubsection{Possibility Based Design Optimization (PBDO)}

The possibility based method is introduced in order to handle uncertainty from lack of information. When uncertain parameters have scanty information, the possibility-based method shows better results since it is easier to identify the more conservative possible design than the more probable design $[67,71]$. This yields desirable merit, since a conservative optimum design is preferred when accurate statistical information is not available. Figure 2.7 shows the general concept of PBDO method and Equation 2.8 shows the general formulation of PBDO for engineering applications [71].

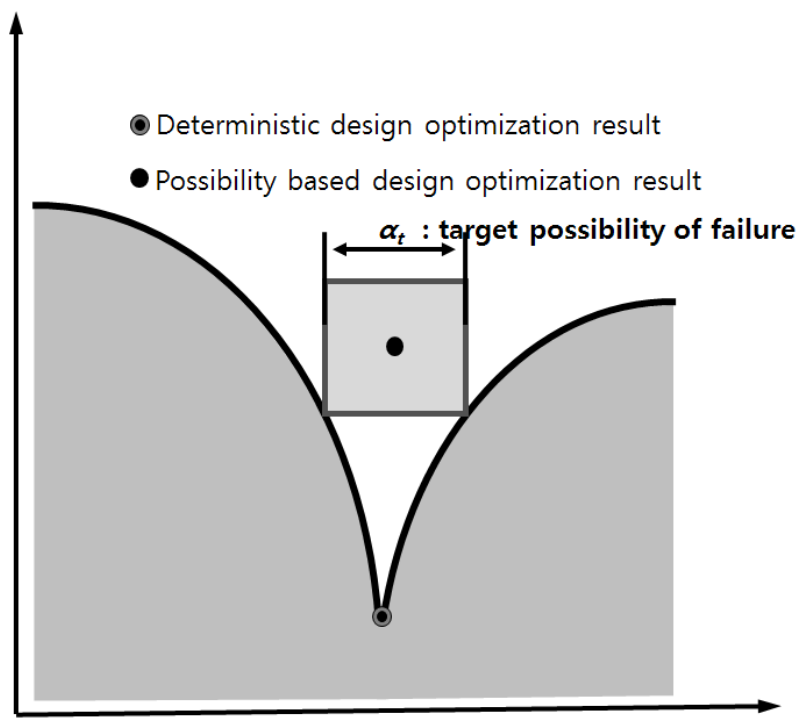

Figure 2.7. The optimum result of PBDO [66] 
Min. $\operatorname{Cost}(d)$

subject to $\Pi\left(G_{i}(d(X))>0\right) \leq a_{t}, i=1,2, \cdots, n p$

$d^{L} \leq d \leq d^{U}$

where $X=\left[X_{i}\right] T \in R_{n r}$ represents the vector of fuzzy variables when the fuzzy variable $X_{i}$ has the membership function $\Pi X_{i}\left(x_{i}\right), \alpha_{t}$ is the target possibility of failure, and $n, n r$ and $n p$ are the number of design variables, fuzzy variables, and possibility constraints respectively

This research assumed the fuzzy variables satisfy the unity, strong convexity and boundedness and be mutually non-interactive. The transformation standardizes the problem as below [71]

$$
U_{i}=\left\{\begin{array}{cc}
\Pi_{X i, L}\left(X_{i}\right)-1 & X_{i} \leq d_{i} \\
1-\Pi_{X i, R}\left(X_{i}\right) & X_{i} \leq d_{i}
\end{array}\right.
$$

where $\Pi_{X i, L}\left(X_{i}\right)$ and $\Pi_{X i, R}\left(X_{i}\right)$ are the left side and right side of the membership function of the input fuzzy variable $X_{i}$ respectively, and $d_{i}$ is the maximal grade of this membership function. After that, solving the following inverse possibility analysis is needed to evaluate of the possibility constraint, which requires Equation 2.10 [10].

$\max . G(U)$

subject to $\|U\|_{\infty} \leq 1-a_{t}$ 


\subsubsection{Performance Measure Approach (PMA)}

To find Most Probable Point (MPP), RIA method is implemented. This method yields for singularity if the design has the zero failure probability [66]. To overcome this difficulty, PMA method is developed. PMA method derives the distance in normal space to MPP to satisfy the desired reliability level $\beta$, resulting in a shift into the feasible design space as shown in Figure 2.8. The reliability index is the number of the standard deviations from the mean of the probability distribution of the constraint function in the standard space. The first order probability performance measure $(G)$ is obtained from non-linear optimization problem in $U$-space, shown below [10]:

$$
\begin{gathered}
\text { maximize } G(U) \\
\text { subject to }\|U\|=\beta_{t}
\end{gathered}
$$

where the optimum point on the target reliability surface is identified as MPP $u_{\beta=\beta_{t}}^{*}$ with a prescribed reliability $\beta_{t}=\left\|u_{\beta=\beta_{t}}^{*}\right\|$. The only direction vector $u_{\beta=\beta_{t}}^{*} /\left\|u_{\beta=\beta_{t}}^{*}\right\|$ needs to be determined by exploring the spherical equality constraint $\|U\|=\beta_{t}$. Karush-Kuhn-Tucker (KKT) necessary condition of Equation 2.11 is defined as [10]

$$
\boldsymbol{u}_{\beta=\beta_{t}}^{*}=\beta_{t} \nabla G\left(\boldsymbol{u}_{\beta=\beta_{t}}^{*}\right) /\left\|\nabla G\left(\boldsymbol{u}_{\beta=\beta_{t}}^{*}\right)\right\|
$$




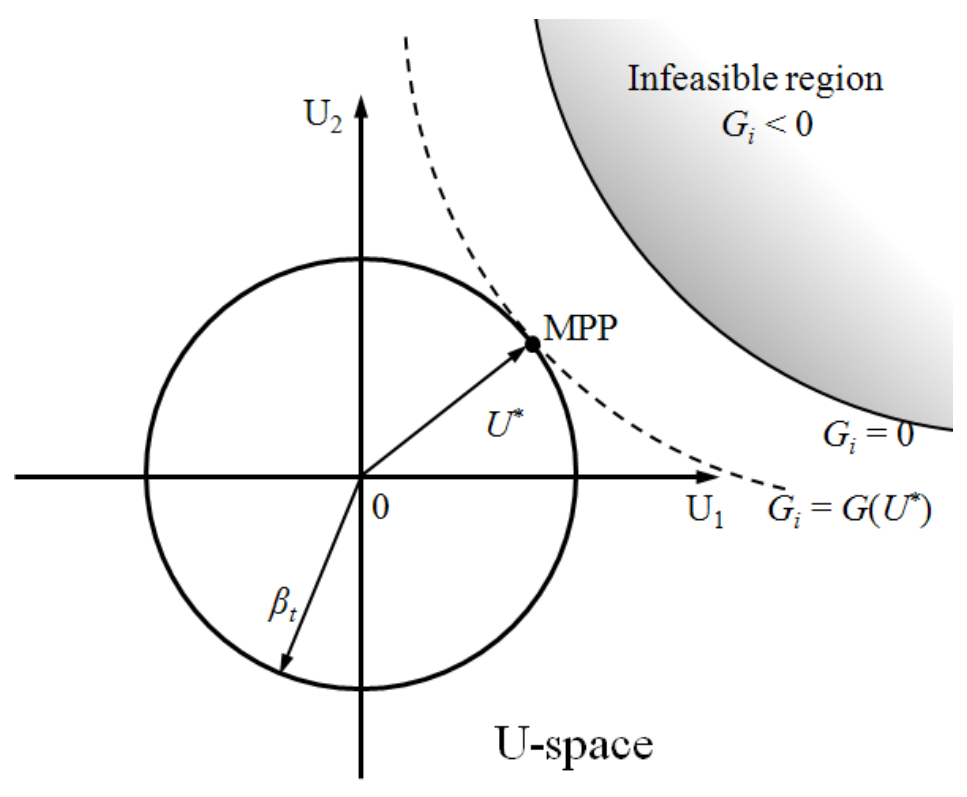

Figure 2.8. PMA approach

General optimization algorithms can be performed to solve the optimization problem of Equation 2.12. In this approach, non-linear constraints become a minimization problems. This is more robust and efficient for most applications than the other approach. In engineering problems, many non-linear constraint functions are enforced so that PMA method is more suitable approach.

\subsection{Summary}

Uncertainty in the simulation based design was described in this chapter. Various descriptions of uncertainty exist and each one of them is applied depending on available information. In general, the distinction can be made between aleatory and epistemic uncertainty. Aleatory uncertainty describes the innate variation of the physical system. This type of uncertainty 
can arise in the form of manufacturing tolerance and uncontrollable variations in the external environment. Epistemic uncertainty appears due to the ignorance of the physical phenomena, the incomplete information and lack of the knowledge of the system characteristics. Sub-categories of uncertainty and its characteristics were described. In addition, uncertainty of each phase of the aerospace system design was also described. Sources of uncertainty from each step of aircraft life cycle were identified and it gave the idea to select the methodology for uncertainty consideration. When the amount of data is considered as sufficient for input statistical distribution, RBDO method is proposed for uncertainty based optimization method. On the other hand, sufficient information for uncertain parameter is not obtained, the probability method cannot be used on the reliability analysis with optimization. To overcome this situation, PBDO method is developed for the design optimization with insufficient information. 


\section{Chapter 3}

\section{Aircraft Derivative Design Optimization}

\section{(ADDOPT) Process}

Many aircraft designs have multiple types or derivatives to satisfy various market requirements. Aircraft manufacturers develop new aircraft as modifications or extensions of existing aircraft to meet new market demands while keeping development time and cost to a minimum. The research of derivative design was surveyed in Chapter 1. This research proposes ADDOPT, the enhanced derivative design process which obtains the global change from the local change. GSA and the expert system were applied to find the important design parameters for designing the derivative aircraft subject to the new design requirements. Additionally, RBDO and 
PBDO methods were applied to handle uncertainty on the design optimization. This design process can be performed to reduce the time and the cost for the aircraft derivative design by reducing the number of design variables. Figure 3.1 shows the flow of ADDOPT process that is proposed in this dissertation. This chapter introduces ADDOT process and describes the implemented methods, Chapter 4 and Chapter 5 show the applications of ADDOPT process.

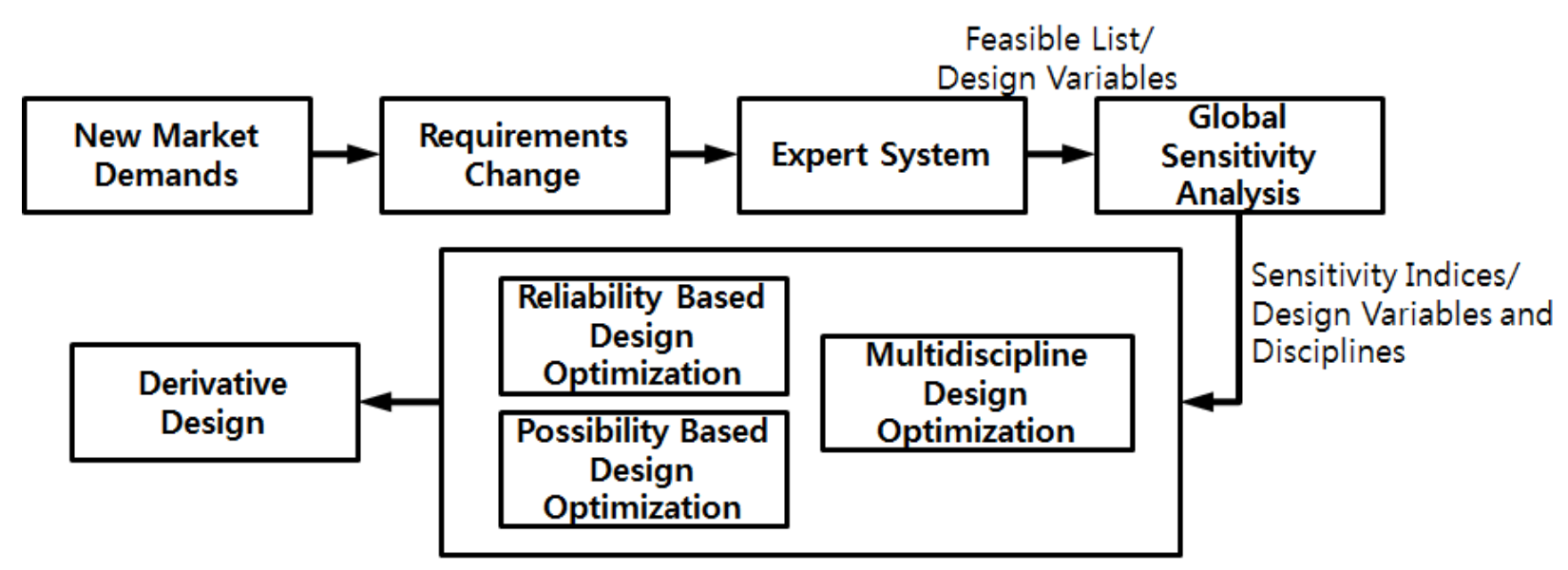

Figure 3.1. Aircraft Derivative Design Optimization (ADDOPT) process

\subsection{Requirement analysis}

When a customer stipulates new requirements, designers analyze the requirements and define the design problem. The analysis for derivatives involves redefining the design requirements and identifying the disciplines to be considered from the baseline design. From the requirements analysis, designer can define the objectives of the derivative designs.

The fuzzy expert system identifies the feasible list of the design variables to satisfy new 
demands based on the requirements analysis. A database for the expert system utilizes data from similar engineering products to the baseline product under the study. The study of the gathered data is necessary for the manufacturer in order to consider the required changes and to gain in the market requirements. The expert system generates the rules from the database in order to identify the range of each design variable. The chosen range ensures accuracy and efficiency for the sensitivity analysis method, the next phase. Figure 3.2 shows this procedure.

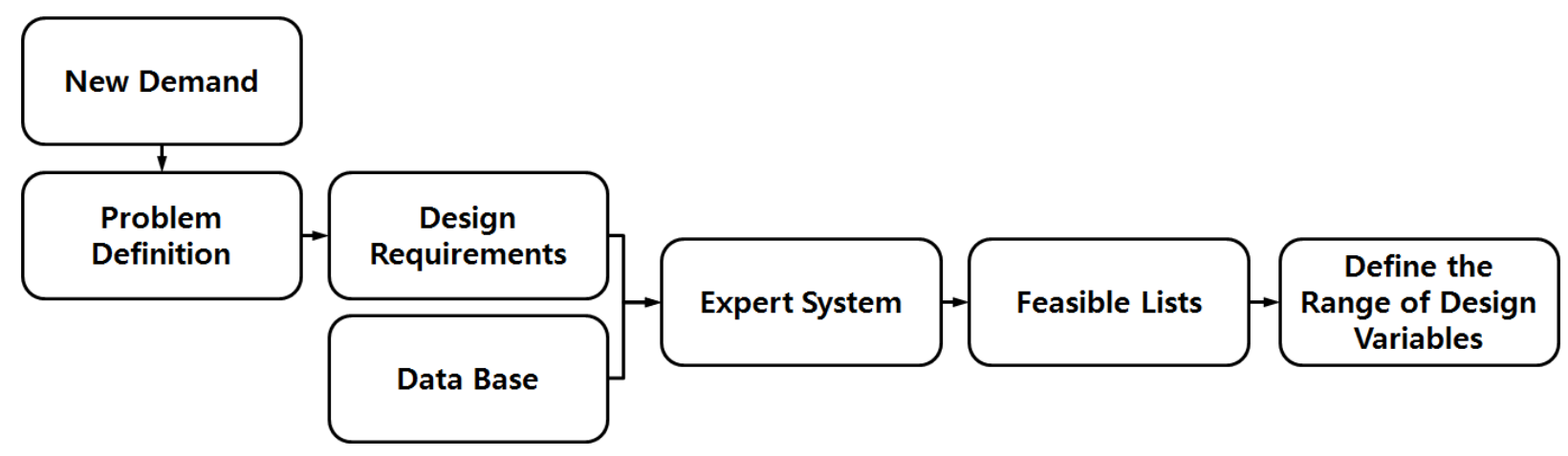

Figure 3.2. Requirement analysis and expert system

\subsubsection{Expert system}

Since most aircraft designs have many derivatives, study of the gathered data is necessary for the manufacturer to handle changes in the market requirements. The database is categorized by the aircraft types and arranged by the parts that are considered to fulfill each additional requirement. It also displays the required parameters and their changes for satisfying the additional requirements. The database then provides the guidance in selecting the design variables for the local design changes. If additional requirements are not in the database, analysis modules and design parameters are added from the requirement analysis results. The first phase of the design process 
specified the design variables relevant to the new demands. The fuzzy expert system is then performed to establish the feasible region of design variables that comply with the new demand. The database of aircraft designs and their derivatives is implemented for the requirement analysis as well as in the inference engine of the expert system. The feasible region for each design variable is utilized in the sensitivity analysis for the next phase $[72,73]$.

The expert system is consisted of the design variables, rules and results. The fuzzy function is applied to design variables for the input into the expert system and the values are normalized between 0 and 1 based on the information in the database. Equation 3.1 is implemented to normalize design variables, where 0 and 1 indicates the minimum and maximum values in the range respectively.

$$
X_{j}=1 / 2-\left(x_{\text {jmean }}-x_{j}\right) /\left(x_{\text {jmax }}-x_{\text {jmin }}\right) \quad j=1,2, \ldots, k
$$

where $X_{j}$ is the normalized design variable value and $x_{j}$ is the real value of the design variable.

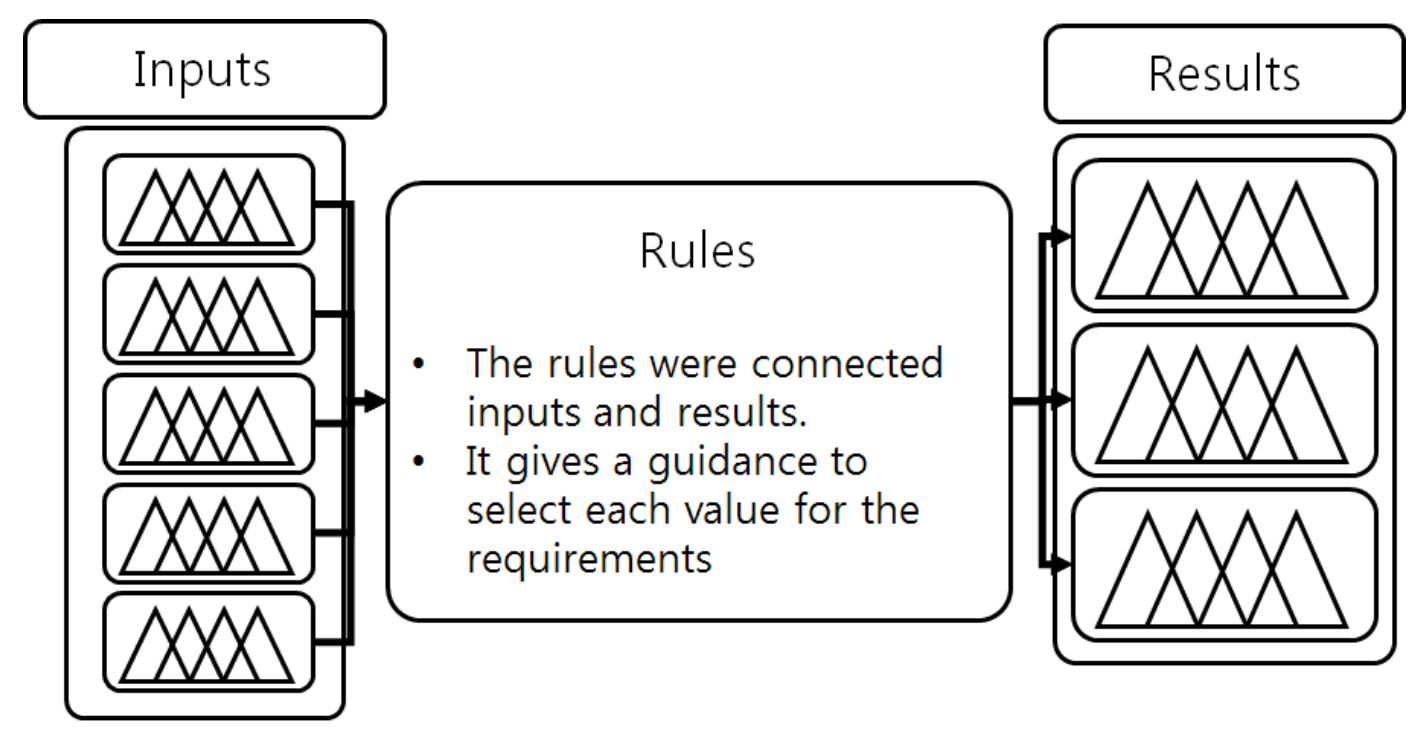

Figure 3.3. Concept of the expert system 
Variables are described by the fuzzy functions in the expert system, then the database rules are applied to yield the design result. Also, the input values that can satisfy new requirements are shown through the application of the expert system. The rules connect the input data to the results and give the guidance in selecting values for the design variables. The input values for the derivatives can be found for selected requirements using the expert system. This concept of the expert system using the fuzzy functions is shown in Figure 3.3.

The implemented expert system is evaluated in following section. GSA employed the result of expert system to increase efficiency by specifying design variables and range for derivative design.

\subsection{Global sensitivity analysis}

GSA evaluates the effects of design factors while other factors are changing. Interactions between variables are described in this way and do not depend on the choice of the nominal point $[74,75]$. The method of global sensitivity indices was first suggested by Sobol' (1990) [76] then developed by Saltelli and Sobol' (1995) [77] as well as Homma and Saltelli (1996) [78]. This method is an efficient GSA techniques and it is one of the variance-based methods. The variancebased method gives the information regarding the importance of various subsets of input variables and their relationship to the output variance. A large number of function evaluation is generally needed to achieve reasonable convergence on this method. From this fact, the variance-based 
method can be impractical for large engineering problems. The other GSA method is a samplingbased method. This method is performed repeatedly with combinations of values from samples in the distribution of the input factors. When samples from various approaches are produced as simple input-output scatter plots. This can be implemented to generate sensitivity measures of the factors [74].

The sensitivity analysis result indicates the design variables that need to be altered to satisfy the new requirements. This information is utilized to reduce the scope of the derivative design optimization problem. Using the sensitivity analysis results, one can reduce the number of design variables and achieve the accuracy and the efficiency in derivative designs and MDO problem. In addition, the case study of sensitivity analysis result defines the screening criteria on the sensitivity indices. The previous work of author for the aircraft derivative design implemented GSA method with the expert system to enhance the GSA results [79]. The details and the numerical evaluation are shown in the following section. eFAST method is performed for GSA method in this dissertation.

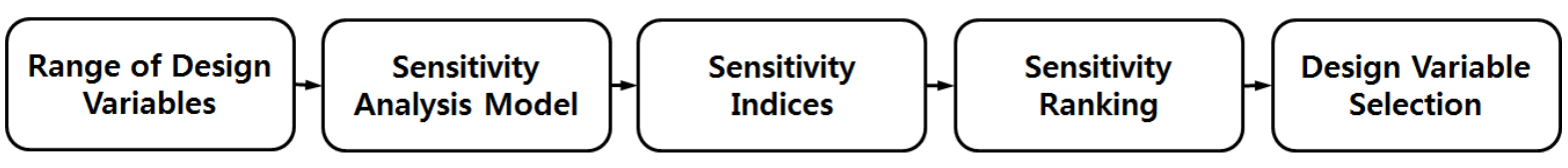

Figure 3.4. Sensitivity analysis to identify the important design variables

\subsubsection{Extended Fourier Amplitude Sensitivity Test (eFAST)}

eFAST method is based on the original FAST and variance decomposition method; input parameters are varied and these generate the variation in model output. This variation is quantified 
using the statistical notion of variance [77]:

$$
s^{2}=\frac{\sum_{i=1}^{N}\left(y_{i}-\bar{y}\right)^{2}}{N-1}
$$

where $N$ is the sample size, $y_{i}$ is the $i^{\text {th }}$ model output and $\bar{y}$ is the sample mean. Fourier analysis then determines the intensity of each parameter's frequency in the model output. These results show how strongly a parameter's frequency propagates from the input, through the model, to the output and performs as an index of the model's sensitivity to the parameter [77].

The algorithm divides the output variance, determining what fraction of the variance can be described by variation in the input parameters. Partitioning of the variance in eFAST is performed by altering different parameters at different frequencies and then encoding the characteristics of parameters in the frequency of their variation. Then Fourier analysis indicates the strength of frequency from each parameter in the model output. [76].

The sampling strategy applied in eFAST establishes the sinusoidal function of particular frequency for each input parameter. From the distribution of desired parameter values, a sinusoidal function is selected. The frequency for each parameter needs to satisfy several criteria so that the frequencies can be differentiated within the Fourier analysis. A re-sampling scheme is applied to enhance the efficiency, since the sinusoidal function has symmetric properties it will reanalyze samples. eFAST algorithm is reiterated by the number of re-sampling $\left(N_{R}\right)$ times and each time a different search curve is designated by introducing a random phase shift into each sinusoidal function. The total number of model simulations $(N)$ is given as [77]:

$$
N=N_{S} \times k \times N_{R}
$$

where $N_{S}$ represents the total number of samples and $k$ denotes the number of parameters analyzed [77]. The ability of calculating both the first-order sensitivity and the total-order sensitivity of each 
input parameter is the principle advantage of the eFAST method. The original FAST method separates the variance for each parameter, whereas eFAST method separates variance into two classes: variance by reason of the parameter of interest $i$ and variance in view of all other parameters. This method is robust and computationally efficient with low sample size [78].

The first-order sensitivity index $\left(S_{i}\right)$ of the given parameter $(i)$ is derived as the variance at a specific parameter's distinct frequency divided by the total variance. First, the Fourier coefficients at the frequency of interest $(j)$ is used to derive the variance $\left(\sigma^{2}\right)[80]$ :

$$
\begin{aligned}
s_{i}^{2} & =2\left(A_{j}^{2}+B_{j}^{2}\right) \\
\text { where } A_{j} & =\frac{1}{\pi} \int_{-\pi}^{\pi} f(x) \cos (j x) d x, \\
B_{j} & =\frac{1}{\pi} \int_{-\pi}^{\pi} f(x) \sin (j x) d x
\end{aligned}
$$

then the first-order $\left(S_{i}\right)$ is calculated as a fraction of total variance $\left(s_{\text {total }}\right)$ :

$$
S_{i}=s_{i}^{2} / s_{\text {total }}^{2}
$$

This index indicates the fraction of the model output variance that is described by the input variation of a given parameter. eFAST method calculates the total sensitivity index. The 'total' represents major effects and all the interaction terms of the factor. To estimate the total-order sensitivity index $\left(S_{T_{i}}\right)$, eFAST computes the total summation of sensitivity index of the whole complementary set of parameters $\left(S_{c i}\right.$, all parameters except $\left.i\right)$. After that, $S_{T i}$ is computed as the rest of variance after the offering of the complementary set is removed [77]. 


$$
S_{T i}=1-\left(s_{c i}^{2} / s_{\text {total }}^{2}\right)
$$

This equation involves higher-order, nonlinear interactions between the parameter of interest and the complementary set of parameters. eFAST indices is also performed to determine the degree of additive of a model.

\subsection{Uncertainty based Multidisciplinary Design Optimization (MDO)}

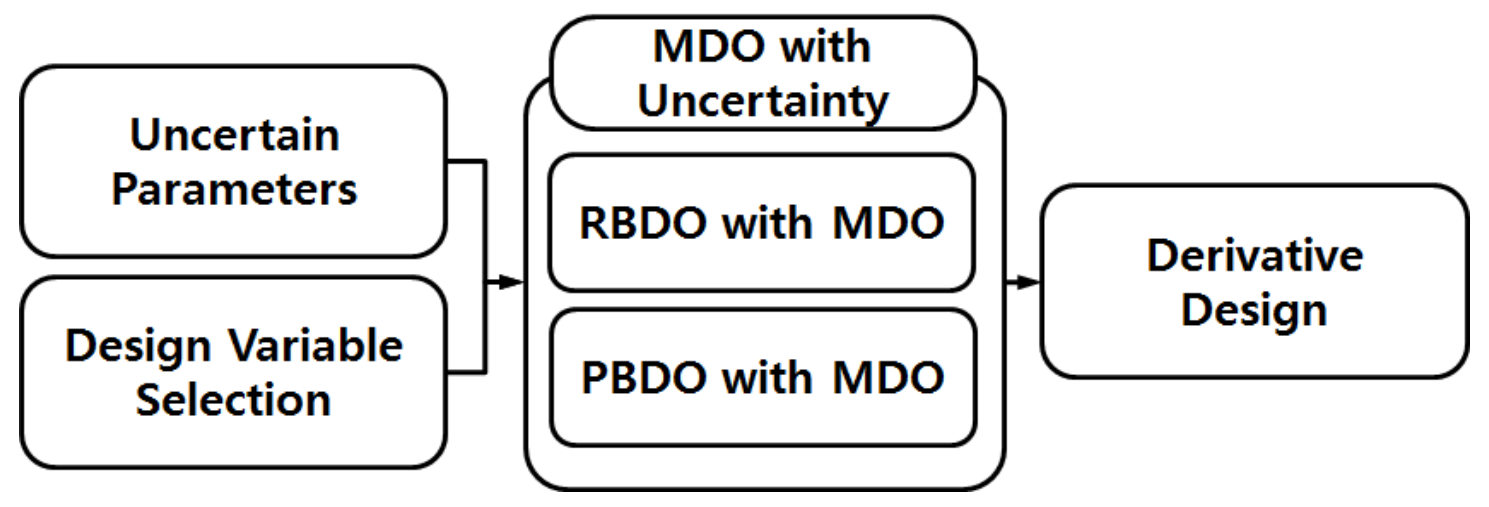

Figure 3.5. Uncertainty based MDO for derivative design

The selected design variables from GSA result were implemented on MDO module of ADDOPT process. The application of RBDO and PBDO methods with MDO technique handles the inherent uncertainty of the low fidelity analysis methods. The optimization method with uncertainty consideration prevents constraint violation via uncertainty disturbance. Many types of uncertainty are inherent in the simulation based design and suitable simulation methods exist for each type of uncertainty. The details of this aspect of uncertainty are described in Chapter 2. 
Many researchers have studied reliability based multidisciplinary design optimization methods. Various MDO techniques were implemented with RBDO and PBDO method [81, 82, 83, 84, 85, 86]. MDF and IDF methods were performed, but these approaches need large scale disciplinary analysis at the system level to find MPP $[87,88]$. CSSO and BLISS methods were

used with RBDO method, but the formulation of CSSO and BLISS is complicated for implementation. From this reason, $\mathrm{CO}$ method was applied to acquire the efficiency in design formulation with uncertainty consideration. The system level objective function remains the same for reliability based optimization and deterministic optimization. Whereas, constraints were updated depending on RBDO and PBDO results which consider uncertain parameters. Since compatibility between disciplines was enforced by the objective function of each local optimization, the auxiliary constraints do not appear in the local optimization problem statements. Therefore, there was no need to modify the reliability analysis with coupling variables and compatibility constraints.

\subsubsection{CO method with uncertainty}

In this dissertation, two different modules were proposed and their results were compared: $\mathrm{CO}$ with RBDO and CO with PBDO. PMA method was performed for the reliability assessment strategy. It is well established and accepted for RBDO and PBDO methods [10, 89]. The system level optimization of CO, Equation 1.2 in Chapter 1, was changed below for RBDO. 
minimize $f\left(z_{S L}, y_{S L}, \bar{p}\right)$

subject to $J_{i}\left(z_{S L}, z_{i}^{*}, y_{S L}, y_{i}^{*}\left(x_{i}^{*}, y_{j}, z_{i}^{*}\right), \bar{p}\right)=0$,

$$
j=1,2, \cdots, n, \quad j \neq i
$$

where $p$ represents the uncertain parameters. The $i^{\text {th }}$ disciplinary level optimization problem was changed to:

$$
\begin{aligned}
& \text { minimize } J_{i}=\sum\left(z_{S L}-z_{i}\right)^{2}+\sum\left(y_{S L}-y_{i}\right)^{2} \\
& \text { subject to } P\left(g_{i}\left(x_{i}, z_{i}, y_{i}\left(x_{i}, y_{j}, z_{i}\right), p\right) \leq 0\right) \geq P_{t}
\end{aligned}
$$

where $P$ is the probability of feasibility for each problem constraints, and $P_{t}$ represents the target probability of feasibility.

$\mathrm{CO}$ with PBDO method formulation of the system level was changed to:

$$
\begin{aligned}
& \text { minimize } f\left(z_{S L}, y_{S L}, \bar{X}\right) \\
& \text { subject to } J_{i}\left(z_{S L}, z_{i}^{*}, y_{S L}, y_{i}^{*}\left(x_{i}^{*}, y_{j}, z_{i}^{*}\right), \bar{X}\right)=0, \\
& j=1,2, \cdots, n, \quad j \neq i
\end{aligned}
$$

where $\bar{X}$ represents the fuzzy parameters. The formulation of $i^{\text {th }}$ disciplinary level optimization was changed to:

$$
\begin{aligned}
& \text { minimize } J_{i}=\sum\left(z_{S L}-z_{i}\right)^{2}+\sum\left(y_{S L}-y_{i}\right)^{2} \\
& \text { subject to } \Pi\left(g_{i}\left(x_{i}, z_{i}, y_{i}\left(x_{i}, y_{j}, z_{i}\right), X\right) \leq 0\right) \leq \alpha_{t}
\end{aligned}
$$

where $\Pi(\bullet)$ is a possibility measure and $\alpha_{t}$ represents target possibility of failure. 


\subsection{Validations of implemented methods}

\subsubsection{Validation of the expert system - Regional jet aircraft}

In this research, 21 regional jet aircraft data were collected and the database was derived [90 - 96]. The aircraft data is shown in Appendix B. The design variables and their fuzzy input range for this research are shown in Table 3.1.

Table 3.1. Design variables and its range for fuzzy function

\begin{tabular}{|c|c|c|c|c|c|}
\hline & Very Low & Low & Medium & High & Very High \\
\hline Engine Thrust (lbf) & 1500 & 2290 & 3080 & 3870 & 4660 \\
\hline Wing Area $\left(f t^{2}\right)$ & 178 & 264 & 350 & 436 & 522 \\
\hline Vertical Tail Area $\left(f t^{2}\right)$ & 46.8 & 47.975 & 49.15 & 50.325 & 51.5 \\
\hline $\begin{array}{l}\text { Horizontal Tail } \\
\text { Area }\left(f t^{2}\right)\end{array}$ & 50 & 62.5 & 75 & 87.5 & 100 \\
\hline Cabin Length $(f t)$ & 13.875 & 17.552 & 21.229 & 24.906 & 28.583 \\
\hline Wheel Base $(f t)$ & 10.167 & 14.5628 & 18.9585 & 23.3543 & 27.75 \\
\hline $\mathrm{W} / \mathrm{S}$ & 41.01 & 49.4725 & 57.935 & 66.3975 & 74.86 \\
\hline $\mathrm{W} / \mathrm{T}$ & & 2.45 & 2.725 & 3 & \\
\hline Tail Span $(f t)$ & 14.333 & 17.229 & 20.125 & 23.021 & 25.917 \\
\hline Range $(N M)$ & 1248 & 1711 & 2174 & 2637 & 3100 \\
\hline Number of Passenger & 6 & 7 & 8 & 9 & 10 \\
\hline
\end{tabular}


The input of expert system in this research used the fuzzy function. The design variables and the rules for expert system were extracted from the database of the regional jet aircraft. When derivatives were considered, these design variables changed to satisfy the new requirements. The concept of the expert system using the fuzzy function is shown in Figure 3.6.

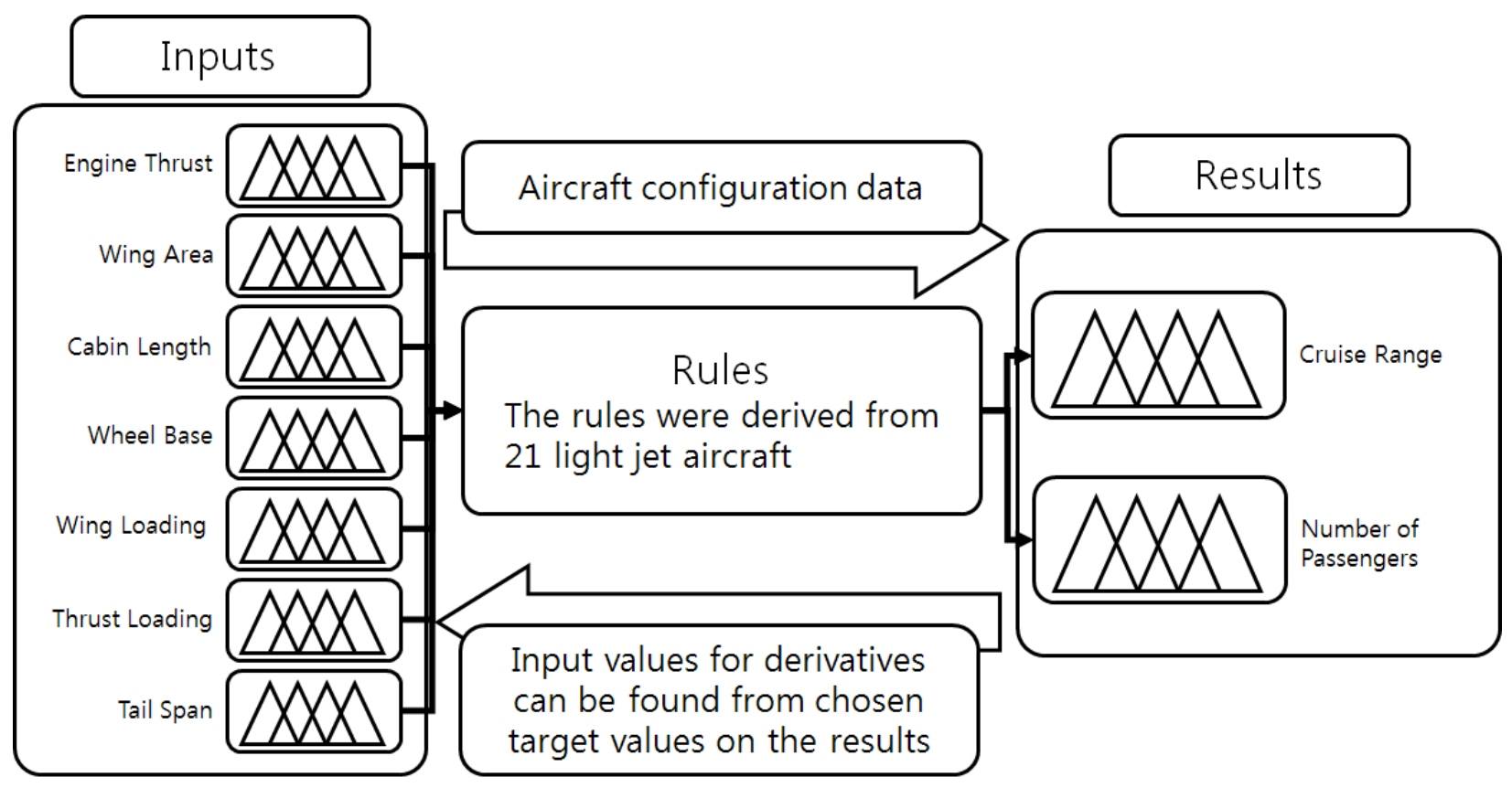

Figure 3.6. Concept of expert system for light jet aircraft

The responses in Figure 3.7 were derived from the expert system and these were based on Cessna CJ1 business aircraft which has been adopted as the baseline concept for this research. The responses for derivative design were proceeded from the database and the rules of the expert system, and it showed trend of the aircraft when design variables were changed. Figure 3.7.(a) shows the trend of the engine thrust for the cruise range. On this figure, the shading area means the design feasible region and dotted line shows the suitable range of each design variable. The target value of the cruise range was defined as 0.29 then the required input value of the engine 
thrust was found as 0.32 . This target value was based on the cruise range of Cessna CJ2. Similarly, Figure 3.7.(b) (g) showed the trend of other design variables for the cruise range.

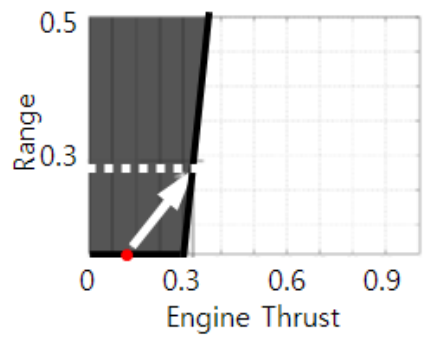

(a) Engine thrust

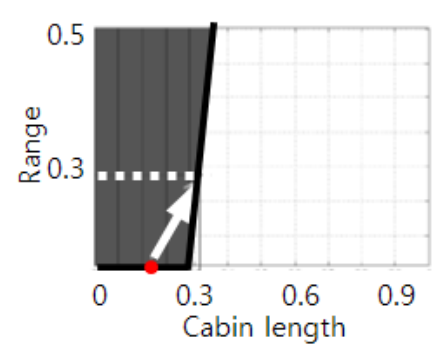

(c) Cabin length

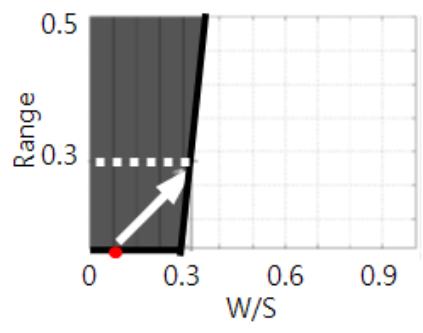

(e) W/S

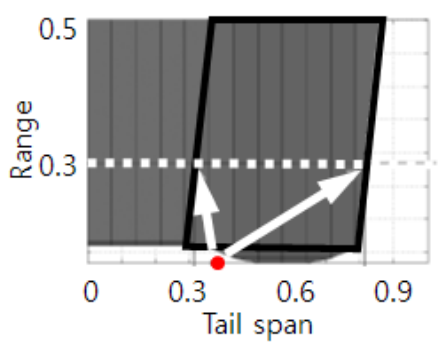

(g) Tail span

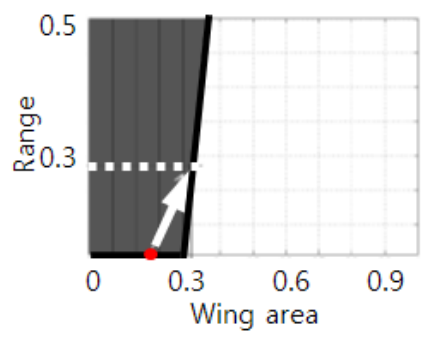

(b) Wing area

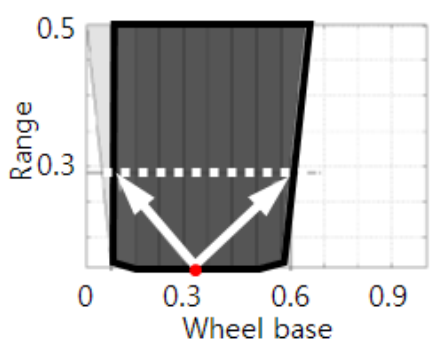

(d) Wheel base

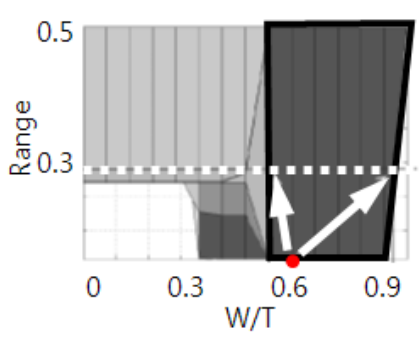

(f) $\mathrm{W} / \mathrm{T}$

Figure 3.7. Responses from expert system 
Table 3.2 and 3.3 show both normalized values and real values of the baseline and the derivative which is based on the cruise range of Cessna $\mathrm{CJ} 2$ respectively.

Table 3.2. Design variables of baseline configuration

\begin{tabular}{c|c|c}
\hline Design variables & Real value & Normalized value \\
\hline Engine Thrust $(l b)$ & 1,900 & 0.13 \\
Wing Area $\left(f t^{2}\right)$ & 240 & 0.18 \\
Cabin Length $(f t)$ & 15.75 & 0.16 \\
Wheel Base $(f t)$ & 15.38 & 0.30 \\
W/S $\left(l b / f t^{2}\right)$ & 44.17 & 0.09 \\
W/T $(l b / l b s t)$ & 2.79 & 0.62 \\
Tail Span $(f t)$ & 18.50 & 0.36 \\
Range $(N M)$ & 1,475 & 0.15 \\
\hline
\end{tabular}

Table 3.3. Target values of derivative

\begin{tabular}{c|r|r}
\hline Design variables & Real value & Normalized value \\
\hline Engine Thrust $(l b)$ & 2,500 & 0.32 \\
Wing Area $\left(f t^{2}\right)$ & 283 & 0.31 \\
Cabin Length $(f t)$ & 18.2 & 0.32 \\
Wheel Base $(f t)$ & $12.0 \sim 20.7$ & $0.1 \sim 0.6$ \\
W/S $\left(l b / f t^{2}\right)$ & 51.6 & 0.31 \\
W/T $(l b / l b s t)$ & $2.77 \sim 2.97$ & $0.58 \sim 0.95$ \\
Tail Span $(f t)$ & $18 \sim 23.8$ & $0.32 \sim 0.82$ \\
Range $(N M)$ & 1,738 & 0.29 \\
\hline
\end{tabular}


Table 3.4. Range of design variables

\begin{tabular}{c|r|r|r|r}
\hline \multirow{2}{*}{ Design variables } & \multicolumn{2}{|c|}{ Without Expert system } & \multicolumn{2}{c}{ With Expert system } \\
\cline { 2 - 5 } & $\begin{array}{c}\text { Lower } \\
\text { boundary }\end{array}$ & $\begin{array}{c}\text { Upper } \\
\text { boundary }\end{array}$ & $\begin{array}{c}\text { Lower } \\
\text { boundary }\end{array}$ & $\begin{array}{c}\text { Upper } \\
\text { boundary }\end{array}$ \\
\hline Aspect ration & 8 & 11 & 8.46 & 10.34 \\
Sweep angle (deg) & -1 & 5 & -1 & 1 \\
Taper ratio & 0.25 & 0.35 & 0.27 & 0.33 \\
$\begin{array}{c}\text { Aspect ratio of } \\
\text { horizontal tail }\end{array}$ & 5 & 1.25 & 0.927 & 1.133 \\
Aspect ratio of \\
vertical tail \\
$\begin{array}{c}\text { Taper ratio of } \\
\text { Vertical tail }\end{array}$
\end{tabular}

The target range of the derivative was 1,738 NM (the normalized value was 0.29 ). The result of the expert system defined the feasible region of each design variables. It provided more compromised range of design variables for GSA to enhance efficiency and accuracy. The range for each design variable was selected as Table 3.4 and this range was implemented for sensitivity analysis to reduce the design space. 


\subsubsection{Validation of global sensitivity analysis methods -18 bar truss problem}

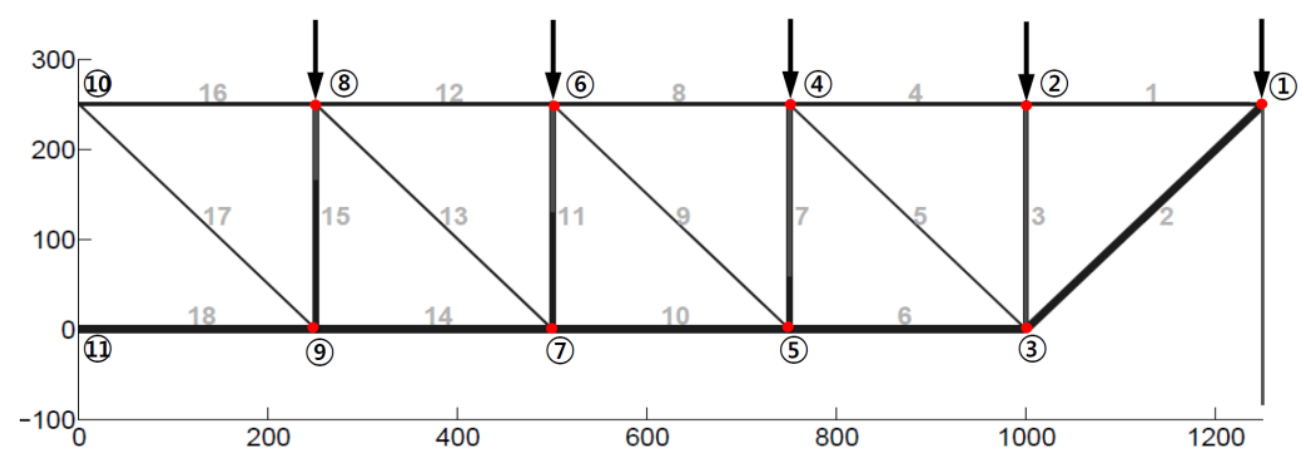

Figure 3.8. Initial 18 bar truss $[97,98]$

eFAST method is applied to the 18 bar truss example below from the deterministic problem proposed in Salajegheh and Vanderplaats [97, 98]. This problem evaluates accuracy and efficiency of the implemented eFAST module. GSA module was implemented to sort out design variables that hold more importance on reducing the dimensionality in optimization problem. An initial set of the design variables were selected to define the truss shape and the element thickness. The objective function minimized the weight of truss structure. The maximum tensile and the compressive stresses in every member must be below the ultimate stress limit and the buckling stress limit. The initial truss structure is shown in Figure 3.8, where the $x$ and $y$ axis units are in inches.

The design variables included four element area variables $\left(x_{1} \sim x_{4}\right)$ and eight variables $\left(x_{5} \sim x_{12}\right)$ which defines the coordinates of the lower nodes [97, 98]. The definitions of variables are shown in Table 3.5, as $x$ denotes the design variable vector, $A$ represents the element areas and $X$ and $Y$ are the coordinates of the lower truss nodes. 
Table 3.5. Design variables and its range $[97,98]$

\begin{tabular}{c|c|r|c|c}
\hline Variables & Definition & \multicolumn{1}{c}{$\begin{array}{c}\text { Initial } \\
\text { value }\end{array}$} & $\begin{array}{c}\text { Lower } \\
\text { boundary }\end{array}$ & $\begin{array}{c}\text { Upper } \\
\text { boundary }\end{array}$ \\
\hline$x_{1}$ & $A_{1}, A_{4}, A_{8}, A_{12}, A_{16}$ & 10.00 & 0.1 & 30 \\
$x_{2}$ & $A_{2}, A_{6}, A_{10}, A_{14}, A_{18}$ & 21.65 & 0.1 & 30 \\
$x_{3}$ & $A_{3}, A_{7}, A_{11}, A_{15}$ & 12.50 & 0.1 & 30 \\
$x_{4}$ & $A_{5}, A_{9}, A_{13}, A_{17}$ & 7.07 & 0.1 & 30 \\
$x_{5}$ & $X_{3}$ & $1,000.00$ & 800 & 1,200 \\
$x_{6}$ & $Y_{3}$ & 0.00 & 0 & 220 \\
$x_{7}$ & $X_{5}$ & 750.0 & 510 & 800 \\
$x_{8}$ & $Y_{5}$ & 0.00 & 0 & 220 \\
$x_{9}$ & $X_{7}$ & 500.00 & 350 & 510 \\
$x_{10}$ & $Y_{7}$ & 0.00 & 0 & 220 \\
$x_{11}$ & $X_{9}$ & 250.00 & 50 & 350 \\
$x_{12}$ & $Y_{9}$ & 0.00 & 0 & 220 \\
\hline
\end{tabular}

The tensile stress and the buckling stress were considered to be the constraints. The ultimate stress $\left(\sigma_{\max }\right)$ was assumed to be normally distributed $(N)$. A normally distributed uniform force was applied to the nodes 1, 2, 4, 6, and 8. Table 3.6 shows these load conditions. The buckling stress $\left(\sigma_{b}\right)$ was defined by the Euler buckling equation, given by Equation 3.11. The elastic modulus $(E)$ has $1.0 \mathrm{E}+4 \mathrm{Kpsi}$. The buckling coefficient $(K)$ was defined as 4.0 and the allowable stress was assumed as $20 \mathrm{Kpsi}$. The element length is denoted by $L$. The material density was assumed to be $0.1 \mathrm{lb} / \mathrm{in}^{3}$. 
Table 3.6. Loading condition for 18 bar truss problem [97, 98]

\begin{tabular}{c|c|c|c}
\hline Node & $F_{x}(\mathrm{lbs})$ & $F_{y}(\mathrm{lbs})$ & $F_{z}(\mathrm{lbs})$ \\
\hline 1 & 0 & $-20,000$ & 0 \\
2 & 0 & $-20,000$ & 0 \\
4 & 0 & $-20,000$ & 0 \\
6 & 0 & $-20,000$ & 0 \\
8 & 0 & $-20,000$ & 0 \\
\hline
\end{tabular}

$$
\sigma_{b}=\frac{-K_{i} E_{i} A_{i}}{L_{i}^{2}}
$$

Table 3.7. Sensitivity indices for 18 bar truss problem

\begin{tabular}{|c|c|c|c|}
\hline $\begin{array}{c}\text { Design } \\
\text { Variables }\end{array}$ & $\begin{array}{c}1^{\text {st }} \text { order } \\
\text { Sensitivity Index }\end{array}$ & $\begin{array}{c}\text { Total } \\
\text { Sensitivity Index }\end{array}$ & Rank \\
\hline$x_{1}$ & 0.5832 & 0.7174 & 1 \\
\hline$x_{2}$ & 0.2855 & 0.3512 & 2 \\
\hline$x_{3}$ & 0.0446 & 0.0549 & 4 \\
\hline$x_{4}$ & 0.0609 & 0.0749 & 3 \\
\hline$x_{5}$ & 0.0065 & 0.0075 & 5 \\
\hline$x_{6}$ & 0.0060 & 0.0073 & 7 \\
\hline$x_{7}$ & 0.0008 & 0.0009 & 10 \\
\hline$x_{8}$ & 0.0061 & 0.0074 & 6 \\
\hline$x_{9}$ & 0.0002 & 0.0003 & 12 \\
\hline$x_{10}$ & 0.0033 & 0.0041 & 8 \\
\hline$x_{11}$ & 0.0006 & 0.0008 & 11 \\
\hline$x_{12}$ & 0.0024 & 0.0029 & 9 \\
\hline
\end{tabular}


eFAST method was performed for GSA to determine the sensitivity index of each design variables with respect to the objective function. The objective function was implemented on eFAST method to derive the sensitivity indices and Table 3.7 shows the results and its sensitivity rank. Nodal position points 7 and $9\left(x_{9}, x_{11}\right)$ were less sensitive than any other nodal positions.

Table 3.8. Comparison of design result

\begin{tabular}{|c|c|c|c|c|c|c|}
\hline $\begin{array}{c}\text { Design } \\
\text { Variables }\end{array}$ & Initial & Case 1 & Case 2 & Case 3 & Case 4 & Case 5 \\
\hline$x_{1}$ & 10.00 & 11.20 & 13.84 & 11.06 & 11.02 & 11.06 \\
\hline$x_{2}$ & 21.65 & 16.63 & 16.76 & 16.60 & 16.60 & 16.60 \\
\hline$x_{3}$ & 12.50 & 2.40 & 3.64 & 2.36 & 5.55 & 5.55 \\
\hline$x_{4}$ & 7.07 & 7.16 & 4.94 & 7.84 & 7.87 & 7.84 \\
\hline$x_{5}$ & 1000.0 & 831.39 & 750.04 & 878.25 & 835.57 & - \\
\hline$x_{6}$ & 0.0 & 162.67 & 170.35 & 185.69 & - & - \\
\hline$x_{7}$ & 750.0 & 580.17 & 660.23 & - & - & - \\
\hline$x_{8}$ & 0.0 & 106.01 & 116.56 & 174.54 & 44.76 & - \\
\hline$x_{9}$ & 500.0 & 287.34 & - & - & - & - \\
\hline$x_{10}$ & 0.0 & 18.35 & 101.64 & 100.14 & - & - \\
\hline$x_{11}$ & 250.0 & 284.53 & - & - & - & - \\
\hline$x_{12}$ & 0.0 & 17.56 & 35.52 & - & - & - \\
\hline Weight $(l b)$ & $6,430.7$ & $4,267.83$ & $4,341.49$ & $4,436.44$ & $5,091.49$ & $5,173.49$ \\
\hline Error & - & - & $1.73 \%$ & $3.95 \%$ & $19.30 \%$ & $21.22 \%$ \\
\hline $\begin{array}{l}\text { Number of } \\
\text { evaluation }\end{array}$ & - & 13,421 & 12,813 & 7,625 & 6,915 & 5,380 \\
\hline Improvement & - & - & $4.53 \%$ & $43.19 \%$ & $48.48 \%$ & $59.91 \%$ \\
\hline
\end{tabular}


The number of design variables was changed through the sensitivity index by fixing the design variables which had the low sensitivity indices. The two design variables $\left(x_{9}, x_{11}\right)$ were fixed in Case 2; four design variables $\left(x_{7}, x_{9}, x_{11}, x_{12}\right)$ were fixed in Case 3 ; six design variables $\left(x_{6}, x_{7}\right.$, $\left.x_{9}, x_{10}, x_{11}, x_{12}\right)$ were fixed in Case 4; only four design variables $\left(x_{1}, x_{2}, x_{3}, x_{4}\right)$ were implemented as design variable in Case 5. These results showed the comparison of accuracy when it changed the number of design variable. Table 3.8 shows result of each case.

Genetic Algorithm (GA) was performed for the optimization method in this dissertation [2, 99, 100]. It had 40 population and 10 operator. These results showed Cases 2 and Cases 3 within $4 \%$ error of Case 1. Moreover, Case 2 and Case 3 performed with far less evaluations as Table 3.7. On the other hand, Case 4 and Cases 5 showed almost 20\% difference of Case 1 with less number of evaluations. Figure 3.9 shows the configurations of optimization result for each case. Case 4 shows unreasonable shape and Case 5 was changed only in thickness of each member as shown in Figure 3.9. This meant that the reduced number of design variable from GSA result is applicable to the conceptual design. Reducing the number of design variable using eFAST method improved the efficiency of computation with tolerable error.

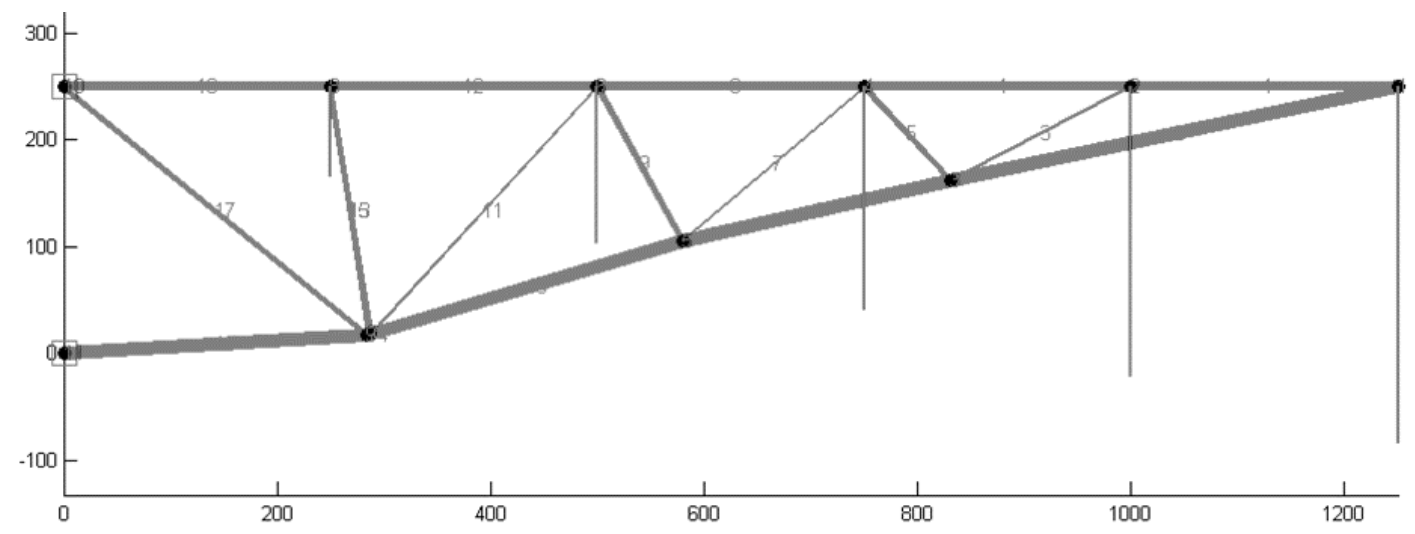

(a) Case 1 


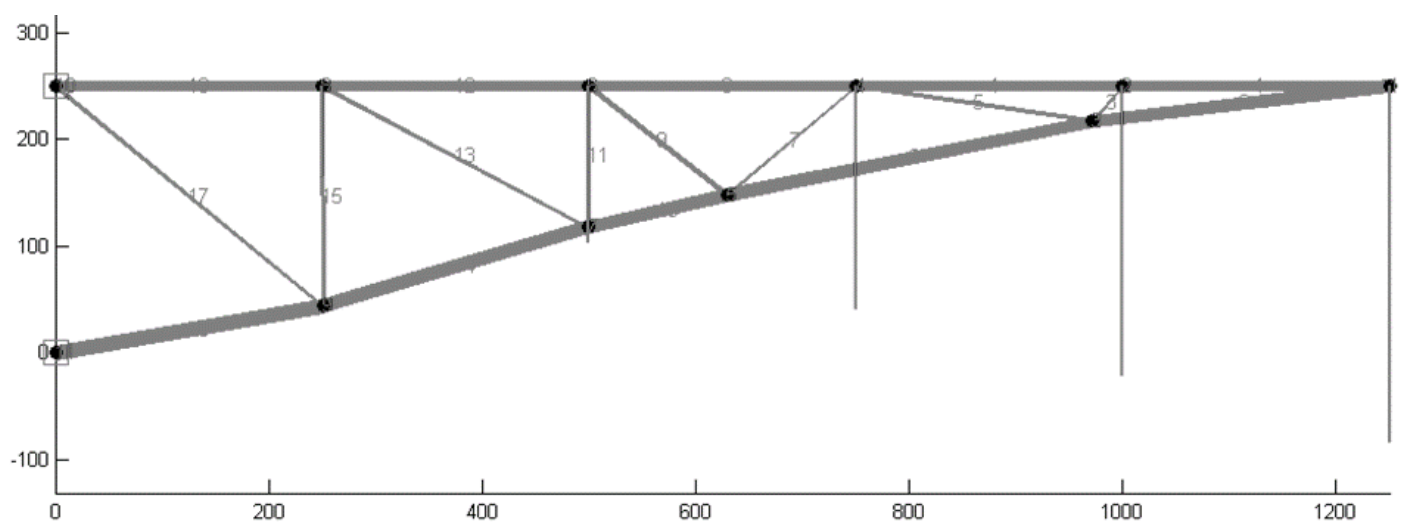

(b) Case 2

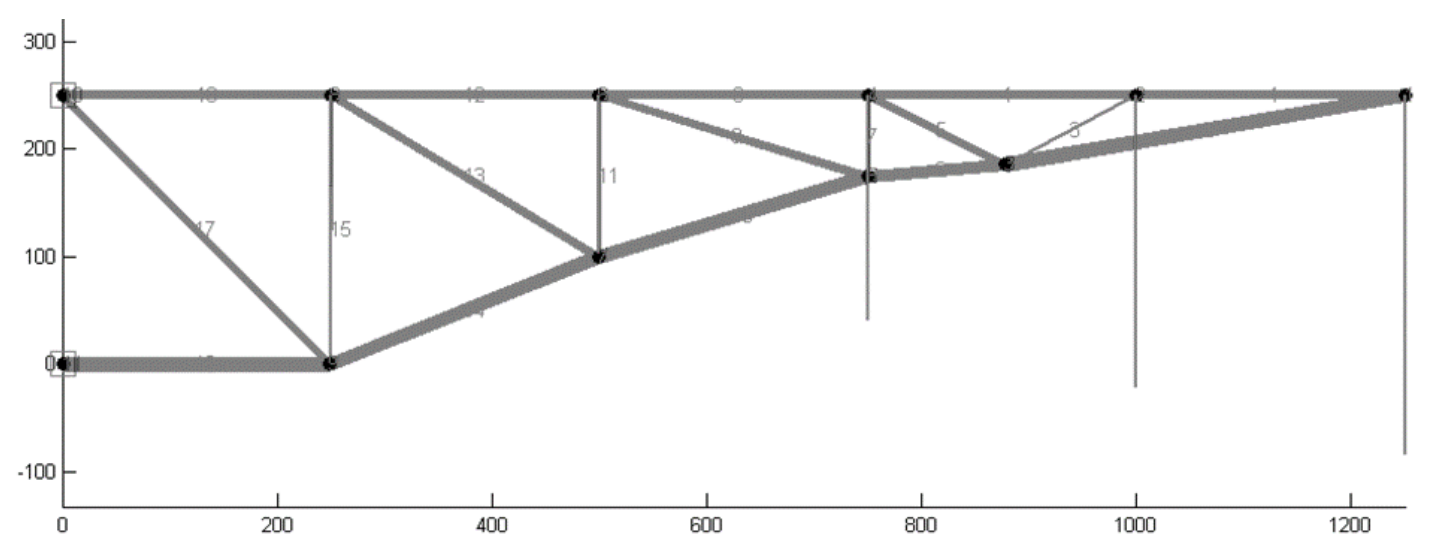

(c) Case 3

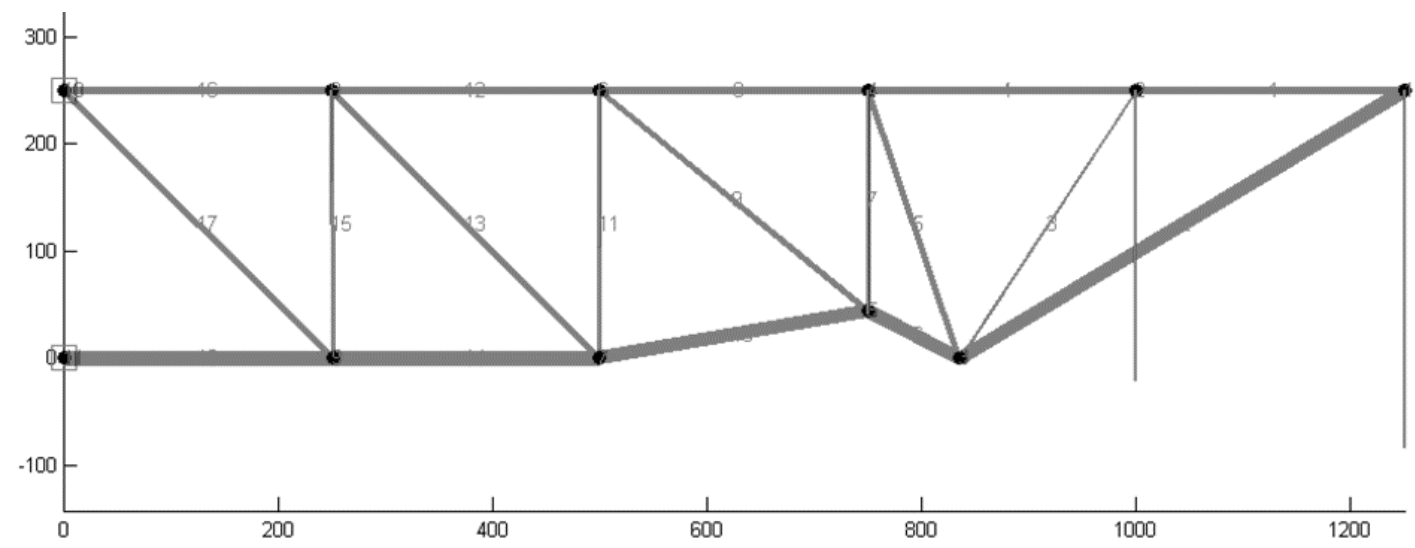

(d) Case 4 


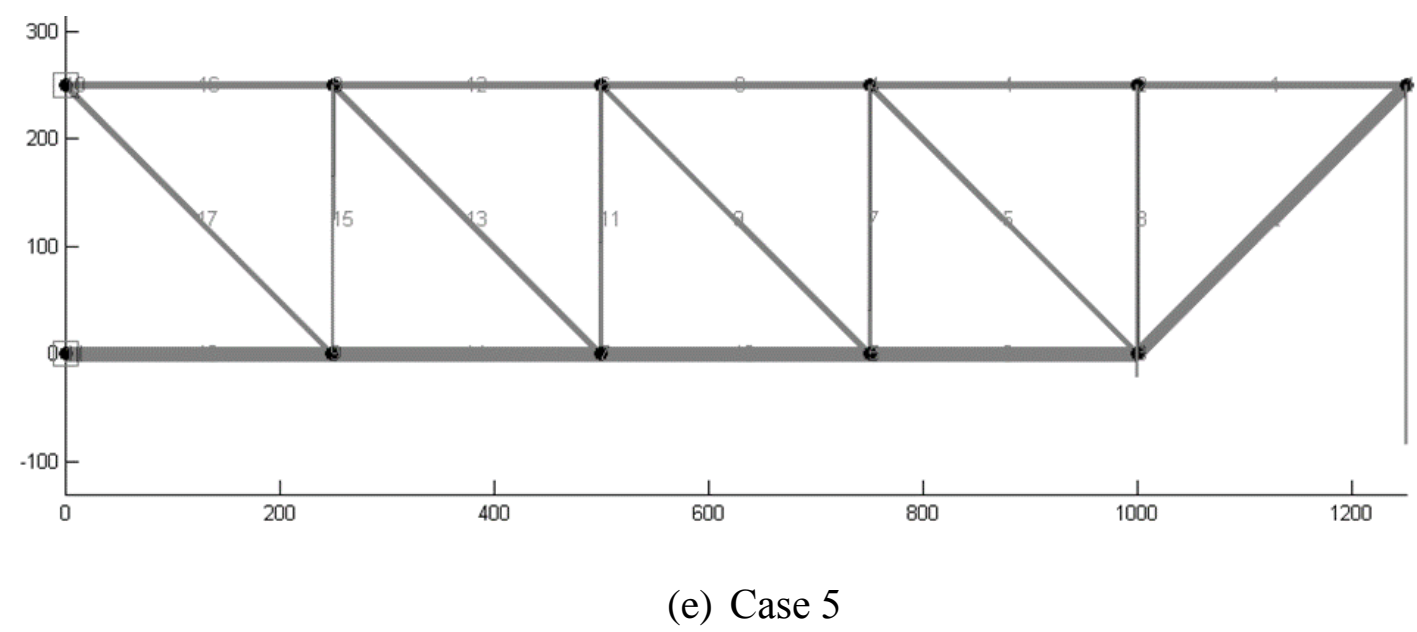

Figure 3.9. 18 bar truss optimization results

\subsubsection{Validation of uncertainty based MDO method}

A multidisciplinary analytical example from Ahn et al. [82], in Equation 3.12, was performed to validate the accuracy of RBDO and PBDO when the number of sample cases for modeling uncertain parameters was varied on MDO problem. This equation consisted of three subsystems with two state variables. It was the simple numerical example to demonstrate results in the context of multidisciplinary problem. The range and mean value of uncertain variables $x_{1}$ and $x_{2}$ are shown in Table 3.8 [82]. These variables were assumed to have Coefficient of Variation $(\mathrm{COV})$ of 0.04 with mean values assigned by the optimizer. COV was defined as the ratio of the standard deviation $(\sigma)$ to the mean value $(\mu)$ of random variable. 


$$
\begin{gathered}
\text { min. } f=-\left(\bar{x}_{1}-6\right)^{3}+y_{1}^{2}-\exp \left(\frac{y_{1}}{y_{2}}\right) \\
y_{1}=x_{1}^{2}+\frac{y_{2}}{2} \\
g_{1}=-y_{2}+\exp \left(y_{1} / y_{2}+2.2 x_{1}\right) \\
y_{2}=x_{1}+x_{2}+\frac{\left(3 x_{1} x_{2}\right)}{y_{1}} \\
g_{2}=y_{2}-y_{1}-\left(x_{2}+1\right)^{2}-\left(x_{2}-4\right)^{3}
\end{gathered}
$$

Table 3.9. The uncertain variables

\begin{tabular}{c|r|r|r}
\hline $\begin{array}{c}\text { Uncertain } \\
\text { Variable }\end{array}$ & Lower Boundary & Mean Value & Upper Boundary \\
\hline$x_{1}$ & 1 & 5 & 19 \\
$x_{2}$ & 1 & 5.01 & 10 \\
\hline
\end{tabular}

\section{System Level Optimizer}

Maximize $f$

Sys. $D V, Z=x_{1}{ }^{*}, x_{2}{ }^{*}, y_{1}{ }^{*}, y_{2}{ }^{*}, \mathrm{~g}_{1}{ }^{*}, \mathrm{~g}_{2}{ }^{*}$

s.t. $J_{1}=0, J_{2}=0, J_{3}=0, J_{4}=0$

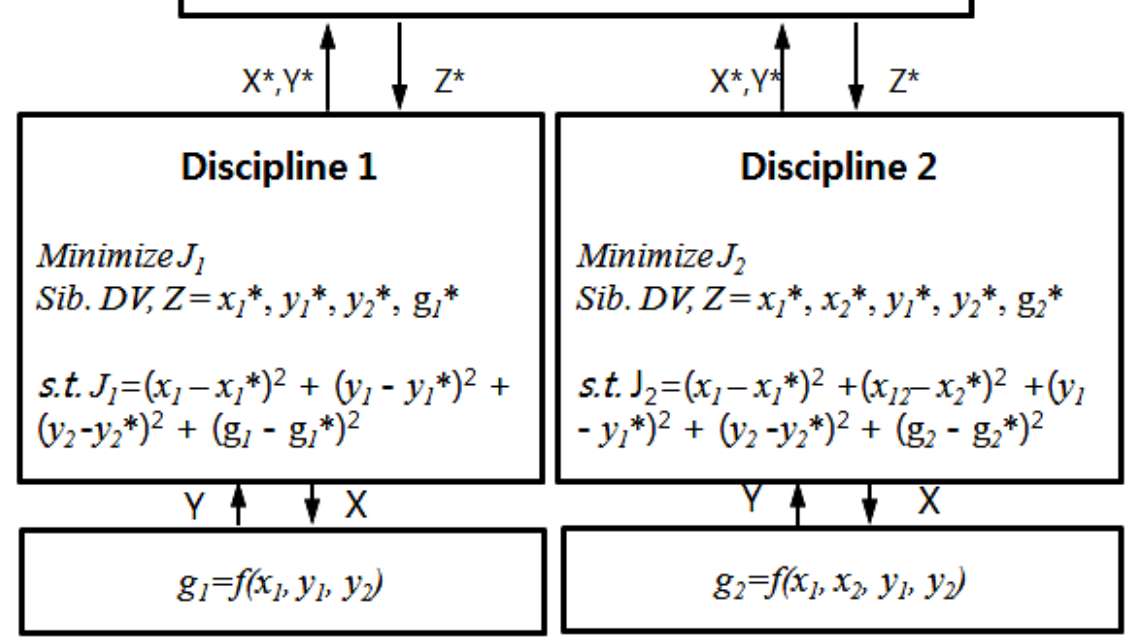

Figure 3.10. $\mathrm{CO}$ formulation 
$\mathrm{CO}$ formulation for this problem is shown in Figure 3.10. The problem was solved for seven cases at the reliability level of $3 \sigma$ and starting vector was $x_{0}=[1.5,1.5]$ and the convergence tolerance was $10^{-5}$. This problem had two uncertain variables, so it required at least two million random numbers to estimate the probability of failure when using Monte-Carlo Simulation (MCS) [101]. Table 3.10 shows the results of RBDO and PBDO for each case.

Table 3.10. Optimization results

\begin{tabular}{r|r|r}
\hline \multicolumn{1}{c|}{$\begin{array}{c}\text { Number of } \\
\text { Case }\end{array}$} & \multicolumn{1}{l|}{ RBDO } & \multicolumn{1}{l}{ PBDO } \\
\hline 10 & 193.288 & 122.052 \\
50 & 119.959 & 121.676 \\
100 & 119.884 & 121.495 \\
200 & 119.813 & 121.492 \\
500 & 119.976 & 121.497 \\
1000 & 121.048 & 121.491 \\
MCS & 120.082 & 121.493 \\
\hline
\end{tabular}

Each case was randomly selected from the range of each uncertain variable. The deterministic optimization result was 115.76 and it had $0.40 \%$ of probability with a given distribution. RBDO result and the MCS result converged when the number of cases for RBDO were increased. On the other hand, PBDO cases showed similar results even when using fifty different values on the uncertain parameters. When ten different values from the uncertain parameters were used, there was a difference between RBDO result and the MCS result. However, 
PBDO result showed similar values regardless of the number of cases. This showed that RBDO result was more dependent on the information of the uncertain parameters in comparison with PBDO result. RBDO result was improved when the number of cases was increased, while on the other hand this did not improve PBDO result.

\subsection{Summary}

This dissertation proposed ADDOPT, the enhanced derivative design process which can satisfy the requirement changes that come from the market demand with uncertainty consideration. The user requirements were analyzed and identified to select the target values for the quantifiable factors. The expert system was implemented using the database of the baseline designs and their derivatives in order to identify the design variable trends and to define the range of design parameters for the new requirements of market. The selected design variables and their ranges were utilized in GSA. This work increased the efficiency and the accuracy of GSA for the derivative design. GSA result was performed to determine the necessary design parameters to fulfill the customer's needs. The decreased design variable reduced the computation time and the cost of redesign. In addition, uncertainty analysis with MDO method was applied as well. RBDO and PBDO method in conjunction with $\mathrm{CO}$ modules were performed. To evaluate the implemented expert, the regional jet design problem was performed and it decreased the range of design variables. The 18 bar truss problem was applied to evaluate the accuracy and the efficiency of the implemented GSA module as well. GSA result showed the sensitivity indices for the objective functions and important design variables for design was derived. The optimization result with 
reduced design variables showed small error while it had reduced iteration number. The multidisciplinary numerical example evaluated accuracy of the implemented MDO modules. This example showed the characteristics of RBDO and PBDO. ADDOPT process was implemented to the wing box design in Chapter 4 and performed for the aircraft conceptual design in Chapter 5. 


\section{Chapter 4}

\section{Wing Box Design}

ADDOPT process was performed on the design optimization of the light jet aircraft wing box structure. The MDO problem was constructed using two disciplines: aerodynamics and structures. In this study, the panel method [102] was performed for aerodynamic analysis and a surrogate model - developed from a sample of FE analyses - was implemented for structural analysis. The Response Surface Method (RSM) was applied for estimating the weight and the maximum stress in the wing box design optimization. 


\subsection{Response Surface Method (RSM)}

In recent years, the computer codes and analysis methods required for engineering design become quite complex. Massive engineering data exchange and multidiscipline system analysis are integral parts of the MDO approach, thus time and cost inefficiencies may arise without careful design strategy $[65,98]$. In the generality of cases, the responses from the analysis of either single or multidiscipline - through the system approach will have numerical noise, irregularity and discontinuity. These issues can make it difficult to obtain gradient information and cause an increase of the computational load [66]. System design using the MDO requires approximation techniques which must be studied carefully in order to resolve these issues. The RSM is a statistical method which utilizes the Design of Experiment (DOE) theory [103]. It constructs a multidimensional surface from experimental model and previously obtained data, in order to predict the response of the non-experimental region. By representing the high fidelity analysis methods mathematically, a procedure for reducing the computational load of optimization can be defined. This method can approximate the global optimum through building a response surface which corresponds to the change of design variables. The second order polynomial function was implemented to represent the response surface [104].

$$
y_{\text {predict }}=b_{0}+\sum_{i=1}^{k} b_{i} x_{i}+\sum_{i=1}^{k} b_{i i} x_{i i}^{2}+\sum_{i=1}^{k-1} \sum_{j=2}^{k} b_{i j} x_{i} x_{j}
$$

where $x_{1}, x_{2}, \ldots, x_{k}$ are the design variables which affect the response, $b_{0}$ and $b_{i}(i=1,2, \ldots, k)$ are the coefficients of the regression function, and $y_{\text {predict }}$ is the predicted value of the regression function. The reliability of the response surface can be inferred using the experimental point. It 
can be estimated by the adjusted R-square $\left(R^{2}{ }_{a d j}\right)$ value that is defined by Equation 4.2 [105].

$$
R_{a d j}^{2}=1-\frac{S S_{E} /(n-m)}{S S_{y} /(n-1)}
$$

where, $S S_{E}$ and $S S_{y}$ represent the error sum of squares and the total sum of squares respectively. $n$ represents the number of experimental points and $m$ is the number of response function coefficients. Typical values for $R^{2}$ adj are between 0.9 and 1.0 when observed response values are accurately predicted by the response surface model. The error associated with the model is represented probabilistically.

\subsection{Problem definition}

A parameterized finite-element model of the generic light business jet wing box was developed with ANSYS and is shown in Figure 4.1. The wing box model was automatically constructed including leading and trailing edge spars, upper and lower skins as well as stringers and ribs using the MATLAB function to generate the ANSYS mesh. The MATLAB function applied random cases of parameter values to generate meshes on ANSYS. ANSYS developed the meshes and analyses the von Mises stress and weight for each case of the MATLAB function. The area mesh implemented an eight node PLANE 82 element. All degrees of freedom at the root was constrained as well as the spars, spar caps, skin, and stringers. The load distribution was defined as an average force for each panel. In this research, 148 cases were derived using Latin Hypercube 
method and analyzed to secure accuracy on the surrogate model, where previous research used 200 samples cases to generate the surrogate model [106]. However, fifty-two cases that violated constraints were removed in this research and remaining cases were kept to generate RSM for nine design variables [105]. These cases are shown in Appendix A. Figure 4.2 shows the procedure for the RSM development from the FE analysis result.
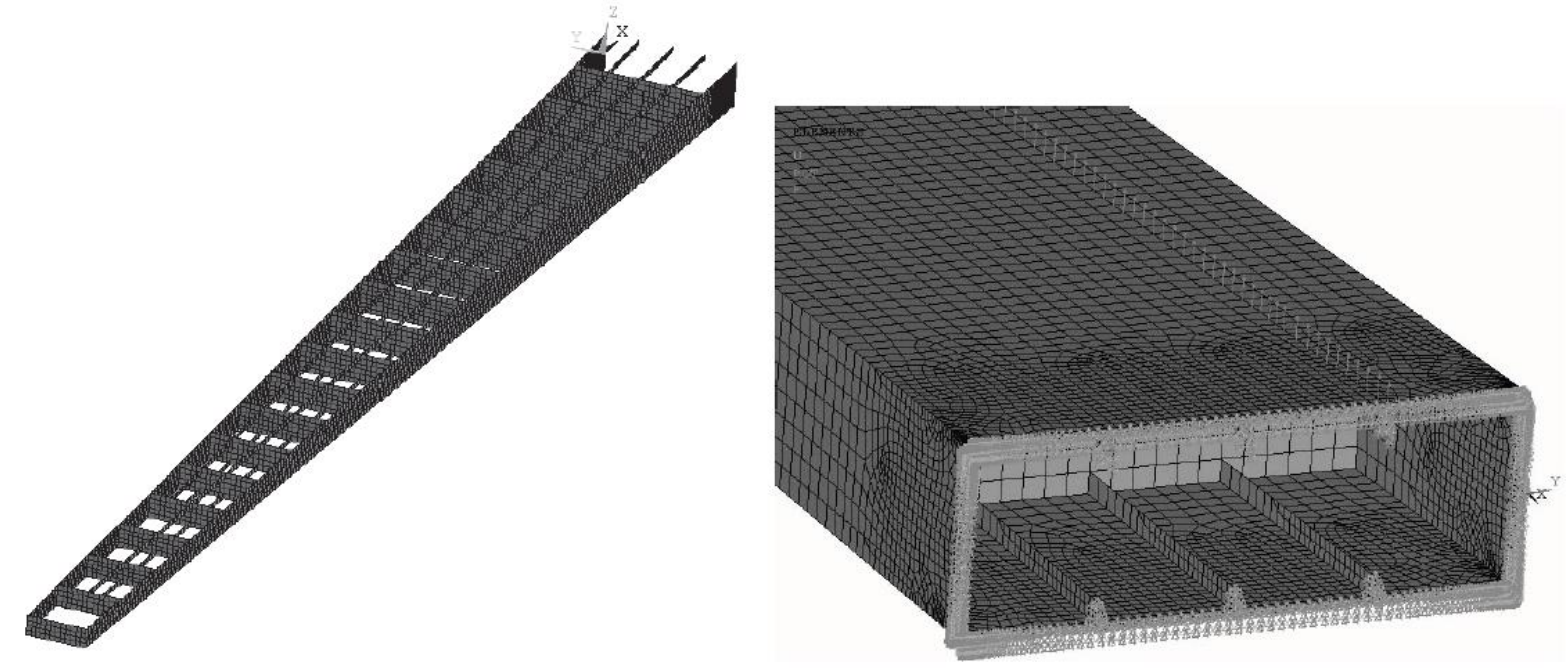

Figure 4.1. Wing box FEM model [106]

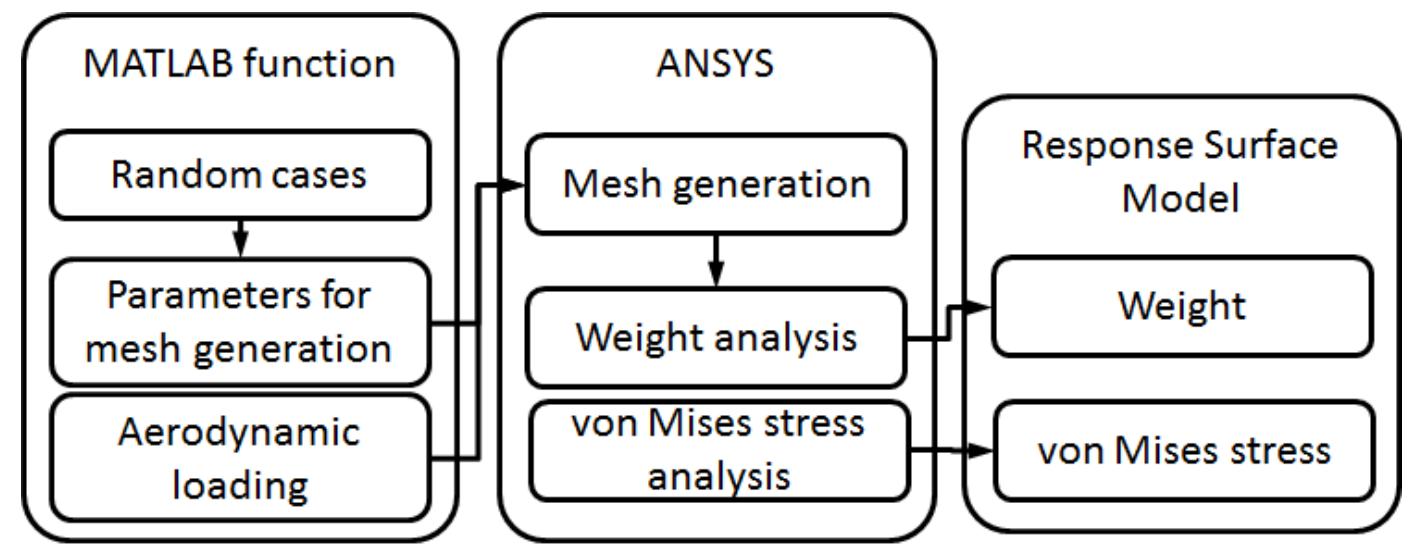

Figure 4.2. Process of Response Surface Model development for wing box 
The aircraft concept considered was similar in size and performance to light jet aircraft such as Cessna Mustang and Diamond Jet. The performance targets for the conceptual wing design were selected to match values typical to small light jet aircraft. The target gross weight was assumed to be $11,460 \mathrm{lb}$ with a wing-stored fuel capacity of 2,650 lb. The wing weight budget was $970 \mathrm{lb}$ for the load bearing structure. The maximum von Mises stress was constrained to be below $360 \mathrm{MPa}$, corresponding to the yield strength of aluminum 7075 with a safety margin of 1.5 as required by airworthiness standards. The objective of optimization was to maximize the wing L/D at the cruise speed of $400 \mathrm{kts}$ and the altitude of 35,000 ft. The L/D from main wing was considered only [106].

The multi-discipline optimization problem was formulated with two disciplines: an aerodynamics solver using panel method and a structures solver consisting of RSM. FE analysis was replaced by RSM. An error term was defined from differences between the stress calculated using FE analysis model and the stress estimated using the approximation model.

RSM for weight and stress analysis were generated from a database of sampled finiteelement solutions in the design space. FE model consisted of twenty-nine member attributes representing the thicknesses of the primary structural members - nineteen ribs, the front and rear spar, six stringers as well as the upper and lower skin. The dimensionality was reduced by linking attributes to seven design variables as shown in Table 4.1 and Figure 4.3. Two variables were introduced to change the overall wing geometry including the span and wing reference area, which makes the total of nine design variables. The sweep angle, taper ratio and airfoil were fixed as constant. Considering all twenty-nine design parameters for wing shape would potentially yield a better design result. However, the accuracy of the surrogate models with thirty-one dimensions is found to be extremely low for given FEA cases. It needs large number of FEA cases to secure 
accuracy of the surrogate model for thirty-one dimensions. 148 test cases were enough for nine design variables, but were not sufficient for thirty-one design variables.

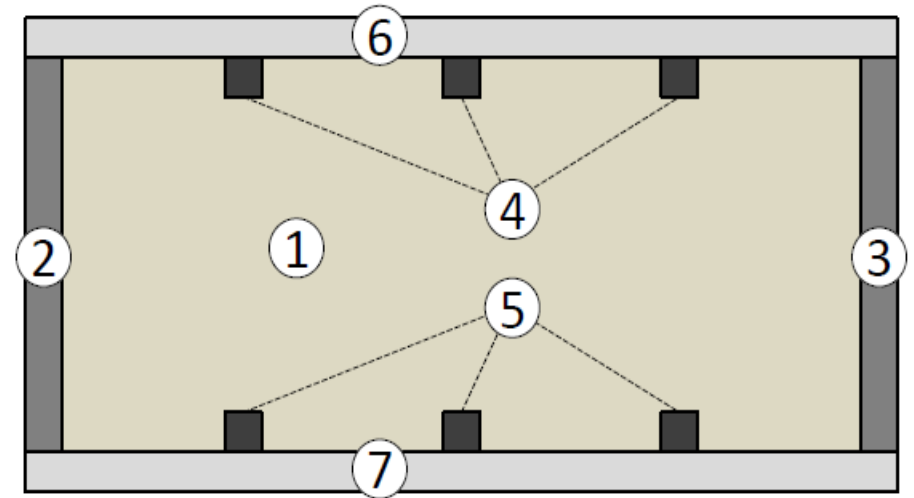

Figure 4.3. Wing box shape and design variables [106]

Table 4.1. Design variables for wing box and its range [106]

\begin{tabular}{c|c|c|c|c|c}
\hline Member & $\begin{array}{c}\text { Design } \\
\text { variable }\end{array}$ & Unit & $\begin{array}{c}\text { Initial } \\
\text { value }\end{array}$ & $\begin{array}{c}\text { Lower } \\
\text { limit }\end{array}$ & $\begin{array}{c}\text { Upper } \\
\text { limit }\end{array}$ \\
\hline Rib 1 19 & $x_{1}$ & in & 0.1379 & 0.0787 & 0.1969 \\
Front spar & $x_{2}$ & in & 0.7874 & 0.3937 & 1.1811 \\
Rear spar & $x_{3}$ & in & 0.7874 & 0.3937 & 1.1811 \\
Upper stringer 1 3 & $x_{4}$ & in & 0.2362 & 0.0787 & 0.3937 \\
Lower stringer 1 3 & $x_{5}$ & in & 0.2362 & 0.0787 & 0.3937 \\
Upper skin & $x_{6}$ & in & 0.8859 & 0.5906 & 1.1811 \\
Lower skin & $x_{7}$ & in & 0.8859 & 0.5906 & 1.1811 \\
Span length $(b)$ & $x_{8}$ & $f t$ & 31 & 26.0 & 36.0 \\
Reference wing area $(S)$ & $x_{9}$ & $f t^{2}$ & 113.25 & 96.50 & 130.0 \\
\hline
\end{tabular}


Table 4.2 shows the sensitivity indices for the weight of wing box. Using this result, seven design variables were selected which had more than 0.004 of total order sensitivity index and two design variables $\left(x_{3}, x_{4}\right)$ were fixed with an initial value. MDO formulation was generated using seven design variables.

Table 4.2. Sensitivity indices of design variables

\begin{tabular}{c|r|r|r}
\hline $\begin{array}{c}\text { Design } \\
\text { variables }\end{array}$ & $\begin{array}{c}1^{\text {st }} \text { order } \\
\text { Sensitivity Index }\end{array}$ & $\begin{array}{c}\text { Total } \\
\text { Sensitivity Index }\end{array}$ & Rank \\
\hline$x_{1}$ & 0.0030 & 0.0059 & 5 \\
$x_{2}$ & 0.0025 & 0.0049 & 6 \\
$x_{3}$ & 0.0013 & 0.0025 & 8 \\
$x_{4}$ & 0.0012 & 0.0023 & 9 \\
$x_{5}$ & 0.0045 & 0.0089 & 4 \\
$x_{6}$ & 0.0023 & 0.0045 & 7 \\
$x_{7}$ & 0.0134 & 0.0266 & 3 \\
$x_{8}$ & 0.7087 & 0.9151 & 1 \\
$x_{9}$ & 0.2631 & 0.4569 & 2 \\
\hline
\end{tabular}

In this research, uncertainty from analysis tool was considered from various types of uncertainty as descripted in Chapter 2. RBDO and PBDO methods were applied to consider uncertainty in RSM. The uncertain parameters were generated from the error between FE analysis result and RSM results. 148 random cases were used for RSM and $R^{2}$ adj value was 0.98 . The error associated with the model was represented probabilistically. The normal distribution and membership function of error were implemented to RBDO and PBDO respectively. The normal distribution had a mean of 0.0010 , variance of 0.0087 and a standard deviation of 0.0932 . In 
addition, the membership function was derived for PBDO method. The target reliability level of RBDO and PBDO was 3 with the probability of $99.87 \%$ while the deterministic optimization result had a $70.52 \%$ of probability. CO method in conjunction with RBDO and PBDO was performed and the results from these two modules were compared. $\mathrm{CO}$ architecture is shown in Figure 4.4. In this research, the DOT (Design Optimization Tool) version 4.0, which has relatively fast and effective tool was utilized for CO formulation [107].

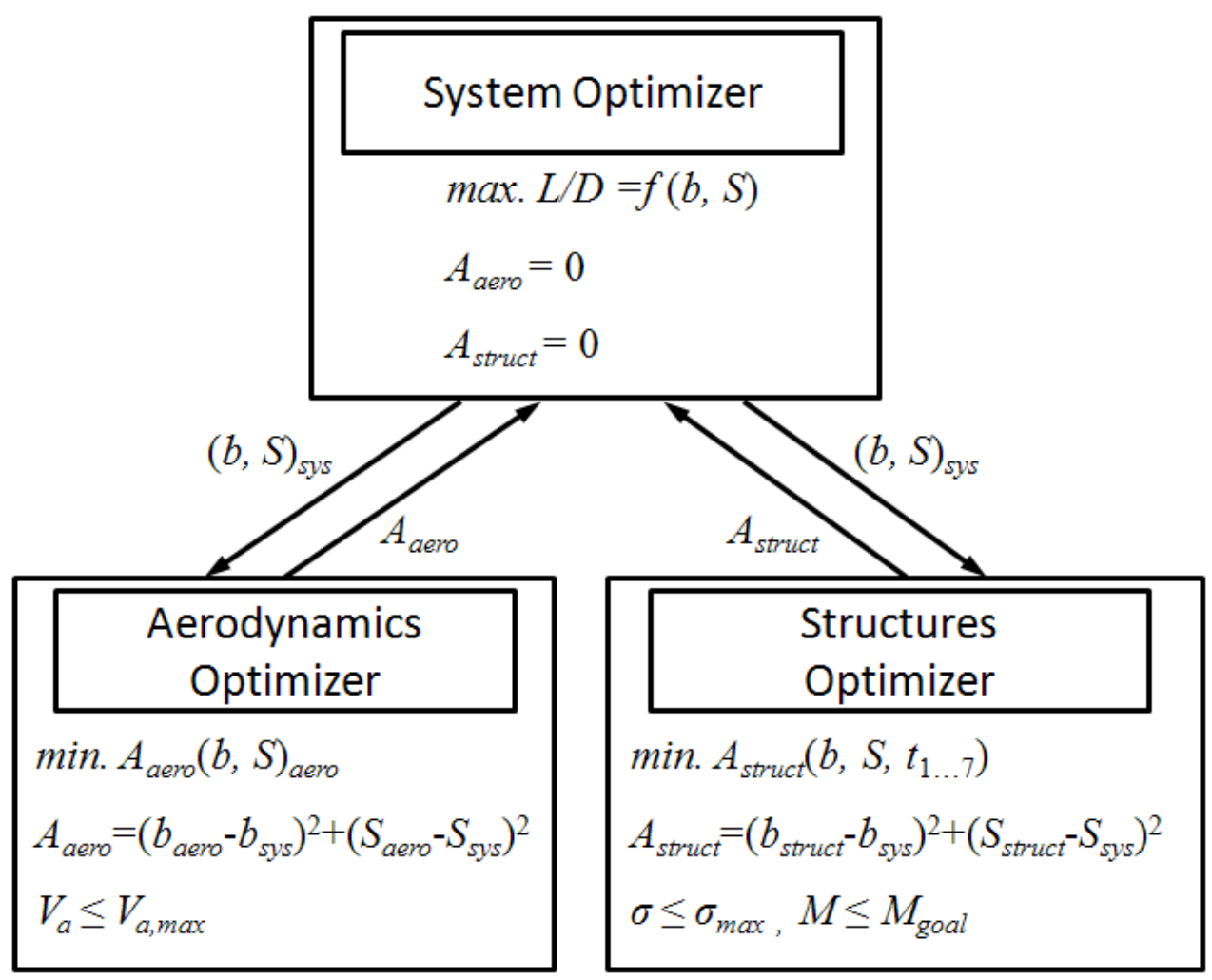

Figure 4.4. $\mathrm{CO}$ architecture

The system objective function was designed to maximize $L / D$. Aaero and $A_{\text {struct }}$ represent auxiliary constraints of aerodynamics and structures discipline respectively, whereas $t$ is the structure thickness value, $M$ is the mass of wing, and $V_{a}$ is the approaching speed. Table 4.3 and Table 4.4 show the constraints and formulations of each method for the structures discipline. 
Minimization of the weight and the stress in the structural analysis decreased the span of the wing geometry and reduced the aerodynamic efficiency. To consider the aerodynamic efficiency, the approach speed was implemented for the constraint of the aerodynamic discipline. Aircraft characteristics such as range and endurance need parameters from performance and thrust disciplines. However, these disciplines were not considered in this paper. On the other hand, an approach speed can be derived from the given parameters in this MDO problem and used to evaluate the system objective function.

Table 4.3. Constraints for wing box conceptual design

\begin{tabular}{c|c|c}
\hline Constraints & Symbol & Value \\
\hline Maximum stress & $\sigma$ & $\leq 360 \mathrm{MPa}$ \\
Mass & $M$ & $\leq 970.034 \mathrm{lb}$ \\
Approach speed & $V_{a}$ & $\leq 120 \mathrm{kts}$ \\
\hline
\end{tabular}

Table 4.4. Formulations for structures discipline

\begin{tabular}{c|c|c|c}
\hline & $\begin{array}{c}\text { Deterministic } \\
\text { optimization }\end{array}$ & RBDO & PBDO \\
\hline Objective & min. $A_{\text {stuct }}\left(b, S, t_{1 \ldots 7}\right)$ & $\operatorname{min.} A_{\text {stuct }}\left(b, S, t_{1 \ldots 7}\right)$ & $\begin{array}{c}\text { min. } A_{\text {stuct }}\left(b, S, t_{1 \ldots 7}\right) \\
\text { Constraint }\end{array}$ \\
& $\begin{array}{c}\sigma \leq \sigma_{\text {max }} \\
M \leq M_{\text {goal }}\end{array}$ & $\begin{array}{c}P\left(\sigma \leq \sigma_{\text {max }}\right) \geq P_{t} \\
M \leq M_{\text {goal }}\end{array}$ & $\begin{array}{c}\Pi\left(\sigma \leq \sigma_{\text {max }}\right) \leq \alpha_{t} \\
M \leq M_{\text {goal }}\end{array}$ \\
\hline
\end{tabular}




\subsection{Optimization results}

The comparison of each result is shown in Table 4.5. Case 1 shows the deterministic optimization result and Case 2 shows the result using selected design variables from the sensitivity analysis. Moreover, Case 3 and Case 4 show RBDO and PBDO results respectively, using selected design variables.

Table 4.5. Comparison of design result

\begin{tabular}{|c|c|c|c|c|}
\hline $\begin{array}{c}\text { Design } \\
\text { variables } \\
\end{array}$ & Case 1 & Case 2 & Case 3 & Case 4 \\
\hline$x_{1}$ & 0.0906 & 0.0906 & 0.0906 & 0.0906 \\
\hline$x_{2}$ & 0.7126 & 0.7047 & 0.7047 & 0.7047 \\
\hline$x_{3}$ & 0.5984 & - & - & - \\
\hline$x_{4}$ & 0.1850 & - & - & - \\
\hline$x_{5}$ & 0.2362 & 0.2362 & 0.2283 & 0.1811 \\
\hline$x_{6}$ & 0.7244 & 0.8858 & 0.7283 & 0.8583 \\
\hline$x_{7}$ & 0.5866 & 0.8858 & 0.6102 & 0.9213 \\
\hline$x_{8}$ & 33.7927 & 33.7927 & 31.6273 & 31.4305 \\
\hline$x_{9}$ & 114.0975 & 114.0975 & 111.9447 & 111.9447 \\
\hline$L / D$ & 31.9 & 30.8 & 30.3 & 30.1 \\
\hline Error & - & $3.45 \%$ & $5.02 \%$ & $5.64 \%$ \\
\hline $\begin{array}{l}\text { Number of } \\
\text { evaluation }\end{array}$ & 158 & 104 & 112 & 111 \\
\hline Improvement & - & $33.55 \%$ & $29.05 \%$ & $29.65 \%$ \\
\hline
\end{tabular}


The fixed design variables were the thickness of the rear spar and the upper stringer. They had a minimal effect on the wing weight. These results represented that Case 2 with the reduced number of design variables, showed an error of $3.45 \%$ and reduced the number of iterations by $33.55 \%$. Case 3 and Case 4 had more number of iterations compared to Case 2 because of the additional reliability and possibility analysis. RBDO and PBDO results specify a smaller wing span and area in order to satisfy the target probability of failure when uncertainty from the structural analysis was considered.

\subsection{Summary}

The number of design variables can be reduced by using GSA results. It showed which design variables could be omitted while still accomplishing the design objective. With less design variables, less computation time is required in redesigning to satisfy new market demands. In addition, $\mathrm{RBDO}$ methods with $\mathrm{CO}$ and $\mathrm{PBDO}$ methods with $\mathrm{CO}$ were implemented to improve the reliability of the result by considering uncertainty introduced from the chosen approximation method. These methods cannot show a global optimum result, however they have small errors when considering uncertainty. These methods prevented constraints from being violated when uncertainty was considered. In this problem, the error between FEM and RSM was performed for uncertain parameters and was applied to the structural discipline. The result of the wing box conceptual design was achieved with less iterations with a reduced number of design variables. In addition, RBDO and PBDO methods maintained their probabilities when uncertainty from approximation models were considered. The sensitivity analysis result can be applied in both RSM and FEM analysis. 
Additional process such as GSA can increase the total computation time. However, the result of sensitivity analysis can be implemented for new derivative designs when the requirements are changed. ADDOPT process is more helpful in reducing the computation time when high fidelity analysis tools are performed, since the computation time of high fidelity analysis tools are highly dependent on number of design variables. 


\section{Chapter 5}

\section{Conceptual Design for Aircraft Derivative}

\subsection{Problem description}

The aircraft conceptual design utilizes many types of low fidelity analysis methods of fast computation time but comparably low in accuracy. The low fidelity analysis tools have uncertainty and this can cause the optimization results to violate certain constraints. RBDO and PBDO algorithms were implemented of in ADDOPT process to manage the errors associated with the traditional low fidelity analysis implemented in the aircraft conceptual design. The error terms can be generated from comparing analysis results using empirical equations and a historical data base. These error terms can influence on each active constraint. RBDO and PBDO targeted only active constraints, adjusting designs away from active constraints within the optimization scheme. 
The conceptual design in this dissertation focused on a commercial jet aircraft. The design requirements shown in Table 5.1 were comparable with B737-900. The baseline was B737-300 and design variables were selected from GSA result. The comparison between B737-800 and different cases with different number of design variables was performed to select design variables for the derivative design. Figure 5.1 shows this procedure.

Table 5.1. Design requirement

\begin{tabular}{c|c}
\hline Requirement & Target Value \\
\hline Passengers & $N_{\text {pax }}=189$ \\
Payload mass & $M_{p l}=45720 \mathrm{lb}$ \\
Range (200 km reserve) & $R \geq 2060 \mathrm{NM}$ \\
Cruise Mach number & $M_{c r}=0.785$ \\
Cruise altitude & $h_{c r}=36,000 \mathrm{ft}$ \\
Empty Weight & $W_{e} \leq 93,655 \mathrm{lb}$ \\
Approach speed & $V_{a} \leq 140 \mathrm{kts}$ \\
\hline
\end{tabular}

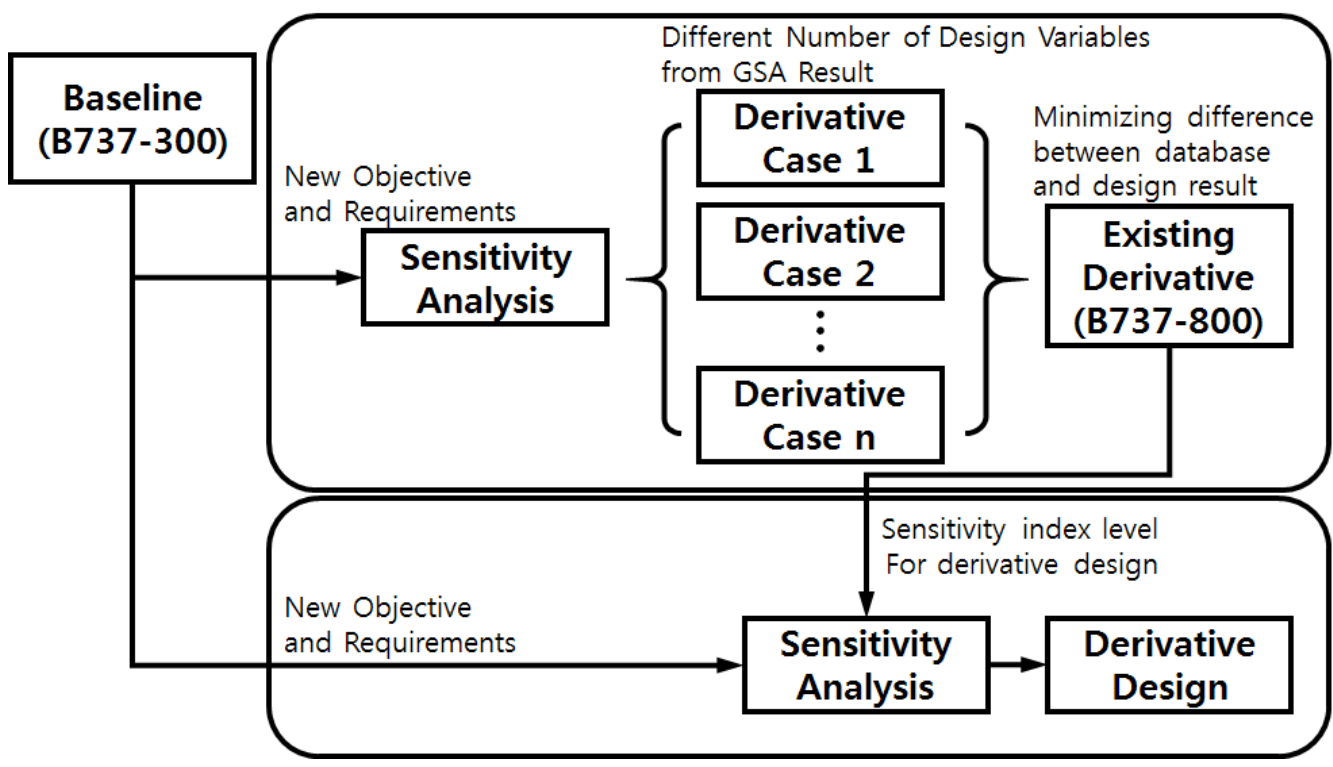

Figure 5.1. Procedure of derivative design 


\subsection{Expert system}

In this research, the database was developed by collecting data from forty different types of the civil jet aircraft $[108,14]$. Appendix C shows the date sheet of forty civil jet aircraft. Figure 5.2 shows the concept of the expert system for this research.

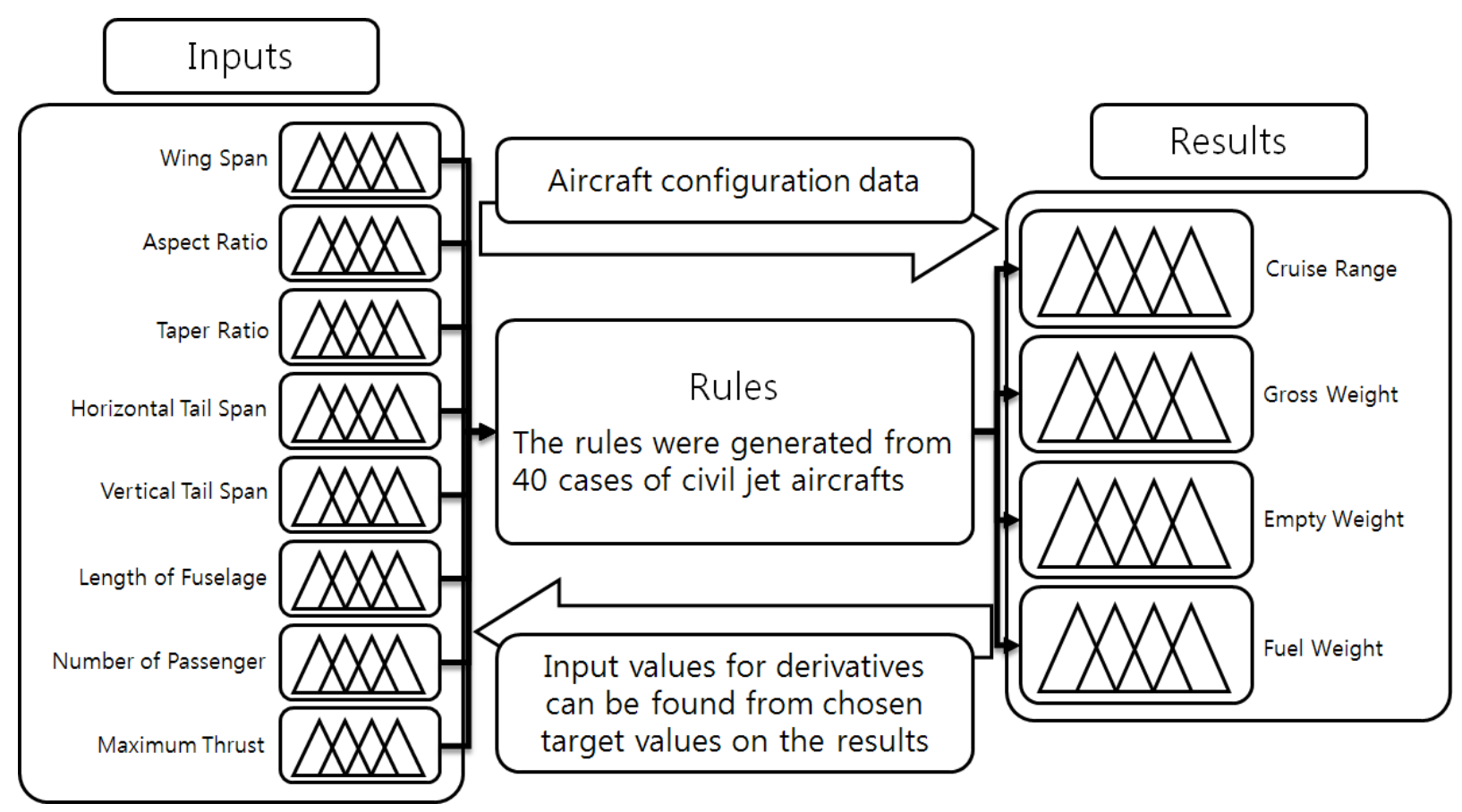

Figure 5.2. Concept of expert system for civil jet aircraft

Table 5.2 presents the design variables and their fuzzy input range from the database. The design variables were selected that show noticeable differences in each configuration. The design variables and the rules for the expert system were extracted from the database of civil jet aircraft. When derivatives were considered, these design variables were changed to satisfy the new requirements. 
Table 5.2. Design variables and its range for fuzzy function

\begin{tabular}{|c|c|c|c|c|c|}
\hline & Very Low & Low & Medium & High & Very High \\
\hline Wing Span $(f t)$ & 85 & 110 & 135 & 160 & 185 \\
\hline $\begin{array}{l}\text { Wing Aspect } \\
\text { Ratio }\end{array}$ & 6.8 & 7.5 & 8.1 & 8.7 & 9.3 \\
\hline $\begin{array}{l}\text { Wing Taper } \\
\text { Ratio }\end{array}$ & 0.15 & 0.2 & 0.25 & 0.29 & 0.35 \\
\hline $\begin{array}{l}\text { Horizontal Tail } \\
\text { Span }(f t)\end{array}$ & 32 & 41.3 & 49.8 & 58.3 & 66.8 \\
\hline $\begin{array}{l}\text { Vertical Tail } \\
\text { Span }(f t)\end{array}$ & 14 & 18.4 & 22.8 & 27.2 & 31.6 \\
\hline $\begin{array}{l}\text { Length of } \\
\text { Fuselage }(f t)\end{array}$ & 93.1 & 123.7 & 154.3 & 184.9 & 215.5 \\
\hline $\begin{array}{l}\text { Number of } \\
\text { Passenger }\end{array}$ & 76 & 170 & 265 & 360 & 455 \\
\hline Range (NM) & 1,298 & 2,768 & 4,238 & 5,709 & 7,179 \\
\hline
\end{tabular}

The responses shown in Figure 5.3 were derived from the expert system based on B737300 aircraft, which has been adopted as the baseline concept for this research. Results showed various aircraft trends when the design variables were changed. Figure 5.3.(a) present the trend of the wingspan with respect to the number of passengers of B737-800 (dotted line, 0.228) and B737900 (solid line, 0.238 ) on the target cruise range as $2,000 \mathrm{NM}$. In this figure, the shading region represented the feasible space. The target of cruise range was defined as 0.1 of normalized value and the corresponding required range for the input value of aspect ratio was found to be $0.5 \sim 1.0$ of normalized value. Similarly, Figure 5.3.(b) 5.2.(f) indicate the trends of other design variables with respect to the target cruise range and the number of passengers. 


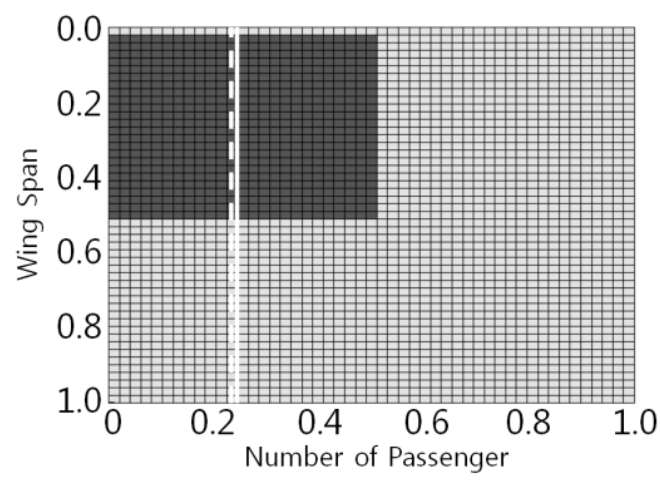

(a) Span of main wing

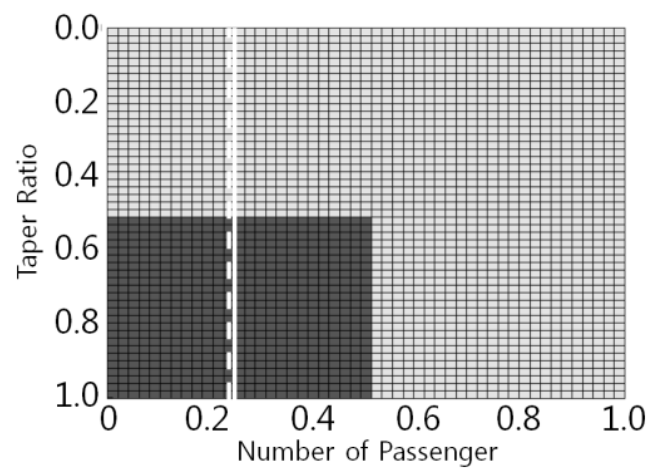

(c) Taper ratio of main wing

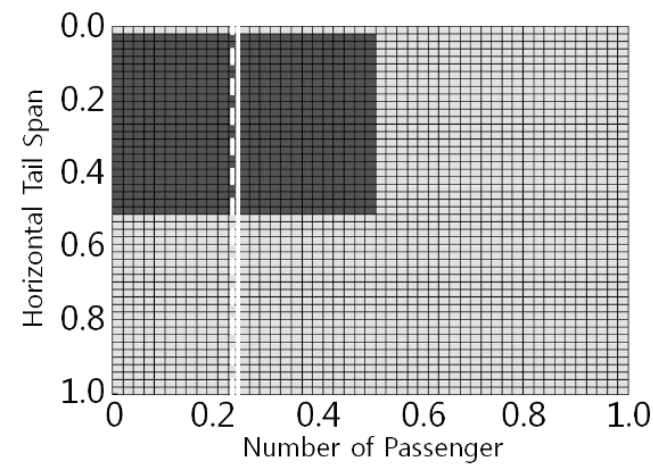

(e) Span of horizontal tail

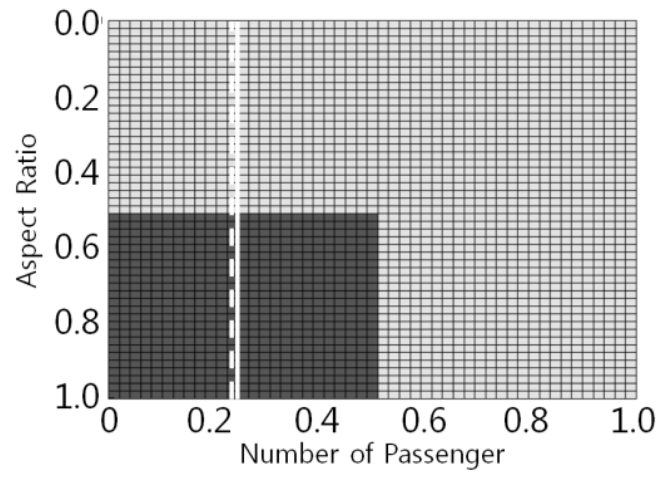

(b) Aspect ratio of main wing

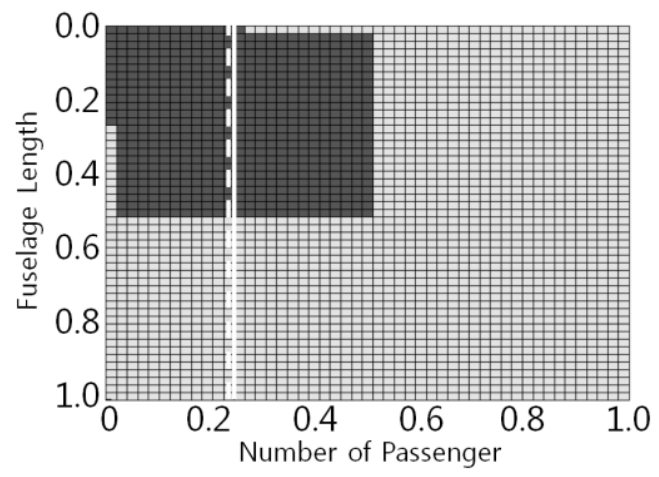

(d) Length of fuselage

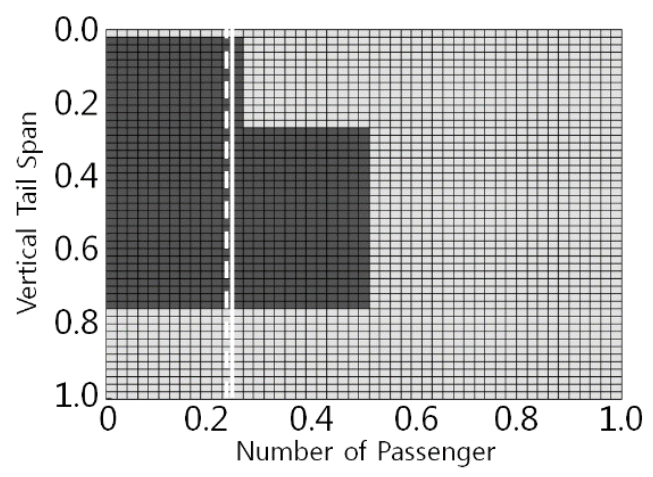

(f) Span of vertical tail

Figure 5.3. Feasible region of major design variables from expert system

Table 5.3 both shows the normalized values and the real values regarding the cruise range related trends for B737-800 and B737-900. The feasible range of design variables was reduced when the values from Table 5.4 were implemented. 
Table 5.3. Normalized value and real value of design variables

\begin{tabular}{|c|c|c|c|c|}
\hline \multirow{2}{*}{ Design variable } & \multicolumn{2}{|c|}{ B737-800 } & \multicolumn{2}{|c|}{ B737-900 } \\
\hline & $\begin{array}{l}\text { Normalized } \\
\text { value }\end{array}$ & Real value & $\begin{array}{l}\text { Normalized } \\
\text { value }\end{array}$ & Real value \\
\hline Wing Span $(f t)$ & 0.206 & 111.52 & 0.206 & 111.52 \\
\hline $\begin{array}{l}\text { Wing Aspect } \\
\text { Ratio }\end{array}$ & 0.566 & 8.73 & 0.566 & 8.73 \\
\hline $\begin{array}{l}\text { Wing Taper } \\
\text { Ratio }\end{array}$ & 0.628 & 0.3 & 0.628 & 0.3 \\
\hline $\begin{array}{l}\text { Horizontal Tail } \\
\text { Span }(f t)\end{array}$ & 0.336 & 47.07 & 0.336 & 47.07 \\
\hline $\begin{array}{l}\text { Vertical Tail } \\
\text { Span }(f t)\end{array}$ & 0.524 & 25.96 & 0.524 & 25.96 \\
\hline $\begin{array}{c}\text { Length of } \\
\text { Fuselage }(f t)\end{array}$ & 0.207 & 124.71 & 0.264 & 133.40 \\
\hline $\begin{array}{l}\text { Number of } \\
\text { Passenger }\end{array}$ & 0.228 & 184 & 0.238 & 189 \\
\hline Range (NM) & 0.10 & 2,000 & 0.10 & 2,000 \\
\hline
\end{tabular}

Table 5.4. Feasible range of design variables

\begin{tabular}{c|r|r|r|r}
\hline \multirow{2}{*}{ Design variable } & \multicolumn{2}{|c|}{ Normalized value } & \multicolumn{2}{|c}{ Real value } \\
\cline { 2 - 5 } & $\begin{array}{c}\text { Lower } \\
\text { boundary }\end{array}$ & $\begin{array}{c}\text { Upper } \\
\text { boundary }\end{array}$ & $\begin{array}{c}\text { Lower } \\
\text { boundary }\end{array}$ & $\begin{array}{c}\text { Upper } \\
\text { boundary }\end{array}$ \\
\hline Wing Span $(f t)$ & 0.02 & 0.52 & 87.83 & 151.66 \\
$\begin{array}{c}\text { Wing Aspect } \\
\text { Ratio }\end{array}$ & 0.5 & 1.0 & 8.52 & 10.10 \\
$\begin{array}{c}\text { Wing Taper } \\
\text { Ratio }\end{array}$ & 0.5 & 1.0 & 0.27 & 0.38 \\
$\begin{array}{c}\text { Horizontal Tail } \\
\text { Span }(f t) \\
\text { Vertical Tail } \\
\text { Span }(f t) \\
\begin{array}{c}\text { Length of } \\
\text { Fuselage }(f t)\end{array}\end{array}$ & 0.02 & 0.5 & 33.65 & 54.05 \\
\hline
\end{tabular}




\subsection{Analysis methods}

\subsubsection{Aerodynamics}

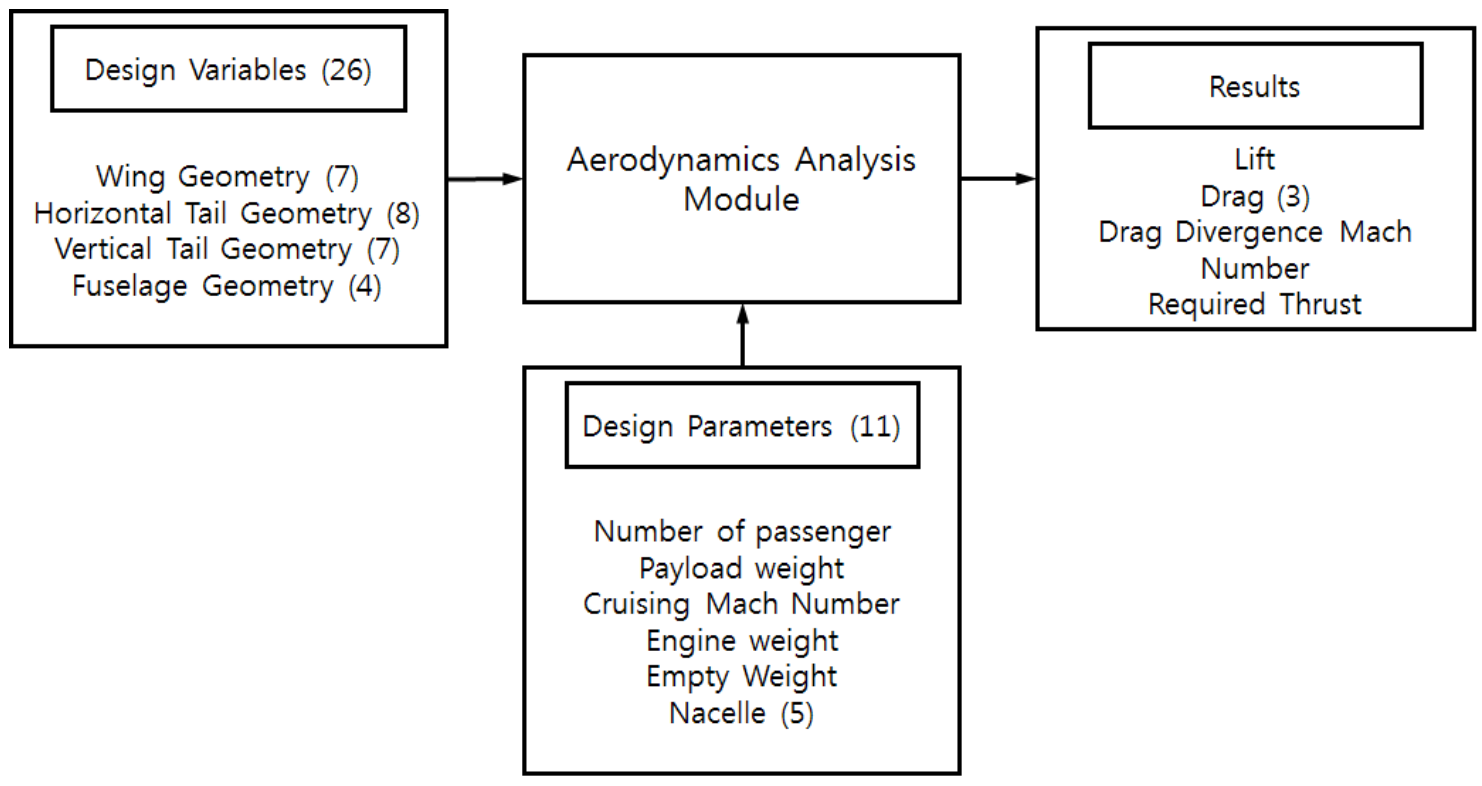

Figure 5.4. Aerodynamics analysis module

The aerodynamics discipline provided the lift and drag characteristics of the aircraft by using empirical equations. Figure 5.4 presents how the aerodynamics discipline was handled. Twenty-six design variables and eleven parameters were implemented in this analysis module. The lift and the drag results derived the thrust required and were compared with the actual aircraft data. The thrust value depends on velocity, altitude, aerodynamic shape and the weight of the aircraft. In this research, eighteen cases of thrust values were compared. Results and errors are shown in Table 5.5. The normal distribution and the membership functions for RBDO and PBDO methods were derived from these cases. The normal distribution had the mean value of 1.0524 , variance of 0.0186 and standard deviation of 0.1365 . 
Table 5.5. Errors of thrust required $(l b)$

\begin{tabular}{|c|c|c|c|}
\hline Aircraft & Database (A) & Analysis result (B) & Error (B/A) \\
\hline B737-100 & $3,870.00$ & $3,273.74$ & 0.8459 \\
\hline B737-200 & $4,252.50$ & $4,352.17$ & 1.0234 \\
\hline B737-300 & $4,907.25$ & $4,708.88$ & 0.9596 \\
\hline B737-400 & $4,927.50$ & $4,708.88$ & 0.9556 \\
\hline B737-500 & $4,907.25$ & $4,708.88$ & 0.9596 \\
\hline B737-600 & $5,215.50$ & $5,554.06$ & 1.0649 \\
\hline B737-700 & $5,485.50$ & $5,554.06$ & 1.0125 \\
\hline B737-800 & $5,485.50$ & $5,554.06$ & 1.0125 \\
\hline B737-900 & $5,485.50$ & $5,554.06$ & 1.0125 \\
\hline B767-200 & $11,340.00$ & $13,594.08$ & 1.1988 \\
\hline B767-300 & $11,722.50$ & $13,594.08$ & 1.1597 \\
\hline B767-400 & $11,340.00$ & $13,203.27$ & 1.1643 \\
\hline B777-200 & $15,750.00$ & $20,573.73$ & 1.3063 \\
\hline B777-300 & $15,750.00$ & $20,573.73$ & 1.3063 \\
\hline A300-600 & $11,340.00$ & $9,565.07$ & 0.8435 \\
\hline A318-100 & $5,756.85$ & $5,249.21$ & 0.9118 \\
\hline A319-100 & $5,756.85$ & $5,815.14$ & 1.0101 \\
\hline A320-200 & $4,860.00$ & $5,815.14$ & 1.1965 \\
\hline
\end{tabular}

The constraints in the aerodynamic discipline required designs to generate the lift force greater than the gross weight. The gross weight value was delivered from the weight estimation discipline, as described in the next section. 


\subsubsection{Weight}

The statistical group weight method was implemented for the aircraft weight estimation. The statistical relationship of the weight and center of gravity for each major aircraft component allowed for an estimate of the overall empty weight of the aircraft. Many aircraft conceptual design publications describe this method in detail $[109,110]$. In general, the statistical equations were functions of the geometry and performance requirements of the aircraft while considering the payload capacity, cruise speed and altitude. Moreover, the empty and gross weight, the center of gravity and the moments of inertia of the aircraft were also calculated. These equations cannot give the exact value for the aircraft weight, but provided reasonable estimation for the group weight. The weight estimation module implemented twenty-nine design variables and seven parameters. Figure 5.5 shows how analysis in the weight discipline was performed.

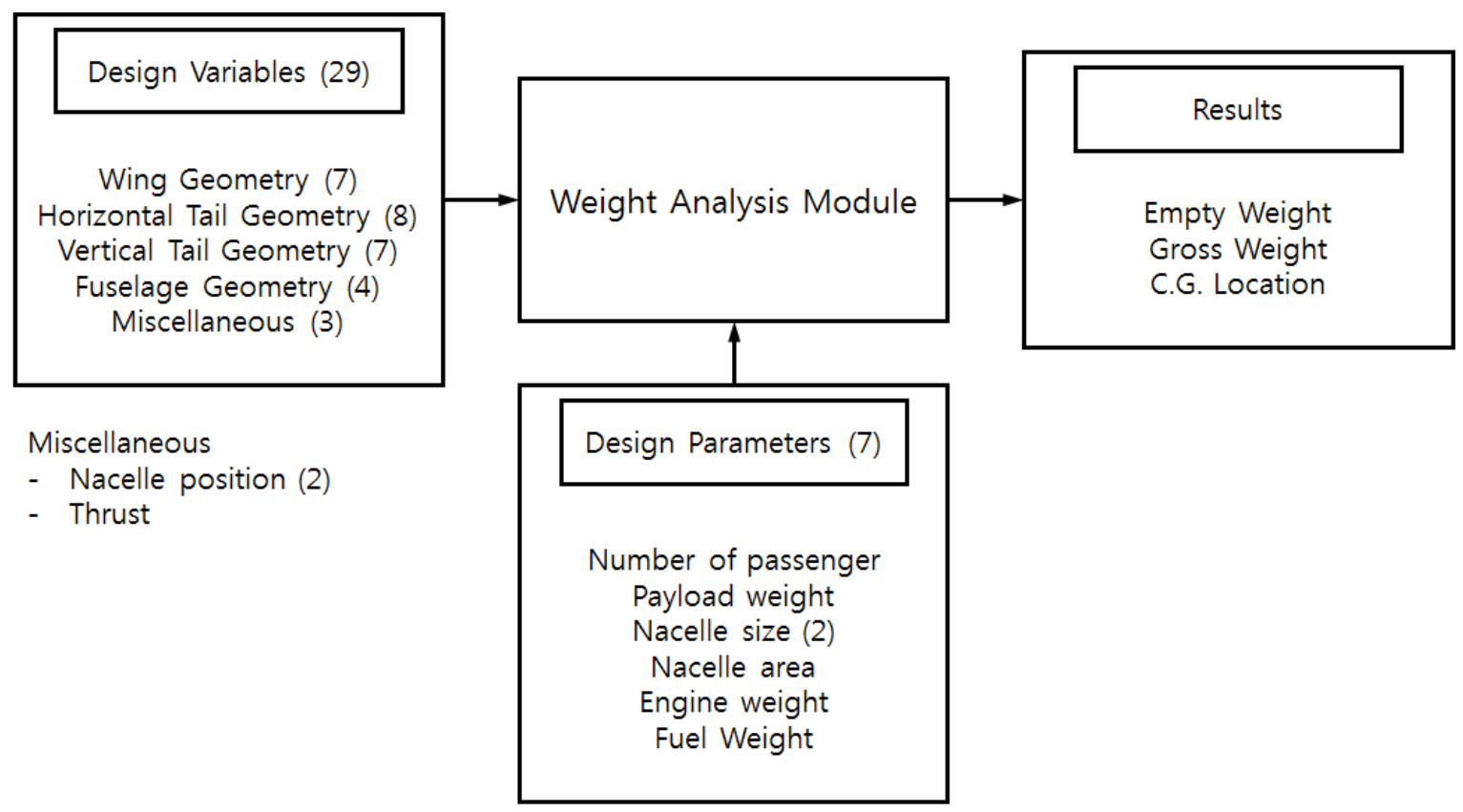

Figure 5.5. Weight analysis module 
The comparison between forty cases of the predicted weight and the database values is shown in Table 5.6. The empty weight error term can be approximated by the normal distribution with the mean of 0.9912 , variance of 0.0024 and the standard deviation of 0.0487 . A triangular distribution was developed using the error data from Table 5.6. The weight constraints coincide with those of B737-900. The empty weight requirement values are shown in Table 5.1.

Table 5.6. Errors of empty weight of aircraft $(l b)$

\begin{tabular}{c|r|r|r}
\hline Aircraft & Database (A) & Analysis result (B) & Error (B/A) \\
\hline A300-600 & $198,492.24$ & $196,398.88$ & 0.9895 \\
A310-200 & $176,628.56$ & $175,385.11$ & 0.9930 \\
A310-300 & $183,300.00$ & $179,805.98$ & 0.9809 \\
A320-200 & $93,449.60$ & $96,251.62$ & 1.0300 \\
A318 & $86,617.20$ & $91,388.70$ & 1.0551 \\
A319 & $89,923.20$ & $93,314.84$ & 1.0377 \\
A321-100 & $106,894.00$ & $102,569.16$ & 0.9595 \\
A321-200 & $106,894.00$ & $102,569.16$ & 0.9595 \\
A330-200 & $265,582.00$ & $263,364.94$ & 0.9917 \\
A330-300 & $274,398.00$ & $266,780.56$ & 0.9722 \\
A340-200 & $285,418.00$ & $266,075.34$ & 0.9322 \\
A340-300 & $286,520.00$ & $266,075.34$ & 0.9286 \\
A340-500 & $376,663.60$ & $392,422.75$ & 1.0418 \\
A350-900 & $255,002.80$ & $65,386.16$ & 0.9317 \\
B737-100 & $62,000.00$ & 1.0532 \\
\hline
\end{tabular}


Table 5.6. Errors of empty weight of aircraft ( $l b$, cont.)

\begin{tabular}{|c|c|c|c|}
\hline Aircraft & Database (A) & Analysis result (B) & Error $(\mathrm{B} / \mathrm{A})$ \\
\hline B737-300 & $72,540.00$ & $74,377.35$ & 1.0253 \\
\hline B737-400 & $74,170.00$ & $75,910.74$ & 1.0235 \\
\hline B737-500 & $69,030.00$ & $73,116.78$ & 1.0592 \\
\hline B737-600 & $81,777.22$ & $77,055.26$ & 0.9423 \\
\hline B737-700 & $84,075.99$ & $82,239.84$ & 0.9782 \\
\hline B737-800 & $90,683.58$ & $92,739.32$ & 1.0227 \\
\hline B737-900 & $93,654.57$ & $95,306.65$ & 1.0176 \\
\hline B747-400 & $397,788.94$ & $383,107.13$ & 0.9631 \\
\hline B747-400ER & $406,781.26$ & $404,949.69$ & 0.9955 \\
\hline B757-200 & $130,410.68$ & $127,947.10$ & 0.9811 \\
\hline B757-300 & $141,651.08$ & $133,507.67$ & 0.9425 \\
\hline B767-200 & $187,251.84$ & $183,679.30$ & 0.9809 \\
\hline B767-300 & $200,145.24$ & $195,867.20$ & 0.9786 \\
\hline B767-400 & $229,000.00$ & $217,108.53$ & 0.9484 \\
\hline B777-200 & $309,882.40$ & $311,350.66$ & 1.0047 \\
\hline B777-300 & $348,298.12$ & $356,588.84$ & 1.0238 \\
\hline DC-8-43 & $136,509.00$ & $118,212.19$ & 0.8660 \\
\hline DC-8-55 & $138,266.00$ & $118,788.11$ & 0.8591 \\
\hline DC-9-15 & $49,020.00$ & $50,631.71$ & 1.0329 \\
\hline DC-10-10 & $240,171.00$ & $230,668.69$ & 0.9604 \\
\hline Embraer 170 & $46,592.56$ & $49,456.27$ & 1.0615 \\
\hline Embraer 175 & $48,069.24$ & $51,120.36$ & 1.0635 \\
\hline Embraer 190 & $61,888.32$ & $64,224.26$ & 1.0377 \\
\hline Embraer 195 & $63,849.88$ & $65,878.14$ & 1.0318 \\
\hline
\end{tabular}




\subsubsection{Performance}

The net force acting on the aircraft was calculated from drag, lift and available thrust forces over a numerical simulation. In this research, the Breguet range equation was used for the jet propelled airplanes [110]. The cruise range was selected as the performance constraint and defined by the performance characteristics of B737-900. The diagram of the performance analysis discipline is shown in Figure 5.6.

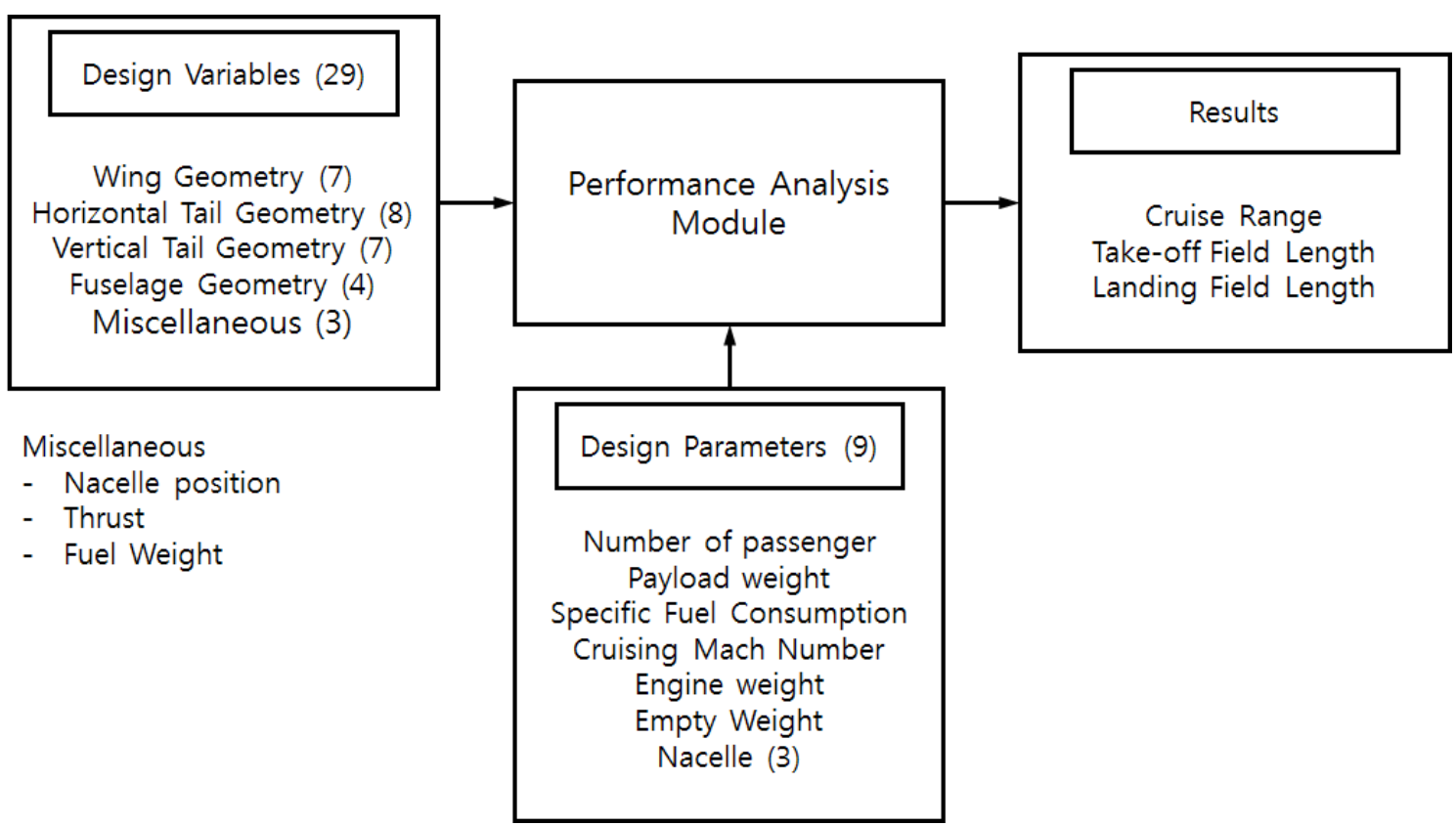

Figure 5.6. Performance analysis module

The forty cases of cruise range prediction results were compared with database and their associated errors are shown in Table 5.7. The errors were represented in the normal distribution and the triangular distribution. The normal distribution had the mean value of 1.0063 as well as the variance and standard deviation of 0.0102 and 0.1010 . 
Table 5.7. Errors of cruise range of aircraft (NM)

\begin{tabular}{|c|c|c|c|}
\hline Aircraft & Database (A) & Analysis result (B) & Error $(\mathrm{B} / \mathrm{A})$ \\
\hline A300-600 & $3,600.00$ & $3,536.17$ & 0.9823 \\
\hline A310-200 & $3,650.00$ & $3,396.27$ & 0.9305 \\
\hline A310-300 & $5,200.00$ & $5,076.90$ & 0.9763 \\
\hline A320-200 & $2,592.00$ & $2,348.21$ & 0.9059 \\
\hline A318 & $1,462.00$ & $1,314.48$ & 0.8991 \\
\hline A319 & $1,813.00$ & $1,863.32$ & 1.0278 \\
\hline A321-100 & $2,138.00$ & $2,314.10$ & 1.0824 \\
\hline A321-200 & $2,700.00$ & $2,314.10$ & 0.8571 \\
\hline A330-200 & $6,650.00$ & $7,386.17$ & 1.1107 \\
\hline A330-300 & $5,600.00$ & $5,036.38$ & 0.8993 \\
\hline A340-200 & $8,000.00$ & $6,908.41$ & 0.8636 \\
\hline A340-300 & $7,200.00$ & $6,874.03$ & 0.9547 \\
\hline A340-500 & $8,650.00$ & $9,035.67$ & 1.0446 \\
\hline A350-900 & $8,100.00$ & $7,894.36$ & 0.9746 \\
\hline B737-100 & $1,720.00$ & $1,505.48$ & 0.8753 \\
\hline B737-200 & $2,645.00$ & $3,495.09$ & 1.3214 \\
\hline B737-300 & $2,950.00$ & $3,109.86$ & 1.0542 \\
\hline B737-400 & $2,800.00$ & $2,366.13$ & 0.8450 \\
\hline B737-500 & $2,950.00$ & $3,148.43$ & 1.0673 \\
\hline B737-600 & $1,340.00$ & $1,363.45$ & 1.0175 \\
\hline B737-700 & $1,540.00$ & $1,552.60$ & 1.0082 \\
\hline B737-800 & $1,990.00$ & $1,993.25$ & 1.0016 \\
\hline B737-900 & $2,060.00$ & $2,713.32$ & 1.3171 \\
\hline B747-400 & $6,185.00$ & $6,996.45$ & 1.1312 \\
\hline B747-400ER & $7,325.00$ & $7,890.04$ & 1.0771 \\
\hline
\end{tabular}


Table 5.7. Errors of cruise range of aircraft (NM, cont.)

\begin{tabular}{c|r|r|r}
\hline Aircraft & \multicolumn{1}{|c|}{ Aircraft } & Aircraft & \multicolumn{1}{|c}{ Aircraft } \\
\hline B757-200 & $2,570.00$ & $2,593.54$ & 1.0092 \\
B757-300 & $2,120.00$ & $2,294.66$ & 1.0824 \\
B767-200 & $5,125.00$ & $5,243.15$ & 1.0231 \\
B767-300 & $5,230.00$ & $4,980.85$ & 0.9524 \\
B767-400 & $5,230.00$ & $4,980.85$ & 0.9524 \\
B777-200 & $3,985.00$ & $4,141.85$ & 1.0394 \\
B777-300 & $3,880.00$ & $4,118.79$ & 1.0615 \\
DC-8-43 & $6,278.00$ & $5,719.83$ & 0.9111 \\
DC-8-55 & $5,077.00$ & $5,463.90$ & 1.0762 \\
DC-9-15 & $1,590.00$ & $1,489.31$ & 0.9367 \\
DC-10-10 & $3,800.00$ & $3,641.45$ & 0.9583 \\
Embraer 170 & $2,100.00$ & $2,104.03$ & 1.0019 \\
Embraer 175 & $1,298.00$ & $1,314.48$ & 1.0127 \\
Embraer 190 & $2,300.00$ & $2,313.97$ & 1.0061 \\
Embraer 195 & $1,400.00$ & 1.0048 \\
\hline
\end{tabular}

\subsubsection{Stability and control}

The static margin, lateral and directional stability were considered in the stability and control discipline. The static margin of 5\% was implemented as the longitudinal stability constraint. The yaw static stability was enforced at a full thrust climb scenario with a failed engine. The stability and control discipline defined the system constraints are given in Table 5.8. However, 
uncertain parameters were not defined in this discipline. Figure 5.7 shows how the stability and control discipline was handled.

Table 5.8. Stability constraints

\begin{tabular}{c|c|c}
\hline Constraint & Description & Value \\
\hline$k_{n}$ & Static margin & $\geq 0.05$ \\
$\lambda_{\text {real }}$ & Motion equation eigenvalues & $<0$ \\
\hline
\end{tabular}

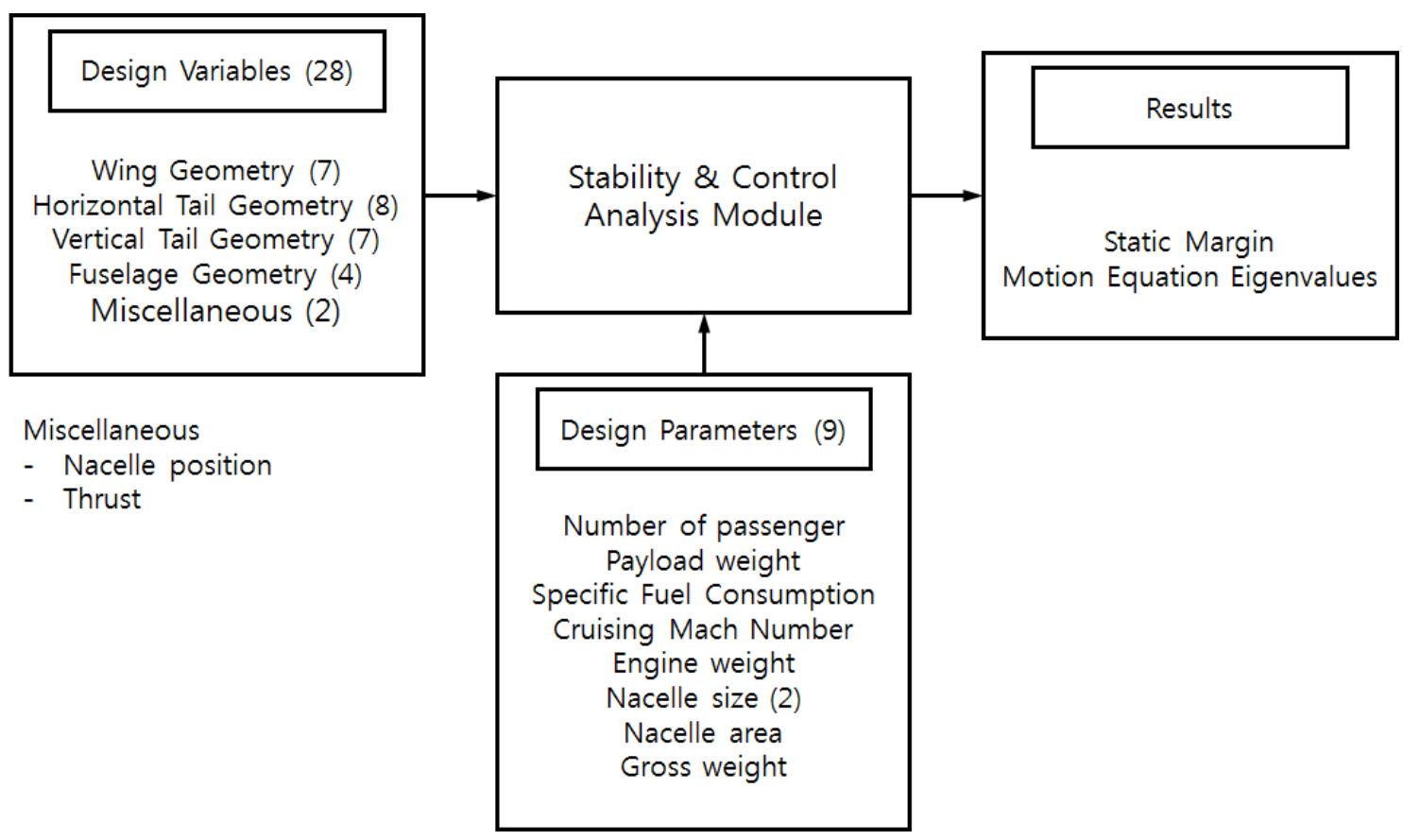

Figure 5.7. Stability and control analysis module

\subsection{Global sensitivity analysis for aircraft conceptual design}

The design variables and their ranges are shown in Table 5.9. These values and ranges were defined using the results of the expert system. The expert system derived feasible list of design 
variable and its boundary for target aircraft. This work was helpful to enhance the accuracy and efficiency of the GSA. Using the ranges of each design variable from Table 5.9, eFAST method was performed for the empty weight and the cruise range.

Table 5.9. Range of design variables

\begin{tabular}{|c|c|c|c|}
\hline \multicolumn{2}{|c|}{ Design Variable } & Lower boundary & Upper boundary \\
\hline \multirow{7}{*}{$\begin{array}{l}\text { Wing } \\
\text { geometry }\end{array}$} & $B_{W}$ & 87.83 & 151.66 \\
\hline & $A R_{W}$ & 8.52 & 10.10 \\
\hline & $T R_{W}$ & 0.27 & 0.38 \\
\hline & $C_{\text {Root_W }}$ & 15.0 & 26.0 \\
\hline & $\Lambda_{L E_{-} W}$ & 20.0 & 30.0 \\
\hline & $S_{W}$ & 1085.0 & 1500.0 \\
\hline & $S_{c s W}$ & 230.0 & 350.0 \\
\hline \multirow{7}{*}{$\begin{array}{l}\text { Horizontal tail } \\
\text { geometry }\end{array}$} & $B_{H}$ & 33.65 & 54.05 \\
\hline & $A R_{H}$ & 3.8 & 6.0 \\
\hline & $T R_{H}$ & 0.2 & 0.3 \\
\hline & $C_{\text {Root_H }}$ & 10.5 & 28.5 \\
\hline & $\Lambda_{L E_{-} H}$ & 30.0 & 40.0 \\
\hline & $S_{H}$ & 300.0 & 380.0 \\
\hline & $S_{c s H}$ & 68.0 & 85.0 \\
\hline \multirow{7}{*}{$\begin{array}{l}\text { Vertical tail } \\
\text { geometry }\end{array}$} & $B_{V}$ & 14.44 & 30.66 \\
\hline & $A R_{V}$ & 1.6 & 2.3 \\
\hline & $T R_{V}$ & 0.2 & 0.35 \\
\hline & $C_{\text {Root_V }}$ & 15.0 & 20.0 \\
\hline & $\Lambda_{L E_{-} V}$ & 35.0 & 45.0 \\
\hline & $S_{V}$ & 230.0 & 300.0 \\
\hline & $S_{c s V}$ & 53.0 & 70.0 \\
\hline \multirow{2}{*}{$\begin{array}{l}\text { Fuselage } \\
\text { geometry }\end{array}$} & $L_{f}$ & 93.10 & 172.54 \\
\hline & $L_{T}$ & 38.0 & 64.0 \\
\hline \multirow{2}{*}{ Engine } & $T$ & $17,000.0$ & $30,000.0$ \\
\hline & $W_{f}$ & $18,000.0$ & $45,100.0$ \\
\hline
\end{tabular}


Table 5.10. Global sensitivity analysis result

\begin{tabular}{|c|c|c|c|c|}
\hline \multicolumn{2}{|c|}{ Design Variable } & $1^{\text {st }}$ order & Total & Rank \\
\hline \multirow{7}{*}{$\begin{array}{l}\text { Wing } \\
\text { geometry }\end{array}$} & $B_{W}$ & 0.03500 & 0.06877 & 11 \\
\hline & $A R_{W}$ & 0.01101 & 0.02189 & 17 \\
\hline & $T R_{W}$ & 0.00113 & 0.00226 & 24 \\
\hline & $C_{\text {Root_W }}$ & 0.04149 & 0.08126 & 9 \\
\hline & $\Lambda_{L E_{-} W}$ & 0.00169 & 0.00338 & 23 \\
\hline & $S_{W}$ & 0.15947 & 0.29351 & 2 \\
\hline & $S_{c s W}$ & 0.00226 & 0.00451 & 22 \\
\hline \multirow{7}{*}{$\begin{array}{l}\text { Horizontal tail } \\
\text { geometry }\end{array}$} & $B_{H}$ & 0.02032 & 0.04023 & 13 \\
\hline & $A R_{H}$ & 0.08863 & 0.16940 & 4 \\
\hline & $T R_{H}$ & 0.00649 & 0.01294 & 19 \\
\hline & $C_{\text {Root_H }}$ & 0.03839 & 0.07530 & 10 \\
\hline & $\Lambda_{L E_{-} H}$ & 0.00001 & 0.00000 & 25 \\
\hline & $S_{H}$ & 0.06181 & 0.11980 & 6 \\
\hline & $S_{c s H}$ & 0.01016 & 0.02022 & 18 \\
\hline \multirow{7}{*}{$\begin{array}{l}\text { Vertical tail } \\
\text { geometry }\end{array}$} & $B_{V}$ & 0.16822 & 0.30814 & 1 \\
\hline & $A R_{V}$ & 0.00452 & 0.00901 & 20 \\
\hline & $T R_{V}$ & 0.05193 & 0.10117 & 8 \\
\hline & $C_{R o o t}$ V & 0.01270 & 0.02524 & 15 \\
\hline & $\Lambda_{L E_{-} V}$ & 0.00226 & 0.00451 & 21 \\
\hline & $S_{V}$ & 0.01242 & 0.02468 & 16 \\
\hline & $S_{c s V}$ & 0.01355 & 0.02691 & 14 \\
\hline \multirow{2}{*}{$\begin{array}{l}\text { Fuselage } \\
\text { geometry }\end{array}$} & $L_{f}$ & 0.10612 & 0.20099 & 3 \\
\hline & $L_{T}$ & 0.06012 & 0.11662 & 7 \\
\hline \multirow{2}{*}{ Engine } & $T$ & 0.06633 & 0.12826 & 5 \\
\hline & $W_{f}$ & 0.02399 & 0.04741 & 12 \\
\hline
\end{tabular}


Table 5.10 shows the sensitivity indices and the ranking for the weighting factors of the objectives from each discipline. The sensitivity analysis results provided which design variables were important for the derivative designs to satisfy new design requirements.

\subsection{Uncertainty based design optimization for aircraft conceptual design}

The important design variables based on the sensitivity rank were selected for the derivative design. The different numbers of the design variables were performed and were compared the results with B787-300 data. The objective function for the derivative was defined as minimizing the performance difference between B737-300 and predicted result.

The error distributions from the low fidelity analysis results of each discipline were simulated while incorporating uncertainty. $\mathrm{CO}$ with $\mathrm{RBDO}$ and $\mathrm{CO}$ with $\mathrm{PBDO}$ algorithms considered uncertainty in each discipline. Four disciplines, described in the previous section, were weighed in $\mathrm{CO}$ method. For RBDO and PBDO formulation, constraints satisfied normal distribution and used the fuzzy membership function that was defined using the error estimation. RBDO and PBDO methods using PMA method had the target reliability level of 3, which has $99.87 \%$ of probability. Figure 5.8 shows the block diagram of CO formulation. 


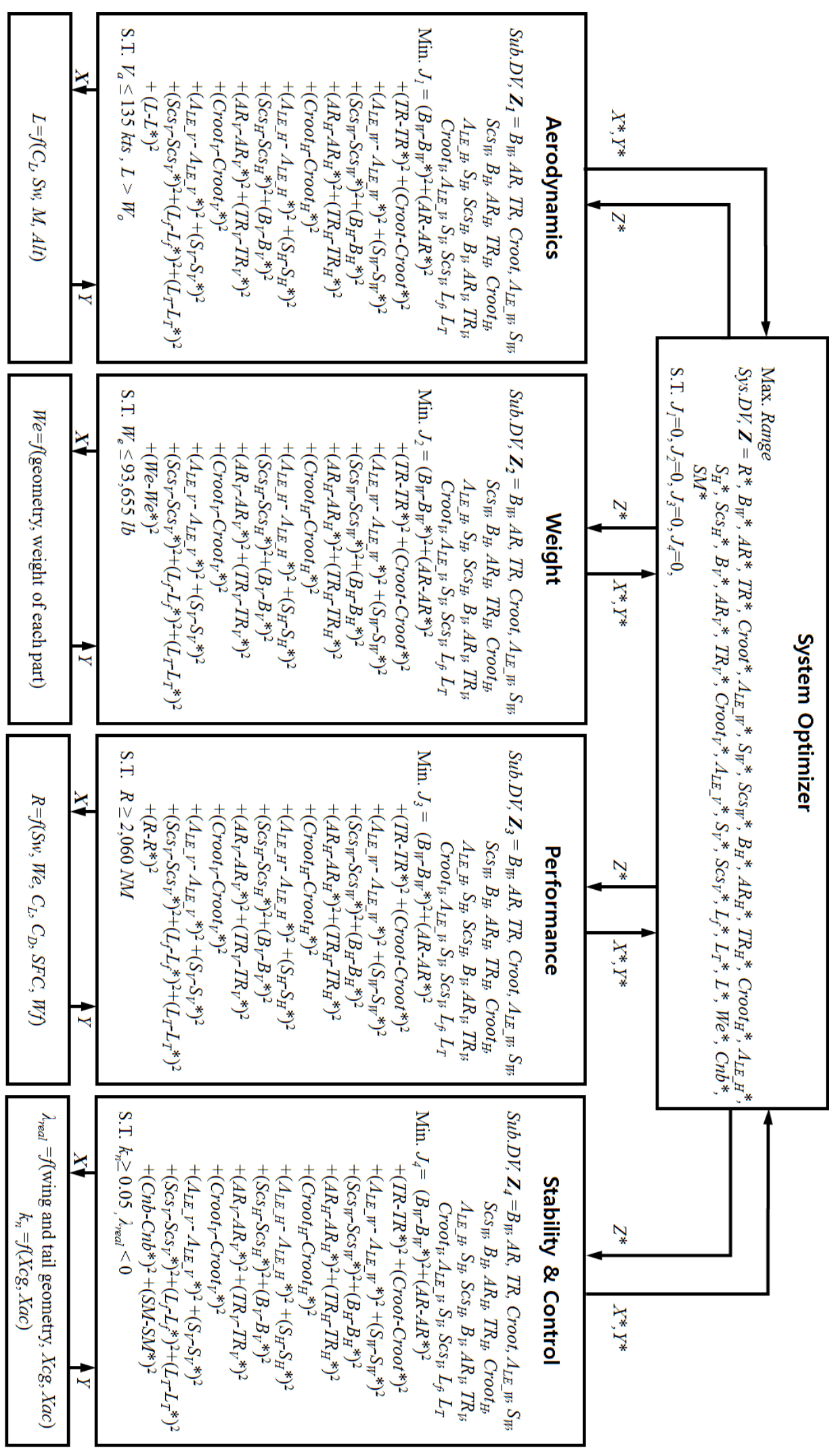

Figure 5.8. CO formulation 
Table 5.11. Comparison of design results (B737-800)

\begin{tabular}{|c|c|c|c|c|c|c|}
\hline \multicolumn{2}{|c|}{ Design Variable } & $\begin{array}{c}\text { B737- } \\
800\end{array}$ & $\begin{array}{c}\text { Case } 1 \\
(25)\end{array}$ & $\begin{array}{c}\text { Case } 2 \\
(18)\end{array}$ & $\begin{array}{c}\text { Case } 3 \\
(13)\end{array}$ & $\begin{array}{c}\text { Case } 4 \\
(9)\end{array}$ \\
\hline \multirow{7}{*}{$\begin{array}{c}\text { Wing } \\
\text { geometry }\end{array}$} & $B_{W(f t)}$ & 111.52 & 112.30 & 111.48 & 111.53 & - \\
\hline & $A R_{W}$ & 8.73 & 8.73 & 8.73 & - & - \\
\hline & $T R_{W}$ & 0.3 & 0.3 & - & - & - \\
\hline & $C_{\text {Root_W }(f t)}$ & 17.29 & 20.0 & 20.0 & 20.0 & 20.0 \\
\hline & $\Lambda_{L E_{-} W(\mathrm{deg})}$ & 25.02 & 25.02 & - & - & - \\
\hline & $S_{W\left(f t^{2}\right)}$ & 1345.5 & 1345.5 & 1345.4 & 1344.8 & 1345.5 \\
\hline & $S_{c S W(f t 2)}$ & 259.95 & 280.0 & - & - & - \\
\hline \multirow{7}{*}{$\begin{array}{l}\text { Horizontal } \\
\text { tail } \\
\text { geometry }\end{array}$} & $B_{H(f t)}$ & 47.068 & 47.08 & 47.07 & 47.06 & - \\
\hline & $A R_{H}$ & 5.88 & 5.0 & 5.0 & 5.0 & 5.0 \\
\hline & $T R_{H}$ & 0.226 & 0.226 & - & - & - \\
\hline & $C_{\text {Root_H(ft) }}$ & 25.85 & 25.85 & 25.80 & 25.84 & - \\
\hline & $\Lambda_{L E_{-} H(d e g)}$ & 34 & 34 & - & - & - \\
\hline & $S_{H(f t 2)}$ & 353.06 & 353.05 & 353.06 & 353.03 & 353.07 \\
\hline & $S_{c s H(f t 2)}$ & 80.95 & 80.94 & 80.95 & - & - \\
\hline \multirow{7}{*}{$\begin{array}{c}\text { Vertical } \\
\text { tail } \\
\text { geometry }\end{array}$} & $B_{V(f t)}$ & 25.49 & 25.43 & 25.46 & 25.44 & 25.44 \\
\hline & $A R_{V}$ & 2.08 & 2.08 & - & - & - \\
\hline & $T R_{V}$ & 0.23 & 0.23 & 0.23 & 0.24 & 0.23 \\
\hline & $C_{\text {Root_V }(f t)}$ & 18.99 & 19.0 & 18.92 & - & - \\
\hline & $\Lambda_{L E_{-} V(\operatorname{deg})}$ & 40 & 40 & - & - & - \\
\hline & $S_{V\left(f t^{2}\right)}$ & 284.17 & 284.16 & 284.17 & - & - \\
\hline & $S_{c S V\left(f t^{2}\right)}$ & 67.08 & 67.09 & 67.03 & - & _ \\
\hline \multirow{2}{*}{$\begin{array}{l}\text { Fuselage } \\
\text { geometry }\end{array}$} & $L_{f(f t)}$ & 124.71 & 123.97 & 123.97 & 123.97 & 123.97 \\
\hline & $L_{T(f t)}$ & 55.348 & 55.35 & 55.35 & 55.35 & 55.35 \\
\hline \multirow{2}{*}{ Engine } & $T_{(l b f)}$ & 27,300 & 27,300 & 27,300 & 27,300 & 27,300 \\
\hline & $W_{f(l b)}$ & 19,500 & 19,500 & 19,500 & 19,500 & _ \\
\hline $\begin{array}{l}\text { Cruise } \\
\text { range }\end{array}$ & $R_{(N M)}$ & 1,990 & 1,960 & 1,920 & 1,844 & 2,168 \\
\hline Error & $(\%)$ & - & $1.51 \%$ & $3.22 \%$ & $7.33 \%$ & $8.96 \%$ \\
\hline
\end{tabular}


Table 5.12. Comparison of design results (B737-900)

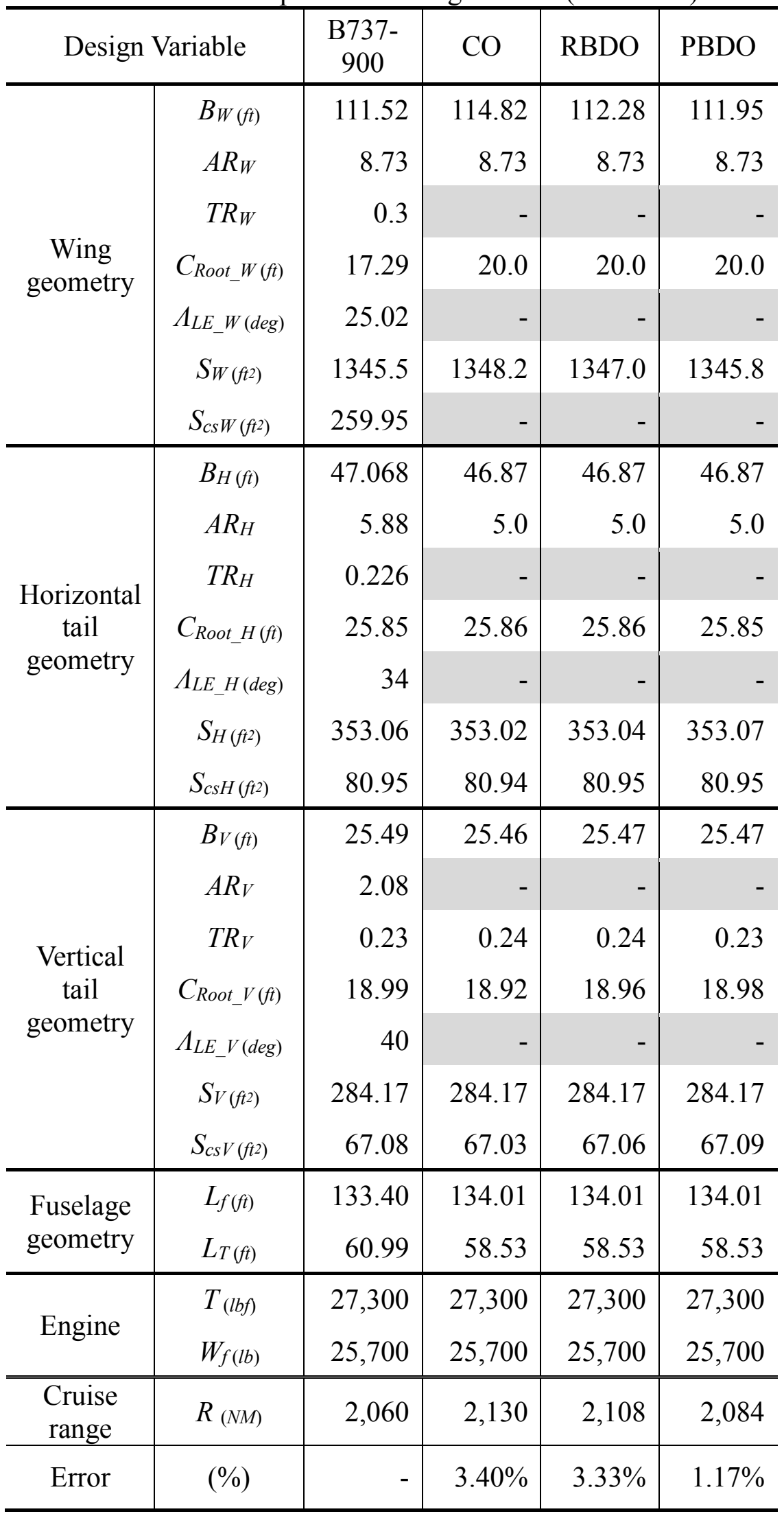




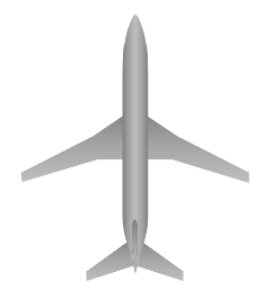

(a) $\mathrm{B} 737-800$

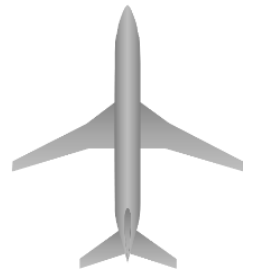

(b) Case 1

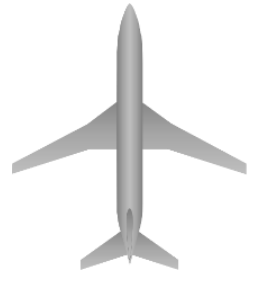

(c) Case 2

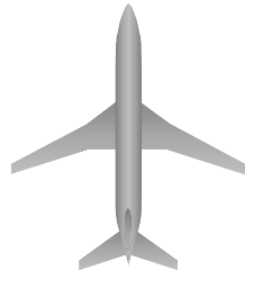

(d) Case 3

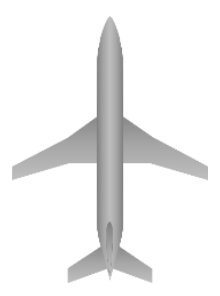

(e) Case 4

Figure 5.9. Comparison of aircraft design result with $B 737-800$

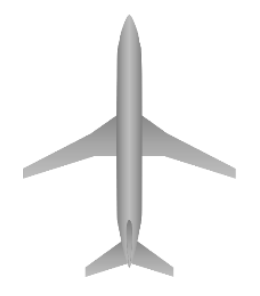

(a) B737-900

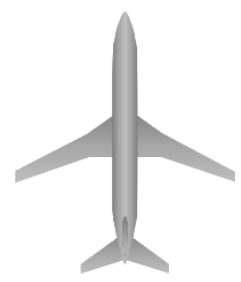

(b) $\mathrm{CO}$ result

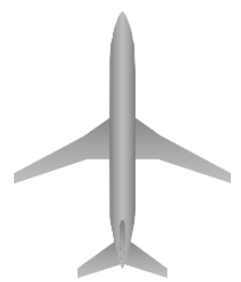

(c) RBDO result

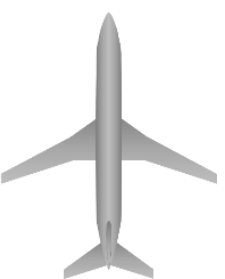

(d) PBDO result

Figure 5.10. Comparison of aircraft design result with $B 737-900$

Table 5.11 shows comparison of design results with actual B737-800 data. Case 2 shows the similar performance characteristics while using the reduced number of design variables. From these results, eighteen design variables were implemented for the aircraft derivative designs that were comparable with B737-900. The system objective function was designed to maximize cruise range while considering the objective and the constraints of the each discipline.

Figure 5.9 and Figure 5.10 show the aircraft configuration of each case. Each case in Figure 5.9 had different number of design variables and Case 4 had similar shape with B737-300, the baseline configuration of the derivative design. The aircraft configurations in Figure 5.10 had the same number of the design variables. In Table 5.12, the performance of B737-900 was compared with the results of deterministic optimization, RBDO, and PBDO with the selected design variables 
and these results showed small errors. RBDO and PBDO results indicated smaller cruise range than the deterministic optimization as $\mathrm{CO}$ result. These results fall in the feasible region when constraints were adjusted to consider uncertainty while satisfying the target reliability index level. The accuracy of each discipline was not same since the aerodynamic discipline shows larger error when dealing with bigger aircraft and the information for uncertain parameter was smaller than other disciplines. Therefore, RBDO result cannot guarantee accuracy in the optimization result since its accuracy depends on the accuracy of the uncertainty distribution even though it showed the better cruise range than PBDO result.

\subsection{Results and discussion}

RBDO with $\mathrm{CO}$ and PBDO with $\mathrm{CO}$ methods of ADDOPT were performed on the aircraft derivative design problem. The comparison between the actual B737-800 characteristics and the derivative design based off the B737-300 was used to evaluate the ADDOPT process. Then the B737-900 was selected as the comparable target of the derivative design. Uncertainty considered in the analysis methods depended on statistical or simplified analytical equations. The comparison between the predicted performance and the observed performance taken from the aircraft from the data base was used to define the error terms.

The deterministic result was better compared with B737-900, but the design results were

closer to the constraint boundaries. Enforcing the target reliability indices moved the optimum result into the feasible region of the design space via the implementation of RBDO and PBDO. 
The accuracy of uncertainty in the analysis module varied because of the lack of information. For this reason, the accuracy of RBDO result was not be guaranteed, the aerodynamic analysis module had relatively low accuracy regarding uncertain parameters. However, PBDO result can be guaranteed even though the analysis module had low accuracy. When the low fidelity analysis tools had insufficient data for uncertain parameters, PBDO method was more suitable than RBDO method. If the aerodynamic analysis module had more data in thrust required, the accuracy of RBDO result would increase. Otherwise, PBDO result will not improve even when the amount of information of uncertain parameter is increased. 


\section{Chapter 6}

\section{Conclusion and Future Work}

\subsection{Conclusion}

In this dissertation, an enhanced derivative design optimization process, ADDOPT was proposed. The expert system as well as sensitivity analysis method of ADDOPT process was applied to select the design variables for the derivative design. The expert system derived the feasible list of the design variable and its boundary to increase accuracy and efficiency of GSA since it depends on the range of design variables. GSA method identifies the necessary design variables for the derivative design. The example on Chapter 3 showed the selection of the design variables from the sensitivity indices will be applicable for the derivative design. The 18 bar truss optimization evaluated the accuracy of the implemented eFAST module. It showed a small error 
when the number of design variables was reduced. ADDOPT process was helpful for decreasing the redesign cost for the developing derivatives of a baseline product by reducing boundary and number of design variables.

Furthermore, the design optimization under uncertainty methods was considered in ADDOPT process to yield the conservative design. RBDO and PBDO methods were proposed to obtain the reliable results with uncertainty. RBDO method operated the PDF for uncertain parameters when it had sufficient information for it. However, it was difficult to obtain sufficient information to simulate uncertain parameters on analysis model in general engineering problems. From this reason, PBDO method was proposed. PBDO method implemented the fuzzy input for uncertainty and was useful to simulate uncertainty with insufficient data.

For the wing box conceptual design case on Chapter 4, eFAST method reduced the number of design variables, and $\mathrm{RBDO}$ with $\mathrm{CO}$ and $\mathrm{PBDO}$ with $\mathrm{CO}$ methods improved the reliability of result when uncertainty of the approximation method was considered. The error between FEM and RSM was performed as uncertain parameter and it was applied to the structural discipline. RBDO and PBDO methods cannot provide the global optimum result, but these methods prevented violation of constraints when uncertainty was considered. The result of wing box conceptual design had less iteration number with the reduced number of design variables while it accomplished the targeted probability.

ADDOPT process was implemented to the aircraft derivative design problem on Chapter 5 either. It performed to compare the actual B737-800 characteristics with the derivative design result that implemented baseline of B737-300. The number of design variable was selected from this comparing result which shows small error with reduced number of design variable. Then B737-900 was defined as the comparable target of the derivative of B737-300. The number of 
design variable was fixed as previous case study with B737-800. In addition, uncertainty considered in the analysis methods depended on the statistical or the simplified analytical equations. The error terms were defined as the ratio of predicted performance to that of the observed performance taken from the aircraft database. The deterministic result had an improvement compared to B737-900, but the design result laid on and near the constraint boundaries. Enforcing target reliability indices moved the optimum result into the feasible region of the design space by implementing RBDO and PBDO. The accuracy of RBDO result was not guaranteed from this result since the aerodynamic analysis module which had the relatively small amount of data on the uncertain parameter. On the other hand, PBDO result can guarantee target probability even though the analysis module had insufficient amount of data for uncertain parameter. If the aerodynamic analysis module increases the data on its uncertain parameter, the accuracy of RBDO result will be increased too. Otherwise, PBDO result will be not improved when it increases the accuracy of the disciplines.

ADDOPT process is applicable to other types of engineering products and may save considerable amount of time and effort for the derivative design. The sensitivity analysis result can be used for not only RSM and the low fidelity analysis tools but also the high fidelity analysis tools such as FEM and CFD. The number of design variable has a significant effect on computation time of FEM and CFD. From this fact, ADDOT process is useful on the conceptual design where it uses high fidelity analysis tools with reduced number of design variable while fixing less effective variables. Moreover, RBDO and PBDO for uncertainty from the low fidelity model improved the probability of design optimization result. In actual engineering problems, the number of cases can be insufficient from the experiment or the high fidelity analysis to derive the approximation model. The developed method as RBDO with $\mathrm{CO}$ and PBDO with $\mathrm{CO}$ are useful 
to consider the error of the approximation models or the low fidelity analysis tools. From such cases, the developed design procedure that reduces dimensionality and considered uncertainty is useful for the conceptual design level using the high fidelity analysis tools to increase the accuracy of result.

In the future, the desirable use of tools for the each design problem should be tested and specified to extend the application of developed process. Moreover, flexible process should be established with uncertainty consideration to satisfy various customer needs. Following sections are showing future works of this research.

\subsection{Future work}

\subsubsection{Uncertainty}

The error of low fidelity analysis tool and approximation model was considered as uncertain parameters in this dissertation. However, many types of uncertainty emerged during each design stage as described on Chapter 2. The various types of uncertain parameters can be considered on various types of engineering design problems. The next step will analyze and simulate other types of uncertainty for the derivative design. For example, an operation environment of engineering products and an application of new technology can be handled as epistemic uncertainty since it does not have enough data. In addition, a material property and a 
manufacturing tolerance can handled as aleatory uncertainty since these parameters can have enough data to simulate uncertain parameter. The future work includes analyzing the characteristics of uncertain parameter. Attention will be also paid on uncertainty based design optimization methods to find suitable method for uncertain parameter. When it uses suitable method for uncertain factor in design problem, the proposed design process can be utilized in widespread field to avoid unexpected response by considering uncertainty with optimization.

\subsubsection{High fidelity analysis}

Computation time of high fidelity analysis methods such as CFD and FEM is depended on the number of design variables. From this fact, ADDOPT process is more useful to a problem that implements high fidelity analysis tools. In this dissertation, the wing box design problem utilize the high fidelity analysis tool for the structural analysis by using RSM method. On the other hand, the aircraft conceptual design problem used the low fidelity analysis tools with simple design variables, and the error of RSM was considered as uncertain parameter. The extended aircraft design problem with the high fidelity analysis methods resulted as the component weight and the drag prediction can give more reasonable results for the aircraft conceptual design. Not only the aircraft design but also an engineering product design problem is eligible application of ADDOPT

process. A part of engineering product needs upgrade when requirements are changed or disadvantages of previous configuration are discovered. ADDOPT process can select necessary design variables for upgrade, and it reduces computation time and effort for redesign while keeping 
reasonable accuracy.

\subsubsection{Certification issue}

The derivative design gives advantages on manufacturing by sharing parts and fabrication process with a baseline aircraft. However, manufacturer should consider the certification issue when they changes design of an aircraft. The certification issues were not considered in this dissertation on the derivative design. The derivative design with the minimum additional certification process is the additional work to enhance ADDOPT process. The certification process of the baseline aircraft should be weighed which criteria are important and which part can be an issue for the derivative design.

Next practical application of ADDOPT process is the derivative design of Found Aircraft Expedition 350. Found Aircraft is a bush light aircraft manufacturer in Ontario, Canada. Found Aircraft Expedition 350 was developed from basic FBA-2 for practice and personal use. The baseline aircraft was manufactured on 1961 to endure and thrive in the tough conditions of North America's undeveloped northern regions for operations on tundra tires, floats and skis. Expedition 350 FM2C3 implemented Lycoming IO-580-B1A engine. This aircraft was FAA type certified in 2008. Found Aircraft developed FM2C3T that used Lycoming TIO-540-AH1A, turbo charger engine to enhance the performance. The geometry of aircraft was not changed so a few certification processes on specific conditions were neglected. The stall speed at power idle stall case did not changed, therefore this test was neglected. In addition, power on stall test at less than 10,000 ft was completed by spot check since it had small power difference. Generally, the certification 
process of the derivative aircraft is depended on the amount of change from baseline aircraft as well as its impact on performance and safety. From this fact, the identification of important design variables for new requirements is essential work for derivative design with minimum certification process. The derivative design for Expedition 350 can evaluate ADDOPT process by using actual performance data for certification as well as connection with certification expert. The objective of the next application is minimizing the certification process while enhancing and optimizing performance of derivative aircraft design.

\subsubsection{Aircraft derivative design}

In this dissertation, derivative design of civil jet aircraft was considered. Many types of derivative are considered in the aerospace industry. Military air vehicle can be modified to be used for civil purpose and vice versa. In addition, UAVs can be developed as a derivative of light aircraft. These types of derivatives are widely required in the market to save the development and manufacturing cost. The next application of ADDOPT process is UAV design based on 2 seat Light Sports Aircraft (LSA). The performance characteristics of 2 seat LSA such as endurance and cruise range are important features for UAV. The application of UAV will be derived based on the performance characteristics of 2 seat LSA. Design requirements of UAV will be also analyzed based on domestic and international market survey with performance and specification survey on competitive UAVs. Operation scenarios of UAV will be generated for the design requirements. Furthermore, required characteristics and certification process of 2 seat LSA and UAV will be compared to find differences. The design objective function and constraints will be studied to 
define design variables and uncertainty parameters for UAV design. GSA method will be applied to identify important design variables for new objectives and constraints for UAV. Uncertainty parameters for UAV design will be studied by considering analysis tools, manufacturing and operating environment. ADDOPT process can reduce the whole design schedule, manufacturing cost and operation cost from commonality. 


\section{Appendix A}

\section{Finite Element Analysis Results}

of Wing Box 
Table A.1. Wing box analysis case

\begin{tabular}{|c|c|c|c|c|c|c|c|c|c|c|c|c|}
\hline Case & $x_{1}$ & $x_{2}$ & $x_{3}$ & $x_{4}$ & $x_{5}$ & $x_{6}$ & $x_{7}$ & $x_{8}$ & $x_{9}$ & $\begin{array}{l}\text { FA } \\
\text { (A) }\end{array}$ & $\begin{array}{c}\text { RSM } \\
\text { (B) }\end{array}$ & $\begin{array}{c}\text { Error } \\
(\mathrm{B} / \mathrm{A} \\
)^{2}\end{array}$ \\
\hline 1 & 0040 & 0161 & 0215 & .0038 & 0.0082 & 0.0166 & 0.0239 & 10.8710 & 8.1060 & 6932 & 0.6908 & 1.0035 \\
\hline 2 & 034 & 0225 & 0185 & 0.0041 & .0051 & 0.0256 & 0.0269 & 7.5370 & 8.4530 & 0.1344 & 0.1603 & 0.8386 \\
\hline 3 & 0.0024 & 0209 & 0.0234 & 0.0040 & 0.0082 & 0.0208 & 0.0209 & 8.2970 & 6.4690 & 0.4105 & .3751 & 1.0943 \\
\hline 4 & 0.0041 & 0.0193 & 0.0179 & 0.0049 & 0.0063 & 0.0214 & 0.0258 & 8.9510 & 7.4480 & 0.3827 & 0.3746 & 1.0216 \\
\hline 5 & 0031 & 0.0240 & .0172 & 0.0043 & 0.0052 & 0.0245 & 0.0250 & 11.0200 & 9.9730 & 0.3661 & 0.3875 & 0.9447 \\
\hline 6 & 0.0036 & 0.0260 & 0.0227 & 0.0041 & 0.0080 & 0.0269 & 0.0184 & 9.1260 & 8.2810 & 0.3605 & 0.3665 & 0.9836 \\
\hline 7 & 0.0024 & 0.0255 & 0.0145 & 0.0049 & 0.0070 & 0.0188 & 0.0192 & 7.8370 & 7.2560 & 0.3255 & 0.3242 & 1.0041 \\
\hline 8 & 0.0028 & 0.0232 & 0.0151 & 0.0047 & 0.0070 & 0.0161 & 0.0265 & 8.5610 & 9.2880 & 0.3074 & .3133 & 0.9813 \\
\hline 9 & 0.0030 & 0.0166 & 0.0162 & 0.0042 & 0.0075 & 0.0146 & 0.0171 & 7.0460 & 7.1140 & 2994 & 3230 & 0.9268 \\
\hline 10 & 0029 & 0.0202 & 0.0252 & 0.0040 & 0.0058 & 0.0146 & 0.0246 & 12.9450 & 8.2070 & .2049 & 2342 & 0.9763 \\
\hline 11 & 0.0037 & 0.0231 & 0257 & 0.0048 & 0.0060 & 0.0151 & 0.0268 & 11.7000 & 8.4380 & 8635 & 3565 & 1.0082 \\
\hline 12 & 0.0025 & 0.0260 & 0.0218 & 0.0042 & 0.0076 & 0.0164 & 0.0159 & 10.5500 & 10.0300 & 0.4677 & 0.4928 & 0.9490 \\
\hline 13 & 025 & 0.0186 & 0.0262 & 0.0036 & 0.0080 & 0.0270 & 0.0205 & 11.5160 & 6.1230 & 1.0519 & 1.0681 & 0.9848 \\
\hline 14 & 0.0039 & 0.0251 & 158 & 0.0054 & 0.0058 & 0.0188 & 0.0270 & 12.2450 & 6.3900 & 1.3212 & 3626 & 0.9696 \\
\hline 15 & 0.0028 & 0.0165 & 0.0184 & 0.0061 & 0.0074 & 0.0189 & 0.0268 & 8.9430 & 9.6300 & 0.2908 & 0.2819 & 1.0316 \\
\hline 16 & 0039 & 0.0244 & 0234 & 0.0055 & 0.0091 & 0.0225 & 0.0174 & 7.8610 & 6.7060 & 0.3858 & 3820 & 1.0101 \\
\hline 17 & 040 & 0.0202 & & 0.0035 & 0.0052 & 0.0254 & 0.0154 & 10.4530 & 10.5730 & 78 & 341 & 0.9626 \\
\hline 18 & 0041 & 0.0164 & 0198 & 0.0047 & 0.0050 & 0.0259 & 0.0271 & 8.9420 & 6.2960 & 0.5500 & 5226 & 1.0525 \\
\hline 19 & 035 & 0.0243 & 162 & 0.0059 & 0.0074 & 0.0215 & 0.0260 & 7.3770 & 6.5150 & 2776 & 849 & 0.9744 \\
\hline 20 & 043 & 0.0212 & 260 & 0.0049 & 0.0074 & 0.0193 & 0.0184 & 8.1220 & 7.3890 & 0.3435 & 3218 & 1.0673 \\
\hline 21 & 0.0038 & 0.0151 & 0.0178 & 0.0039 & 0.0080 & 0.0156 & 0.0168 & 12.1140 & 7.9300 & 1.1014 & 0816 & 1.0183 \\
\hline 22 & 031 & 0.0190 & 219 & 0.0051 & 0.0068 & 0.0255 & 0.0200 & 9.9210 & 8.8490 & 3776 & 725 & 1.0136 \\
\hline 23 & 0.0029 & 0.0257 & 0.0242 & 0.0036 & 0.0063 & 0.0182 & 0.0195 & 7.9360 & 9.4190 & 0.1909 & 0.2225 & 0.8578 \\
\hline 24 & 0033 & 0.0229 & .0249 & 0.0045 & 0.0083 & 0.0265 & 0.0233 & 10.6200 & 9.8990 & 0.3079 & 3009 & 1.0232 \\
\hline 2 & & & & & & & & & & & & .0241 \\
\hline 26 & 0027 & 0.0247 & 0157 & 0.0045 & 0.0052 & 0.0160 & 0.0266 & 7.6780 & 10.6070 & 0.2423 & 1993 & 1.2157 \\
\hline 27 & 0031 & 0.0232 & 0.0236 & 0.0051 & 0.0058 & 0.0252 & 0.0222 & 8.2850 & 8.2380 & 0.2148 & 2192 & 0.9800 \\
\hline 28 & 033 & & & 0.0046 & 0.0069 & 0.0222 & 0.0153 & 7.6950 & 10.1440 & 0.2185 & 0.2302 & 0.9492 \\
\hline 29 & 0038 & 0.0228 & 0208 & 0.0055 & 0.0060 & 0.0163 & 0.0190 & 10.5540 & 9.7280 & 0.4770 & 0.4921 & 0.9693 \\
\hline 30 & 0.0025 & 0.0186 & 0262 & 0.0036 & 0.0080 & 0.0270 & 0.0205 & 11.5160 & 6.1230 & 1.0519 & 0681 & 0.9848 \\
\hline 31 & 0.0041 & 0.0173 & 0.0161 & 0.0046 & 0.0075 & 0.0187 & 0.0276 & 9.2010 & 9.5160 & 0.3017 & 3006 & 1.0036 \\
\hline 32 & 0028 & 0.0190 & 0243 & 0.0059 & .0061 & 0.0242 & 0.0268 & 12.5090 & 10.6320 & 0.4654 & 0.4794 & 0.9708 \\
\hline 33 & & & & 0.0037 & 0.0088 & 0.0165 & & 11.1030 & 8.7570 & 0.6753 & 808 & 0.9919 \\
\hline 34 & .0039 & 0.0237 & & 0.0049 & 0.0089 & 0.0186 & 0.0158 & 7.0330 & 8.0650 & 0.2178 & 0.2549 & 0.8544 \\
\hline 35 & 0.0027 & 0.0193 & 0173 & 0.0039 & 0.0076 & 0.0254 & 0.0159 & 10.3860 & 6.4770 & 0.9005 & .9085 & 0.9912 \\
\hline 36 & 0.0040 & 0.0174 & 0219 & 0.0045 & 0.0076 & 0.0177 & 0.0198 & 10.0400 & 9.1690 & 0.4124 & 0.4183 & 0.9858 \\
\hline 37 & 0.0031 & & & 0.0033 & 0.0065 & 0.0153 & 0.0213 & 12.2180 & 7.9540 & 1.0662 & 1.0734 & 0.9933 \\
\hline 38 & 0.0033 & 0.0214 & 0.0148 & 0.0043 & 0.0056 & 0.0221 & 0.0239 & 7.6240 & 5.9500 & 0.3978 & .4014 & 0.9911 \\
\hline 39 & 0.0024 & 0.0187 & 0.0165 & 0.0054 & 0.0053 & 0.0178 & 0.0163 & 7.9890 & 7.5220 & 0.3395 & 0.3559 & 0.9539 \\
\hline 40 & 0.0032 & 0.0230 & .0201 & 0.0038 & 0.0070 & 0.0193 & 0.0249 & 12.0690 & 7.6650 & 0.8974 & 0.8315 & 1.0792 \\
\hline 41 & 0.0040 & & 0.0209 & 0.0059 & & 0.0202 & 0.0264 & 11.0010 & 9.3680 & & 0.5030 & 0.9551 \\
\hline 42 & 0.0038 & 0.0258 & 0.0149 & 0.0039 & 0.0079 & 0.0251 & 0.0189 & 9.9640 & 10.9810 & 0.2972 & 0.2906 & 1.0226 \\
\hline 43 & 0.0039 & 0.0173 & 0.0229 & 0.0058 & 0.0071 & 0.0205 & 0.0203 & 11.2790 & 9.0830 & 0.5827 & 0.5558 & 1.0483 \\
\hline 44 & 0.0038 & 0.0255 & 0.0229 & 0.0041 & 0.0059 & 0.0209 & 0.0267 & 7.7630 & 7.3330 & 0.2403 & 0.2508 & 0.9582 \\
\hline 45 & 0.0025 & 0.0206 & 0.0153 & 0.0048 & 0.0064 & 0.0226 & 0.0184 & 9.6380 & 6.7570 & 0.6623 & 0.6575 & 1.0073 \\
\hline 46 & 0.0030 & 0.0168 & 0.0190 & 0.0044 & 0.0064 & 0.0248 & 0.0203 & 9.4990 & 9.7090 & 0.2824 & 0.3154 & 0.8953 \\
\hline 47 & 0.0040 & 0.0220 & 0.0187 & 0.0037 & 0.0083 & 0.0191 & 0.0268 & 8.3430 & 9.7150 & 0.1992 & 0.2097 & 0.9501 \\
\hline 48 & 0.0027 & 0.0249 & 0.0256 & 0.0059 & 0.0081 & 0.0255 & 0.0191 & 9.2350 & 6.9350 & 0.4946 & 0.4767 & 1.0376 \\
\hline 49 & 0.0039 & 0.0218 & 0.0184 & 0.0039 & 0.0088 & 0.0167 & 0.0165 & 12.8470 & 7.3790 & 1.3071 & 1.3146 & 0.9943 \\
\hline 50 & 0.0033 & 0.0196 & 0.0262 & 0.0060 & 0.0068 & 0.0258 & 0.0271 & 12.6660 & 9.5020 & 0.5745 & 0.5740 & 1.0008 \\
\hline
\end{tabular}


Table A.1. Wing box analysis case (cont.)

\begin{tabular}{|c|c|c|c|c|c|c|c|c|c|c|c|c|}
\hline Case & $x_{1}$ & $x_{2}$ & $x_{3}$ & $x_{4}$ & $x_{5}$ & $x_{6}$ & $x_{7}$ & $x_{8}$ & $x_{9}$ & $\begin{array}{l}\text { FA } \\
(\mathrm{A}) \\
\end{array}$ & $\begin{array}{c}\text { RSM } \\
\text { (B) } \\
\end{array}$ & $\begin{array}{l}\text { Error } \\
(\mathrm{B} / \mathrm{A}) \\
\end{array}$ \\
\hline 51 & .0034 & 0258 & 0.0177 & 0.0053 & 0.0052 & 0.0242 & 0.0228 & 11.9890 & 10.6150 & 0.4537 & 0.4434 & 1.0233 \\
\hline 52 & 0.0037 & 0.0226 & 0.0214 & 0.0058 & 0.0078 & 0.0253 & 0.0160 & 7.0600 & 8.5490 & 0.2574 & 0.2187 & 1.1771 \\
\hline 53 & 0.0035 & 0.0236 & 0.0169 & 0.0054 & 0.0069 & 0.0170 & 0.0226 & 10.5870 & 7.6350 & 0.7038 & 0.6968 & 1.0100 \\
\hline 54 & 0.0027 & 0.0260 & 0.0154 & 0.0044 & 0.0084 & 0.0160 & 0.0220 & 7.9900 & 9.6220 & 0.2674 & 0.2627 & 1.0179 \\
\hline 55 & 0.0034 & 0.0175 & 0.0237 & 0.0039 & 0.0057 & 0.0149 & 0.0213 & 11.9290 & 6.1260 & 1.5024 & 1.6058 & 0.9356 \\
\hline 56 & 0.0037 & 0.0210 & 0.0170 & 0.0054 & 0.0089 & 0.0217 & 0.0182 & 8.8240 & 7.2210 & 0.4578 & 0.4248 & 1.0777 \\
\hline 57 & 0.0028 & 0.0234 & 0.0187 & 0.0060 & 0.0071 & 0.0193 & 0.0209 & 8.9450 & 10.0110 & 0.2271 & 0.2441 & 0.9302 \\
\hline 58 & 0.0026 & 0.0208 & 0.0213 & 0.0060 & 0.0083 & 0.0214 & 0.0270 & 7.0750 & 8.5630 & 0.1370 & 0.1472 & 0.9307 \\
\hline 59 & 0.0026 & 0.0163 & 0.0184 & 0.0060 & 0.0068 & 0.0221 & 0.0213 & 10.0660 & 8.4640 & 0.4670 & 0.4749 & 0.9833 \\
\hline 60 & 0.0039 & 0.0184 & 0.0234 & 0.0052 & 0.0064 & 0.0224 & 0.0189 & 7.0490 & 8.0770 & 0.1553 & 0.1860 & 0.8351 \\
\hline 61 & 0.0032 & 0.0213 & 0.0195 & 0.0057 & 0.0078 & 0.0208 & 0.0154 & 7.3440 & 6.7570 & 0.3457 & 0.3728 & 0.9272 \\
\hline 62 & 0.0026 & 0.0154 & 0.0260 & 0.0043 & 0.0060 & 0.0234 & 0.0164 & 8.6570 & 6.3260 & 0.5873 & 0.5810 & 1.0109 \\
\hline 63 & 0.0032 & 0.0244 & 0.0199 & 0.0053 & 0.0052 & 0.0217 & 0.0185 & 12.6040 & 5.9760 & 1.5660 & 1.5341 & 1.0208 \\
\hline 64 & 0.0031 & 0.0264 & 0.0156 & 0.0033 & 0.0054 & 0.0231 & 0.0176 & 11.8380 & 9.2220 & 0.6661 & 0.6665 & 0.9994 \\
\hline 65 & 0.0042 & 0.0266 & 0.0262 & 0.0053 & 0.0087 & 0.0243 & 0.0176 & 12.7750 & 7.5270 & 1.0737 & 1.0903 & 0.9848 \\
\hline 66 & 0.0030 & 0.0178 & 0.0145 & 0.0055 & 0.0066 & 0.0260 & 0.0233 & 7.0130 & 7.1680 & 0.2267 & 0.2211 & 1.0252 \\
\hline 67 & 0.0033 & 0.0196 & 0.0262 & 0.0060 & 0.0068 & 0.0258 & 0.0271 & 12.6660 & 9.5020 & 0.5745 & 0.5740 & 1.0008 \\
\hline 68 & 0.0028 & 0.0179 & 0.0249 & 0.0039 & 0.0090 & 0.0222 & 0.0214 & 9.1280 & 9.3720 & 0.2841 & 0.2818 & 1.0080 \\
\hline 69 & 0.0035 & 0.0153 & 0.0264 & 0.0038 & 0.0051 & 0.0149 & 0.0240 & 7.9020 & 6.1210 & 0.5570 & 0.5056 & 1.1017 \\
\hline 70 & 0.0042 & 0.0209 & 0.0174 & 0.0046 & 0.0067 & 0.0220 & 0.0187 & 12.3690 & 8.3120 & 0.8897 & 0.8371 & 1.0628 \\
\hline 71 & 0.0031 & 0.0234 & 0.0227 & 0.0040 & 0.0082 & 0.0174 & 0.0248 & 10.9270 & 8.6850 & 0.5666 & 0.5838 & 0.9705 \\
\hline 72 & 0.0035 & 0.0268 & 0.0153 & 0.0042 & 0.0052 & 0.0161 & 0.0161 & 9.2620 & 7.5220 & 0.6235 & 0.5781 & 1.0785 \\
\hline 73 & 0.0026 & 0.0250 & 0.0155 & 0.0036 & 0.0084 & 0.0197 & 0.0254 & 11.9060 & 9.1450 & 0.6416 & 0.6657 & 0.9637 \\
\hline 74 & 0.0032 & 0.0168 & 0.0226 & 0.0042 & 0.0071 & 0.0158 & 0.0154 & 9.5960 & 6.7230 & 0.7860 & 0.7314 & 1.0747 \\
\hline 75 & 0.0036 & 0.0172 & 0.0179 & 0.0048 & 0.0075 & 0.0154 & 0.0263 & 9.7250 & 6.6190 & 0.7874 & 0.7612 & 1.0344 \\
\hline 76 & 0.0038 & 0.0168 & 0.0235 & 0.0054 & 0.0062 & 0.0238 & 0.0267 & 9.0440 & 10.5060 & 0.2188 & 0.2293 & 0.9543 \\
\hline 77 & 0.0035 & 0.0236 & 0.0183 & 0.0055 & 0.0078 & 0.0173 & 0.0273 & 8.7560 & 10.8600 & 0.2846 & 0.2321 & 1.2260 \\
\hline 78 & 0.0032 & 0.0157 & 0.0153 & 0.0052 & 0.0051 & 0.0237 & 0.0164 & 11.3540 & 9.2670 & 0.6809 & 0.6335 & 1.0749 \\
\hline 79 & 0.0040 & 0.0247 & 0.0248 & 0.0048 & 0.0069 & 0.0229 & 0.0265 & 10.4480 & 10.8670 & 0.2759 & 0.2478 & 1.1134 \\
\hline 80 & 0.0024 & 0.0248 & 0.0173 & 0.0044 & 0.0061 & 0.0210 & 0.0174 & 10.4240 & 6.4840 & 0.8806 & 0.8613 & 1.0224 \\
\hline 81 & 0.0039 & 0.0184 & 0.0234 & 0.0052 & 0.0064 & 0.0224 & 0.0189 & 7.0490 & 8.0770 & 0.1553 & 0.1860 & 0.8351 \\
\hline 82 & 0.0033 & 0.0209 & 0.0202 & 0.0056 & 0.0049 & 0.0152 & 0.0154 & 12.6870 & 9.8660 & 0.8949 & 0.8578 & 1.0433 \\
\hline 83 & 0.0041 & 0.0239 & 0.0255 & 0.0036 & 0.0064 & 0.0260 & 0.0157 & 11.2540 & 9.7480 & 0.5736 & 0.5843 & 0.9818 \\
\hline 84 & 0.0031 & 0.0174 & 0.0246 & 0.0050 & 0.0066 & 0.0175 & 0.0216 & 10.4770 & 7.6100 & 0.6853 & 0.6441 & 1.0639 \\
\hline 85 & 0.0038 & 0.0175 & 0.0145 & 0.0038 & 0.0066 & 0.0236 & 0.0161 & 7.4720 & 10.6450 & 0.1997 & 0.1705 & 1.1714 \\
\hline 86 & 0.0035 & 0.0242 & 0.0161 & 0.0056 & 0.0057 & 0.0237 & 0.0228 & 11.6230 & 10.6100 & 0.4151 & 0.4364 & 0.9512 \\
\hline 87 & 0.0027 & 0.0153 & 0.0146 & 0.0051 & 0.0056 & 0.0194 & 0.0249 & 8.8680 & 6.9960 & 0.5269 & 0.5105 & 1.0322 \\
\hline 88 & 0.0027 & 0.0186 & 0.0209 & 0.0039 & 0.0060 & 0.0149 & 0.0234 & 8.4710 & 10.2110 & 0.2451 & 0.2775 & 0.8834 \\
\hline 89 & 0.0025 & 0.0251 & 0.0213 & 0.0033 & 0.0082 & 0.0234 & 0.0229 & 7.4740 & 7.6670 & 0.1767 & 0.1858 & 0.9513 \\
\hline 90 & 0.0034 & 0.0170 & 0.0226 & 0.0046 & 0.0091 & 0.0254 & 0.0155 & 11.6940 & 7.4270 & 0.9821 & 0.9928 & 0.9892 \\
\hline 91 & 0.0023 & 0.0172 & 0.0182 & 0.0043 & 0.0052 & 0.0169 & 0.0158 & 8.8220 & 7.3750 & 0.5069 & 0.4900 & 1.0344 \\
\hline 92 & 0.0043 & 0.0165 & 0.0180 & 0.0045 & 0.0051 & 0.0181 & 0.0155 & 12.2860 & 5.9670 & 1.7359 & 1.7619 & 0.9852 \\
\hline 93 & 0.0040 & 0.0223 & 0.0163 & 0.0041 & 0.0086 & 0.0198 & 0.0200 & 11.4880 & 10.8710 & 0.4021 & 0.4288 & 0.9377 \\
\hline 94 & 0.0028 & 0.0198 & 0.0205 & 0.0046 & 0.0070 & 0.0171 & 0.0182 & 8.4560 & 6.3050 & 0.5504 & 0.5261 & 1.0462 \\
\hline 95 & 0.0023 & 0.0268 & 0.0166 & 0.0038 & 0.0060 & 0.0198 & 0.0205 & 9.3410 & 8.5670 & 0.3567 & 0.3561 & 1.0017 \\
\hline 96 & 0.0031 & 0.0264 & 0.0156 & 0.0033 & 0.0054 & 0.0231 & 0.0176 & 11.8380 & 9.2220 & 0.6661 & 0.6665 & 0.9994 \\
\hline 97 & 0.0041 & 0.0208 & 0.0170 & 0.0042 & 0.0084 & 0.0244 & 0.0171 & 7.7780 & 9.5900 & 0.2144 & 0.2080 & 1.0306 \\
\hline 98 & 0.0027 & 0.0270 & 0.0221 & 0.0053 & 0.0083 & 0.0238 & 0.0161 & 8.4780 & 7.3580 & 0.4175 & 0.4445 & 0.9394 \\
\hline 99 & 0.0033 & 0.0196 & 0.0262 & 0.0060 & 0.0068 & 0.0258 & 0.0271 & 12.6660 & 9.5020 & 0.5745 & 0.5740 & 1.0008 \\
\hline 100 & 0.0030 & 0.0161 & 0.0188 & 0.0061 & 0.0062 & 0.0208 & 0.0248 & 10.8720 & 6.0430 & 1.0401 & 1.0626 & 0.9789 \\
\hline
\end{tabular}


Table A.1. Wing box analysis case (cont.)

\begin{tabular}{|c|c|c|c|c|c|c|c|c|c|c|c|c|}
\hline Case & $x_{1}$ & $x_{2}$ & $x_{3}$ & $x_{4}$ & $x_{5}$ & $x_{6}$ & $x_{7}$ & $x_{8}$ & $x_{9}$ & $\begin{array}{l}\text { FA } \\
\text { (A) }\end{array}$ & $\begin{array}{c}\text { RSM } \\
\text { (B) }\end{array}$ & $\begin{array}{l}\text { Error } \\
(\mathrm{B} / \mathrm{A})\end{array}$ \\
\hline 101 & 0041 & 0184 & 0.0246 & 0.0041 & 0.0052 & 0.0192 & 0.0216 & 8.2420 & 9.5430 & 0.1949 & 0.2122 & 0.9186 \\
\hline 102 & 0035 & 215 & 0246 & 0042 & 0.0071 & 0.0231 & .0225 & 9.2570 & 8.1160 & 0.3066 & 0.3186 & 0.9624 \\
\hline 103 & 0.0041 & 0202 & .0167 & 0.0058 & 0.0090 & 0.0222 & 0.0205 & 7.5480 & 6.7330 & 0.3239 & 0.2907 & 1.1143 \\
\hline 104 & 0.0035 & 0.0260 & 0.0213 & 0.0038 & 0.0084 & 0.0204 & 0.0220 & 12.8900 & 8.6620 & 0.8257 & 0.7716 & 1.0701 \\
\hline 105 & 0.0028 & 0.0190 & 0.0216 & 0.0041 & 0.0071 & 0.0208 & 0.0166 & 10.9320 & 7.1920 & 0.8527 & 0.8404 & 1.0146 \\
\hline 106 & 0.0037 & 0.0237 & 0.0169 & 0.0040 & 0.0081 & 0.0242 & 0.0202 & 10.1930 & 6.0020 & 0.8132 & 0.8452 & 0.9622 \\
\hline 107 & 0.0040 & 0.0239 & 0.0235 & 0.0050 & 0.0088 & 0.0210 & 0.0181 & 11.2430 & 8.3710 & 0.6442 & 0.6384 & 1.0091 \\
\hline 108 & 0.0036 & 0191 & 0.0202 & 0.0040 & 0.0086 & 0.0219 & 0.0232 & 8.4490 & 8.4240 & 0.2158 & 0.2630 & 0.8204 \\
\hline 109 & 0.0028 & 0.0184 & 0.0213 & 0.0048 & 0.0056 & 0.0258 & 0.0230 & 11.3790 & 7.1550 & 0.8191 & 0.7775 & 1.0535 \\
\hline 110 & 0.0031 & 0232 & 0.0236 & 0.0051 & 0.0058 & 0.0252 & 0.0222 & 8.2850 & 8.2380 & 0.2148 & 0.2192 & 0.9800 \\
\hline 111 & 0.0029 & 0.0210 & 0.0227 & 0.0051 & 0.0076 & 0.0198 & 0.0197 & 7.1140 & 10.8450 & 0.1098 & 0.1167 & 0.9412 \\
\hline 112 & 0.0027 & 0.0228 & 0.0159 & 0.0044 & 0.0085 & 0.0222 & 0.0233 & 10.7080 & 10.0390 & 0.3661 & 0.3906 & 0.9373 \\
\hline 113 & 0.0034 & 208 & 0.0198 & 0.0047 & 0.0067 & 0.0240 & 0156 & 11.8410 & 9.2310 & 0.6838 & 0.7370 & 0.9279 \\
\hline 114 & 0.0035 & 0.0207 & 0.0186 & 0.0042 & 0.0084 & 0.0193 & 0.0199 & 10.8080 & 7.3390 & 0.7493 & 0.6842 & 1.0952 \\
\hline 115 & 0.0038 & 0.0235 & 0.0180 & 0.0055 & 0.0074 & 0.0174 & 0.0236 & 11.6490 & 10.8370 & 0.4531 & 0.4833 & 0.9375 \\
\hline 116 & 0.0027 & 0.0189 & 0.0266 & 0.0061 & 0.0056 & 0.0149 & 0.0204 & 9.7840 & 10.2280 & 0.3691 & 0.3961 & 0.9319 \\
\hline 117 & 0.0024 & 0.0256 & 0.0250 & 0.0053 & 0.0081 & 0.0197 & 0.0265 & 9.8030 & 6.7300 & 0.5681 & 0.5705 & 0.9959 \\
\hline 118 & 0.0027 & 156 & 0.0225 & 0.0043 & 0.0066 & 0.0243 & 0.0194 & 8.7740 & 10.5190 & 0.2304 & 0.2410 & 0.9559 \\
\hline 119 & 0.0031 & 0.0264 & 0.0208 & 0.0042 & 0.0065 & 0.0166 & 0.0254 & 8.6850 & 9.8070 & 0.2688 & 0.2903 & 0.9260 \\
\hline 120 & 0.0039 & 257 & 0.0244 & 0.0042 & 0.0089 & 0.0234 & 0.0179 & 12.0700 & 10.9330 & 0.4721 & 0.4977 & 0.9485 \\
\hline 121 & 0.0038 & 190 & 0.0154 & 0.0053 & 0.0053 & 0.0195 & 0.0214 & 7.8780 & 8.8490 & 0.1986 & 0.2169 & 0.9156 \\
\hline 122 & 0.0038 & 233 & 0.0156 & 0.0044 & 0.0061 & 0.0218 & 0.0177 & 10.8930 & 5.9470 & 1.1389 & 1.1764 & 0.9681 \\
\hline 123 & 0.0025 & 0.0156 & 0.0221 & 0.0045 & 0.0053 & 0.0169 & 0.0163 & 11.9140 & 5.9840 & 1.5618 & 1.6117 & 0.9690 \\
\hline 124 & 0.0036 & 0.0153 & 0.0222 & 0.0058 & 0.0073 & 0.0194 & 0.0205 & 9.5920 & 8.1390 & 0.4630 & 0.4860 & 0.9527 \\
\hline 125 & 0.0040 & 0.0178 & 0.0234 & 0.0046 & 0.0058 & 0.0158 & 0.0215 & 12.1360 & 8.1260 & 1.0254 & 0.9596 & 1.0686 \\
\hline 126 & 0.0036 & 0.0148 & 0.0245 & 0.0049 & 0.0086 & 0.0181 & 0.0267 & 12.3360 & 8.1950 & 0.9204 & 0.9779 & 0.9412 \\
\hline 127 & 0.0031 & 0.0193 & 0.0264 & 0.0037 & 0.0056 & 0.0231 & 0.0157 & 8.1410 & 10.8630 & 0.2402 & 0.2094 & 1.1473 \\
\hline 128 & 0.0034 & 0225 & 0.0150 & 0.0041 & 0.0058 & 0.0250 & 0.0177 & 7.5350 & 9.2790 & 0.1894 & 0.1998 & 0.9481 \\
\hline 129 & 0.0035 & 150 & 199 & 0.0046 & 0.0079 & 0.0194 & 0.0173 & 8.0270 & 10.0120 & 0.2064 & 0.2285 & 0.9035 \\
\hline 130 & 0.0032 & 0.0150 & 0.0238 & 0.0061 & 0.0082 & 0.0153 & 0.0266 & 12.3220 & 9.5420 & 0.8144 & 0.7759 & 1.0496 \\
\hline 131 & 0.0023 & & & 0.0055 & 0.0085 & 0.0147 & 0.0267 & & 7.8330 & 0.3951 & 0.3848 & 1.0267 \\
\hline 132 & 0.0034 & 215 & 189 & 0.0038 & 0.0089 & 0.0179 & 0.0249 & 10.6440 & 7.8860 & 0.6313 & 0.6175 & 1.0224 \\
\hline 133 & 0.0034 & 0.0175 & 0.0190 & 0.0034 & 0.0059 & 0.0229 & 0.0268 & 11.7370 & 6.6660 & 1.0211 & 1.0008 & 1.0202 \\
\hline 134 & 0.0038 & 0.0190 & 0.0154 & 0.0053 & 0.0053 & 0.0195 & 0.0214 & 7.8780 & 8.8490 & 0.1986 & 0.2169 & 0.9156 \\
\hline 135 & 0.0033 & 0.0215 & 0.0237 & 0.0033 & 0.0074 & 0.0255 & 0.0196 & 11.1990 & 8.6100 & 0.5508 & 0.5295 & 1.0401 \\
\hline 136 & 0.0040 & 0.0202 & 0.0174 & 0.0035 & 0.0052 & 0.0254 & 0.0154 & 10.4530 & 10.5730 & 0.4178 & 0.4341 & 0.9626 \\
\hline 137 & 0.0032 & 0.0236 & 0.0258 & 0.0051 & 0.0083 & 0.0205 & 0.0222 & 7.5490 & 7.9760 & 0.1736 & 0.2063 & 0.8414 \\
\hline 138 & 0.0034 & 0.0190 & 0.0184 & 0.0040 & 0.0078 & 0.0175 & 0.0241 & 7.3550 & 7.6210 & 0.2096 & 0.2468 & 0.8494 \\
\hline 139 & 0.0025 & 0.0188 & 0.0168 & 0.0049 & 0.0062 & 0.0196 & 0.0155 & 12.7540 & 9.3130 & 0.8867 & 0.9094 & 0.9750 \\
\hline 140 & 0.0040 & 0.0261 & 0.0174 & 0.0039 & 0.0081 & 0.0248 & 0.0202 & 7.2240 & 10.2510 & 0.1408 & 0.1325 & 1.0625 \\
\hline 141 & 0.0042 & 0.0262 & 0.0215 & 0.0041 & 0.0071 & 0.0160 & 0.0185 & 12.0440 & 8.6140 & 0.8785 & 0.8831 & 0.9948 \\
\hline 142 & 0.0038 & 0.0216 & 0.0178 & 0.0052 & 0.0089 & 0.0158 & 0.0220 & 9.6940 & 10.2540 & 0.3488 & 0.3736 & 0.9336 \\
\hline 143 & 0.0029 & 0.0236 & 0.0244 & 0.0043 & 0.0051 & 0.0236 & 0.0165 & 10.7100 & 7.4780 & 0.7718 & 0.7570 & 1.0196 \\
\hline 144 & 0.0030 & 0.0221 & 0.0268 & 0.0045 & 0.0077 & 0.0229 & 0.0270 & 11.2290 & 10.5030 & 0.3325 & 0.3295 & 1.0092 \\
\hline 145 & 0.0028 & 0.0237 & 0.0223 & 0.0054 & 0.0082 & 0.0263 & 0.0241 & 11.1060 & 8.9920 & 0.4097 & 0.3962 & 1.0341 \\
\hline 146 & 0.0032 & 0.0160 & 0.0261 & 0.0048 & 0.0053 & 0.0260 & 0.0265 & 9.8110 & 10.9640 & 0.2647 & 0.2633 & 1.0055 \\
\hline 147 & 0.0040 & 0.0166 & 0.0156 & 0.0039 & 0.0091 & 0.0179 & 0.0202 & 9.9100 & 10.2550 & 0.3535 & 0.3504 & 1.0088 \\
\hline 148 & 0.0025 & 0.0165 & 0.0227 & 0.0034 & 0.0086 & 0.0205 & 0.0207 & 12.8810 & 10.9760 & 0.6340 & 0.5997 & 1.0571 \\
\hline
\end{tabular}




\section{Appendix B}

Light Jet Aircraft Specifications

for Database 
Table B.1. Light jet aircraft specifications for database

\begin{tabular}{|c|c|c|c|c|c|c|}
\hline Parameter & $\mathrm{CJ} 1$ & $\mathrm{CJ} 2$ & $\mathrm{CJ} 3$ & Bravo & Encore 560 & $\begin{array}{l}\text { Encore } \\
560 X \mathrm{XL}\end{array}$ \\
\hline $\begin{array}{l}\begin{array}{l}\text { Number } \\
\text { (people) }\end{array} \\
\text { of passenger }\end{array}$ & 5 & 6 & 6 & 7 & 8 & 10 \\
\hline Wing span $(f t)$ & 46.791 & 49 & 52.916 & 52.208 & 54.083 & 56.312 \\
\hline Taper ratio & 0.35 & 0.3 & 0.33 & & & \\
\hline Aspect ratio & 9.1 & 9.4 & 9.5 & 8.4 & 9 & 8.4 \\
\hline Tail span $(f t)$ & 18.5 & 20.791 & 20.75 & 19 & 21.5 & 21.5 \\
\hline Fuselage length $(f t)$ & 42.583 & 47.667 & 52.167 & 47.208 & 48.854 & 51.792 \\
\hline Fuselage height $(f t)$ & 13.77 & 13.896 & 15.104 & 15 & 15.188 & 17.375 \\
\hline Wheel-base $(f t)$ & 15.354 & 18.333 & 20 & 18.5 & 13.292 & 21.896 \\
\hline Cabin length $(f t)$ & 15.75 & 18.833 & 20.833 & 20.917 & 22.583 & 24.25 \\
\hline Cabin max. height $(f t)$ & 4.75 & 4.75 & 4.75 & 4.688 & 4.708 & 5.688 \\
\hline Cockpit length $(f t)$ & 11 & 13.75 & 13.833 & 15.583 & 17.25 & 18.667 \\
\hline Wing area $\left(f t^{2}\right)$ & 240 & 264 & 294.1 & 342.6 & 322.3 & 369.7 \\
\hline Vertical tail area $\left(f t^{2}\right)$ & 46.8 & 46.8 & 56.3 & 50.9 & 50.9 & 50.9 \\
\hline Horizontal tail area $\left(f t^{2}\right)$ & 60.7 & 70.7 & 70.68 & 69.8 & 84.8 & 84.8 \\
\hline Operate empty weight $(l b)$ & 6670 & 7640 & 8260 & 8980 & 10120 & 12300 \\
\hline Usable fuel weight $(l b)$ & 3220 & 3930 & 4710 & 4860 & 5440 & 6740 \\
\hline Max take-off weight $(l b)$ & 10600 & 12375 & 13870 & 14800 & 16630 & 20000 \\
\hline Payload weight (lb) & 675 & 800 & 800 & & & \\
\hline Max. landing weight $(l b)$ & 9800 & 11500 & 12750 & 13500 & 15200 & 18700 \\
\hline Zero fuel weight $(l b)$ & & 9300 & 10510 & 11300 & 12600 & 15000 \\
\hline Max. W/S & 44.17 & 46.88 & 47.16 & 45.83 & 51.6 & 54.1 \\
\hline Max. W/T & 2.79 & 2.58 & 2.49 & 2.56 & 2.45 & 2.64 \\
\hline Max Mach number & 0.71 & 0.72 & 0.72 & 0.7 & 0.75 & 0.75 \\
\hline Cruise Mach number & 0.7 & 0.7 & 0.7 & 0.7 & 0.75 & 0.73 \\
\hline Altitude $(f t)$ & 41000 & 45000 & 45000 & 43000 & 45000 & 45000 \\
\hline Takeoff field length $(f t)$ & 3280 & 3420 & 3450 & & 3490 & 3590 \\
\hline Landing field length $(f t)$ & 2760 & 2980 & 3070 & & 2770 & 28600 \\
\hline Range $(N M)$ & 1248 & 1550 & 1771 & 1744 & 1178 & 1847 \\
\hline Engine thrust $(l b)$ & 1900 & 2400 & 2780 & 2500 & 3400 & 3800 \\
\hline
\end{tabular}


Table B.1. Light jet aircraft specifications for database (cont.)

\begin{tabular}{|c|c|c|c|c|c|c|}
\hline Parameter & $\begin{array}{l}\text { LearJet } \\
31 \mathrm{~A}\end{array}$ & $\begin{array}{l}\text { LearJet } \\
31 \mathrm{~A} / \mathrm{ER}\end{array}$ & $\begin{array}{l}\text { LearJet } \\
40\end{array}$ & $\begin{array}{l}\text { LearJet } \\
40 X R\end{array}$ & $\begin{array}{l}\text { LearJet } \\
45\end{array}$ & $\begin{array}{l}\text { LearJet } \\
45 \mathrm{XR}\end{array}$ \\
\hline $\begin{array}{l}\text { Number } \\
\text { (people) }\end{array}$ of passenger & 7 & 7 & 7 & 7 & 8 & 8 \\
\hline Wing span $(f t)$ & 43.833 & 43.833 & 47.781 & 47.781 & 47.77 & 47.77 \\
\hline Taper ratio & & & & & & \\
\hline Aspect ratio & 7.2 & 7.2 & 7.3 & 7.3 & 7.3 & 7.3 \\
\hline Tail span $(f t)$ & 14.708 & 14.708 & 16.87 & 16.87 & 17.2 & 17.2 \\
\hline Fuselage length $(f t)$ & 48.667 & 48.667 & 55.56 & 55.56 & 58.417 & 58.417 \\
\hline Fuselage height $(f t)$ & 12.25 & 12.25 & 14.13 & 14.13 & 14.083 & 14.083 \\
\hline Wheel-base $(f t)$ & & & 25.792 & 25.792 & 25.813 & 25.813 \\
\hline Cabin length $(f t)$ & 21.75 & 20.583 & 22.688 & 22.688 & 22.688 & 22.688 \\
\hline Cabin max. height $(f t)$ & 4.25 & 4.25 & 4.9 & 4.9 & 4.917 & 4.917 \\
\hline Cockpit length $(f t)$ & 17.083 & 15.917 & 17.6667 & 17.667 & 19.75 & 19.75 \\
\hline Wing area $\left(f t^{2}\right)$ & 264.5 & 264.5 & 311.6 & 311.6 & 311.6 & 311.6 \\
\hline Vertical tail area $\left(f t^{2}\right)$ & 38.4 & 38.4 & 52.89 & 52.89 & 49.82 & 49.82 \\
\hline Horizontal tail area $\left(f t^{2}\right)$ & 54 & 54 & 67.81 & 67.81 & 66.57 & 66.57 \\
\hline Operate empty weight $(l b)$ & 10253 & 10253 & 12740 & 12740 & 12780 & 12939 \\
\hline Usable fuel weight $(l b)$ & 2804 & 2826 & 5300 & 5300 & 6062 & 6062 \\
\hline Max take-off weight $(l b)$ & 17000 & 17700 & 20350 & 20350 & 20500 & 21500 \\
\hline Payload weight (lb) & 1976 & 2400 & 2305 & 2305 & & \\
\hline Max. landing weight $(l b)$ & 16000 & 16000 & 19200 & 19200 & 19200 & 19200 \\
\hline Zero fuel weight $(l b)$ & 13500 & 13500 & 16000 & 16000 & 16000 & 16000 \\
\hline Max. W/S & 64.27 & 66.92 & 65.31 & 65.31 & 65.79 & 69 \\
\hline Max. W/T & 2.43 & 2.53 & 2.91 & 2.91 & 2.93 & 3.07 \\
\hline Max Mach number & 0.81 & 0.81 & 0.81 & 0.81 & 0.81 & 0.8 \\
\hline Cruise Mach number & 0.78 & 0.76 & 0.78 & 0.78 & 0.78 & 0.78 \\
\hline Altitude $(f t)$ & 51000 & & 51000 & 51000 & 51000 & 5100 \\
\hline Takeoff field length $(f t)$ & 3490 & 3800 & 4285 & 4285 & 4350 & 5060 \\
\hline Landing field length $(f t)$ & 2866 & 2866 & 2660 & 2660 & 2660 & 2660 \\
\hline Range $(N M)$ & 1259 & 1488 & 1692 & 1692 & 2098 & 2098 \\
\hline Engine thrust $(l b)$ & 3500 & 3500 & 3500 & 3500 & 3500 & 3500 \\
\hline
\end{tabular}


Table B.1. Light jet aircraft specifications for database (cont.)

\begin{tabular}{|c|c|c|c|c|c|c|c|}
\hline Parameter & BC 300 & FJ-100 & $\mathrm{SJ} 30-2 \mathrm{~A}$ & SJ30-2B & Premier & Horizon & $\begin{array}{l}\text { Falcon } \\
50\end{array}$ \\
\hline $\begin{array}{l}\text { Number of passenger } \\
\text { (people) }\end{array}$ & 8 & 7 & 6 & 6 & 6 & 8 & 9 \\
\hline Wing span $(f t)$ & 63.833 & 36.667 & 42.333 & 42.333 & 44.5 & 61.75 & 61.875 \\
\hline Taper ratio & & & 0.21 & 0.21 & & & \\
\hline Aspect ratio & & 7.6 & 9.4 & 9.4 & 8 & 7.2 & 7.6 \\
\hline Tail span $(f t)$ & 23.708 & 14.333 & 14.74 & 14.74 & 15.81 & 25.917 & 25.396 \\
\hline Fuselage length $(f t)$ & 68.667 & 38.583 & 46.792 & 46.792 & 46 & 69.25 & 57.917 \\
\hline Fuselage height $(f t)$ & 20.25 & 14.5 & 14.25 & 14.25 & 15.333 & 19.583 & 22.895 \\
\hline Wheel-base (ft) & 27.75 & 10.167 & 18.708 & 18.708 & 17.583 & 27.75 & 23.75 \\
\hline Cabin length $(f t)$ & 28.583 & 13.875 & 17.583 & 17.583 & 18.667 & 25 & 23.5 \\
\hline Cabin max. height $(f t)$ & 6.083 & 3.958 & 4.292 & 4.292 & 5.417 & 6 & 5.896 \\
\hline Cockpit length $(f t)$ & & & & & & & \\
\hline Wing area $\left(f t^{2}\right)$ & 522 & 178 & 190.7 & 190.7 & 247 & 531 & 504.1 \\
\hline Vertical tail area $\left(f t^{2}\right)$ & & & & & 51.5 & 25.87 & 105.7 \\
\hline Horizontal tail area $\left(f t^{2}\right)$ & & & & & 50 & 140 & 143.69 \\
\hline Operate empty weight $(l b)$ & 22350 & 4200 & 7800 & 7800 & & & 21170 \\
\hline Usable fuel weight $(l b)$ & 13700 & 2494 & 4950 & 4400 & 3670 & 14300 & 15520 \\
\hline Max take-off weight $(l b)$ & 37500 & 7300 & 13500 & 12500 & 12500 & 37500 & 39700 \\
\hline Payload weight $(l b)$ & & & & & & & 3770 \\
\hline Max. landing weight $(l b)$ & 33750 & & 12540 & 12500 & 11600 & 33500 & 35715 \\
\hline Zero fuel weight $(l b)$ & 25350 & 5900 & 10000 & 10000 & 10000 & 25000 & 25570 \\
\hline Max. W/S & 71.84 & 41.01 & 70.79 & 65.55 & 50.61 & 70.62 & 78.75 \\
\hline Max. W/T & 2.88 & & 2.93 & 2.72 & 2.72 & 2.72 & 3.58 \\
\hline Max Mach number & 0.82 & 0.71 & 0.8 & 0.8 & 0.8 & 0.84 & 0.86 \\
\hline Cruise Mach number & 0.82 & 0.7 & 0.78 & 0.78 & 0.8 & 0.82 & 0.8 \\
\hline Altitude $(f t)$ & 45000 & 41000 & 49000 & 49000 & 41000 & & 41000 \\
\hline Takeoff field length $(f t)$ & 4950 & 1900 & 3993 & 3620 & 3795 & 4900 & 4890 \\
\hline Landing field length $(f t)$ & 2600 & 1600 & 3420 & 2420 & 3170 & 2340 & 2185 \\
\hline Range $(N M)$ & 3100 & 1550 & 2500 & 1840 & 1460 & 3400 & 3025 \\
\hline Engine thrust $(l b)$ & 3800 & 1500 & 2300 & 2300 & 2300 & 6900 & 3700 \\
\hline
\end{tabular}




\section{Appendix C}

\section{Civil Jet Aircraft Specifications}

for Database 
Table C.1. Civil jet aircraft specifications for database

\begin{tabular}{|c|c|c|c|c|c|c|c|}
\hline & eter & A $300-600$ & A $310-200$ & A310-300 & A320-200 & A318 & A319 \\
\hline Wing & \begin{tabular}{|l|} 
Span $(f t)$ \\
AR \\
TR \\
Root chord $(f t)$ \\
Swept back angle $(\mathrm{deg})$ \\
Area $\left(f t^{2}\right)$ \\
Control surface area $\left(f t^{2}\right)$ \\
\end{tabular} & $\begin{array}{r}147.0752 \\
7.7 \\
0.384 \\
30.83 \\
30 \\
2798.64 \\
835.28 \\
\end{array}$ & \begin{tabular}{r|}
143.992 \\
8.8 \\
0.26 \\
27.49 \\
28 \\
2357.32 \\
930.76 \\
\end{tabular} & \begin{tabular}{r|}
143.992 \\
8.8 \\
0.26 \\
27.49 \\
28 \\
2357.32 \\
930.76 \\
\end{tabular} & $\begin{array}{r}111.8152 \\
9.5 \\
0.301 \\
20.01 \\
25 \\
1317.51 \\
461.62 \\
\end{array}$ & $\begin{array}{r}111.848 \\
8.8 \\
0.26 \\
24.48 \\
25 \\
1317.51 \\
461.62 \\
\end{array}$ & $\begin{array}{r}111.8152 \\
9.5 \\
0.301 \\
20.01 \\
25 \\
1317.51 \\
461.62 \\
\end{array}$ \\
\hline H-tail & \begin{tabular}{|l|} 
Span $(f t)$ \\
AR \\
TR \\
Root chord $(f t)$ \\
Swept back angle (deg) \\
Area $\left(f t^{2}\right)$ \\
Control surface area $\left(f t^{2}\right)$ \\
H-T height (above fuse)
\end{tabular} & $\begin{array}{r}53.33 \\
4.31 \\
0.41 \\
18.15 \\
38 \\
533.72 \\
206.67 \\
0.00 \\
\end{array}$ & $\begin{array}{r}53.33 \\
4.31 \\
0.41 \\
21.09 \\
35 \\
533.72 \\
206.67 \\
0.00 \\
\end{array}$ & $\begin{array}{r}53.33 \\
4.31 \\
0.41 \\
21.09 \\
35 \\
533.72 \\
206.67 \\
0.00 \\
\end{array}$ & $\begin{array}{r}40.87 \\
4.58 \\
0.27 \\
12.41 \\
35 \\
333.68 \\
192.68 \\
0.00 \\
\end{array}$ & $\begin{array}{r}53.33 \\
4.74 \\
0.23 \\
12.41 \\
35 \\
333.68 \\
192.68 \\
0.00 \\
\end{array}$ & $\begin{array}{r}40.87 \\
4.58 \\
0.27 \\
12.41 \\
35 \\
333.68 \\
192.68 \\
0.00\end{array}$ \\
\hline V-tail & \begin{tabular}{|l|} 
Span $(f t)$ \\
AR \\
TR \\
Root chord $(f t)$ \\
Swept back angle (deg) \\
Area $\left(f t^{2}\right)$ \\
Control surface area $\left(f t^{2}\right)$ \\
\end{tabular} & $\begin{array}{r}30.21 \\
1.71 \\
0.37 \\
26.01 \\
43 \\
537.12 \\
146.07\end{array}$ & $\begin{array}{r}30.21 \\
1.71 \\
0.37 \\
26.01 \\
43 \\
534.36 \\
146.07\end{array}$ & $\begin{array}{r}30.21 \\
1.71 \\
0.37 \\
26.01 \\
43 \\
534.36 \\
146.07\end{array}$ & $\begin{array}{r}22.76 \\
1.71 \\
0.31 \\
17.19 \\
40 \\
231.43 \\
75.42\end{array}$ & $\begin{array}{r}22.76 \\
1.71 \\
0.31 \\
17.19 \\
40 \\
231.43 \\
75.42\end{array}$ & $\begin{array}{r}22.76 \\
1.71 \\
0.31 \\
17.19 \\
40 \\
231.43 \\
75.42\end{array}$ \\
\hline Fuselage & \begin{tabular}{|l|} 
Height $(f t)$ \\
Width $(f t)$ \\
Length $(f t)$ \\
Crew (people) \\
Passenger (people) \\
Tail length (ft,wing 1/4 \\
MAC $\sim$ H-tail 1/4 MAC) \\
\end{tabular} & $\begin{array}{r}10.99 \\
18.50 \\
174.82 \\
3 \\
375 \\
80.33\end{array}$ & $\begin{array}{r}18.50 \\
18.50 \\
148.03 \\
7 \\
280 \\
67.50\end{array}$ & $\begin{array}{r}18.50 \\
18.50 \\
148.03 \\
7 \\
280 \\
67.50\end{array}$ & $\begin{array}{r}13.58 \\
12.92 \\
123.23 \\
7 \\
180 \\
53.98\end{array}$ & $\begin{array}{r}13.58 \\
12.92 \\
103.12 \\
5 \\
136 \\
54.18\end{array}$ & $\begin{array}{r}13.58 \\
12.92 \\
111.00 \\
5 \\
156 \\
65.09\end{array}$ \\
\hline Engine & \begin{tabular}{|l|} 
Max. T @SL $(l b f)$ \\
Ttot/Wo \\
Eng. W $(l b)$ \\
Nacelle position $(f t$, \\
from cockpit) \\
Nacelle width $(f t)$ \\
Nacelle length $(f t)$ \\
Duct length $(f t)$ \\
Nacelle area $\left(f t^{2}\right)$
\end{tabular} & $\begin{array}{r}63,500 \\
0.3492 \\
9047 \\
94.56 \\
8.52 \\
22.53 \\
1.10 \\
151.93\end{array}$ & $\begin{array}{r}53,200 \\
0.3400 \\
9047 \\
71.32 \\
9.10 \\
24.30 \\
1.10 \\
169.21\end{array}$ & $\begin{array}{r}59,000 \\
0.3569 \\
9155 \\
71.32 \\
9.10 \\
24.30 \\
1.10 \\
169.21\end{array}$ & $\begin{array}{r}27,000 \\
0.3333 \\
5250 \\
59.96 \\
7.73 \\
18.29 \\
1.10 \\
121.00\end{array}$ & $\begin{array}{r}23,300 \\
0.3109 \\
5250 \\
55.98 \\
7.73 \\
18.29 \\
1.10 \\
121.00\end{array}$ & $\begin{array}{r}27,000 \\
0.3245 \\
5250 \\
66.96 \\
7.73 \\
18.29 \\
1.10 \\
121.00\end{array}$ \\
\hline Mass & $\begin{array}{l}\text { Gross mass }(l b) \\
\text { Empty mass }(l b) \\
\text { Fuel mass }(l b) \\
\text { Wf/Wo } \\
\text { Max. payload }(l b)\end{array}$ & $\begin{array}{r}363,660 \\
198,492 \\
109,728 \\
0.3017 \\
95,402\end{array}$ & $\begin{array}{r}312,968 \\
176,629 \\
97,196 \\
0.3106 \\
72,419\end{array}$ & $\begin{array}{r}330,600 \\
183,300 \\
108,082 \\
0.3269 \\
71,383\end{array}$ & \begin{tabular}{r|}
161,994 \\
93,450 \\
42,226 \\
0.2607 \\
41,067 \\
\end{tabular} & $\begin{array}{r}149,872 \\
86,617 \\
52,587 \\
0.3509 \\
30,788 \\
\end{array}$ & $\begin{array}{r}166,402 \\
89,923 \\
41,290 \\
0.2481 \\
36,714\end{array}$ \\
\hline Performance & $\begin{array}{l}\text { Altitude }(f t) \\
\text { Range }(N M) \\
\text { Cruise speed }(M) \\
\text { Max. M } \\
\text { Stall speed }(k t s)\end{array}$ & $\begin{array}{r}38,000 \\
3600 \\
0.78 \\
0.84 \\
115.5\end{array}$ & $\begin{array}{r}38,000 \\
3,650 \\
0.80 \\
0.84 \\
112.08\end{array}$ & $\begin{array}{r}38,000 \\
5,200 \\
0.80 \\
0.84 \\
112.08\end{array}$ & $\begin{array}{r}36,998 \\
2,592 \\
0.78 \\
0.82 \\
107.5\end{array}$ & $\begin{array}{r}40,016 \\
1,462 \\
0.78 \\
0.82 \\
107.5\end{array}$ & $\begin{array}{r}40,016 \\
1,813 \\
0.78 \\
0.82 \\
107.5\end{array}$ \\
\hline
\end{tabular}


Table C.1. Civil jet aircraft specifications for database (cont.)

\begin{tabular}{|c|c|c|c|c|c|}
\hline & arameter & A321-100 & A321-200 & A330-200 & A $330-300$ \\
\hline Wing & \begin{tabular}{|l|} 
Span $(f t)$ \\
AR \\
TR \\
Root chord $(f t)$ \\
Swept back angle (deg) \\
Area $\left(f t^{2}\right)$ \\
Control surface area $\left(f t^{2}\right)$ \\
\end{tabular} & $\begin{array}{r}111.8152 \\
9.5 \\
0.301 \\
20.01 \\
25 \\
1317.51 \\
461.62 \\
\end{array}$ & $\begin{array}{r}111.8152 \\
9.5 \\
0.301 \\
20.01 \\
25 \\
1317.51 \\
461.62\end{array}$ & $\begin{array}{r}197.784 \\
10.1 \\
0.24 \\
34.77 \\
32 \\
3892.26 \\
945.22 \\
\end{array}$ & $\begin{array}{r}197.784 \\
10.1 \\
0.24 \\
34.77 \\
32 \\
3892.26 \\
945.22\end{array}$ \\
\hline H-tail & $\begin{array}{l}\text { Span }(f t) \\
\text { AR } \\
\text { TR } \\
\text { Root chord }(f t) \\
\text { Swept back angle (deg) } \\
\text { Area }\left(f t^{2}\right) \\
\text { Control surface area }\left(f t^{2}\right) \\
\text { H-T height (above fuse) }\end{array}$ & $\begin{array}{r}40.87 \\
4.58 \\
0.27 \\
12.41 \\
35 \\
333.68 \\
192.68 \\
0.00 \\
\end{array}$ & $\begin{array}{r}40.87 \\
4.58 \\
0.27 \\
12.41 \\
35 \\
333.68 \\
192.68 \\
0.00 \\
\end{array}$ & $\begin{array}{r}63.50 \\
4.48 \\
0.43 \\
21.91 \\
34 \\
640.71 \\
185.80 \\
0.00 \\
\end{array}$ & $\begin{array}{r}63.50 \\
4.48 \\
0.43 \\
21.91 \\
34 \\
640.71 \\
185.80 \\
0.00\end{array}$ \\
\hline V-tail & \begin{tabular}{|l|} 
Span $(f t)$ \\
AR \\
TR \\
Root chord $(f t)$ \\
Swept back angle (deg) \\
Area $\left(f t^{2}\right)$ \\
Control surface area $\left(f t^{2}\right)$ \\
\end{tabular} & $\begin{array}{r}22.76 \\
1.71 \\
0.31 \\
17.19 \\
40 \\
231.43 \\
75.42\end{array}$ & $\begin{array}{r}22.76 \\
1.71 \\
0.31 \\
17.19 \\
40 \\
231.43 \\
75.42\end{array}$ & $\begin{array}{r}31.82 \\
1.68 \\
0.40 \\
26.64 \\
44 \\
604.04 \\
180.41\end{array}$ & $\begin{array}{r}31.82 \\
1.68 \\
0.40 \\
26.64 \\
44 \\
604.04 \\
180.41\end{array}$ \\
\hline Fuselage & \begin{tabular}{|l|} 
Height $(f t)$ \\
Width $(f t)$ \\
Length $(f t)$ \\
Crew (people) \\
Passenger (people) \\
Tail length (ft,wing 1/4 \\
MAC $\sim$ H-tail 1/4 MAC) \\
\end{tabular} & $\begin{array}{r}13.58 \\
12.92 \\
145.99 \\
7 \\
220 \\
64.88\end{array}$ & $\begin{array}{r}13.58 \\
12.92 \\
145.99 \\
7 \\
220 \\
64.88\end{array}$ & $\begin{array}{r}18.50 \\
18.50 \\
193.52 \\
7 \\
380 \\
84.91\end{array}$ & $\begin{array}{r}18.50 \\
18.50 \\
208.54 \\
7 \\
440 \\
95.17\end{array}$ \\
\hline Engine & $\begin{array}{l}\text { Max. T @SL }(l b f) \\
\text { Ttot/Wo } \\
\text { Eng. W }(l b) \\
\text { Nacelle position }(f t \text {, } \\
\text { from cockpit) } \\
\text { Nacelle width }(f t) \\
\text { Nacelle length }(f t) \\
\text { Duct length }(f t) \\
\text { Nacelle area }\left(f t^{2}\right) \\
\end{array}$ & $\begin{array}{r}33,000 \\
0.3365 \\
4995 \\
90.12 \\
7.73 \\
18.29 \\
1.10 \\
121.00 \\
\end{array}$ & $\begin{array}{r}33,000 \\
0.3365 \\
4995 \\
90.12 \\
7.73 \\
18.29 \\
1.10 \\
121.00 \\
\end{array}$ & $\begin{array}{r}72,000 \\
0.2841 \\
9000 \\
114.70 \\
9.06 \\
22.64 \\
1.10 \\
105.55 \\
\end{array}$ & $\begin{array}{r}72,000 \\
0.2804 \\
9000 \\
134.06 \\
10.02 \\
25.47 \\
1.10 \\
199.08 \\
\end{array}$ \\
\hline Mass & $\begin{array}{l}\text { Gross mass }(l b) \\
\text { Empty mass }(l b) \\
\text { Fuel mass }(l b) \\
\text { Wf/Wo } \\
\text { Max. payload }(l b)\end{array}$ & $\begin{array}{r}196,156 \\
106,894 \\
41,788 \\
0.2130 \\
50,247 \\
\end{array}$ & $\begin{array}{r}196,156 \\
106,894 \\
41,788 \\
0.2130 \\
55,539 \\
\end{array}$ & $\begin{array}{r}506,920 \\
265,582 \\
240,645 \\
0.4747 \\
104,690 \\
\end{array}$ & $\begin{array}{r}513,532 \\
274,398 \\
168,741 \\
0.3286 \\
106,894 \\
\end{array}$ \\
\hline Performance & \begin{tabular}{|l|} 
Altitude $(f t)$ \\
Range $(N M)$ \\
Cruise speed $(M)$ \\
Max. M \\
Stall speed $(k t s)$
\end{tabular} & $\begin{array}{r}39,000 \\
2,138 \\
0.78 \\
0.82 \\
107.5\end{array}$ & $\begin{array}{r}39,000 \\
2,700 \\
0.78 \\
0.82 \\
107.5\end{array}$ & $\begin{array}{r}36,080 \\
6,650 \\
0.82 \\
0.86 \\
110.83\end{array}$ & $\begin{array}{r}36,080 \\
5,600 \\
0.82 \\
0.86 \\
110.833\end{array}$ \\
\hline
\end{tabular}


Table C.1. Civil jet aircraft specifications for database (cont.)

\begin{tabular}{|c|c|c|c|c|c|}
\hline & Parameter & A340-200 & A340-300 & A340-500 & A350-900 \\
\hline Wing & \begin{tabular}{|l|} 
Span $(f t)$ \\
AR \\
TR \\
Root chord $(f t)$ \\
Swept back angle (deg) \\
Area $\left(f t^{2}\right)$ \\
Control surface area $\left(f t^{2}\right)$
\end{tabular} & $\begin{array}{r}197.784 \\
10.1 \\
0.24 \\
34.77 \\
32 \\
3892.26 \\
945.22 \\
\end{array}$ & $\begin{array}{r}197.784 \\
10.1 \\
0.24 \\
34.77 \\
32 \\
3892.26 \\
945.22 \\
\end{array}$ & $\begin{array}{r}208.116 \\
9.3 \\
0.22 \\
40.02 \\
32 \\
4729.70 \\
1232.93 \\
\end{array}$ & $\begin{array}{r}212.3472 \\
9.01826667 \\
0.16 \\
38.94 \\
36 \\
5000.00 \\
1285.56\end{array}$ \\
\hline H-tail & $\begin{array}{l}\text { Span }(f t) \\
\text { AR } \\
\text { TR } \\
\text { Root chord }(f t) \\
\text { Swept back angle (deg) } \\
\text { Area }\left(f t^{2}\right) \\
\text { Control surface area }\left(f t^{2}\right) \\
\text { H-T height (above fuse) }\end{array}$ & $\begin{array}{r}63.50 \\
4.48 \\
0.43 \\
21.91 \\
34 \\
640.71 \\
185.80 \\
0.00 \\
\end{array}$ & $\begin{array}{r}63.50 \\
4.48 \\
0.43 \\
21.91 \\
34 \\
640.71 \\
185.80 \\
0.00 \\
\end{array}$ & $\begin{array}{r}75.31 \\
5.26 \\
0.33 \\
21.00 \\
35 \\
1,077.33 \\
306.40 \\
0.00 \\
\end{array}$ & $\begin{array}{r}63.07 \\
8.70 \\
0.39 \\
20.54 \\
37 \\
457.11 \\
110.35 \\
0.00 \\
\end{array}$ \\
\hline V-tail & $\begin{array}{l}\text { Span }(f t) \\
\text { AR } \\
\text { TR } \\
\text { Root chord }(f t) \\
\text { Swept back angle }(\mathrm{deg}) \\
\text { Area }\left(f t^{2}\right) \\
\text { Control surface area }\left(f t^{2}\right) \\
\end{array}$ & $\begin{array}{r}31.82 \\
1.68 \\
0.40 \\
26.64 \\
44 \\
604.04 \\
180.41 \\
\end{array}$ & $\begin{array}{r}31.82 \\
1.68 \\
0.40 \\
26.64 \\
44 \\
604.04 \\
180.41 \\
\end{array}$ & $\begin{array}{r}33.46 \\
1.56 \\
0.28 \\
36.06 \\
48 \\
717.80 \\
0.00 \\
\end{array}$ & $\begin{array}{r}30.90 \\
1.88 \\
0.41 \\
24.49 \\
44 \\
507.03 \\
172.87 \\
\end{array}$ \\
\hline Fuselage & \begin{tabular}{|l|} 
Height $(f t)$ \\
Width $(f t)$ \\
Length $(f t)$ \\
Crew (people) \\
Passenger (people) \\
Tail length (ft,wing $1 / 4$ \\
MAC $\sim$ H-tail 1/4 MAC) \\
\end{tabular} & $\begin{array}{r}18.50 \\
18.50 \\
194.90 \\
375 \\
92.02\end{array}$ & $\begin{array}{r}18.50 \\
18.50 \\
208.87 \\
\\
375\end{array}$ & $\begin{array}{r}18.50 \\
18.50 \\
221.43 \\
\\
375 \\
113.90\end{array}$ & $\begin{array}{r}19.98 \\
19.55 \\
214.09 \\
\\
475 \\
97.07\end{array}$ \\
\hline Engine & \begin{tabular}{|l|} 
Max. T @SL $(l b f)$ \\
Ttot/Wo \\
Eng. W $(l b)$ \\
Nacelle position $(f t$, \\
from cockpit) \\
Nacelle width $(f t)$ \\
Nacelle length $(f t)$ \\
Duct length $(f t)$ \\
Nacelle area $\left(f t^{2}\right)$
\end{tabular} & $\begin{array}{r}34,000 \\
0.2434 \\
4670 \\
293.76 \\
7.52 \\
19.66 \\
1.10 \\
133.98\end{array}$ & $\begin{array}{r}34,000 \\
0.2434 \\
4670 \\
293.76 \\
7.52 \\
19.66 \\
1.10 \\
133.98\end{array}$ & $\begin{array}{r}58,000 \\
0.2860 \\
10660 \\
136.34 \\
11.92 \\
24.29 \\
1.10 \\
196.90\end{array}$ & $\begin{array}{r}84,000 \\
0.2844 \\
10660 \\
127.42 \\
13.11 \\
25.34 \\
1.10 \\
244.25\end{array}$ \\
\hline Mass & $\begin{array}{l}\text { Gross mass }(l b) \\
\text { Empty mass }(l b) \\
\text { Fuel mass }(l b) \\
\text { Wf/Wo } \\
\text { Max. payload }(l b)\end{array}$ & $\begin{array}{r}558,714 \\
285,418 \\
243,326 \\
0.4355 \\
100,348\end{array}$ & \begin{tabular}{r|}
558,714 \\
286,520 \\
243,326 \\
0.4355 \\
112,184 \\
\end{tabular} & $\begin{array}{r}811,072 \\
376,664 \\
371,651 \\
0.4582 \\
119,236\end{array}$ & $\begin{array}{r}590,672 \\
255,003 \\
238,759 \\
0.4042 \\
167,550 \\
\end{array}$ \\
\hline Performance & $\begin{array}{l}\text { Altitude }(f t) \\
\text { Range }(N M) \\
\text { Cruise speed }(M) \\
\text { Max. M } \\
\text { Stall speed }(k t s)\end{array}$ & $\begin{array}{r}36,080 \\
8,000 \\
0.82 \\
0.86 \\
123.33\end{array}$ & $\begin{array}{r}36,080 \\
7,200 \\
0.82 \\
0.86 \\
123.33\end{array}$ & $\begin{array}{r}36,080 \\
8,650 \\
0.83 \\
0.86 \\
127.5\end{array}$ & $\begin{array}{r}39,983 \\
8,100 \\
0.85 \\
0.89\end{array}$ \\
\hline
\end{tabular}


Table C.1. Civil jet aircraft specifications for database (cont.)

\begin{tabular}{|c|c|c|c|c|c|c|}
\hline & Parameter & B737-100 & B737-200 & B737-300 & B737-400 & B737-500 \\
\hline Wing & $\begin{array}{l}\text { Span }(f t) \\
\text { AR } \\
\text { TR } \\
\text { Root chord }(f t) \\
\text { Swept back angle }(\mathrm{deg}) \\
\text { Area }\left(f t^{2}\right) \\
\text { Control surface area }\left(f t^{2}\right)\end{array}$ & $\begin{array}{r}93 \\
8.83 \\
0.266 \\
24.02 \\
28 \\
1097.91 \\
318.39\end{array}$ & $\begin{array}{r}93 \\
8.83 \\
0.266 \\
24.02 \\
28 \\
1097.91 \\
318.39\end{array}$ & \begin{tabular}{r|}
93 \\
9.16 \\
0.24 \\
24.02 \\
28 \\
1134.52 \\
329.01 \\
\end{tabular} & $\begin{array}{r}94.75 \\
9.16 \\
0.24 \\
24.02 \\
28 \\
1134.52 \\
329.01 \\
\end{array}$ & $\begin{array}{r}94.75 \\
9.16 \\
0.24 \\
24.02 \\
28 \\
1134.52 \\
329.01\end{array}$ \\
\hline H-tail & $\begin{array}{l}\text { Span }(f t) \\
\text { AR } \\
\text { TR } \\
\text { Root chord }(f t) \\
\text { Swept back angle (deg) } \\
\text { Area }\left(f t^{2}\right) \\
\text { Control surface area }\left(f t^{2}\right) \\
\text { H-T height (above fuse) }\end{array}$ & $\begin{array}{r}36.00 \\
4.15 \\
0.26 \\
13.42 \\
34 \\
312.05 \\
70.50 \\
0.00\end{array}$ & $\begin{array}{r}36.00 \\
4.15 \\
0.26 \\
13.42 \\
34 \\
312.05 \\
70.50 \\
0.00\end{array}$ & $\begin{array}{r}41.67 \\
4.04 \\
0.26 \\
12.86 \\
34 \\
337.99 \\
70.50 \\
0.00\end{array}$ & $\begin{array}{r}41.67 \\
4.04 \\
0.26 \\
14.22 \\
34 \\
337.99 \\
70.50 \\
0.00 \\
\end{array}$ & $\begin{array}{r}41.67 \\
4.04 \\
0.26 \\
14.22 \\
34 \\
337.99 \\
70.50 \\
0.00\end{array}$ \\
\hline V-tail & $\begin{array}{l}\text { Span }(f t) \\
\text { AR } \\
\text { TR } \\
\text { Root chord }(f t) \\
\text { Swept back angle }(\mathrm{deg}) \\
\text { Area }\left(f t^{2}\right) \\
\text { Control surface area }\left(f t^{2}\right)\end{array}$ & $\begin{array}{r}20.18 \\
1.64 \\
0.29 \\
18.99 \\
40 \\
224.00 \\
56.19 \\
\end{array}$ & $\begin{array}{r}20.18 \\
1.64 \\
0.29 \\
18.99 \\
40 \\
224.00 \\
56.19 \\
\end{array}$ & $\begin{array}{r}20.18 \\
1.81 \\
0.31 \\
16.73 \\
40 \\
248.97 \\
56.19 \\
\end{array}$ & $\begin{array}{r}20.18 \\
1.81 \\
0.31 \\
18.35 \\
40 \\
248.97 \\
56.19 \\
\end{array}$ & $\begin{array}{r}20.18 \\
1.81 \\
0.31 \\
17.96 \\
40 \\
248.97 \\
56.19 \\
\end{array}$ \\
\hline Fuselage & \begin{tabular}{|l|} 
Height $(f t)$ \\
Width $(f t)$ \\
Length $(f t)$ \\
Crew (people) \\
Passenger (people) \\
Tail length (ft,wing 1/4 \\
MAC $\sim$ H-tail $1 / 4$ MAC) \\
\end{tabular} & $\begin{array}{r}12.40 \\
12.40 \\
94.00 \\
\\
124 \\
38.82\end{array}$ & $\begin{array}{r}12.40 \\
12.40 \\
100.20 \\
136 \\
42.19\end{array}$ & $\begin{array}{r}12.40 \\
12.40 \\
102.00 \\
\\
148 \\
41.25\end{array}$ & $\begin{array}{r}12.40 \\
12.40 \\
120.00 \\
\\
189 \\
48.56\end{array}$ & $\begin{array}{r}13.17 \\
12.40 \\
101.75 \\
140 \\
41.61\end{array}$ \\
\hline Engine & \begin{tabular}{|l|} 
Max. T @SL $(l b f)$ \\
Ttot/Wo \\
Eng. W $(l b)$ \\
Nacelle position $(f t$, \\
from cockpit) \\
Nacelle width $(f t)$ \\
Nacelle length $(f t)$ \\
Duct length $(f t)$ \\
Nacelle area $\left(f t^{2}\right)$ \\
\end{tabular} & $\begin{array}{r}14,500 \\
0.2636 \\
3200 \\
28.67 \\
4.92 \\
18.39 \\
\\
169.84 \\
\end{array}$ & $\begin{array}{r}14,500 \\
0.2511 \\
3500 \\
31.69 \\
4.92 \\
18.62 \\
\\
164.64 \\
\end{array}$ & $\begin{array}{r}20,000 \\
0.2963 \\
4301 \\
26.36 \\
6.56 \\
14.80 \\
\\
124.88 \\
\end{array}$ & $\begin{array}{r}23,500 \\
0.3133 \\
4301 \\
34.35 \\
6.56 \\
16.43 \\
\\
152.30 \\
\end{array}$ & $\begin{array}{r}20,000 \\
0.2941 \\
4276 \\
23.91 \\
6.56 \\
16.53 \\
1.10 \\
150.31 \\
\end{array}$ \\
\hline Mass & $\begin{array}{l}\text { Gross mass }(l b) \\
\text { Empty mass }(l b) \\
\text { Fuel mass }(l b) \\
\text { Wf/Wo } \\
\text { Max. payload }(l b)\end{array}$ & $\begin{array}{r}110,000 \\
62,000 \\
31,624 \\
0.2875 \\
12,701 \\
\end{array}$ & $\begin{array}{r}115,500 \\
66,800 \\
32,026 \\
0.2773 \\
28,200 \\
\end{array}$ & $\begin{array}{r}135,000 \\
72,540 \\
41,011 \\
0.3038 \\
33,960 \\
\end{array}$ & $\begin{array}{r}150,000 \\
74,170 \\
42,177 \\
0.2812 \\
42,830 \\
\end{array}$ & $\begin{array}{r}136,000 \\
69,030 \\
42,177 \\
0.3101 \\
33,701\end{array}$ \\
\hline Performance & $\begin{array}{l}\text { Altitude }(f t) \\
\text { Range }(N M) \\
\text { Cruise speed }(M) \\
\text { Max. M } \\
\text { Stall speed }(k t s)\end{array}$ & $\begin{array}{r}30,000 \\
1,720 \\
0.74 \\
0.82\end{array}$ & $\begin{array}{r}30,000 \\
2,645 \\
0.74 \\
0.82\end{array}$ & $\begin{array}{r}35,000 \\
2,950 \\
0.74 \\
0.82\end{array}$ & $\begin{array}{r}35,000 \\
2,800 \\
0.74 \\
0.82\end{array}$ & $\begin{array}{r}35,000 \\
2,950 \\
0.74 \\
0.82\end{array}$ \\
\hline
\end{tabular}


Table C.1. Civil jet aircraft specifications for database (cont.)

\begin{tabular}{|c|c|c|c|c|c|}
\hline & Parameter & B737-600 & B737-700 & B737-800 & B737-900 \\
\hline Wing & $\begin{array}{l}\text { Span }(f t) \\
\text { AR } \\
\text { TR } \\
\text { Root chord }(f t) \\
\text { Swept back angle (deg) } \\
\text { Area }\left(f t^{2}\right) \\
\text { Control surface area }\left(f t^{2}\right)\end{array}$ & \begin{tabular}{r|}
111.52 \\
8.73 \\
0.3 \\
17.29 \\
25 \\
1345.50 \\
259.95 \\
\end{tabular} & \begin{tabular}{r|}
111.52 \\
8.73 \\
0.3 \\
17.29 \\
25.02 \\
1345.50 \\
259.95 \\
\end{tabular} & \begin{tabular}{r|}
111.52 \\
8.73 \\
0.3 \\
17.29 \\
25.02 \\
1345.50 \\
259.95 \\
\end{tabular} & $\begin{array}{r}111.52 \\
8.73 \\
0.3 \\
17.29 \\
25.02 \\
1345.50 \\
259.95\end{array}$ \\
\hline H-tail & $\begin{array}{l}\text { Span }(f t) \\
\text { AR } \\
\text { TR } \\
\text { Root chord }(f t) \\
\text { Swept back angle (deg) } \\
\text { Area }\left(f t^{2}\right) \\
\text { Control surface area }\left(f t^{2}\right) \\
\text { H-T height (above fuse) }\end{array}$ & $\begin{array}{r}47.07 \\
5.88 \\
0.23 \\
25.85 \\
34 \\
353.06 \\
80.95 \\
0.00 \\
\end{array}$ & $\begin{array}{r}47.07 \\
5.88 \\
0.23 \\
25.85 \\
34 \\
353.06 \\
80.95 \\
0.00 \\
\end{array}$ & $\begin{array}{r}47.07 \\
5.88 \\
0.23 \\
25.85 \\
34 \\
353.06 \\
80.95 \\
0.00 \\
\end{array}$ & $\begin{array}{r}47.07 \\
5.88 \\
0.23 \\
25.85 \\
34 \\
353.06 \\
80.95 \\
0.00\end{array}$ \\
\hline V-tail & $\begin{array}{l}\text { Span }(f t) \\
\text { AR } \\
\text { TR } \\
\text { Root chord }(f t) \\
\text { Swept back angle (deg) } \\
\text { Area }\left(f t^{2}\right) \\
\text { Control surface area }\left(f t^{2}\right)\end{array}$ & \begin{tabular}{r|}
25.49 \\
2.08 \\
0.23 \\
18.99 \\
40 \\
284.17 \\
67.08
\end{tabular} & $\begin{array}{r}25.49 \\
2.08 \\
0.23 \\
18.99 \\
40 \\
284.17 \\
67.08\end{array}$ & $\begin{array}{r}25.49 \\
2.08 \\
0.23 \\
18.99 \\
40 \\
284.17 \\
67.08 \\
\end{array}$ & $\begin{array}{r}25.49 \\
2.08 \\
0.23 \\
18.99 \\
40 \\
284.17 \\
67.08\end{array}$ \\
\hline Fuselage & $\begin{array}{l}\text { Height }(f t) \\
\text { Width }(f t) \\
\text { Length }(f t) \\
\text { Crew (people) } \\
\text { Passenger (people) } \\
\text { Tail length (ft,wing } 1 / 4 \\
\text { MAC } \sim \text { H-tail 1/4 MAC) }\end{array}$ & $\begin{array}{r}12.96 \\
12.96 \\
102.47 \\
5 \\
130 \\
43.50\end{array}$ & $\begin{array}{r}12.96 \\
12.96 \\
105.55 \\
5 \\
148 \\
43.50\end{array}$ & $\begin{array}{r}12.96 \\
12.96 \\
124.71 \\
5 \\
184 \\
55.35\end{array}$ & $\begin{array}{r}12.96 \\
12.96 \\
133.40 \\
5 \\
189 \\
60.99\end{array}$ \\
\hline Engine & $\begin{array}{l}\text { Max. T@SL }(l b f) \\
\text { Ttot/Wo } \\
\text { Eng. W }(l b) \quad \text { position }(f t \text {, } \\
\text { Nacelle } \\
\text { from cockpit) Nacelle width }(f t) \\
\text { Nacelle length }(f t) \\
\text { Duct length }(f t) \\
\text { Nacelle area }\left(f t^{2}\right) \\
\end{array}$ & \begin{tabular}{r|}
22,700 \\
0.3662 \\
5216 \\
45.48 \\
8.00 \\
15.73 \\
1.10 \\
100.55 \\
\end{tabular} & $\begin{array}{r}22,700 \\
0.3414 \\
5216 \\
54.68 \\
8.00 \\
15.73 \\
1.10 \\
100.55 \\
\end{array}$ & $\begin{array}{r}27,300 \\
0.3512 \\
5216 \\
71.02 \\
8.00 \\
15.73 \\
1.10 \\
100.55 \\
\end{array}$ & $\begin{array}{r}27,300 \\
0.3310 \\
5216 \\
71.02 \\
8.00 \\
15.73 \\
1.10 \\
100.55 \\
\end{array}$ \\
\hline Mass & $\begin{array}{l}\text { Gross mass }(l b) \\
\text { Empty mass }(l b) \\
\text { Fuel mass }(l b) \\
\text { Wf/Wo } \\
\text { Max. payload }(l b)\end{array}$ & \begin{tabular}{r|}
123,964 \\
81,777 \\
46,063 \\
0.3716 \\
33,300
\end{tabular} & \begin{tabular}{r|}
132,967 \\
84,076 \\
46,063 \\
0.3464 \\
37,500 \\
\end{tabular} & $\begin{array}{r}155,459 \\
90,684 \\
19,500 \\
0.1254 \\
44,700\end{array}$ & $\begin{array}{r}164,947 \\
93,655 \\
25,700 \\
0.1558 \\
45,720\end{array}$ \\
\hline $\begin{array}{l}\text { Perform } \\
\text { ance }\end{array}$ & $\begin{array}{l}\text { Altitude }(f t) \\
\text { Range }(N M) \\
\text { Cruise speed }(M) \\
\text { Max. M } \\
\text { Stall speed }(k t s)\end{array}$ & $\begin{array}{r}41,000 \\
1,340 \\
0.785 \\
0.82 \\
115.00\end{array}$ & $\begin{array}{r}41,000 \\
1,540 \\
0.785 \\
0.82 \\
115.00\end{array}$ & $\begin{array}{r}38,294 \\
1,990 \\
0.785 \\
0.82 \\
116.67\end{array}$ & $\begin{array}{r}36,785 \\
2,060 \\
0.785 \\
0.82 \\
116.67\end{array}$ \\
\hline
\end{tabular}


Table C.1. Civil jet aircraft specifications for database (cont.)

\begin{tabular}{|c|c|c|c|c|c|}
\hline \multicolumn{2}{|r|}{ Parameter } & B747-400 & B747-400ER & B $757-200$ & B757-300 \\
\hline Wing & \begin{tabular}{|l|} 
Span $(f t)$ \\
AR \\
TR \\
Root chord $(f t)$ \\
Swept back angle $(\mathrm{deg})$ \\
Area $\left(f t^{2}\right)$ \\
Control surface area $\left(f t^{2}\right)$ \\
\end{tabular} & $\begin{array}{r}212.9376 \\
7.7 \\
0.3 \\
47.99 \\
41 \\
5825.05 \\
678.52\end{array}$ & $\begin{array}{r}212.9376 \\
7.7 \\
0.3 \\
47.99 \\
41 \\
5825.05 \\
678.52\end{array}$ & \begin{tabular}{r|}
124.804 \\
7.8 \\
0.21 \\
26.90 \\
28 \\
1994.03
\end{tabular} & $\begin{array}{r}124.804 \\
7.8 \\
0.21 \\
26.90 \\
28 \\
1994.03\end{array}$ \\
\hline H-tail & \begin{tabular}{|l|} 
Span $(f t)$ \\
AR \\
TR \\
Root chord $(f t)$ \\
Swept back angle (deg) \\
Area $\left(f t^{2}\right)$ \\
Control surface area $\left(f t^{2}\right)$ \\
H-T height (above fuse)
\end{tabular} & \begin{tabular}{r|}
72.72 \\
3.58 \\
0.29 \\
32.42 \\
43 \\
$1,475.58$ \\
327.01 \\
0.00
\end{tabular} & $\begin{array}{r}72.72 \\
3.58 \\
0.29 \\
32.42 \\
43 \\
1,475.58 \\
327.01 \\
0.00\end{array}$ & $\begin{array}{r}49.89 \\
11.36 \\
0.41 \\
16.75 \\
34 \\
219.05 \\
134.98 \\
0.00 \\
\end{array}$ & $\begin{array}{r}49.89 \\
11.36 \\
0.41 \\
16.75 \\
34 \\
219.05 \\
134.98 \\
0.00\end{array}$ \\
\hline V-tail & \begin{tabular}{|l|} 
Span $(f t)$ \\
AR \\
TR \\
Root chord $(f t)$ \\
Swept back angle $(\mathrm{deg})$ \\
Area $\left(f t^{2}\right)$ \\
Control surface area $\left(f t^{2}\right)$ \\
\end{tabular} & $\begin{array}{r}35.92 \\
1.32 \\
0.35 \\
40.31 \\
49 \\
978.21 \\
230.03 \\
\end{array}$ & $\begin{array}{r}35.92 \\
1.32 \\
0.35 \\
40.31 \\
49 \\
978.21 \\
230.03 \\
\end{array}$ & $\begin{array}{r}25.49 \\
2.08 \\
0.23 \\
27.06 \\
43 \\
425.32 \\
151.18 \\
\end{array}$ & $\begin{array}{r}25.49 \\
2.08 \\
0.23 \\
27.06 \\
43 \\
124.97 \\
124.97 \\
\end{array}$ \\
\hline Fuselage & \begin{tabular}{|l|} 
Height $(f t)$ \\
Width $(f t)$ \\
Length $(f t)$ \\
Crew (people) \\
Passenger (people) \\
Tail length (ft,wing $1 / 4$ \\
MAC H-tail $1 / 4$ MAC) \\
\end{tabular} & $\begin{array}{r}21.32 \\
21.32 \\
225.11 \\
9 \\
400 \\
95.48\end{array}$ & $\begin{array}{r}21.32 \\
21.32 \\
225.11 \\
9 \\
400 \\
95.48\end{array}$ & $\begin{array}{r}12.96 \\
12.96 \\
154.00 \\
5 \\
221 \\
64.38\end{array}$ & $\begin{array}{r}12.96 \\
12.96 \\
177.38 \\
5 \\
280 \\
78.46\end{array}$ \\
\hline Engine & $\begin{array}{l}\text { Max. T @SL }(l b f) \\
\text { Ttot/Wo } \\
\text { Eng. W }(l b) \\
\text { Nacelle position }(f t \text {, } \\
\text { from cockpit) } \\
\text { Nacelle width }(f t) \\
\text { Nacelle length }(f t) \\
\text { Duct length }(f t) \\
\text { Nacelle area }\left(f t^{2}\right) \\
\end{array}$ & \begin{tabular}{r|}
56,700 \\
0.2836 \\
\\
120.36 \\
8.98 \\
24.09 \\
1.10 \\
139.23 \\
\end{tabular} & $\begin{array}{r}56,700 \\
0.2493 \\
\\
120.36 \\
8.98 \\
24.09 \\
1.10 \\
139.23 \\
\end{array}$ & $\begin{array}{r}43,734 \\
0.3977 \\
7100 \\
97.82 \\
7.70 \\
17.21 \\
1.10 \\
122.69 \\
\end{array}$ & $\begin{array}{r}43,734 \\
0.3240 \\
7100 \\
97.82 \\
7.70 \\
17.21 \\
1.10 \\
122.69 \\
\end{array}$ \\
\hline Mass & $\begin{array}{l}\text { Gross mass }(l b) \\
\text { Empty mass }(l b) \\
\text { Fuel mass }(l b) \\
\text { Wf/Wo } \\
\text { Max. payload }(l b)\end{array}$ & $\begin{array}{r}799,777 \\
397,789 \\
358,326 \\
0.4480 \\
148,054\end{array}$ & $\begin{array}{r}909,745 \\
406,781 \\
425,052 \\
0.4672 \\
148,054 \\
\end{array}$ & $\begin{array}{r}219,937 \\
130,411 \\
75,529 \\
0.3434 \\
55,605\end{array}$ & $\begin{array}{r}269,924 \\
141,651 \\
76,959 \\
0.2851 \\
68,181\end{array}$ \\
\hline Performance & $\begin{array}{l}\text { Altitude }(f t) \\
\text { Range }(N M) \\
\text { Cruise speed }(M) \\
\text { Max. M } \\
\text { Stall speed }(k t s)\end{array}$ & $\begin{array}{r}34,686 \\
6,185 \\
0.85 \\
\\
121.05\end{array}$ & $\begin{array}{r}32,800 \\
7,325 \\
0.85 \\
\\
130.47\end{array}$ & $\begin{array}{r}38,294 \\
2,570 \\
0.8 \\
\\
109.84\end{array}$ & $\begin{array}{r}36,096 \\
2,120 \\
0.8 \\
\\
118.81\end{array}$ \\
\hline
\end{tabular}


Table C.1. Civil jet aircraft specifications for database (cont.)

\begin{tabular}{|c|c|c|c|c|c|c|}
\hline \multicolumn{2}{|r|}{ Parameter } & B767-200 & B767-300 & B767-400 & B777-200 & B777-300 \\
\hline Wing & \begin{tabular}{|l} 
Span $(f t)$ \\
AR \\
TR \\
Root chord $(f t)$ \\
Swept back angle $(\mathrm{deg})$ \\
Area $\left(f t^{2}\right)$ \\
Control surface area $\left(f t^{2}\right)$
\end{tabular} & $\begin{array}{r}149.4696 \\
8 \\
0.21 \\
28.11 \\
34 \\
3049.44 \\
315.30\end{array}$ & \begin{tabular}{r|}
149.4696 \\
8 \\
0.21 \\
28.11 \\
34 \\
3049.44 \\
315.30
\end{tabular} & $\begin{array}{r}170.5272 \\
9.3 \\
0.21 \\
28.11 \\
34 \\
3129.09 \\
315.30\end{array}$ & $\begin{array}{r}199.8504 \\
8.7 \\
0.21 \\
40.54 \\
34 \\
4604.84 \\
799.11\end{array}$ & $\begin{array}{r}199.8504 \\
8.7 \\
0.21 \\
40.54 \\
34 \\
4604.84 \\
799.11\end{array}$ \\
\hline H-tail & $\begin{array}{l}\text { Span }(f t) \\
\text { AR } \\
\text { TR } \\
\text { Root chord }(f t) \\
\text { Swept back angle (deg) } \\
\text { Area }\left(f t^{2}\right) \\
\text { Control surface area }\left(f t^{2}\right) \\
\text { H-T height (above fuse) }\end{array}$ & $\begin{array}{r}61.07 \\
6.61 \\
0.25 \\
19.09 \\
38 \\
644.55 \\
191.71 \\
26.16 \\
\end{array}$ & $\begin{array}{r}61.07 \\
6.61 \\
0.25 \\
19.09 \\
38 \\
644.55 \\
191.71 \\
26.16\end{array}$ & $\begin{array}{r}61.07 \\
6.61 \\
0.25 \\
19.09 \\
38 \\
644.55 \\
191.71 \\
26.16\end{array}$ & $\begin{array}{r}70.59 \\
4.66 \\
0.33 \\
27.47 \\
38 \\
1,089.96 \\
274.27 \\
26.16 \\
\end{array}$ & $\begin{array}{r}70.59 \\
4.66 \\
0.33 \\
27.47 \\
38 \\
1,089.96 \\
274.27 \\
26.16\end{array}$ \\
\hline V-tail & $\begin{array}{l}\text { Span }(f t) \\
\text { AR } \\
\text { TR } \\
\text { Root chord }(f t) \\
\text { Swept back angle }(\text { deg }) \\
\text { Area }\left(f t^{2}\right) \\
\text { Control surface area }\left(f t^{2}\right)\end{array}$ & $\begin{array}{r}34.18 \\
1.82 \\
0.25 \\
25.67 \\
45 \\
632.34 \\
171.69\end{array}$ & $\begin{array}{r}34.18 \\
1.82 \\
0.25 \\
25.67 \\
45 \\
632.34 \\
171.69\end{array}$ & $\begin{array}{r}34.18 \\
1.82 \\
0.25 \\
25.67 \\
45 \\
632.34 \\
171.69\end{array}$ & $\begin{array}{r}35.46 \\
1.93 \\
0.26 \\
35.58 \\
43 \\
572.97 \\
195.47\end{array}$ & $\begin{array}{r}35.46 \\
1.93 \\
0.26 \\
35.58 \\
43 \\
572.97 \\
195.47\end{array}$ \\
\hline Fuselage & $\begin{array}{l}\text { Height }(f t) \\
\text { Width }(f t) \\
\text { Length }(f t) \\
\text { Crew (people) } \\
\text { Passenger (people) } \\
\text { Tail length (ft,wing } 1 / 4 \\
\text { MAC } \sim \text { H-tail } 1 / 4 \text { MAC) }\end{array}$ & $\begin{array}{r}16.50 \\
16.50 \\
154.95 \\
9 \\
225 \\
64.47\end{array}$ & $\begin{array}{r}16.50 \\
16.50 \\
176.04 \\
9 \\
269 \\
75.76\end{array}$ & $\begin{array}{r}16.50 \\
16.50 \\
201.29 \\
9 \\
409 \\
83.96\end{array}$ & $\begin{array}{r}20.34 \\
20.34 \\
205.79 \\
9 \\
375 \\
88.06\end{array}$ & $\begin{array}{r}20.34 \\
20.34 \\
224.16 \\
9 \\
451 \\
107.35\end{array}$ \\
\hline Engine & $\begin{array}{l}\text { Max. T @SL }(l b f) \\
\text { Ttot/Wo } \\
\text { Eng. W }(l b) \\
\text { Nacelle position }(f t \text {, } \\
\text { from cockpit) } \\
\text { Nacelle width }(f t) \\
\text { Nacelle length }(f t) \\
\text { Duct length }(f t) \\
\text { Nacelle area }\left(f t^{2}\right)\end{array}$ & $\begin{array}{r}59,500 \\
0.3450 \\
9047 \\
92.44 \\
9.42 \\
20.15 \\
1.10 \\
134.40\end{array}$ & $\begin{array}{r}59,500 \\
0.3132 \\
9047 \\
111.48 \\
9.42 \\
20.15 \\
1.10 \\
134.40\end{array}$ & $\begin{array}{r}59,500 \\
0.2644 \\
9047 \\
133.62 \\
9.42 \\
20.15 \\
1.10 \\
134.40\end{array}$ & $\begin{array}{r}77,000 \\
0.3044 \\
16644 \\
122.18 \\
13.35 \\
23.71 \\
1.10 \\
237.59\end{array}$ & $\begin{array}{r}98,000 \\
0.2971 \\
16644 \\
154.70 \\
13.35 \\
23.71 \\
1.10 \\
237.59\end{array}$ \\
\hline Mass & $\begin{array}{l}\text { Gross mass }(l b) \\
\text { Empty mass }(l b) \\
\text { Fuel mass }(l b) \\
\text { Wf/Wo } \\
\text { Max. payload }(l b)\end{array}$ & \begin{tabular}{r|}
344,904 \\
187,252 \\
112,691 \\
0.3267 \\
71,450 \\
\end{tabular} & $\begin{array}{r}379,892 \\
200,145 \\
112,691 \\
0.2966 \\
91,620 \\
\end{array}$ & $\begin{array}{r}450,000 \\
229,000 \\
161,738 \\
0.3594 \\
101,000 \\
\end{array}$ & $\begin{array}{r}505,981 \\
309,882 \\
207,639 \\
0.4104 \\
121,100\end{array}$ & $\begin{array}{r}659,811 \\
348,298 \\
299,402 \\
0.4538 \\
141,200\end{array}$ \\
\hline Performance & $\begin{array}{l}\text { Altitude }(f t) \\
\text { Range }(N M) \\
\text { Cruise speed }(M) \\
\text { Max. M } \\
\text { Stall speed }(k t s)\end{array}$ & \begin{tabular}{r|}
38,000 \\
5,125 \\
0.8 \\
0.83 \\
114.17
\end{tabular} & \begin{tabular}{r|}
35,100 \\
5,230 \\
0.8 \\
0.83 \\
120.83
\end{tabular} & \begin{tabular}{r|}
35,100 \\
5230 \\
0.8 \\
0.83 \\
120.83
\end{tabular} & \begin{tabular}{r|}
39,393 \\
3,985 \\
0.84 \\
0.86 \\
113.33
\end{tabular} & $\begin{array}{r}35,998 \\
3,880 \\
0.84 \\
0.86 \\
124.17\end{array}$ \\
\hline
\end{tabular}


Table C.1. Civil jet aircraft specifications for database (cont.)

\begin{tabular}{|c|c|c|c|c|c|}
\hline \multicolumn{2}{|r|}{ Parameter } & DC- $8-43$ & DC-8-55 & DC-9-15 & DC-10-10 \\
\hline Wing & \begin{tabular}{|l|} 
Span $(f t)$ \\
AR \\
TR \\
Root chord $(f t)$ \\
Swept back angle $(\mathrm{deg})$ \\
Area $\left(f t^{2}\right)$ \\
Control surface area $\left(f t^{2}\right)$ \\
\end{tabular} & \begin{tabular}{r|}
142.4 \\
7.025131616 \\
0.21 \\
32.70 \\
35 \\
2886.46 \\
452.83 \\
\end{tabular} & \begin{tabular}{r|}
142.4 \\
7.025131129 \\
0.21 \\
32.70 \\
35 \\
2886.46 \\
452.83 \\
\end{tabular} & \begin{tabular}{r|}
89.38 \\
8.550555924 \\
0.27 \\
16.85 \\
28 \\
934.30 \\
162.23 \\
\end{tabular} & $\begin{array}{r}155.3 \\
6.94400969 \\
0.29 \\
35.07 \\
39 \\
3473.22 \\
949.56\end{array}$ \\
\hline H-tail & \begin{tabular}{|l|} 
Span $(f t)$ \\
AR \\
TR \\
Root chord $(f t)$ \\
Swept back angle (deg) \\
Area $\left(f t^{2}\right)$ \\
Control surface area $\left(f t^{2}\right)$ \\
H-T height (above fuse)
\end{tabular} & \begin{tabular}{r|}
47.50 \\
3.92 \\
0.32 \\
18.14 \\
40 \\
576.27 \\
176.46 \\
0.00
\end{tabular} & $\begin{array}{r}47.50 \\
3.92 \\
0.32 \\
18.14 \\
40 \\
576.27 \\
176.46 \\
0.00\end{array}$ & $\begin{array}{r}36.80 \\
4.79 \\
0.39 \\
11.14 \\
35 \\
282.57 \\
111.45 \\
15.64\end{array}$ & $\begin{array}{r}71.15 \\
3.80 \\
0.39 \\
28.05 \\
41 \\
1,331.46 \\
341.39 \\
0.00\end{array}$ \\
\hline V-tail & \begin{tabular}{|l|} 
Span $(f t)$ \\
AR \\
TR \\
Root chord $(f t)$ \\
Swept back angle (deg) \\
Area $\left(f t^{2}\right)$ \\
Control surface area $\left(f t^{2}\right)$
\end{tabular} & $\begin{array}{r}23.10 \\
1.83 \\
0.30 \\
19.42 \\
40 \\
290.97 \\
125.25\end{array}$ & $\begin{array}{r}23.10 \\
1.83 \\
0.30 \\
19.42 \\
40 \\
290.97 \\
125.25\end{array}$ & $\begin{array}{r}14.00 \\
0.90 \\
0.70 \\
16.40 \\
47 \\
217.74 \\
60.93\end{array}$ & $\begin{array}{r}22.71 \\
1.53 \\
0.44 \\
21.80 \\
44 \\
337.82 \\
115.11\end{array}$ \\
\hline Fuselage & $\begin{array}{l}\text { Height }(f t) \\
\text { Width }(f t) \\
\text { Length }(f t) \\
\text { Crew (people) } \\
\text { Passenger (people) } \\
\text { Tail length (ft,wing } 1 / 4 \\
\text { MAC } \sim \text { H-tail 1/4 MAC) }\end{array}$ & \begin{tabular}{r|}
13.55 \\
12.25 \\
182.90 \\
3 \\
177 \\
66.03
\end{tabular} & $\begin{array}{r}13.55 \\
12.25 \\
182.90 \\
3 \\
189 \\
66.03\end{array}$ & $\begin{array}{r}11.00 \\
11.00 \\
93.10 \\
2 \\
90 \\
44.30\end{array}$ & $\begin{array}{r}19.80 \\
19.80 \\
170.50 \\
5 \\
399 \\
59.13\end{array}$ \\
\hline Engine & \begin{tabular}{|l|} 
Max. T @SL $(l b f)$ \\
Ttot/Wo \\
Eng. W $(l b)$ \\
Nacelle position $(f t$, \\
from cockpit) \\
Nacelle width $(f t)$ \\
Nacelle length $(f t)$ \\
Duct length $(f t)$ \\
Nacelle area $\left(f t^{2}\right)$ \\
\end{tabular} & \begin{tabular}{r|}
16,800 \\
0.2133 \\
4960 \\
250.76 \\
5.20 \\
18.00 \\
1.10 \\
501.00 \\
\end{tabular} & $\begin{array}{r}21,000 \\
0.2585 \\
5100 \\
166.90 \\
5.20 \\
18.00 \\
1.10 \\
501.00 \\
\end{array}$ & $\begin{array}{r}14,000 \\
0.3087 \\
3200 \\
105.32 \\
4.72 \\
17.60 \\
1.10 \\
72.26 \\
\end{array}$ & $\begin{array}{r}40,000 \\
0.2791 \\
9047 \\
256.14 \\
9.24 \\
24.60 \\
1.10 \\
159.83 \\
\end{array}$ \\
\hline Mass & $\begin{array}{l}\text { Gross mass }(l b) \\
\text { Empty mass }(l b) \\
\text { Fuel mass }(l b) \\
\text { Wf/Wo } \\
\text { Max. payload }(l b)\end{array}$ & $\begin{array}{r}315,000 \\
136,509 \\
153,248 \\
0.4865 \\
41,691\end{array}$ & $\begin{array}{r}325,000 \\
138,266 \\
153,248 \\
0.4715 \\
51,734\end{array}$ & $\begin{array}{l}90,700 \\
49,020 \\
24,743 \\
0.2728 \\
24,838\end{array}$ & $\begin{array}{r}430,000 \\
240,171 \\
142,563 \\
0.3315 \\
94,829\end{array}$ \\
\hline Performance & $\begin{array}{l}\text { Altitude }(f t) \\
\text { Range }(N M) \\
\text { Cruise speed }(M) \\
\text { Max. M } \\
\text { Stall speed }(k t s)\end{array}$ & $\begin{array}{r}35,000 \\
6,278 \\
0.82 \\
\\
101.54\end{array}$ & \begin{tabular}{r|}
35,000 \\
5,077 \\
0.82 \\
\\
106.15
\end{tabular} & $\begin{array}{r}25,000 \\
1,590 \\
0.82 \\
\\
102\end{array}$ & $\begin{array}{r}35,000 \\
3,800 \\
0.82 \\
0.88 \\
107.69\end{array}$ \\
\hline
\end{tabular}


Table C.1. Civil jet aircraft specifications for database (cont.)

\begin{tabular}{|c|c|c|c|c|c|}
\hline \multicolumn{2}{|r|}{ Parameter } & Embraer 170 & Embraer 175 & Embraer 190 & Embraer 195 \\
\hline Wing & $\begin{array}{l}\text { Span }(f t) \\
\text { AR } \\
\text { TR } \\
\text { Root chord }(f t) \\
\text { Swept back angle }(\mathrm{deg}) \\
\text { Area }\left(f t^{2}\right) \\
\text { Control surface area }\left(f t^{2}\right)\end{array}$ & $\begin{array}{r}85.28 \\
8.6 \\
0.34 \\
13.86 \\
26 \\
782.76 \\
214.15\end{array}$ & $\begin{array}{r}85.28 \\
8.6 \\
0.34 \\
13.86 \\
26 \\
782.76 \\
214.15\end{array}$ & $\begin{array}{r}94.2016 \\
8.1 \\
0.33 \\
15.93 \\
29 \\
995.67 \\
219.02 \\
\end{array}$ & $\begin{array}{r}94.2016 \\
8.1 \\
0.33 \\
15.93 \\
29 \\
995.67 \\
219.02 \\
\end{array}$ \\
\hline H-tail & $\begin{array}{l}\text { Span }(f t) \\
\text { AR } \\
\text { TR } \\
\text { Root chord }(f t) \\
\text { Swept back angle (deg) } \\
\text { Area }\left(f t^{2}\right) \\
\text { Control surface area }\left(f t^{2}\right) \\
\text { H-T height (above fuse) }\end{array}$ & \begin{tabular}{r|}
32.80 \\
4.30 \\
0.45 \\
10.96 \\
33 \\
250.26 \\
0.00 \\
0.00 \\
\end{tabular} & $\begin{array}{r}32.80 \\
4.30 \\
0.45 \\
10.96 \\
33 \\
250.26 \\
0.00 \\
0.00\end{array}$ & $\begin{array}{r}39.62 \\
4.01 \\
0.40 \\
11.18 \\
37 \\
279.86 \\
0.00 \\
0.00 \\
\end{array}$ & $\begin{array}{r}39.62 \\
4.01 \\
0.40 \\
11.18 \\
37 \\
279.86 \\
0.00 \\
0.00 \\
\end{array}$ \\
\hline V-tail & $\begin{array}{l}\text { Span }(f t) \\
\text { AR } \\
\text { TR } \\
\text { Root chord }(f t) \\
\text { Swept back angle }(\mathrm{deg}) \\
\text { Area }\left(f t^{2}\right) \\
\text { Control surface area }\left(f t^{2}\right)\end{array}$ & $\begin{array}{r}19.68 \\
1.70 \\
0.28 \\
15.55 \\
40 \\
174.38 \\
58.54\end{array}$ & $\begin{array}{r}19.68 \\
1.70 \\
0.28 \\
15.55 \\
40 \\
174.38 \\
58.54\end{array}$ & $\begin{array}{r}19.68 \\
1.66 \\
0.22 \\
16.04 \\
43 \\
174.38 \\
58.70\end{array}$ & $\begin{array}{r}19.68 \\
1.66 \\
0.22 \\
16.04 \\
43 \\
174.38 \\
58.70 \\
\end{array}$ \\
\hline Fuselage & \begin{tabular}{|l|} 
Height $(f t)$ \\
Width $(f t)$ \\
Length $(f t)$ \\
Crew (people) \\
Passenger (people) \\
Tail length $(f t$,wing $1 / 4$ \\
MAC $\sim$ H-tail 1/4 MAC) \\
\end{tabular} & \begin{tabular}{r|}
10.99 \\
9.87 \\
98.07 \\
2 \\
76 \\
42.17
\end{tabular} & $\begin{array}{r}10.99 \\
9.87 \\
103.91 \\
2 \\
86 \\
42.17\end{array}$ & $\begin{array}{r}10.99 \\
9.87 \\
118.87 \\
2 \\
104 \\
53.23\end{array}$ & $\begin{array}{r}10.99 \\
9.87 \\
126.77 \\
2 \\
110 \\
53.23\end{array}$ \\
\hline Engine & \begin{tabular}{|l|} 
Max. T @SL $(l b f)$ \\
Ttot/Wo \\
Eng. W $(l b)$ \\
Nacelle position $(f t$, \\
from cockpit) \\
Nacelle width $(f t)$ \\
Nacelle length $(f t)$ \\
Duct length $(f t)$ \\
Nacelle area $\left(f t^{2}\right)$
\end{tabular} & $\begin{array}{r}13,800 \\
0.3479 \\
2408 \\
50.62 \\
5.56 \\
12.32 \\
1.10 \\
43.80\end{array}$ & $\begin{array}{r}13,800 \\
0.3339 \\
2408 \\
50.62 \\
5.56 \\
12.32 \\
1.10 \\
43.80\end{array}$ & $\begin{array}{r}18,500 \\
0.3513 \\
3700 \\
64.72 \\
6.67 \\
14.89 \\
1.10 \\
58.48\end{array}$ & $\begin{array}{r}18,500 \\
0.3441 \\
3700 \\
64.72 \\
6.67 \\
14.89 \\
1.10 \\
58.48\end{array}$ \\
\hline Mass & $\begin{array}{l}\text { Gross mass }(l b) \\
\text { Empty mass }(l b) \\
\text { Fuel mass }(l b) \\
\text { Wf/Wo } \\
\text { Max. payload }(l b)\end{array}$ & $\begin{array}{l}79,322 \\
46,593 \\
20,779 \\
0.2620 \\
20,056\end{array}$ & $\begin{array}{l}82,650 \\
48,069 \\
20,779 \\
0.2514 \\
22,481\end{array}$ & \begin{tabular}{r|}
105,329 \\
61,888 \\
28,652 \\
0.2720 \\
28,432 \\
\end{tabular} & $\begin{array}{r}107,533 \\
63,850 \\
28,872 \\
0.2685 \\
30,415 \\
\end{array}$ \\
\hline Performance & $\begin{array}{l}\text { Altitude }(f t) \\
\text { Range }(N M) \\
\text { Cruise speed }(M) \\
\text { Max. M } \\
\text { Stall speed }(k t s)\end{array}$ & $\begin{array}{r}34,991 \\
2,100 \\
0.8 \\
0.82 \\
109.00\end{array}$ & $\begin{array}{r}34,991 \\
1,298 \\
0.8 \\
0.82 \\
129.17\end{array}$ & $\begin{array}{r}34,991 \\
2,300 \\
0.8 \\
0.82 \\
129.17\end{array}$ & $\begin{array}{r}34,991 \\
1,400 \\
0.8 \\
0.82 \\
129.17\end{array}$ \\
\hline
\end{tabular}


Appendix D

Flow Chart of Aircraft Derivative Design

Optimization (ADDOPT) Process 


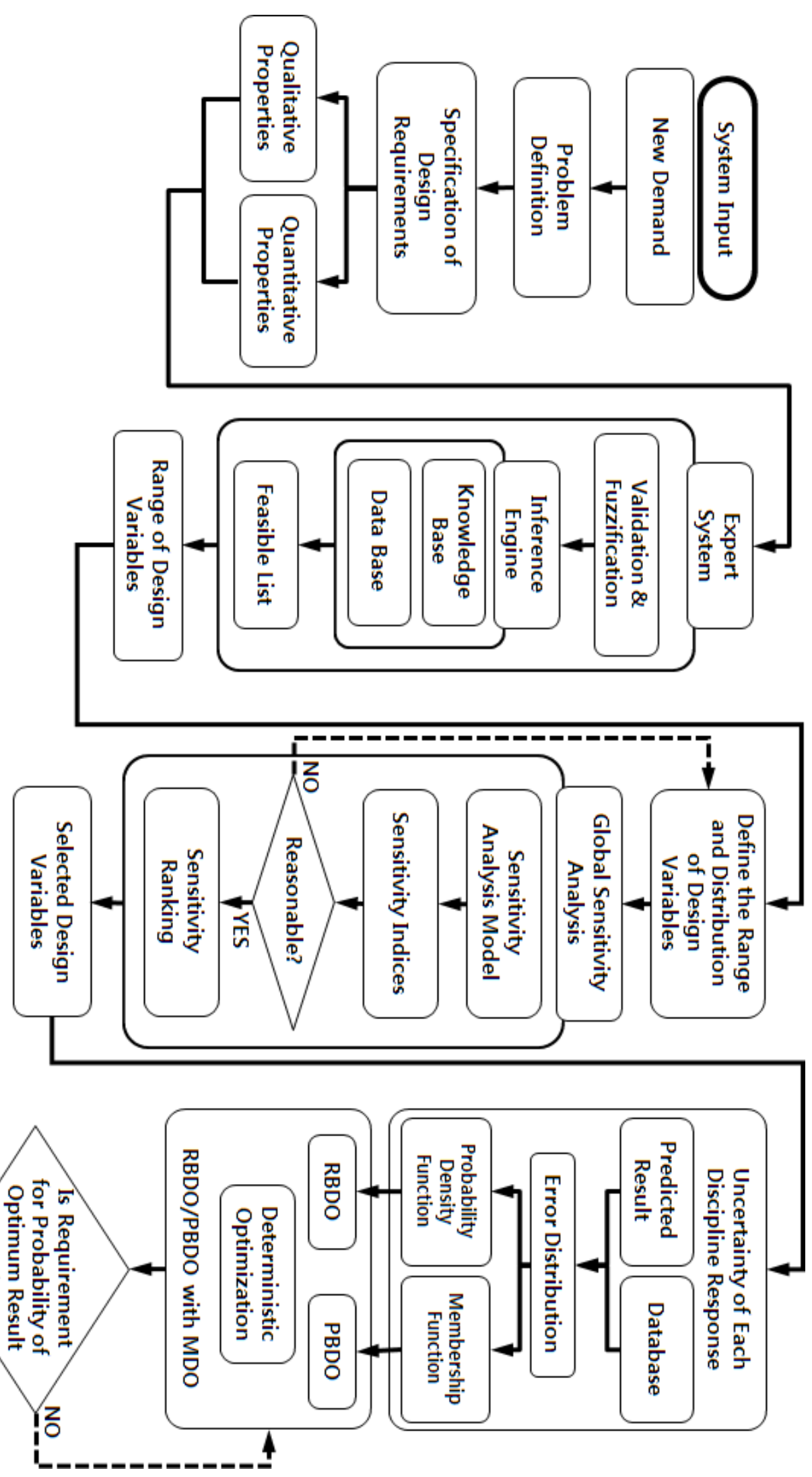




\section{References}

1. D.L. Robinson, M.F. Melary, Large Airplane Derivative Development Methodology, AIAA/AHS/ASEE Aircraft Design Systems and Operations Meeting, Colorado Springs, Colorado, 14-16 October 1985.

2. Ruben E. Perez, Joon Chung, Kamran Behdinan, Aircraft Conceptual Design Using Genetic Algorithms, 8th AIAA/USAF/NASA/SSMO Symposium on Multidisciplinary Analysis and Optimization, Long Beach, California, 6-8 September 2000.

3. George H. Kidwell, Megan A. Eskey, Expert System and Their Use in Augmenting Design Optimization, AIAA/AHS/ASEE Aircraft Design System and Operations Meeting, Colorado Springs, Colorado, 14-16 October 1985.

4. Lotfi A. Zadeh, George J. Klir, Bo Yuan, Fuzzy Sets, Fuzzy Logic, and Fuzzy Systems, World Scientific, 1996.

5. Chonggang Xu, George Z. Gertner, Extending a Global Sensitivity Analysis Technique to Models with Correlated Parameters, Computational Statistics \& Data Analysis, Vol. 51, 2007, pp. 5579-5590.

6. Byeng D. Youn and Kyung K. Choi, Selecting Probabilistic Approaches for ReliabilityBased Design Optimization, AIAA Journal, Vol. 42, No. 1, 2003, pp. 124-131.

7. Daniel J. Neufeld, Joon Chung, Kamran Behdinan, Aircraft Conceptual Design Optimization with Uncertain Contributing Analyses, AIAA Modeling and Simulation Technologies Conference and Exhibit, Chicago, Illinois, 10-13 August 2009. 
8. Daniel J. Neufeld, Nguyen Nhu-Van, Jae-Woo Lee, Sango Kim, A Multidisciplinary Possibilistic Approach to Light Aircraft Conceptual Design, 53rd AIAA/ASME/ASCE/AHS/ASC Structures, Structural Dynamics and Materials Conference, Honolulu, Hawaii, 23-26 April 2012.

9. Hyeong-Uk Park, Joon Chung, Jae-Woo Lee, Kamran Behdinan, Daniel Neufeld, Reliability and Possibility Based Multidisciplinary Design Optimization for Aircraft Conceptual Design, 11th AIAA Aviation Technology, Integration, and Operations Conference, Virginia Beach, Virginia, 20-22 September 2011.

10. Liu Du, Kyong K. Choi, Byeng D. Youn, David Gorsich, Possibility-Based Design Optimization Method for Design Problems with both Statistical and Fuzzy Input Data, Journal of Mechanical Design, Vol. 128, No. 4, 2005, pp. 928-935.

11. Jonathan D. Yearsley, Christopher A. Mattson, Product Family Design using a Smart Pareto Filter, 46th AIAA Aerospace Sciences Meeting and Exhibit, Reno, Nevada, 7-10 January 2008.

12. Richard Hibma, Don Wegner, The Evolution of a Strategic Bomber, AlAA 1981 Annual Meeting and Technical Display, Long Beach, California, 12-14 May 1981.

13. Somasundaram. Valliyappan, Timothy W. Simpson, Exploring Visualization Strategies to Support Product Family Design Optimization, 11th AIAA/ISSMO Multidisciplinary Analysis and Optimization Conference, Portsmouth, Virginia, 6-8 September 2006.

14. Boeing Company, www.boeing.com.

15. Robert H. Fulford, Airplane Criteria Process, World Aviation Congress \& Exposition, Anaheim, California, 13 October 1997.

16. Robert B. Brown, John M. Swihart, A New Family of Passenger Friendly Commercial Air 
Transports, 39th AIAA Aerospace Sciences, Meeting \& Exhibit, Reno, Nevada, 8-11 January 2001.

17. Deepak Kumar, Wei Chen, Timothy W. Simpson, A Market-Driven Approach to the Design of Platform-Based Product Families, 11th AIAA/ISSMO Multidisciplinary Analysis and Optimization Conference, Portsmouth, Virginia, 6-8 September 2006.

18. Timothy W. Simpson, Brayan D'Souza, Assessing Variable Levels of Platform Commonality within a Product Family Using a Multiobjective Genetic Algorithm, 9th AIAA/ISSMO Symposium on Multidisciplinary Analysis and Optimization, Atlanta, Georgia, 4-6 September 2002.

19. Aida Khajavirad, Jeremy J. Michalek, Timothy W. Simpson, A Decomposed Genetic Algorithm for Solving the Joint Product Family Optimization Problem, 48th AIAA/ASME/ASCE/AHS/ASC Structures, Structural Dynamics, and Materials Conference, Honolulu, Hawaii, 23-26 April 2007.

20. Jonathan D. Yearsley, Christopher A. Mattson, Interactive Design of Combined Scalebased and Module-based Product Family Platforms, 12th AIAA/ISSMO Multidisciplinary Analysis and Optimization Conference, Victoria, British Columbia Canada, 10-12 September 2008.

21. B. Grossman, R.T. Haftka, P.J. Kao, D.M. Polen, M. Rais-Rohani, Integrated Aerodynamic-Structural Design of a Transport Wing, Journal of Aircraft, Vol. 27, No. 12, 1990, pp. 1050-1056.

22. B. Grossman, Z. Gurdal, G.J. Strauch, W.M. Eppard, R.T. Haftka, Integrated Aerodynamic/Structural Design of a Sailplane Wing, Journal of Aircraft, Vol. 25, No. 9, 1988, pp. 855-860. 
23. Eli Livne, Lucien A. Schmit, Jr., Peretz P. Friedmann, Towards Integrated Multidisciplinary Synthesis of Actively Controlled Fiber Composite Wings, Journal of Aircraft, Vol. 27, No. 12, December 1990, pp. 979-992.

24. Holt Ashley, On Making Things the Best - Aeronautical Uses of Optimization, Journal of Aircraft, Vol. 19, No. 1, 1982, pp. 5-28.

25. John A. Green, Aeroelastic Tailoring of Aft-Swept High-Aspect-Ratio Composite Wings, Journal of Aircraft, Vol. 24, No. 11, 1987, pp. 812-819.

26. Lucien A. Schmit, Jr., Structural Design by Systematic Synthesis, 2nd Conference on Electronic Computation, ASCE, Pittsburgh, Pennsylvania, 8-9 September 1960.

27. Lucien A. Schmit, Jr., Structural Synthesis - Its Genesis and Development, AIAA Journal, Vol. 19, No. 10, 1981, pp. 1249-1263.

28. Lucien A. Schmit, Jr., William A. Thornton, Synthesis of an Airfoil at Supersonic Mach Number, Technical Report. CR 144, NASA, January 1965.

29. Eli Livne, Integrated Aeroservoelastic Optimization: Status and Direction, Journal of Aircraft, Vol. 36, No. 1, 1999, pp. 122-145.

30. Ilan M. Kroo, Steve Altus, Robert Braun, Peter Gage, Ian Sobieski, Multidisciplinary Optimization Methods for Aircraft Preliminary Design, 5th AIAA/USAF/NASA/ISSMO Symposium on Multidisciplinary Analysis and Optimization, Panama City Beach, Florida, 7-9 September 1994.

31. Nicolas E. Antoine, Ilan M. Kroo, Framework for Aircraft Conceptual Design and Environmental Performance Studies, AIAA Journal, Vol. 43, No. 10, 2005, pp. 2100-2109.

32. Peter W. Jansen, Ruben E. Perez, Joaguim R.R.A. Martins, Aerostructural Optimization of Nonplanar Lifting Surfaces, Journal of Aircraft, Vol. 47, No. 5, 2010, pp. 1491-1503. 
33. Andrew Ning, Ilan M. Kroo, Multidisciplinary Considerations in the Design of Wings and Wing Tip Devices, Journal of Aircraft, Vol. 47, No. 2, 2010, pp. 534-543.

34. Valerie M. Manning, Large-Scale Design of Supersonic Aircraft via Collaborative Optimization, Ph.D. Thesis, Stanford University, 1999.

35. Juan J. Alonso, Michael R. Colonno, Multidisciplinary Optimization with Applications to Sonic-Boom Minimization, Annual Review of Fluid Mechanics, Vol. 44, No. 1, 2012, pp. $505-526$.

36. Ryan P. Henderson, Joaquim R.R.A. Martins, Ruben E. Perez, Aircraft Conceptual Design for Optimal Environmental Performance, The Aeronautical Journal, Vol. 116, No. 1175, 2012, pp. 1-22.

37. Evin J. Cramer, J.E. Dennis Jr., Paul D. Frank, Robert M. Lewis, Gregory R. Shubin, Problem Formulation for Multidisciplinary Optimization, SIAM Journal on Optimization, Vol. 4, No. 4, 1994, pp. 754-776.

38. Gaetan Kenway, Graeme Kennedy, Joaquim R.R.A. Martins, A Scalable Parallel Approach for High-Fidelity Aerostructural Analysis and Optimization, 53rd AIAA/ASME/ASCE/AHS/ASC Structures, Structural Dynamics, and Materials Conference, Honolulu, Hawaii, 23-26 April 2012.

39. Natalia M. Alexandrov, Robert M. Lewis, Analytical and Computational Aspects of Collaborative Optimization for Multidisciplinary Design, AIAA Journal, Vol. 40, No. 2, 2002, pp. 301-309.

40. Richard J. Balling, Jaroslaw Sobieszczanski-Sobieski, Optimization of Coupled Systems: A Critical Overview of Approaches, AIAA Journal, Vol. 34, No. 1, 1996, pp. 6-17. 41. Ilan M. Kroo, MDO for Large-Scale Design, Multidisciplinary Design Optimization: 
State-of-the-Art, Proceedings of the ICASE/NASA Langley Workshop on Multidisciplinary Design Optimization, SIAM, 1997, pp. 22-44.

42. Jason E. Hicken, David W. Zingg, Aerodynamic Optimization Algorithm with Integrated Geometry Parameterization and Mesh Movement, AIAA Journal, Vol. 48, No. 2, 2009, pp. $400-413$.

43. Christopher Marriage, Automatic Implementation of Multidisciplinary Design Optimization Architectures Using MDO, Master's Thesis, University of Toronto, 2008.

44. Robert D. Braun, Collaborative Optimization: An Architecture for Large-Scale Distributed Design, Ph.D. Thesis, Stanford University, 1996.

45. Robert D. Braun, Peter J. Gage, Ilan M. Kroo, Ian P. Sobieski, Implementation and Performance Issues in Collaborative Optimization, 6th AIAA/USAF/NASA/ISSMO Multidisciplinary Analysis and Optimization Symposium, Bellevue, Washington, 4-6 September 1996.

46. Xiaoyu S. Gu, John E. Renaud, Charles L. Penninger, Implicit Uncertainty Propagation for Robust Collaborative Optimization, Journal of Mechanical Design, Vol. 128, No. 4, 2006, pp. 1001-1013.

47. Robert D. Braun, Ilan M. Kroo, Development and Application of the Collaborative Optimization Architecture in a Multidisciplinary Design Environment, Technical Report, NASA Langley Technical Report Server, 14 August 1995.

48. Christina L. Bloebaum, Prabhat Hajela, Jaroslaw Sobieszczanski-Sobieski, NonHierarchic System Decomposition in Structural Optimization, Engineering Optimization, Vol. 19, No. 3, 1992, pp. 171-186.

49. Jayashree Shankar, Calvin J. Ribbens, Raphael T. Haftka, Layne T. Watson, 
Computational Study of a Nonhierarchical Decomposition Algorithm, Computational Optimization and Applications, Vol. 2, 1993, pp. 273-293.

50. Jaroslaw Sobieszczanski-Sobieski, Optimization by Decomposition: A Step from Hierarchic to Non-Hierarchic Systems, Technical Report, NASA Langley Research Center, Hampton, VA, September 1988.

51. Ravindra V. Tappeta, Somanath Nagendra, John E. Renaud, A Multidisciplinary Design Optimization Approach for High Temperature Aircraft Engine Components, Structural Optimization, Vol. 18, No. 2-3, 1999, pp. 134-145.

52. Hongman Kim, Scott Ragon, Grant Soremekun, Brett Malone, Jaroslaw SobieszczanskiSobieski, Flexible Approximation Model Approach for Bi-Level Integrated System Synthesis, 10th AIAA/ISSMO Multidisciplinary Analysis and Optimization Conference, Albany, New York, 30 August-1 September 2004.

53. Jaroslaw Sobieszczanski-Sobieski, Jeremy S. Agte, Robert R. Sandusky Jr., Bilevel Integrated System Synthesis, AIAA Journal, Vol. 38, No. 1, 2000, pp. 164-172.

54. Jaroslaw Sobieszczanski-Sobieski, Sensitivity of Complex, Internally Coupled Systems, AIAA Journal, Vol. 28, No. 1, 1990, pp. 153-160.

55. Srinivas Kodiyalam, Jaroslaw Sobieszczanski-Sobieski, Bilevel Integrated System Synthesis with Response Surfaces, AIAA Journal, Vol. 38, No. 8, 2000, pp. 1479-1485.

56. Matthew J. Dasilewiez, Brian J. German, Timothy T. Takahashi, Shane Donovan, Arvin Shajanian, Effects of disciplinary uncertainty on multi-objective optimization in aircraft conceptual design, Structural and Multidisciplinary Optimization, Vol. 44, Issue 6, 2011, pp. 831-846.

57. L. Jaeger, C. Gogu, S. Segonds, C. Bes, Aircraft Multidisciplinary Design Optimization 
Under Both Model and Design Variables Uncertainty, Journal of Aircraft, Vol. 50, No. 2, 2013, pp. 528-538.

58. William L. Oberkampf, Jon C. Helton, Kari Sentz, Mathematical Representation of Uncertainty, 42nd AIAA/ASME/ASCE/AHS/ASC Structures, Structural Dynamics, and Materials Conference \& Exhibit, Seattle, Washington, 16-19 April 2001.

59. Bilal M. Ayyub, George J. Klir, Uncertainty Modeling and Analysis in Engineering and the Sciences, Chapman \& Hall/CRC, 2006.

60. M.Elisabeth Pate-Cornel, Uncertainties in Risk Analysis: Six Levels of Treatment, Reliability Engineering \& System Safety, Vol. 54, No. 2-3, 1996, pp. 95-111.

61. William L. Oberkampf, Sharon M. Deland, Brian M. Rutherford, Kathleen V. Diegert, Kenneth F. Alvin, A New Methodology for the Estimation of Total Uncertainty in Computational Simulation, The 40th AIAA / ASME / ASCE / AHS / ASC Structures, Structural Dynamics, and Materials Conference, St. Louis, Missouri, 12-15 April 1999.

62. Yannis Tsompanakis, Nikos D. Lagaros, Manolis Papadrakakis, Structural Design Optimization Considering Uncertainties, Taylor \& Francis, 24 March 2008.

63. Byeng D. Youn, Kyung K. Choi, Young H. Park, Hybrid Analysis Method for ReliabilityBased Design Optimization, Journal of Mechanical Design, Vol. 125, No. 2, 2003, pp. 221-232.

64. Kyung K. Choi, Liu Du, Byeng D. Youn, A New Fuzzy Analysis Method for PossibilityBased Design Optimization, 10th AIAA/ISSMO Multidisciplinary Analysis and Optimization Conference, Albany, New York, 30 August-1 September, 2004.

65. Dong Zhao, Deyi Xue, Parametric Design with Neural Network Relationships and Fuzzy Relationships Considering Uncertainties, Computers in Industry, Vol. 61, 2010, pp. 287- 
296.

66. Harish Agarwal, Reliability Based Design Optimization: Formulations and Methodologies, Ph.D. Thesis, University of Notre Dame, 2004.

67. Kyung K. Choi, Byeng D. Youn, Hybrid Analysis Method for Reliability-Based Design Optimization, 27th ASME Design Automation Conference, Pittsburgh, Pennsylvania, 9-12 September 2001.

68. H.O. Madsen, S. Krenk, Niels C. Lind, Methods of Structural Safety, $2^{\text {nd }}$ ed., Dover Publications, 2006.

69. Palle Thoft-Christopher, Michael J. Baker, Structural Reliability Theory and Its Applications. Berlin, Heidelberg, New York, Springer, 1982.

70. Michael Hohenbichler, Rudiger Rackwitz, Non-Normal Dependent Vectors in Structural Safety, Journal of the Engineering Mechanics Division, Vol. 107, No. 6, 1981, pp. 12271238.

71. Marco Savoia, Structural Reliability Analysis through Fuzzy Number Approach, with Application to Stability, Computers \& Structures, Vol. 80, Issue 12, 2002, pp. 1087-1102.

72. Georgios Athanasopoulos, Carles R. Riba, Christina Athanasopoulou, A Decision Support System for Coating Selection Based on Fuzzy Logic and Multi-Criteria Decision Making, Expert Systems with Applications, Vol. 36, Issue 8, 2009, pp. 10848-10853.

73. Junichiro Sumita, An Application of Fuzzy Expert Concept for Unmanned Air Vehicles, 2nd AIAA Unmanned Unlimited Systems, Technologies, and Operations - Aerospace, Land, and Sea Conference, San Diego, California, 15-18 September 2003.

74. Andrea Saltelli, K. Chan, E.M. Scott, Sensitivity Analysis, John Wiley \& Sons publishers, Probability and Statistics series, 2009. 
75. Andrea Saltelli, Stefano Tarantola, Francesca Campolongo, Marco Ratto, Sensitivity Analysis in Practice. A Guide to Assessing Scientific Models, John Wiley \& Sons publishers, Probability and Statistics series, 2004.

76. Ilya M. Sobol', Global Sensitivity Indices for Nonlinear Mathematical Models and Their Monte Carlo Estimates, Mathematics and Computers in Simulation, Vol. 55, Issue 1-3, 2001, pp. 271-280.

77. Andrea Saltelli, Ilya M. Sobol'. About the Use of Rank Transformation in Sensitivity Analysis of Model Output. Reliability Engineering \& System Safety, Vol. 50, No. 3, 1995, pp. 225-239.

78. H. Christopher Frey, Sumeet R. Patil, Identification and Review of Sensitivity Analysis Methods, Risk Analysis, Vol. 22, No. 3, 2002, pp. 553-578.

79. Hyeong-Uk Park, Kamran Behdinan, Joon Chung, and Jae-Woo Lee, Development of the Aircraft Derivative Design Process using Sensitivity Analysis and Expert System, 6th China-Japan-Korea Joint Symposium on Optimization of Structural and Mechanical Systems, Kyoto, Japan, 22-25 June, 2010.

80. Andrea Saltelli, Stefano Tarantola, Kwok-Pong S. Chan, A Quantitative ModelIndependent Method for Global Sensitivity Analysis of Model Output, Technimetrics, Vol. 41, 1999, pp. 39-56.

81. Fan Hui, Li Weiji, An Efficient Method for Reliability-based Multidisciplinary Design Optimization, Chinese Journal of Aeronautics, Vol. 21, 2008, pp. 335-340.

82. J. Ahn, J.H. Kwon, An Efficient Strategy for Reliability-Based Multidisciplinary Design Optimization using BLISS, Journal of Structural and Multidisciplinary Optimization, Vol. 31, 2006, pp. 363-372. 
83. Mark McDonald, Sankaran Mahadevan, All-At-Once Multidisciplinary Optimization with System and Component-Level Reliability Constraints, 12th AIAA/ISSMO multidisciplinary analysis and optimization conference, Victoria, British Columbia, 10-12 September 2008.

84. Patrick N. Koch, Brett Wujek, Oleg Golovidov, A Multi-Stage, Parallel Implementation of Probabilistic Design Optimization in an MDO Framework, 8th AIAA/USAF/NASA/ISSMO Symposium on Multidisciplinary Analysis and Optimization, Long Beach, California, 6-8 September 2000.

85. Yong-Hee Jeon, Sangook Jun, Seungon Kang, Dong-Ho Lee, Systematic Design Space Exploration and Rearrangement of the MDO Problem by Using Probabilistic Methodology, Journal of Mechanical Science and Technology, Vol. 26, No. 9, 2012, pp. 2825-2836.

86. Daniel Neufeld, Nguyen Nhu-Van, Jae-Woo Lee, Sango Kim, A Multidisciplinary Possibilistic Approach to Light Aircraft Conceptual Design, 53rd AIAA/ASME/ASCE/AHS/ASC Structures, Structural Dynamics and Material Conference, Honolulu, Hawaii, 23-26 April 2012.

87. Xiaoping Du, Jia Guo, Harish Beeram, Sequential Optimization and Reliability Assessment for Multidisciplinary Systems Design, Journal of Structural and Multidisciplinary Optimization, Vol. 35, 2008, pp. 117-130.

88. Xiaoping Du, Wei Chen, Collaborative Reliability Analysis under the Framework of Multidisciplinary Systems Design, Optimization and Engineering, Vol. 6, 2005, pp. 6384.

89. Byeng D. Youn, Kyung K. Choi, Liu Du, Enriched Performance Measure Approach for Reliability-Based Design Optimization, AIAA Journal, Vol. 43, No. 4, 2005, pp. 874-884. 
90. Beechcraft Corporation, www.hawkerbeechcraft.com.

91. Bombardier Aerospace, www.aerospace.bombardier.com.

92. Cessna Aircraft Company, www.cessna.com

93. Embraer, www.embraer.com.

94. Grob Aircraft, www.grob-aircraft.eu.

95. Jane's All The World's Aircraft 2004 2005.

96. Syber Jet Aircraft, www.sj30jet.com

97. Eysa Salajegheh, Garret N. Vanderplaats, Optimum Design of Trusses with Discrete Sizing and Shape Variables, Structural and Multidisciplinary Optimization, Vol. 6, 1993, pp. 79-85.

98. Nicholas F. Ali, Optimization of Engineering Systems using Genetic Algorithm Enhanced Computational Techniques, Master's Thesis, Ryerson University, 2002.

99. Daniel J. Nuefeld, Joon Chung, Unmanned Aerial Vehicle Conceptual Design Using a Genetic Algorithm and Data Mining, AIAA Infotech@Aerospace Advancing Contemporary Aerospace Technologies and Their Integration, Arlington, Virginia, 26-29 September 2005.

100. Joon Chung, Tae-Cheol Jung, Optimization of an Air Cushion Vehicle Bag and Finger Skirt Using Genetic Algorithms, Aerospace Science and Technology, Vol. 8, 2003, pp. 219-229.

101. Morris H. DeGroot, Mark J. Schervish, Probability and Statistics, 3rd ed., AddisonWesley, 2002.

102. Larry L. Erickson, Panel Methods - An Introduction, NASA Technical Paper 2995, 1990. 103. Susan Burge, Anthony A. Giunta, Vladimir Balabanov, Bernard Grossman, William H. 
Mason, Robert Narducci, Raphael T. Haftka, Layne T. Watson, A Coarse-Grained Parallel Variable-Complexity Multidisciplinary Optimization Paradigm, International Journal of Supercomputing Applications and High Performance Computing, Vol. 10, No. 4, 1996, pp. 269-299.

104. Raymond H. Myers, Douglas C. Montgomery, Christine M. Anderson-Cook, Response Surface Methodology: Process and Product Optimization Using Designed Experiments, $3^{\text {rd }} e d .$, John Wiley \& Sons publishers, New York, 2009.

105. Jae-Woo Lee, Byung-Young Min, Yung-Hwan Byun, Sang-Jin Kim, Multi-Point Nose Shape Optimization of Space launcher Using Response Surface method, AIAA Journal of Spacecraft and Rockets, Vol. 43, No. 1, 2006, pp. 137-146.

106. Daniel J. Neufeld, Kamran Behdinan, Joon Chung, Aircraft Wing Box Optimization Considering Uncertainty in Surrogate Models, Structural and Multidisciplinary Optimization, Vol. 42, No. 5, 2010, pp. 745-753.

107. DOT User Manual, Vanderplaats Research \& Development, Inc., 1995.

108. Airbus, An EADS Company, www.airbus.com.

109. Daniel P. Raymer, Aircraft Design: A Conceptual Approach, $3^{\text {rd }}$ ed., American Institute of Aeronautics and Astronautics, 1999.

110. Egbert Torenbeek, Synthesis of Subsonic Airplane Design, Delft University Press, 1976. 


\section{Hyeong-Uk Park}

70 Holmes Ave.

North York, Ontario

M2N 4M2, Canada

\section{Education}

2008 - $\quad$ Ryerson University

Ph.D Candidate

$2007 \quad$ Konkuk University

Master of Applied Science in Aerospace Information Engineering, February 2007

$2005 \quad$ Konkuk University

Bachelor of Applied Science in Aerospace Information Engineering, February 2005

\section{Honors and Reward}

2013 Ryerson Aerospace Engineering Graduate Student Research Excellence Award (AEGSRE)

2008-2011 Ryerson Graduate Scholarship (RGS)

2008-2011 ATOP Ryerson Graduate Scholarship (RGA)

2008-2011 Ryerson International Student Scholarship (RISS)

2008-2009 Seoul Scholarship

\section{Research Interests}

Multidisciplinary Design Optimization 
Aircraft Conceptual Design

Aircraft Derivative Design

Robust Design Optimization

Reliability Based Design Optimization

Possibility Based Design Optimization

\section{Graduate Assistant at Ryerson University}

I have held graduate assistant positions in the following courses at Ryerson University. My duties have included lab instruction, tutorial lectures, and marking

AER-622 Gas Dynamics

AER-716 Aircraft Stability and Control

AER-817 Systems Engineering

\section{List of Publications}

\section{Journal}

1. Hyeong-UK Park, Joon Chung, Kamran Behdinan, and Jae-Woo Lee, Uncertainty based multidisciplinary design optimization for aircraft conceptual design, Aircraft Engineering and Aerospace Technology. (on the review)

2. Nhu Van Nguyen, Daeyon Lee, Hyeong-Uk Park, Maxim Tyan, and Jae-Woo Lee, A Multidisciplinary Robust Optimization Framework for UAV Conceptual Design, Aeronautics Journal. (Accepted with modifications on November 2013)

3. Hyeong-UK Park, Joon Chung, Kamran Behdinan, and Jae-Woo Lee, Enhanced Derivative Design Considering Sensitivity of Design Variables with MDO Technique, Journal of Mechanical Science and Technology. (Accepted on October 2013)

4. Hyeong-Uk Park, Jae-Woo Lee, Yung-Hwan Byun, Joon Chung, and Kamran Behdinan, A New Process for the Requirements Based Aerospace System Design and Optimization, Journal of Korean Society for Aeronautical \& Space Sciences, Vol. 37, No. 3, March 2009, pp. 255-266. 


\section{Conference}

1. Hyeong-Uk Park, Kamran Behdinan, Joon Chung, and Jae-Woo Lee, Enhance Derivative Design Considering Global Sensitivity of Design Parameters, Canadian Engineering Education Association 4th Annual Conference, Montreal, Canada, 17-20 June 2013.

2. Nhu Van Nguyen, Tyan Maxim, Hyeong-Uk Park, SangHo Kim, and Jae-Woo Lee, A Multidisciplinary Roust Optimization Framework for UAV Conceptual Design, 10th World Congress on Structural and Multidisciplinary Optimization, Orlando, Florida, 1924 May 2013.

3. Hyeong-Uk Park, Joon Chung, Kamran Behdinan, Jae-Woo Lee, and Daniel Neufeld, Development of Aircraft Derivative Design Process with Reliability and Possibility Based Multidisciplinary Design Optimization, CASI 60th Aeronautics Conference and AGM, Toronto, Ontario, 30 April-2 May 2013.

4. Hyeong-Uk Park, Jae-Woo Lee, Kamran Behdinan, and Joon Chung, Development of the Aircraft Derivative Design Process Considering Sensitivity and Uncertainty of Design Parameters, The 7th China-Japan-Korea Joint Symposium on Optimization of Structural and Mechanical Systems, Huangshan, China, 18-21 June 2012.

5. Hyeong-UK Park, Joon Chung, Jae-Woo Lee, Kamran Behdinan, and Daniel Neufeld, Reliability and Possibility Based Multidisciplinary Design Optimization for Aircraft Conceptual Design, 11th AIAA ATIO Conference, AIAA Centennial of Naval Aviation Forum, Virginia Beach, Virginia, 20-22 September 2011.

6. Hyeong-Uk Park, Joon Chung, Kamran Behdinan and Jae-Woo Lee, Development of Enhanced Derivative Design Process Considering Uncertainties from Analysis Tools, Canada-Korea Conference on Science and Technology 2011, Sheraton Vancouver Guilford Hotel in Surrey, BC., 7-8 August 2011.

7. Hyeong-Uk Park, Kamran Behdinan, Jae-Woo Lee, Joon Chung, and Daniel Neufeld, Study of Probability and Possibility Based Design Optimization for Variation of Sample in Uncertain Parameters, 9th World Congress on Structural and Multidisciplinary Optimization, Shizuoka, Japan, 13-17 June 2011.

8. Hyeong-UK Park, Kamran Behdinan, Jae-Woo Lee, and Joon Chung, Development of a Derivative Design Process Considering Uncertainties from Low Fidelity Analysis Tools, Canadian Engineering Education Association 2nd Annual Conference, Memorial University St. John's, Newfoundland, Canada, 6-8 June 2011.

9. Hyeong-Uk Park, Jae-Woo Lee, Kamran Behdinan, and Joon Chung, Wing Configuration of VLJ Aircraft Optimization for Noise Reduction, 2nd International Forum on Rotorcraft Multidisciplinary Technology, Seoul, Korea, 19-20 October 2009. 